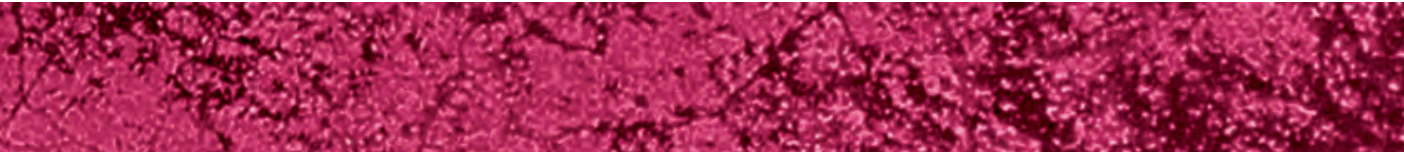

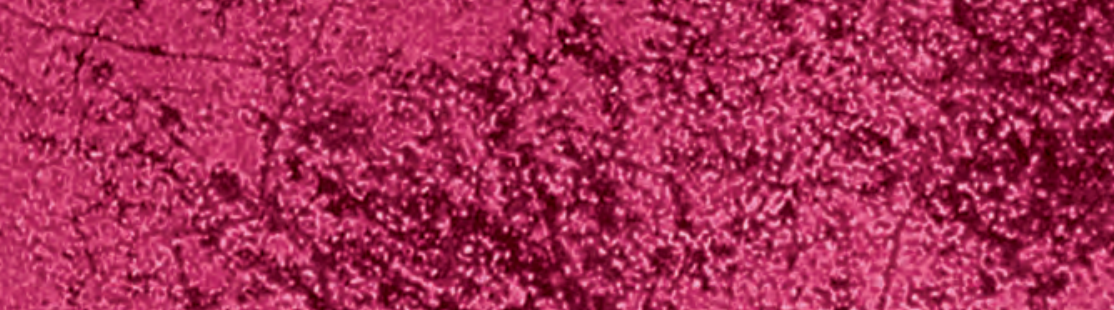

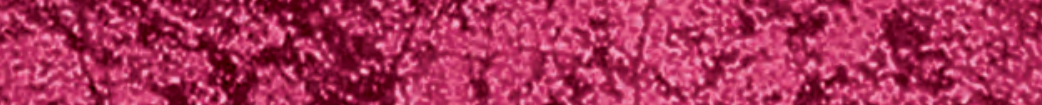

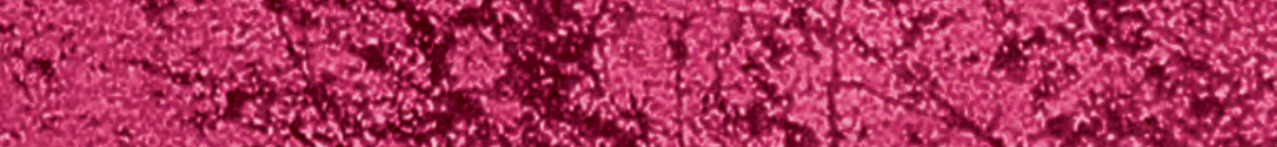

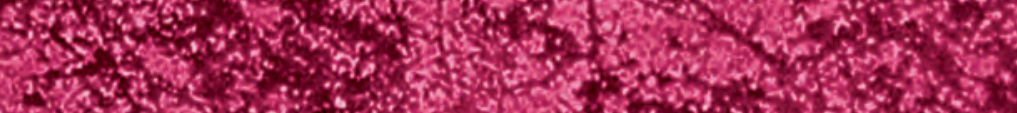

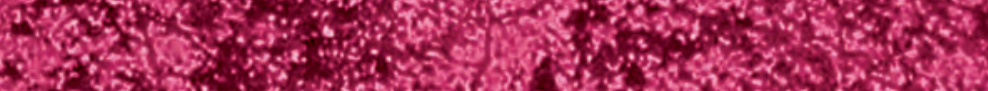

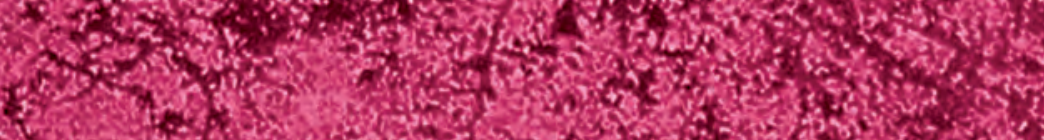

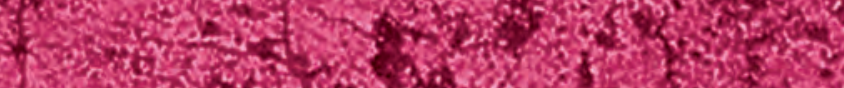
39.

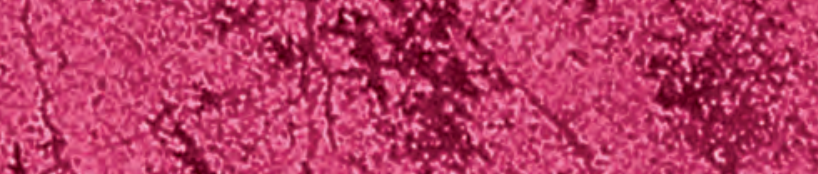

13.0. 3.5.

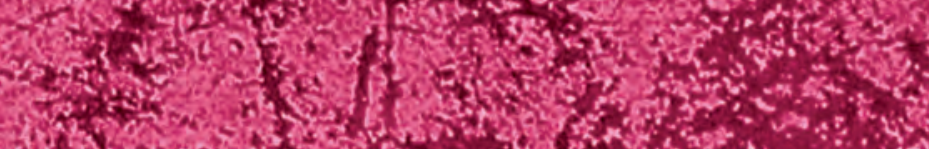

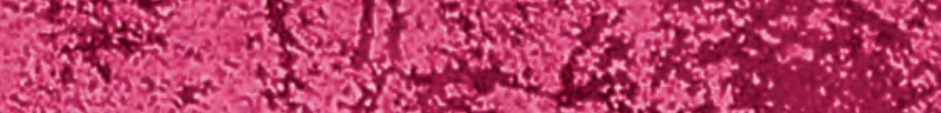

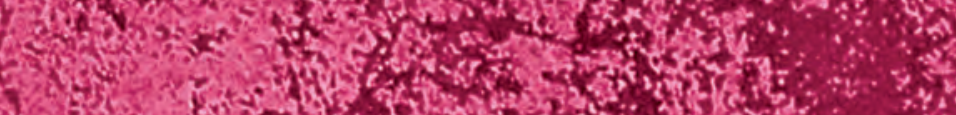

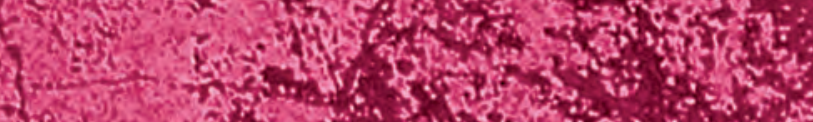

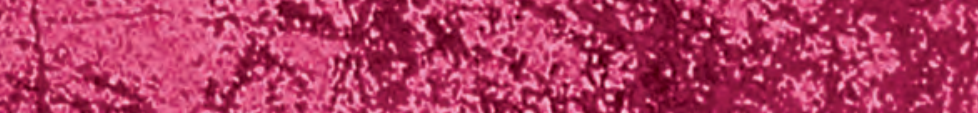
1.20

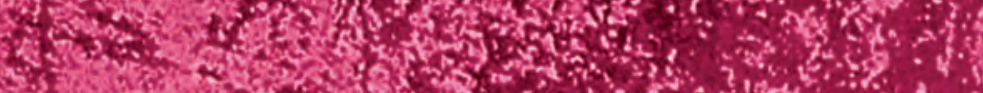

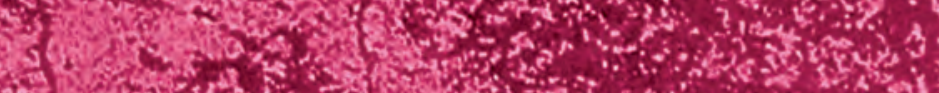

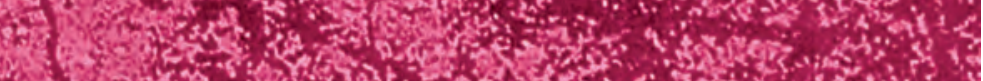

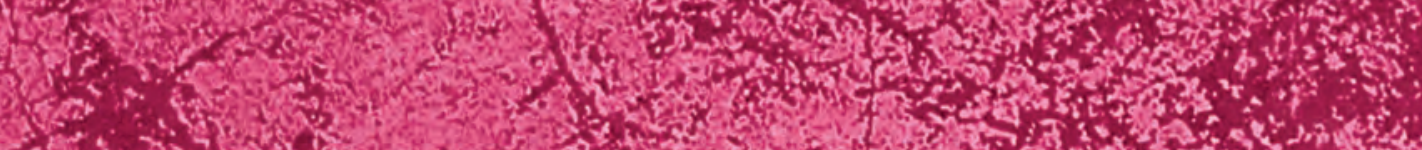

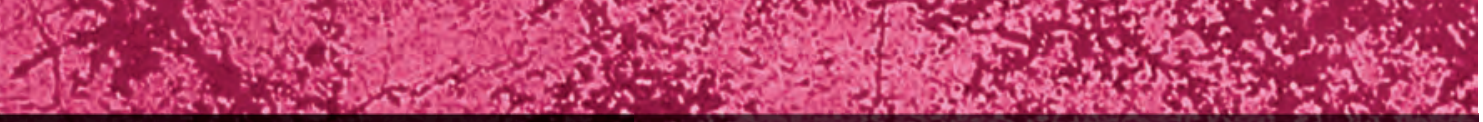
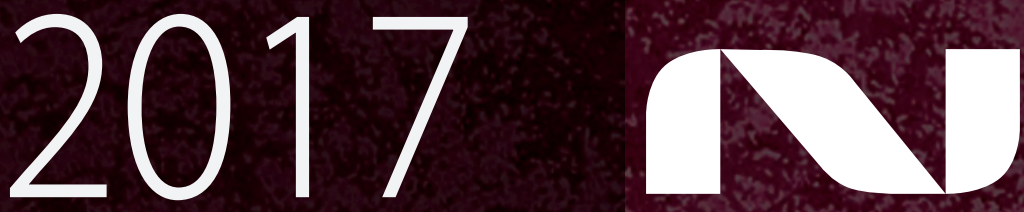

NOVOS CADERNOS NAEA

volume 20 |número 3 | set-dez

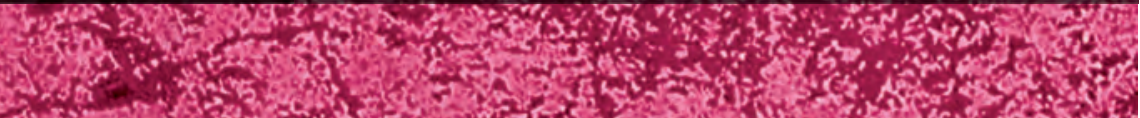

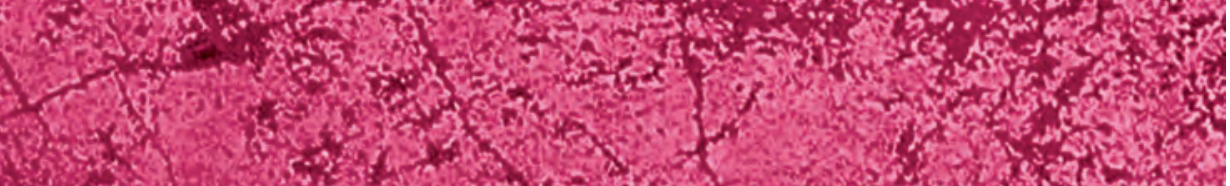

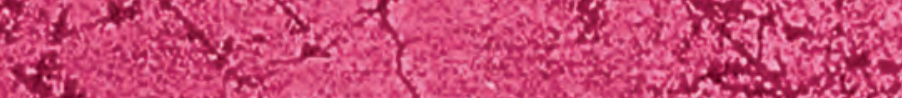




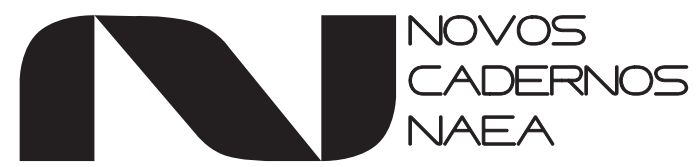

v. 20 , n. $3 \bullet$ setembro-dezembro, 2017 


\section{UNIVERSIDADE FEDERAL DO PARÁ}

Reitor: Emmanuel Zagury Tourinho

Pró-Reitora de Pesquisa e Pós-Graduação: Iracilda Sampaio

\section{NÚCLEO DE ALTOS ESTUDOS AMAZÔNICOS}

Diretor Geral - Durbens Martins Nascimento • Diretor Adjunto - Armin Mathis

\section{NOVOS CADERNOS NAEA}

Publicação do Núcleo de Altos Estudos Amazônicos (NAEA) Universidade Federal do Pará (UFPA)

Periodicidade quadrimestral, volume 20, número 3, setembro-dezembro de 2017

Print ISSN: 1516-6481 - Eletrônica ISSN: 2179-7536 - DOI:10.5801/S21797536

\section{EDITOR CIENTÍFICO}

Edna Maria Ramos de Castro - NAEA/UFPA

\section{COMISSÃO EDITORIAL • NAEA}

Edna Ramos de Castro $\bullet$ Sociologia | Francisco de Assis Costa $\bullet$ Economia

Luís Aragon Vaca $\bullet$ Geografia | Oriana Trindade $\bullet$ Economia

Raimundo Heraldo Maués • Antropologia | Silvio Figueiredo • Sociologia

\section{CONSELHO EDITORIAL}

Alfredo Wagner de Almeida $\bullet$ Universidade do Estado do Amazonas, Manaus, Brasil

Andréa Zhouri • Universidade Federal de Minas Gerais, Belo Horizonte, Brasil

Ana Maria Araújo • Universidad de la República, Uruguay

Célio Bermann • Universidade de São Paulo, São Paulo, Brasil

César Barreira • Universidade Federal do Ceará, Fortaleza, Brasil

Christian Azais • Université d'Amiens, Amiens, França

Clóvis Cavalcanti • Fundação Joaquim Nabuco, Recife, Brasil

German Palacio • Universidad Nacional de Colômbia, Letícia, Colômbia

Eduardo José Viola • Universidade de Brasília, Brasília, Brasil

Elmar Altvater • Instituto Hudson, Berlin, Alemanha

Emilio Moran $•$ Indiana University, Indiana, Estados Unidos

Geraldo Magela Costa $\bullet$ Universidade Federal de Minas Gerais, Belo Horizonte, Brasil

Henri Acselrad • Universidade Federal do Rio de Janeiro, Rio de Janeiro, Brasil

Heloisa Costa $\bullet$ Universidade Federal de Minas Gerais, Belo Horizonte, Brasil

Ignacy Sachs • École dês Hautes Etudes em Sciences Sociales, Paris, França

Jose Ricardo Ramalho $\bullet$ Universidade Federal do Rio de Janeiro, Rio de Janeiro, Brasil

José Vicente T. dos Santos • Universidade Federal do Rio Grande do Sul, Porto Alegre, Brasil

Marcel Bursztyn • Universidade de Brasília, Brasília, Brasil

Marcelo Sampaio Carneiro • Universidade Federal do Maranhão, São Luís, Brasil

Maria Manoel Batista $\bullet$ Universidade de Aveiro, Aveiro, Portugal

Marilene da Silva Freitas $\bullet$ Universidade Federal do Amazonas, Manaus, Brasil

Martin Coy • Universität Innsbruck, Innsbruck, Áustria

Paola Bolados • Universidade de Valparaíso, Chile

Pedro Jacobi • Universidade de São Paulo, São Paulo, Brasil

Pierre Salama • Université Paris XIII, Paris, França

Pierre Teisserenc • Université Paris XIII, Paris, França

\section{EQUIPE TÉCNICA}

Assistentes editoriais: Iraneide Silva, Jondison Cardoso Rodrigues, Rafaela Santos Carneiro, Cleyson Nunes Chagas

Revisão: Albano Rita Gomes, Iraneide Silva, James Leon Parra Mondsalve, Welson Cardoso

Editoração eletrônica: Ione Sena

Capa: Andrea Pinheiro 
Universidade Federal do Pará

Núcleo de Altos Estudos Amazônicos

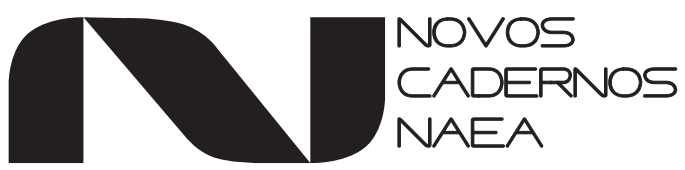

Novos Cadernos NAEA •v. 20, n. $3 \cdot$ p. 1-262 $\bullet$ setembro-dezembro, 2017 Print ISSN: 1516-6481 - Eletrônica ISSN: 2179-7536 - DOI:10.5801/S21797536 
A Revista Novos Cadernos NAEA é um periódico quadrimestral, de caráter interdisciplinar, dedicado à publicação de trabalhos científicos e acadêmicos sobre temas relevantes às áreas do desenvolvimento, sociedade, economia e meio ambiente, com o objetivo de fomentar o diálogo entre as diversas áreas do conhecimento e suas competências, de pesquisadores e instituições de ensino e pesquisa do Brasil e do exterior.

A revista publica textos originais e inéditos em português, espanhol, inglês e francês. Adota a avaliação anônima por pares (peer review) para trabalhos submetidos às seções: artigos originais e de revisão, resenhas, notas de pesquisa, conferências e, eventualmente, dossiês temáticos, volumes especiais e/ou suplementos

\section{INDEXADORES}

Latindex - Crossref - Portal de Periódicos da CAPES - Google Scholar - Research Bib - e-Revistas/Plataforma Open access de Revistas Científicas Electrónicas Espanholas y Latinoamericanas - Directory of Open Acess Journals (DOAJ) - DRJI - Directory of Research Journal Indexing

\section{IDENTIFICADORES}

Univrsal Impact Factor - Journal For Free - Portal para Periódicos de Livre Acesso na Internet - LivRe Diretório Luso-Brasileiro IBICT - Sumarios.org - Repositório Científico de Acesso Aberto de Portugual Microsoft Academic Search - Library of Congress/HLAS Online - Elektronische Zeitschriftenbibliothek (EZB) - Georgetown University Library - SEER IBICT - Cibera: Iberoamérica/España/Portugal - Library Catalog - University of Texas at Austin - WordCat - Diadorim - Diretório de Políticas de Acesso Aberto das Revistas Científicas Brasileiras

\section{CONTATOS}

Núcleo de Altos de Estudos Amazônicos/Universidade Federal do Pará

Rua Augusto Corrêa, no 1, Campus Universitário do Guamá

CEP: 66.075-900, Belém, Pará, Brasil

Tel: (+55-91) 32018515

e-mail: revistanovoscadernosnaea@gmail.br

\section{SUBMISSÃO DE ARTIGOS}

http://www.periodicos.ufpa.br/index.php/ncn

Homepage do NAEA: www2.ufpa.br/naea

Dados Internacionais de Catalogação na Publicação - CIP

(Câmara Brasileira do Livro, SP, Brasil)

Novos Cadernos NAEA, v. 20, n. 3 - setembro-dezembro, 2017 - Belém. Núcleo de Altos Estudos Amazônicos/UFPA, 2016.

Quadrimensal

ISSN Print 1516-6481

ISSN Eletrônico 2179-7536

DOI: $10.5801 / \mathrm{S} 21797536$

O vol. 1, no 1 desta Revista foi publicado em junho de 1998. 1. Desenvolvimento - Periódicos. 2. Meio Ambiente - Periódicos. 3. Amazônia - Periódicos.

CDD 338.9811

(C) Copyright/Direitos de cópia para este número: NAEA/UFPA

Título e textos amparados pela Lei 5.988, de 14 de dezembro de 1973.
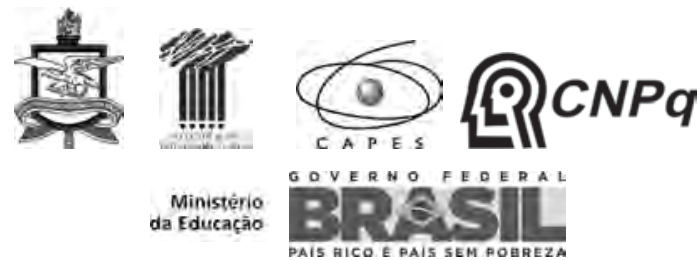

Ministério da Educaçăo 


\section{S U M Á R I O}

\section{Editorial}

\section{Artigos}

09 The logic of the valorization of natural resources in Brazil: historical relationship between the electricity sector and the mining industry in the Amazon

A lógica de valorização dos recursos naturais no Brasil: relação histórica entre o setor elétrico e o setor mineral na Amazônia

André Cutrim Carvalbo e Cleyton Alves Candeira Pimentel

31 Interfaces dos saberes ambientais: complexidade e educação política difusa

Interfaces of environmental knowledge: complexity and diffuse policy education

Antonio Teixeira de Barros

53 Mudanças climáticas: efeitos sociais sobre povos e comunidades tradicionais da Amazônia Climate change: social effects on people and traditional communities in the Amazon

Thereza Cristina Cardoso Menezes e Ana Carla dos Santos Bruno

81 Representação descritiva comprometida com o desenvolvimento das mulheres: quais critérios importam?

Descriptive representation committed to the development of women: what criteria matter?

Rayza Sarmento

97 A construção da rodovia BR-153 na fronteira e urbanização da cidade de Araguaína, Tocantins

The construction of the BR-153 road at the border and urbanization in the city of Araguaína, Tocantins

Roberto Souza Santos

115 A habitação de interesse social no Brasil e sua expressão em Manaus

The social interest housing in Brazil and its expression in Manaus

Elane de Azevedo Pires e Marcelo Gustavo Aguilar Calegare

137 Analysis of industry based on resources and institutions National Desazolves case

Análise da indústria com base em recursos e instituições Caso de Desasufros Nacional

José G. Vargas-Hernández e Gabriela Sarahi González González. 
147 Comunidades negras no Ceará: da invisibilidade à formação dos quilombos contemporâneos Black communities in Ceará: from invisibility to the formation of contemporary quilombos

Leilane Oliveira Chaves e Edson Vicente da Silva

161 Dinâmicas da agricultura familiar com cultura do dendezeiro no município de Moju, na Amazônia paraense

Dynamics of family agriculture with oil palm crops in the municipality of Moju, Amazon region of the state of Pará, Brazil

João Santos Nabum, Cleison Bastos dos Santos e Ana Cláudia Alves de Carvalho

181 Mudanças socioambientais no uso da terra em Altamira, Amazônia oriental

Environmental changes in land use in Altamira, Eastern Amazon

Maristela Marques Silva, Francisco Assis Oliveira e Antônio Cordeiro Santana

203 Agricultura de corte e queima e alternativas agroecológicas na Amazônia

Slash and burn agriculture and agroecological alternatives in the amazon

Anna Karyne Costa Rego e Osvaldo Ryohei Kato

225 Aprendizagem experiencial na formação de gestores socioambientais

Experencial learning in formation of leaders in social and environmental management

Walterlina Brasil, Solange Arrolho e Berenice Simão

\section{Resenhas}

245 Livro: PIZARRO, Ana. Amazônia: as vozes do rio: imaginário e modernização. Trad. Rômulo Monte Alto. Belo Horizonte: Editora da UFMG, 2012.

Cesar Mauricio de Abreu Mello, Juliana Azevedo Hamoy e Leonard J. Grala Barbosa

259 Livro: CAVALCANTI, Clóvis. Pensamento socioambiental e a economia ecológica: nova perspectiva para pensar a sociedade. Revista Desenvolvimento e Meio Ambiente, Curitiba, v. 35, p. 169-178, 2015.

Anna Paula Santos Paiva 


\section{EDITORIAL}

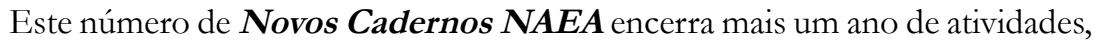
contribui assim ao debate nacional que se impõe, atualmente, de forma seminal, marcado por tensões políticas, avanço de um pensamento conservador que solapa, em várias direções e simultaneamente, um certo padrão de solidariedade construído duramente por gerações anteriores e atuais, de regulamentos de direitos sociais, da natureza, bem como sobre os limites e os deveres de uma vida social que não pode se pautar na desigualdade social, na exclusão e na manutenção sem limites dos benefícios de elites que erigiram, para si, a distância do contrato social, e republicanos, e, por isso, do sentido profundo de cidadania e democracia. Efetivamente, um campo do direito vem sendo construído desde as últimas décadas do século passado, ampliando-o para abrigar os processos de mudança, da sociedade à economia e à natureza, e as novas demandas sobre a diferença, a heterogeneidade, a auto-identidade e a liberdade de ser sujeito.

Nessa linha de pensar o campo político do direito, na relação coma sociedade, a economia e a natureza, apontamos para uma literatura crítica considerável produzida sobre a implantação de empreendimentos minerais no Brasil, decididos e construídos de forma autoritária, de costas para as dinâmicas sociais, econômicas e culturais das regiões onde se instalam e distantes do debate sobre outras opções possíveis no campo do desenvolvimento nacional, regional. Não sem razão, as narrativas dos movimentos sociais sobre os empreendimentos de energia e de mineração, estão associadas à tensão que emerge com sua chegada, devido disputas por territórios e recursos. Práticas coloniais observadas, igualmente, nos estudos sobre os grandes projetos de energia, notadamente Hidrelétricas e Plantas Aeólicas, associadas aos grandes projetos de mineração, de capital nacional/internacional, a exemplo dos estudos referidos a sua expansão.

$\mathrm{O}$ artigo The logic of the valorization of natural resources in Brazil historical relationship between the electricity sector and the mining industry in the Amazon ao procurar analisar a relação entre o setor elétrico e o setor mineral na Amazônia brasileira, considera que esta região possui uma lógica econômica específica que aparece nessa relação entre o setor elétrico e o setor mineral. A demonstração empírica pode ajudar a montar uma cartografia desses processos a partir do olhar de atores diversos - locais, nacionais e internacionais - envolvidos em criar um campo de experimentação do desenvolvimento regional a partir do olhar de baixo, da experiência localizada.

Antonio Teixeira de Barros no artigo Interfaces dos saberes ambientais: complexidade e educação política difusa analisa as interfaces dos saberes ecológicos com a educação ambiental e política, ambas entendidas como educação difusa que se realiza no âmbito das relações sociais e educativas do cotidiano. Considera relevante a conversação civil e a cidadania, numa perspectiva interdisciplinar. Em outro artigo sobre a relação sociedade, economia e ambiente, na perspectiva antropolóogica, Menezes e Bruno examinam as discussões sobre mudanças climáticas perguntando se elas não estariam 
influenciando práticas de povos e comunidades tradicionais em Tis e UCs, tendo como foco os efeitos sociais das políticas públicas e a incorporação da temática das mudanças climáticas nas agendas dos movimentos sociais. A desigualdade também vista pela dimensão de gênero é contemplada neste número da revista. No artigo Representação descritiva comprometida com o desenvolvimento das mulberes, a autora informa ser reduzida a discussão sobre a representação descritiva comprometida com causas feministas. Procura demonstrar, teoricamente, que ela pode ser um instrumento para se pensar parâmetros da representação no cenário político brasileiro.

A partir dos projetos de colonização e de desenvolvimento regional, Roberto Santos cartografa os impactos territoriais de empreendimentos desenhados no espaço urbano de Araguaina, estado do Tocantins. Ainda sobre a crise urbana e a desigualdade no Brasil, Pires e Aguilar Calegare apontam resultados de pesquisa sobre a habitação de interesse social no Brasil, as políticas habitacionais e a questão social, tendo como espaço empírico a cidade de Manaus. Outra perspectiva, a da observação sobre processos industriais, no México, e a composição de empresas de gestão ambiental, nas áreas urbanas, o artigo - Analysis of industry based on resources and institutions. National Desazolves case - identifica a dinâmica da gestão de resíduos, e examina a empresa National Desaz̧olves, as instituições formais, e as regras limitantes de poluição ambiental.

Vários artigos tratam de temas relevantes no campo da agricultura familiar e da participação política. Chaves e Silva arrolam processos de invisibilidade no Ceará frente ao reconhecimento de certas comunidades quilombolas. Disputas territoriais são ressaltadas na expansão da dendeicultura, decorrente de Programas Nacionais que propugnavam a associação entre agricultura familiar e empreendimento intensivos de dendê, e, com dados de pesquisas recentes, os autores trazem os resultados da expansão da referida associação na dendeicultura. Mais voltado a pensar a produção familiar, na relação com práticas que mostraram eficácia entre grupos tradicionais, e a agricultura de corte e queima, Karyne Rego e Kato analisam formas de uso do solo baseadas nos princípios agroecológicos, e identificam novas formas de cultivo mais sustentáveis. $\mathrm{Na}$ direção de pensar os usos sociais e econômicos da terra, centrando na reflexão sobre as mudanças socioambientais, Maristela Silva, Francisco Oliveira e Antônio Cordeiro Santana tratam dos sistemas produtivos e a adoção de atividades variadas na composição da renda do grupo analisado, e das mudanças socioambientais.

O artigo de Brasil, Arrolho e Simão analisa a educação ambiental com base na teoria de sistemas socioecológicos complexos e na experimentação metodológica para subsidiar e identificar a efetividade da prática exponencial na formação profissional.

Este número de NCNAEA traz duas resenhas, sendo a primeira sobre o festejado livro de Ana Pizarro, Amazônia - as vozes do rio: imaginário e modernização, de autoria de Cesar Mauricio de Abreu Mello, Juliana Azevedo Hamoy e Leonard Grala Barbosa. A segunda, sobre a publicação de Clóvis Cavalcanti intitulada Pensamento socioambiental e a economia ecológica: nova perspectiva para pensar a sociedade, feita por Anna Paula Santos Paiva.

Edna Ramos de Castro Editora da Revista 


\section{The logic of the valorization of natural resources in Brazil: historical relationship between the electricity sector and the mining industry in the Amazon}

\section{A lógica de valorização dos recursos naturais no Brasil: relação histórica entre o setor elétrico e o setor mineral na Amazônia}

André Cutrim Carvalho - Holds a doctorate in Economic Development and a Postdoctorate in Economy from the Instituto de Economia (IE) at the UNICAMP. He is a professor at the Faculdade de Ciências Econômicas (FACECON), and on the Postgraduate Program in the Management of Natural Resources and Local Development in the Amazon (NUMA) at the UFPA, and is a Visiting Professor at the IE/UNICAMP. E-mail: andrecc83@gmail.com

Cleyton Alves Candeira Pimentel - is currently completing his graduate studies in Economics at the Faculdade de Ciências Econômicas (FACECON), linked to the Instituto de Ciências Sociais Aplicadas (ICSA), at the UFPA. E-mail: cleyton_underline@hotmail.com

\begin{abstract}
Resumo
O presente artigo procura traçar uma análise do ponto de vista histórico para, posteriormente, compreender a relação econômica entre os fenômenos históricos ocorridos no Governo Militar e, recentemente, no governo do expresidente, Luiz Inácio Lula da Silva. Nestas condições, o artigo procura concentrar sua análise no entendimento da relação entre o setor elétrico e o setor mineral na Amazônia brasileira, principalmente na Amazônia Oriental. A principal conclusão é que a Amazônia brasileira e Oriental possui uma lógica econômica local específica, que impacta (in)diretamente no desenvolvimento do setor elétrico e no setor mineral do país. Contudo, há espaço para a promoção de uma conexão muito mais íntima entre esses setores e, é claro, um potencial intenso para a exploração de reservas minerais, inclusive, com a perspectiva de verticalização da produção e geração de emprego, renda e agregação de valor para a economia nacional e regional.
\end{abstract}

\section{Palavras-chave}

Setor Elétrico. Setor Mineral. Amazônia Brasileira. Amazônia Oriental. Verticalização da Produção.

\begin{abstract}
The aim of this article is to construct an historical analysis in order to understand the economic relationship between the historical phenomena that occurred during the Military Government and more recently, during the government of (former) President Luiz Inacio Lula da Silva. Accordingly, the article seeks to focus its analysis on understanding the relationship between the electricity sector and the mining industry in the Brazilian Amazon, especially in Eastern Amazon. The main conclusion is that both the Brazilian and Eastern Amazon demonstrate a specific local economic logic, which have impacted (in) directly on the development of the electricity sector and in the mining industry throughout the country. However, it has also been possible to promote a much closer connection between these two sectors and, likewise, a strong potential for exploiting mineral reserves, together with the verticalization of production and the generation of employment, income and added value to the national and regional economy.
\end{abstract}

\section{Keywords}

Electricity Sector. Mining Industry. Brazilian Amazon. Eastern Amazon. Verticalization of Production. 


\section{INTRODUCTION}

At the outset, it is essential to highlight Brazil's extraordinarily high capacity to supply raw materials. Within this context, the first historical moments in which this may be observed occur within the period of military rule (1964-1985), with particular emphasis on both the Radar project in the Amazon, better known as RADAM, and the Mineral Resources Research Company (CPRM) implanted in 1970 and 1969, respectively.

Within these terms, the Brazilian Amazon assumes an important economic role in concentrating an enormous potential for mining and, as will be observed, energy. Following the historical context of the military regime, the aims of the abovementioned projects were considerably centered on locating areas in the Amazon that contained ore reserves, specifically in the eastern part of the region, i.e., in the so-called Eastern Amazon, which is composed of municipalities located in the states of Amapá, Maranhão, Pará, Tocantins and Mato Grosso, with the exception of municipalities in the Pantanal region of Mato Grosso.

Studies by Lobo (1996) demonstrate that the dynamics of mining in the state of Pará, especially near the region of Carajás, were driven and accompanied by the use of the Tucuruí Hydropower Plant (HPP), which was a key factor in intensifying the exploration and export of raw materials. Lobo (1996) also observes that the Tucuruí HPP, located in the municipality of Tucuruí, was initially planned in accordance with agreements made between international mining firms, and as such, was made effective through investments from the Brazilian government.

Under these conditions, therefore, it is possible to realize that in a partially exclusive manner, the Tucuruí HPP provided electric energy to support the production of the mining companies across the region and, conclusively, this is linked to production localization factors. This would seem to signify that the hydroelectric potential of electric energy production in Tucuruí was leveraged and potentialized as a result of the mining production in force during the period of the Brazilian military government.

According to research by Lobo (1996) and Silva (2011), from an historical viewpoint, during the military regime, both the mining industry and the electricity sector in the Brazilian Amazon were directly affected by the national economic development plans. The main aim was to increase the growth of the country's gross domestic product (GDP), as envisaged through the National Development Plans I and II (known as PND I and II), the Government Economic Action Program (PAEG) and the Strategic Development Plan (PED). 
Once the Brazilian political structure had undergone a period of redemocratization, primarily after the 1988 Federal Constitution, the political and economic orientation adopted by Brazil in relation to the electricity sector and mining industry, both nationally and regionally, very closely approached that of the military regime.

In terms of Eastern Amazon, and knowing that historically both the electricity sector and the mining industry are regionally sensitive in relation to planning guidelines and macroeconomic governance, it is possible to relate these two sectors in the sense of only consolidating the national development megaprojects. In other words, this should be understood in its totality, one that encompasses scales of both national and regional development, in which megaprojects are directed towards logistics, mining and energy.

In recent studies by authors such as Monteiro (2005) and Coelho et al. (2011), it has been possible to verify that the national projects and plans proposed during the government of former President Luiz Inacio Lula da Silva (who was always simply referred to as Lula), such as the Growth Acceleration Programs I and II (PAC I and II), brought about the same impact on the electricity sector and mining industry as PND I and II, PAEG and PED.

Within such conditions, the plans linked to the Initiative for the Integration of Regional Infrastructure in South America (IIRSA) also draw attention to the (in)direct mediation of an effectively singular relationship between the mining industry and the electricity sector in the Amazon Region, starting from an international context.

The present article therefore seeks to investigate the economic relationship between the historical phenomena, from a historical-theoretical perspective, i.e., the impact that the development of the mining economy in the Amazon has produced for structuring the electricity sector across the region and, consequently, the economic planning involved in the region, through the socalled constitutionally democratic Brazilian state during the Lula government, from 2003 to 2010.

This paper is divided into six sections, in addition to this introductory section and the final considerations presented in the last section. In the second section, the methodological aspects of the research are objectively presented; the third section discusses the electricity-mining sector situated within a national and regional macroeconomic context during the period of the military regime; the fourth section demonstrates a correlation between the national plans and the regional expansion of the Brazilian electricity sector during the democratic period of the Lula government (2003-2010); and the fifth section presents the 
logic of the valorization of mineral resources and the centrality of the energy economy in the Eastern Amazon during the Lula administration.

\section{METHODOLOGY}

According to Carvalho (2005, p. 11), "methodological specification constitutes a mandatory part of academic research, which adopts a scientific method. However, it is necessary to distinguish between the method of approach and the said methods of investigation". Carvalho (2005, p.11) observed that "the method of approach is related to the philosophical affiliation and the degree of abstraction from the studied phenomenon, since the research methods or the research procedures consist of concrete stages of investigation and the use of appropriate research techniques".

In the social sciences, a methodological restriction is generally imposed: which is the need to confront a perceived reality, detached from that which is concrete, with the empirical reality, i.e., that which is perceived by our senses. On the other hand, as Lakatos and Marconi (1991, p. 106) observed, "practical knowledge is submitted to the need of an immediate connection with the reality to which it refers."

Therefore, in order to develop this article in the best possible manner, we have adopted a methodology involving a historical-theoretical analysis, which comprises the statistical data from the electricity sectors, based on the national and 10-year plans for developing energy in Brazil.

\subsection{DATA SOURCE}

First, it should be emphasized that the study object of this research is Eastern Amazon. Therefore, in order to analyse the mining industry in question, we will use a database, referring to the exportation of iron ore, obtained from the Ministry of Industrial Development and Foreign Trade (MDIC) and, also, from the Brazilian Mining Institute (IBRAM).

According to decree-law no 291/1967 and no 356/1968, Eastern Amazon is geographically composed of the states of Pará, Amapá, Maranhão, Tocantins and Mato Grosso, as illustrated in Figure 1. The most outstanding cities/ municipalities in Eastern Amazon that present significant levels of mineral reserves of iron, magnesium, aluminium, alumina and bauxite are located in the states of Pará (PA), Maranhão (MA) and Amapá (AP). 
Figure 1 - The Brazilian states that constitute Eastern Amazon

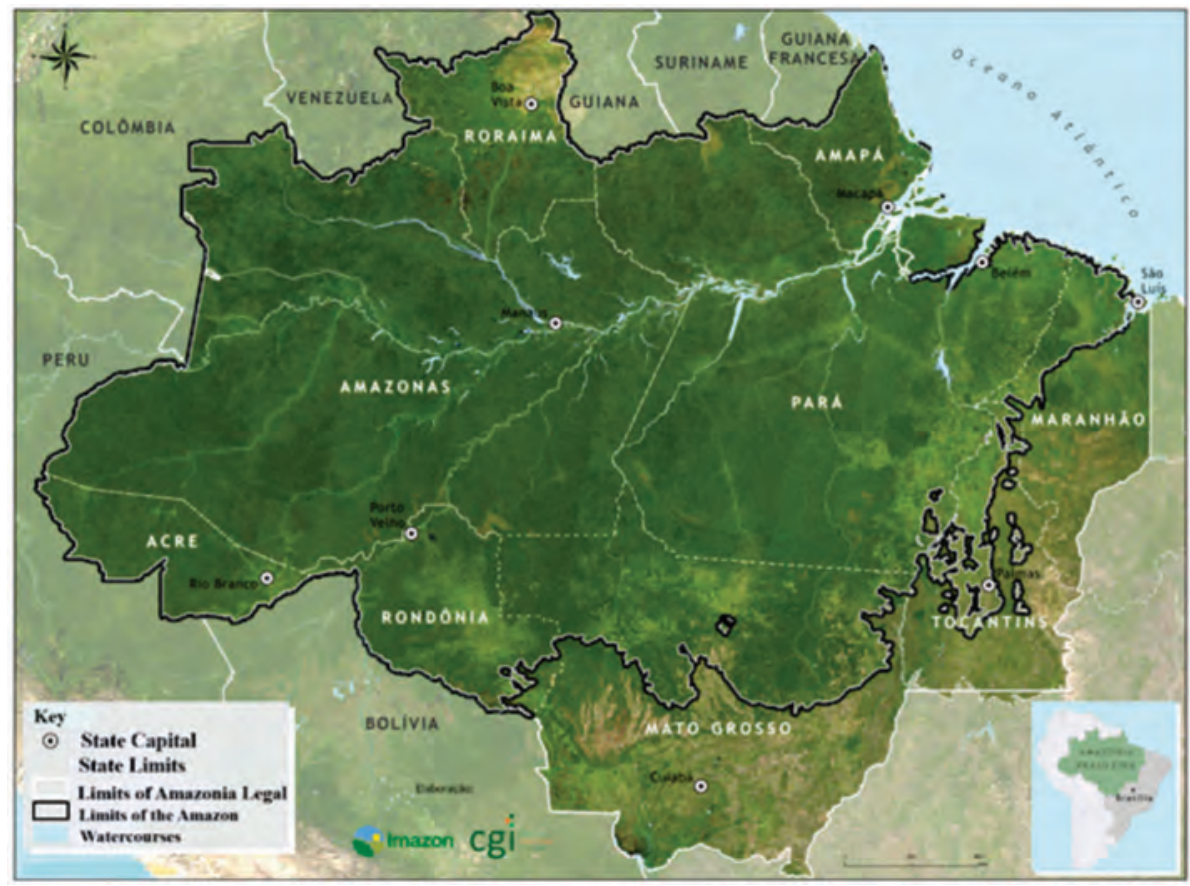

Sourge: IMAZON (2016). * Legend Adapted by the authors.

Source of Images: Modis, NASA.

The states that make up Western Amazon on the other hand are Amazonas, Acre, Rondônia and Roraima. However, the main difference between Eastern Amazon and Western Amazon lies precisely in its economic terms. While the economic strength of the western side is concentrated in the Manaus Free Trade Zone (ZFM), ecotourism, the petrochemical complex of Urucu-Coari-Manaus and vegetal/mineral extractive activities, Eastern Amazon is mostly centered on the metallic and non-metallic mineral economy, livestock farming and on the production of primary goods and food - even being low value-added activities - for exportation.

2 THE ELECTRICITY-MINING SECTOR IN THE NATIONAL MACROECONOMIC CONTEXT: SECTORAL GROWTH MODELS DURING THE PERIOD OF THE MILITARY GOVERNMENT (1964-1985)

According to Gomes and Vieira (2009), the electricity sector, to a certain extent, played a leading role in the Brazilian economy during the military government, specifically when this merger resulted in the creation of a "state 
model" for economic performance, i.e., when Brazil actually began to operate within the electricity sector. In the words of Gomes and Vieira (2009: 300), "ELETROBRAS entered as the main institutional medium, as well as the company that induced the nationalization and state control of the electricity sector", thereby enabling the distribution of large investments to the sector throughout the country.

Silva (2011) outlines three historical stages that may be used to establish a chronological understanding of the impacts of the macroeconomic planning on the electricity sector during the military government. They are as follows: 1) seeking the recovery of public finances and economic stabilization (1964-1967); 2) the economic miracle (1968-1973); and 3) depletion of the model (1974-1985).

Table 1 presents the macroeconomic development plans, their objectives and the impacts on the Brazilian electricity sector. In the historical conception of several authors, such as: Gomes et al. (2002), Gomes and Vieira (2009) and Silva (2011), the first stage was marked by the need to fund government spending, and expenses were thus centered on infrastructure, and consequently on the infrastructure of the electricity sector.

Table 1 - The macroeconomic plans and their impacts on the electricity sector

\begin{tabular}{|c|c|c|}
\hline Plan & Method used & $\begin{array}{l}\text { Changes in the electricity } \\
\text { sector and projects }\end{array}$ \\
\hline $\begin{array}{l}\text { The Government's } \\
\text { Economic Action } \\
\text { Plan (PAEG) - } 1964\end{array}$ & $\begin{array}{l}\text { Increased government } \\
\text { spending on economic and } \\
\text { social infrastructure, with } \\
\text { emphasis on public investment. }\end{array}$ & $\begin{array}{l}\text { New financing mechanisms } \\
\text { according to Laws } 4,357 / 64 \\
\text { and } 54,936 / 64 \text {, which related } \\
\text { the obligations of the National } \\
\text { Treasury and the monetary } \\
\text { correction of fixed assets to } \\
\text { sectoral investment. (LIMA, } \\
\text { 1999). }\end{array}$ \\
\hline $\begin{array}{l}\text { The Strategic } \\
\text { Development Plan } \\
(\text { PED) - } 1968\end{array}$ & $\begin{array}{l}\text { Consolidation of the internal } \\
\text { market and price stabilization } \\
\text { for greater participation on the } \\
\text { international market. }\end{array}$ & $\begin{array}{l}\text { An increase in international } \\
\text { investments within the sector } \\
\text { and tariff reforms due to tax } \\
\text { and fiscal changes. }\end{array}$ \\
\hline $\begin{array}{l}\text { The National } \\
\text { Development Plan } \\
\text { (PND I and PND II) } \\
-1972-1979\end{array}$ & $\begin{array}{l}\text { Developing the production of } \\
\text { capital goods and increasing } \\
\text { industrial production in } \\
\text { response to the international } \\
\text { crisis. }\end{array}$ & $\begin{array}{l}\text { The creation of "Plan } \\
90 ", \text { aiming at a scaled-up } \\
\text { expansion of the electric } \\
\text { sector for the growth in } \\
\text { energy demand brought on by } \\
\text { industrialization. }\end{array}$ \\
\hline
\end{tabular}

Source: Silva (2011). 
In the first stage it is possible to identify the dominant presence of the Government's Economic Action Plan (PAEG), while simultaneously, the second stage is linked to the National Development Plan (PND) and, in accordance with the third, we may identify an attempt to restructure the Brazilian electricity sector.

The second stage is characterized by a significant expansion of the electricity sector, which was marked mainly by PND I and PND II. The major milestone of this stage involved the creation of state-owned companies in the Brazilian electricity sector, which were subsidiaries of ELETROBRAS, such as Centrais Elétricas do Sul do Brasil S.A. (commonly referred to as ELETROSUL), and later, Centrais Elétricas do Norte do Brasil S.A (ELETRONORTE).

During the third historical part of the military government, the most outstanding central aspects regarded the changes in absorbing investments related to the inability of ELETROBRAS to self-fund and, consequently, its gradual loss of significance, besides several other problems connected to electric energy tariffs, as defended by Silva (2011).

Indeed, all these situations during the third historical part arose in reaction to the Brazilian macroeconomic environment, which, in an inflationary environment with high interest rates, was an extremely unfavorable context for many enterprises. On the other hand, the Brazilian electricity sector during the period of the military regime, demonstrated a significant expansion of its supply, particularly in its institutional activities.

\subsection{THE POSITION OF THE ELECTRICITY SECTOR IN EASTERN AMAZON AND ITS RELATIONSHIP WITH THE MINING INDUSTRY DURING THE MILITARY GOVERNMENT}

According to Lemos (2004), during the military government, the electricity sector in the Brazilian Amazon served as an incentive for regional industry, i.e., the manner in which the military government handled the sector was directly linked to industry. During the first and second phases of the military government, the management and planning of the electricity sector was under the responsibility of the Superintendency of the Amazon Economic Recovery Plan (SPVEA) and later the Superintendency of the Development of the Amazon (SUDAM).

However, it may be stated that the electricity sector in Eastern Amazon only received its due attention and importance, through the receipt of national investments, after the third historical moment of the military government, specifically with the creation of ELETRONORTE, in 1973. Initially, it is possible 
to confirm that the connection between the electricity sector and the mining industry was also possible due to the facilities made available to the federal government through the legislative apparatus.

In 1967, for example, the new Brazilian Mining Code was introduced, which implemented the res nullius regime, providing mining and electric energy companies with incentives in order to exploit natural resources. During this historical interval in the military government, certain important events took place, especially the discovery of ore reserves around the Trombetas River in the 1960s, specifically in the municipality of Oriximiná in the state of Pará, and in other places with equally strategic mining potential, such as Serra do Navio-AP, Marabá-PA, São Luís-MA, Paragominas-PA and Carajás-PA.

According to Lobo (1996) and Gonçalves (2015), the period 1974-1975 was characterized by the creation of the Program for Amazonian Agricultural/ Livestock and Agromineral Centres (POLAMAZONIA) and the Amazon Radar Project (RADAM), which prompted a number of geological surveys on water and mining potentials in Eastern Amazon.

In general, the POLAMAZONIA and RADAM occurred in the same period as the so-called "Plan 90". According to Gonçalves (2015), there was as yet no demand in Eastern Amazon for an electric supply capacity that would fully support the industrial sector of the time, however, it was only because of these events that the region's electricity sector received the due and legitimate importance in national economic planning.

Silva (2011) emphasizes that "Plan 90" contained the same premises as PND II, and thereby not only aimed at expanding sectoral arrangements of electric energy, but also at bringing about a significantl change in its energy production base and, on the part of the federal government, there was an initiative to execute megaprojects throughout the region. Given this context, it is therefore possible to verify that the development of electric power in Eastern Amazon was effectuated according to the growth of mining in the region.

As Gonçalves (2015, p.76) states: “the dynamics of the region's electricity sector were due to the expansion of the industrial production capacity of mining". The first large-scale plant built in Eastern Amazon was the Coaracy Nunes HPP in the state of Amapá. According to Lemos (2004), the primary objective of this HPP was to meet the demands of the mining companies in the region, as was the case, for example, with the Industry and Trade of Ore Company, known as ICOMI.

In 1980, with the introduction of the Grande Carajás Program (PGC), ELETRONORTE became responsible for conducting several research 
projects, with the objective of expanding its energy production base owing to the exploitation of aluminum, alumina and iron in the region between Carajás and the state capital of Maranhão, São Luís. Amongst the main companies that demonstrated a keen interest in the region, and especially for these developments in particular, the most significant were Japanese companies such as Nippon Amazon Aluminum Corporation (NAAC).

Lobo (1996) and Gonçalves (2015) stress that these foreign companies required a significant contribution from public investments in infrastructure and energy to complement their investments. In 1985, the construction of the Tucuruí HPP was successfully completed in the state of Pará, becoming one of the largest Brazilian hydropower plants - with an operating capacity of 8,370 MW - just slightly less than the Itaipu HPP, in the state of Paraná.

According to Pinto (2012), the aim of the Tucuruí HPP was to meet the demand of companies such as NAAC, and other Japanese companies in association with the Vale do Rio Doce Company (CVRD), Alumínio Brasileiro S.A. (ALBRAS), the Alumina do Norte do Brasil S.A. (ALUNORTE), and the Aluminum Consortium of Maranhão (ALUMAR).

It may therefore be seen that the national macroeconomic plans assumed during the military government eventually took on a very particular, unique significance through the regional-territorial binome of Eastern Amazon. These programs promoted a significant growth in mining production and enabled a broad expansion of supply and institutional arrangements for the electricity sector within the region.

3 THE NATIONAL DEVELOPMENT PLANS AND THE REGIONAL EXPANSION OF THE ELECTRICITY SECTOR DURING THE DEMOCRATIC PERIOD OF THE LUIZ INÁCIO LULA DA SILVA GOVERNMENT (2003-2010)

The basic premise of the historically inherited model for the electricity sector, identified in the government of the former president of Brazil, Luiz Inácio Lula da Silva, was the adoption of a previous sector model termed the Project for Restructuring the Brazilian Electricity System (RESEB), instituted through Law 9.648/98, in 1998.

The main aim of this model was to allocate the sector into its respective functionalities, to divide the respective tariffs of each service into the generation, transmission and distribution of electric power and, finally, to bring strong competition onto the market, which provided the conditions for the appearance 
of a new economic agent: the energy marketer, whose role, as Silva highlighted (2011), was to make the market more "liquid".

In 2013 - with the interruption of the RE-SEB - a new sectoral growth model was established based on new structuring, and with differentiated aspects. In 2004, however, Law $\mathrm{n}^{-}$10,848 became institutionalized, and promoted the Regulated Contracting Environment (ACR) and the Free Contracting Environment (ACL) in the electricity sector, whereby both contracts had to be duly registered with the Chamber of Commerce for Electric Energy (CCEE).

Thus, the basic aims of these contracting environments were defined as a means of conducting electric energy auctions, which thereby enabled greater dynamics for the economic sector and, above all, veracity. It should be noted that the ACL was inserted into the scope of distributing electric energy to the ACR, which included free consumers and traders in electric energy.

However, Silva (2011) observes that the ACR demonstrated an important capacity for maintaining safety in stabilizing tariffs from the forms of market competition. However, the basic assumptions of both the ACR and the ACL were in the electric energy trading agent and also in the flexibility of raising funds for the sector, which eventually formalized the Wholesale Electric Energy Market (MAE).

Thus, the change from RE-SEB to the ACR and ACL standards altered the way in which electric energy in Brazil was traded, thereby enabling a fully competitive market for the generation of electric power, and allowing the auction prices of the Brazilian energy sector market to become better established.

In other words, a fertile field was established for a high level of competition between companies in the sector. In addition, in 2004, alongside this, the Energy Research Company (EPE) was created, and was responsible for conducting studies to take greater advantage of energy in Brazil.

During the Lula administration, the Brazilian electricity sector eventually underwent a great degree of structuring through the National Energy Plan 2030 (PNE 2030), launched in 2006 through the EPE, which stipulated a diversity of investments for the electricity sector. Therefore, the national electricity sector felt the need to consolidate a funding base, which duly took form through the following agents: the National Bank for Economic and Social Development (BNDES), the Ministry of Mining and Energy (MME) and, lastly, the National Electric Energy Agency (ANEEL), as adopted by Brazil (2007).

Thus, with a well-defined funding base, more significant conditions were potentiated and integrated into the electric sector so that it was able to adopt an investment capitalization model through energy auctions per Megawatt (MW). 
Silva (2011) upholds that this historical framework gave the Brazilian electricity sector a much more dynamic structure than the previous - instituted in RE-SEB - with a more dynamic, broader financial capacity.

Tolmasquim, Guerreiro, and Gorini (2007) address this issue when discussing contracting for the electric sector after the enactment of Law № 10.848, which legitimized the sale of energy as either a regulated contract or a free contract within the National Integrated System (SIN), and Law № 10,847, which gave broader responsibilities and competencies to the EPE, as may be observed through data from Brazil (2007).

Examples of this new dynamization in the sector may be observed in the contracting that took place between 2005 and 2010. During this period, thirtyseven contracting events were held, where 6,237 TWh (terawatt-hour) of energy were traded, bringin the installed capacity in 2010 to approximately 113.3 GW (gigawatt) of power.

Tolmasquim, Guerreiro and Gorini (2007) considered that this new model for the Brazilian electric sector enabled the generation of a large capacity so as to expand energy production. As a result, it became a potential force for attracting investment, which brought a reasonably safe stability to the supply and distribution of electricity in Brazil.

\subsection{EXPANSION PLANNING AND PROJECTS IN THE ELECTRICITY SECTOR IN EASTERN AMAZON DURING THE LULA GOVERNMENT: THE REPRESENTATIVE CASE OF THE BELO MONTE HPP}

In the view of Gonçalves (2015), the series of blackouts that occurred in the years 1999, 2001 and 2002 were, in fact, decisive for creating major plans and forms of planning for the Brazilian electricity sector, which eventually also encompassed the Amazon Region as a target for future investments. Gonçalves (2015) indicated that a region calculated as being "underused", according to the Ten-Year Energy Expansion Plan 2022 (PDE 2022), instituted in 2013, presented in the region of twenty-three hydroelectric projects destined for the hydrological exploration of the Brazilian Amazon Growth Acceleration Programme (PAC).

From the perspective discussed in Brazil (2013), the PDE 2022 states that the execution of works in the Amazon is divided into two stages: 1) Period 2013-2018, forecasting a future potential of 20,683 MW; 2) Period 2018-2022, 
forecasting a future potential of 19,917 MW and possibly an increase of 41,000 to the National Interconnected System (SIN) ${ }^{1}$. As a result, a further 12,283 MW of capacity will be added and consequently made available to the North - including the states of Amazonas, Amapá, Sergipe, Goiás, Acre, Roraima and Mato Grosso - which together will total 4,110 MW until the year 2022.

Gonçalves (2015) predicts that the potential for the generation of electricity in Eastern Amazon will correspond to a higher average of 57,410 MW, or approximately $48.03 \%$ of all electricity capacity in the country. Gonçalves (2015) highlights that the Amazonian electricity distribution system contains two subsystems: the Northern subsystem is composed of the states of Pará, Tocantins and Maranhão, and the isolated subsystem is composed of the states of Amazonas, Amapá and Roraima².

In this context, the expansion of SIN in the Brazilian Amazon became a higher priority objective, especially regarding the need to increase the distribution networks, as well as the region's capacity to generate electric energy. The national interconnected system was of extreme importance since it sought to integrate the Brazilian Amazon into a macro supply of electric energy, which represented an alternative attraction for companies and other activities such as metallic and nonmetallic ore.

Within the logic of expanding the electricity sector in the Amazon, in addition to planning the distribution and the interconnection of networks based in the Amazon region, the main outstanding construction works were the Belo Monte HPP, the Jirau HPP, and the Santo Antônio HPP. According to Coelho et al. (2011), the Belo Monte HPP project originated from the time of the military regime, but was only actually implemented in 2015, after several attempts throughout the process to remodel it and reorganize it structurally. The capacity of the Belo Monte HPP is around 11,223 MW, which represents a greater energy production capacity than that of Tucuruí, making it the third largest hydropower plant in the world.

According to Coelho et al. (2011, p.90), "The estimated value of the project cost around $\mathrm{R} \$ 28.5$ billion, way above the official forecast of $\mathrm{R} \$ 19$ billion". Moreover, the companies involved in the enterprise were divided into a) management: the National Electric Energy Agency (ANEEL), ELETROBRAS;

1 The National Interconnected System (SIN) is responsible for connecting the transmission and production of energy in which the hydroelectric and thermoelectric plants function, both of which are interconnected through na electric energy transmission network.

2 According to the Ten-Year Energy Expansion Plan, between 2006 and2015, the basic premises for understanding the interconnection of subsystems are precisely through the inclusion of the Acre/Rondônia system in the SE/CO subsystem (Southeast and Central-West) and the isolated Amazonas/Amap/Roraima isolated system - termed the "N" subsystem. 
b) the construction companies: Andrade Gutierrez; and c) the consumers: mining companies such as Vale and Alcoa. Amongst these categories of companies that make up the Belo Monte Construction Consortium (CCBM), we would highlight CVRD, ALCOA, the Companhia Siderúrgica Nacional (CSN), the Votorantim Group and other "commodity producers".

Furthermore, decisions taken by these companies occurred within a financial environment, more precisely where the central financing structure of the Brazilian electricity sector functions, i.e., within the Wholesale Energy Market (MAE), thereby enabling the CCBM to enter the configurations of the ACR and ACL types.

4 THE LOGIC OF THE VALORIZATION OF MINERAL RESOURCES AND THE CENTRALITY OF THE ENERGY ECONOMY IN EASTERN AMAZON DURING THE LULA GOVERNMENT

Also, within the scope of the federal government, there was a profound change in the format of regional development. During the period of the military regime, the fundamental aim of the planning model was to modernize the Amazon Region. However, as Monteiro (2005) emphasizes, after 1990, regional development took a new direction: that of the structural axes for national and international integration, which promoted a sophisticated mining logic within the region.

These axes provided a better link between the different regions through an increase in the flow of transport, which responded to the actions of opening highways and waterways in order to improve the competitive capacity of the market. The significance of this action was termed by Monteiro (2005, p.195) apud Brasil (1997a, p.106) as being a "generation of productive integration chains".

A key factor in the political decisions of this new model, through Constitutional Amendment $\mathrm{n}^{\mathrm{0}}$ 6, was to permit the entry of foreign capital, and allow it to have a majority participation in the mining companies. For Monteiro (2005, p.195), "one example of the ease with which this capital entered was given in relation to the rights of chromium ore reserves in the municipality of MazagãoAP, which were acquired by the Norwegian company Elkem, and which started to run activities for the company Mineração da Vila Nova. "

Within this context, as a fundamental determination, the government of (former) President Lula presented a policy based on the logic of the valorization of mineral resources. Thus, the direction and execution of the National Regional Development Plan (PNDR) aimed to "keenly explore the endogenous potentials 
of the magnificent, diversified regional base of development, in accordance with the current social foundations of a more diversified production," as may be confirmed in Brazil (2003a, p.12).

The Brazilian government's incentive in exports and market integration culminated with extreme balances for companies such as ALUNORTE, which had a significant jump in its exports from 730 thousand tons to 1.4 million tons a year. In 2004, this situation was repeated with the company CVRD, which in the Carajás-PA region over the next two decades became responsible for the annual commodification of 140,000 tons of copper ore in the Sossego/Sequeirinho complex. According to Monteiro (2005: 197-198):

The government's objective was to valorise the surplus and its participatory expansion in the trade balance. The logic behind mining-metallurgy in the region was to ensure its economic viability based on the guarantee of using the comparative advantages arising from the possibility of accessing environmental resources and services at a low cost.

In the state of Pará, access to natural resources was key to the dynamization process of the region around the logics of the valorization of mining. Data by Monteiro (2005), for example, demonstrates that the amount of mineralmetallurgical exports in 1976 amounted to approximately US\$109.83 million of the trade balance of Pará. In addition, in 2004, total exports reached US \$ 3.8 billion, or $77 \%$ of the total value of exports from the state of Pará, which displays the importance of this sector to the local economy.

\subsection{THE MINING-ELECTRICITY SECTOR BIOME: THE INTERESTS OF THE INTERNATIONAL MARKET IN EASTERN AMAZON AND THE CONTINUITY OF THE MEGAPROJECTS}

From a historical viewpoint, changes in the production and distribution models of electric energy have sought to place great emphasis on the production of the infrastructural capacity of hydropower plants, with the aim of maintaining greater dynamism in the generation of electric energy, mainly supported by SIN and, by vast incentives to the electricity distribution companies across the country.

These profound structural changes in the national electricity sector have allowed the development of the Amazonian electric sector, alongside the mining industry, inducing them towards possible mergers in the market. Under these conditions, the question that immediately springs to mind is, how? The main hypothesis, arising from this question, is that the effect of the electric energy marketer provided investment flexibility in order to provide funding for the sector, which led to the possibility of achieving a greater flow of circulating capital. 
From the perspective of Castro (2012) and Coelho and Monteiro (2013), it is possible to state that the mining companies are affiliated to the electric power companies in Eastern Amazon, indicating future mergers between the two sectors, i.e., it is clear that this opening for mergers between these two sectors is not limited to any one region.

For Castro (2012), national policies, especially PAC I and PAC II, are harnessed to the intervention of the Initiative for the Integration of the Regional Infrastructure in South America (IIRSA) ${ }^{3}$, which has sought to adopt modernization models based on megaprojects, especially in the sense of "competitive integration", whereby both are linked by the integration and development axes ${ }^{4}$.

The electric energy integrations with the ore deposits in the Brazilian Amazon are directly connected to the Tucuruí hydropower plant in the state of Pará and, in the future, will be interconnected by the electric power transmission system with the Belo Monte HPP, also in the state of Pará. Authors such as Coelho and Monteiro (2013, pp. 36-37) state that:

Transmission lines run from Tucuruí practically in a straight line, to the municipality - Barcarena, located on the Marajó basin, directly in contact with the Atlantic Ocean - for the prime purpose of supplying Albrás with electric energy. In addition to the Tucuruí-Barcarena line, there is another heading south - where the mining companies are located, Mineração Buritirama in Marabá, MRN on the Trombetas River and CVRD in Parauapebas. From this last line, at Marabá, there is a branch that stretches east, in the direction leading to Alunorte, in São Luís [...].

In general, the IIRSA consists of several axes of integration, totalling ten in all. However, Castro (2012, p. 49) focuses his discussions on only three that interconnect the Amazon, which are:

The Amazonian axis (Brazil, Colombia, Ecuador and Peru) along which there are two hydropower projects on the Madeira River in Brazil (Jirau and Santo Antônio), and in the same basin another two hydropower plants in Bolivia and four in Peru. The Guiana Shield axis, which is situated in eastern Venezuela, in the extreme north of Brazil (the states of Amapá and Roraima), and through the Guianas and Suriname, in which there are reference cities for transportation logistics and services such as Manaus, Georgetown, Paramaribo, Boa Vista, Cayenne etc. and finally the Brazil, Peru and Bolivia axis in the direction of the Pacific.

3 The IIRSA was created in 1999, and is made up of 12 Pan American countries, but it was only in 2004 that the investment strategies were approved.

4 The concept of integration brings with it the presupposition of state actions in a supranational sphere, therefore, the integration of the region's market is suggested. 
Boyer (2006), however, stresses that BNDES investments, and the interconnection of this financial institution to international capital, have been of paramount importance to demonstrate the local position of Eastern Amazon within an international perspective and also within the financial entities involved in these enterprises. In the words of Chesnais (1996, p. 80):

The World Bank, the International Monetary Fund, the Inter-American Development Bank (IDB), the European Commission (EC), the Organization for Economic Co-operation and Development (OECD), the Economic Commission for Latin America and the Caribbean (ECLAC) and the International Maritime Organization (IMO). [All] support the territorial physical infrastructural integration of the Amazon to the world market.

In addition to these important factors - such as flexible credit mechanisms that allow a greater flow of funding - Castro (2012) draws attention to another differentiated factor, which involves financial capital and its circulation, the development of the means of transportation. For Castro (2012, pp. 51-52), "the main objective is the integration of the transportation infrastructure to potentialize market integration in the Amazon", as presented in Table 2.

Table 2 - IIRSA investments on the Amazonian, Guiana Shield and Peru-BrazilBolivia Axes

\begin{tabular}{l|c|l}
\hline $\begin{array}{c}\text { Integration Axes in } \\
\text { Pan-Amazonia }\end{array}$ & $\begin{array}{c}\text { Allocated Re- } \\
\text { sources (R\$) }\end{array}$ & \multicolumn{1}{|c}{$\begin{array}{c}\text { Intended connections and areas of } \\
\text { interest }\end{array}$} \\
\hline Amazonian Axis & $\mathrm{R} \$ 91,323,220.000$ & $\begin{array}{l}\text { Access to the Solimões-Amazonian Wa- } \\
\text { terway } \\
\text { Access to the Ucalyali Waterway } \\
\text { Network of Amazonian Waterway }\end{array}$ \\
\hline Guiana Shield Axis & $\mathrm{R} \$ 1,098,000.000$ & $\begin{array}{l}\text { The Guiana-Suriname-French Guiana } \\
\text {-Brazil Interconnection } \\
\text { The Venezuela-Brazil Interconnection } \\
\text { The Brazil-Guiana Interconnection }\end{array}$ \\
\hline $\begin{array}{l}\text { Peru-Brazil-Bolivia } \\
\text { Axis }\end{array}$ & $835,592,293.930$ & $\begin{array}{l}\text { The Porto Velho-Rio Branco Corridor- } \\
\text { The Pacific Assis-port Maldonado-Cus- } \\
\text { co/Juliaca-ports (Brazil/Peru } \\
\text { The Rio Branco-Cobija-Riberalta-Yucu- } \\
\text { mo-La Paz Corridor (Brazil/Bolivia) } \\
\text { The fluvial corridor on the Madeira-Ma- } \\
\text { dre de Dios-Beni Rivers (Brazil/Peru) }\end{array}$ \\
\hline
\end{tabular}

Source: Castro (2012, p. 50) apud IIRSA (2011). 
Over recent years, according to the Brazilian Mining Institute (IBRAM), national investments in the mining industry have grown steadily, especially in the period from 2007 to 2014. At first it obtained US\$28.3 billion and subsequently reached its goal of US $\$ 55$ billion, with productivity rising from US $\$ 5$ billion in 2001 to US\$ 44 billion in 2013, according to IBRAM (2014a) data.

In sum, there has been a large-scale growth of mining productivity in the region of Eastern Amazon, since the megaprojects were introduced by the IIRSA. In addition, there was a significant increase in the Brazilian trade surplus as well as in that of the states in the mining economy in the years 2003, 2007 and 2010, as demonstrated in Table 3.

Table 3 - Trade exports and the relative weight of the trade balances of the states (Pará, Amapá and Maranhão) in 2003, 2007 and 2010*

\begin{tabular}{l|r|r|r|r|r|c}
\hline \multicolumn{1}{c|}{ State } & \multicolumn{1}{c|}{$\mathbf{2 0 0 3}$} & $\mathbf{( \% )}$ & \multicolumn{1}{c|}{$\mathbf{2 0 0 7}$} & $\mathbf{( \% )}$ & \multicolumn{1}{c}{$\mathbf{2 0 1 0}$} & $\mathbf{( \% )}$ \\
\hline Pará & $1,680,234,517.00$ & 62.81 & $5,320,685,645.00$ & 67.17 & $10,666,288,302.00$ & 83.13 \\
\hline Amapá & - & - & $79.543 .889,00$ & 62.15 & $281,101,916.00$ & 79.63 \\
\hline Maranhão & $495,867,949.00$ & 67.02 & $1,859,853,362.00$ & 85.42 & $2,407,799,795.00$ & 82.45 \\
\hline
\end{tabular}

Source: Ministry of Industry, Foreign Trade and Services (MDIC), in 2016. *Values in US\$.

Table 4 illustartes the significant amount of investments directed towards the Belo Monte HPP and the Carajás Iron S11D project. The S11D is characterized by an iron ore project in the region of Canaã dos Carajás-PA, which expects to produce 90 million tons of iron per year starting in 2016.

Table 4 - Regional Bulletin of Financial Investments

\begin{tabular}{l|l}
\hline Investment (R\$) & Sector \\
\hline $\mathrm{R} \$ 30$ million & Belo Monte HPP \\
\hline $\mathrm{R} \$ 24$ million & The Carajás Iron Project S11D \\
\hline $\mathrm{R} \$ 5,200$ million & Logistics for the Carajás Railway \\
\hline
\end{tabular}

Source: ENERGIA (2012) and VALE (2014).

With regard to this, according to data obtained from Vale (2014, p. 13):

The production flow, which includes the construction of a railway branch, linking the S11D processing plant to the Carajás Railway (EFC) [...] One of the main innovations is the adoption of the truckless concept. In this system, about 100 off-road trucks, which would be responsible for transporting the sterilized ore, will be replaced by a gigantic $37 \mathrm{~km}$ structure of conveyor belts. 
The problem, however, denotes a greater dependence of the regional economy on the commodities market, with the share of commodities in the Brazilian economy growing since 2006, where its share corresponded to $41 \%$, then $48 \%$ in 2008 and, finally, 54\% in 2009. In 2010, dependence was accentuated, mainly in the participation of metallic and agricultural products within total national exports of commodities, corresponding to more than $60 \%$, as verified in Brazil (2014).

\section{FINAL CONSIDERATIONS}

Within this context, Eastern Amazon is not only characteristic of having an autonomous local position in terms of economic growth, but also a local position in terms of the interests of the national and international economy, i.e., from the entry of international capital into the region, with related interests to many countries and economic blocs, such as the U.S., China and Europe.

For Bunker (2003), therefore, the Amazonian Region becomes a central point of action of these countries and blocs, since all global interests point towards themselves. On this issue, the fundamental deduction is that the national plans for regional and national development closely resemble the parameters of the plans developed in the period 1964-1985, as already observed in analysing the directives of action during the Brazilian military government.

This can be conceptually encircled by central common aspects, such as: 1) the presence of international market interests; 2) the manner in which the Brazilian government should assume responsibility for investments in logistics and energy infrastructure across the country; and (3) the sectoral objectives of the regions, which should be in line with the national development plans of the time.

Hence, the national plans for sectoral development in electric specificity gain a logic all of their own when located in Eastern Amazon. This signifies that the electric sector is subject to the logic of the valorisation of resources from the Brazilian Amazon, and thus begins to direct its forms of growth, with emphasis on the participation of mining companies such as Vale, in the electric energy auctions, and with interest in the Belo Monte HPP project, which indicates the importance of the electricity sector for mining production, and vice versa.

Therefore, the Amazon Region represents a kind of escape valve for the flow of investments, especially in the electricity sector and mining industry. With the development of local hydropower plants, according to PNE 2030, with the construction of more than 30 HPPs in the Brazilian Amazon, an even greater 
impulse is expected for a more intimate connection between the electricity sector and the mining industry, and also a much more intense potential for the exploration of mineral reserves, including the perspective of verticalizing production with the generation of employment, income and added value, as defended by Carvalho (2005), Carvalho (2012) and Carvalho et al. (2017).

\section{REFERENCES}

BOYER, R. L'économie des conventions 15 ans après: un point de vue à partir de la théorie de la régulation. In: EYMARD-DUVERNAY, François (Dir.) L'économie des conventions: méthodes et résultats. Paris: La Découverte, 2006. Tome II. p. 45-66, 2006.

BRASIL. Ministério de Minas Indústria, Comércio Exterior e Serviços. Estatísticas de Comércio Exterior. 2014. Available at: http://www.mdic.gov.br/comercioexterior/estatisticas-de-comercio-exterior/balanca-comercial-brasileira-acumuladodo-ano. Viewed on: 21/07/2016.

Ministério de Minas e Energia, Empresa de Pesquisa Energética. Plano Decenal de Expansão de Energia 2022. Brasília: MME/EPE, 2013.

Empresa de Pesquisa Energética. Plano Nacional de Energia 2030. Rio de Janeiro: EPE, 2007.

Plano Decenal de Expansão de Energia 2006-2015. Brasília: MME/ EPE, 2006.

- Ministério da Integração Nacional. Política Nacional de Desenvolvimento Regional. Proposta para discussão. Brasília, 2003a.

Ministério do Planejamento e Orçamento e Gestão. Plano Plurianual 2004-2007, Brasília, 2003b.

BRASIL. Projeto de desenvolvimento integrado da região norte. Brasília, Universa, 1997a.

Banco Central do Brasil. Available at: http://www.bcb.gov.br/?ECOIMPEXT. Viewed on: 21/07/2016.

BUNKER, S. G. Matter, Space, Energy, And Political Economy: The Amazon in the Wolrd-System. Journal of World-Systems Research, IX, 2, Summer 2003, p. 219-258. Special Issue: Globalization and the Environment, 2003.

Underdeveloping the Amazon: Extraction, Unequal Exchange, and the Failure of the Modern State. Urbana, IL, University of Illinois Press. 1985. 
CASTRO, E. Expansão da fronteira, megaprojetos de infraestrutura e integração sulamericana. Caderno CRH, Salvador, v.25, n.64, p. 45-61, Jan./Abr. 2012.

CHESNAIS, F. A mundialização do capital. Trad.: Silvana Finzi. São Paulo: Xamã, 1996.

COELHO, M. et al. Questão energética na Amazônia: disputa em torno de um novo padrão de desenvolvimento econômico e social. Novos Cadernos NAEA, [S.1.], v. 13, n. 2, abr. 2011. ISSN 2179-7536. Available at: http://www.periodicos.ufpa. br/index.php/ncn/article/view/475. Viewed on: 07/02/2018. doi: http://dx.doi. org/10.5801/ncn.v13i2.475.

COELHO, Maria Célia Nunes; MONTEIRO, Maurílio de Abreu. Verticalização da produção e variedade de situações sociais no espaço funcional do alumínio nos baixos vales do Amazonas e Tocantins. Revista Território, Rio de Janeiro - Ano VII - no11, 12 e 13 - set/out, 2013.

CARVALHO, André Cutrim. Análise da Indústria Mineral Metálica e seus Impactos na Amazônia. Belém-PA. Trabalho de Conclusão de Curso em Economia - Universidade da Amazônia (UNAMA), Centro de Estudos Sociais Aplicados (CESA), 2005.

André Cutrim. Expansão da Fronteira Agropecuária e a Dinâmica do Desmatamento Florestal na Amazônia Paraense. Campinas, SP. 2012. Tese (Doutorado em Economia) - Instituto de Economia, Universidade Estadual de Campinas, Campinas-SP, 2012.

CARVAlHO, André Cutrim; CARVALHO, David Ferreira; FARIAS, André Luís Assunção de; AIRES, Alana Paula de Araújo. Economia Extrativa Mineral da Amazônia Paraense: Indústria-Motriz ou Economia de Enclave (Ainda)?. Revista de Desenvolvimento Econômico (Impresso), v. 2, p. 159-185, 2017. Available at: http://www.revistas.unifacs.br/index.php/rde/article/view/4901/3234.Viewed on: $07 / 02 / 2018$.

ENERGIA, Norte. Conheça a UHE Belo Monte. Brasília: [sn], 19, 2012.

GOMES, A. C. S et al. BNDES 50 anos - Histórias setoriais: O setor elétrico. dez. 2002.

GOMES, João P. P.; VIEIRA, Marcelo Milano Falcão. O campo da energia elétrica no Brasil de 1880 a 2002. rap-rio de Janeiro, v. 43, n. 2, p. 295-321, 2009.

GONÇALVES, Emanoel. José. Augusto. R. A Amazônia na configuração do setor elétrico brasileiro. Trabalho de conclusão de curso (Monografia). Universidade Federal do Pará. Belém, Pará. 2015. 
IBRAM. Instituto Brasileiro de Mineração. Balança comercial mineral do Brasil em milhões de dólares. 2014a.

Investimentos do setor mineral em bilhões de dólares, apuração anual para períodos de cinco anos. 2014b.

IMAZON - Instituto do Homem e Meio Ambiente da Amazônia. Available at: http://imazon.org.br/mapas/amazonia-legal/. Viewed on: 4/10/2016.

LAKATOS, Eva Maria; MARCONI, Marina de Andrade. Fundamentos de metodologia científica. São Paulo: Atlas, 1991.

LEMOS, Chélen Fischer de. Energia na Amazônia: caminho para o desenvolvimento ou aprofundamento da exclusão. In: ENCONTRO ANPPAS, 2. Indaiatuba, 2004.

Anais... 2004.

LOBO, Marco Aurélio Arbage. Estado e Capital Transnacional na Amazônia: O caso da Albrás-Alunorte. Belém: UFPA/NAEA, 1996.

MONTEIRO, Maurílio de Abreu. Meio século de mineração industrial na Amazônia e suas implicações para o desenvolvimento regional. Estudos Avançados, São Paulo, v. 19, n. 53, 2005.

Ministério de Indústria, Comércio Exterior e Serviços. MDIC. Balança Comercial. Available at: http://www.mdic.gov.br/balanca-comercial. Viewed on: 03/10/2016.

PINTO, Lúcio Flávio. De Tucuruí a Belo Monte: a história avança mesmo? Boletim do Museu Paraense Emílio Goeldi. Ciências Humanas, Belém, v. 7, n. 3, p. 777 782, 2012.

SILVA, B. G. Evolução do setor elétrico brasileiro no contexto econômico nacional: Uma análise histórica e econométrica de longo prazo. Dissertação (Mestrado). Programa de pós-graduação em energia- EP/FEA/IEE/IF da Universidade de São Paulo. São Paulo, 2011.

TOLMASQUIM, Mauricio T.; GUERREIRO, Amilcar; GORINI, Ricardo. Matriz energética brasileira: uma prospectiva. Novos estudos-CEBRAP, São Paulo, n. 79, p. 47-69, 2007.

VALE. Relatório A vale em Canaã dos Carajás. 2014. Available at: http://www. vale.com/PT/Paginas/Landing.aspx. Viewed on: 22/7/2015. 


\section{Interfaces dos saberes ambientais: complexidade e educação política difusa}

\section{Interfaces of environmental knowledge: complexity and diffuse policy education}

Antonio Teixeira de Barros - Doutor em Sociologia pela Universidade de Brasília. Pós-doutor em Comunicação pela Universidade Fernando Pessoa. Docente e pesquisador do Programa de Mestrado em Ciência Política do Centro de Formação da Câmara dos Deputados (CEFOR).E-mail: antonibarros@gmail.com

\section{Resumo}

Analisa as interfaces dos saberes ecológicos com a educação ambiental e política, ambas entendidas como educação difusa, que se realiza no âmbito das relações sociais e educativas do cotidiano, relevantes do ponto de vista da conversação civil e da cidadania. Ressalta a visão de interdisciplina e complexidade do ambientalismo e sua dimensão educativa e política. Tanto a educação como o ambientalismo constituem campos convergentes na dimensão de (re) construção e (re)produção simbólica da realidade e de suas estruturas políticas. Além disso, a educação ambiental é entendida como instrumento para formar cidadãos para atuarem na sociedade, assumindo a responsabilidade pelo ambiente natural, a cultura local e o meio social.

\section{Palavras-chave}

Educação, Sociedade e Cultura. Educação Ambiental Difusa. Complexidade Sociocultural e Educativa. Educação Ambiental e Educação Política.

\begin{abstract}
This paper analyzes the ecological knowledge interfaces with environmental education and politics, both understood as diffuse education which takes place in the context of social and educational relations of everyday life and it is relevant from the point of view of civil conversation and citizenship. Emphasizes the vision of interdiscipline and complexity of environmentalism and its educational and political dimension. Both education as environmentalism are convergent fields in the dimension of (re)construction and (re)production symbolic of reality and their political structures. In addition, environmental education is understood as a tool to educate citizens to act in society, assuming responsibility for the natural environment, local culture and the social environment.
\end{abstract}

\section{Keywords}

Education, Society and Culture. Diffuse Environmental Education. Educational and Sociocultural Complexity. Environmental Education and Political Education. 


\section{INTRODUÇÃO}

O ambientalismo reúne, desde suas pioneiras e tímidas manifestações, nas primeiras décadas do século XX, conhecimentos e referências dos mais diversos campos do conhecimento, tanto das ciências naturais como das sociais, todos com interface com a educação, especialmente a educação política em sua dimensão difusa. Iniciado como movimentos de defesa, proteção e conservação do meio natural, vinculado, portanto a saberes específicos desse campo, com o passar do tempo adquiriu projeção política e tornou-se um dos desafios para a educação, em sua dimensão de formação de mentalidades para a atuação consciente de cidadãos no mundo globalizado.

Diante do posto, discute-se neste texto a hipótese de que a educação ambiental, da forma como é entendida hoje, é tributária de um ideário político gestado pelos diferentes movimentos ambientalistas em sua dimensão convergente de transformação social, econômica, cultural e política das sociedades contemporâneas. Assim, parece coerente argumentar que a educação ambiental especializada e institucionalizada, tão em voga atualmente, foi precedida por uma visão anterior que integrava os ideários ecológicos ancorados nas ideologias de transformação das estruturas sociais e políticas. Assim, pode-se afirmar que o ambientalismo trouxe consigo uma concepção de educação política difusa, a qual serviu de base para a posterior definição de ideias para a educação ambiental em suas diversas interfaces, inclusive com a educação política em sentido estrito, uma vez que a consciência ambiental requer que o cidadão também esteja ciente de seus direitos, de seus deveres e do seu papel como agente político de transformação da sociedade. No contexto atual, portanto, talvez o mais adequado seja afirmar que a educação política e a educação ambiental fazem parte da mesma lógica, assumindo a dimensão de um binômio ontológico e epistêmico, integrando o ser e o conhecimento de si, da natureza e da sociedade.

O pressuposto que norteia o estudo é o de que os discursos sociais sobre ambiente e sobre educação política e ambiental não devem ser entendidos como produção autônoma, uma vez que se reportam às concepções aos e saberes produzidos por diversos atores sociais, políticos, culturais e educacionais (instituições estatais, partidos políticos, entidades científicas, universidades, movimentos sociais e ambientalistas). Além da diversidade de atores, o debate público no plano educacional e político passou a incorporar diferentes fatores relacionados aos temas ambientais (fatores naturais, políticos, econômicos, culturais, ideológicos). Trata-se, portanto, de um discurso condicionado por 
múltiplos fatores, atores sociais, culturais, educacionais e políticos em suas diversas configurações de relações e interações.

Entendendo que a educação deriva da inserção em relações sociais multifuncionais (PETITAT, 2011) é que se justifica tal enfoque, assentado da hipótese de que o desenvolvimento do ambientalismo implica sua inserção no campo dessas relações, implicadas no conceito de educação difusa, ou seja, práticas educativas em sua dimensão mais ampla (além do contexto escolar) que envolve atividades sociais, culturais e políticas "orientadas à transmissão de comportamentos, disposições, crenças e competências” (PETITAT, 2011, p.366). Isso envolve uma concepção de educação integrada às relações e atividades do cotidiano, isto é, as relações educativas não especializadas e não regulamentadas, inseridas nas novas dinâmicas de socialização e aprendizagem da chamada “modernidade líquida” (BAUMAN, 2001).

$\mathrm{O}$ argumento desenvolvido ao longo do texto problematiza como as concepções supracitadas se aplicam ao ambientalismo, no âmbito da discussão sobre como se deu a inserção dos saberes ecológicos no âmbito da educação, a partir de duas perspectivas específicas, as quais são articuladas no escopo analítico do texto: a educação ambiental e a educação política difusas. A escolha dessas duas perspectivas se justifica pela afinidade de ambas com a abordagem da educação difusa, tão em voga atualmente, sob o prisma sociológico do estudo das relações sociais no âmbito da educação.

O texto está organizado em três partes que se complementam, segundo a progressão das ideias desenvolvidas no escopo analítico. A primeira apresenta um panorama da evolução histórica da relação entre os saberes ambientais e o contexto da educação, entendendo tal contexto como o solo epistemológico para a emergência da educação política difusa expressa pelas ideias ecológicas. A segunda enfatiza a dimensão política do ambientalismo como consequência do processo de racionalização cultural e ampliação dos espaços de educação em sua dimensão difusa. A terceira contextualiza o debate sobre a evolução do pensamento ambiental na perspectiva de integração com outros saberes, na vertente denominada pensamento complexo.

\section{A INSERÇÃO DO AMBIENTALISMO NA PERSPECTIVA DA EDUCAÇÃO}

A construção das interfaces dos saberes ambientais com a educação, em nível internacional, começou a ser modelada em decorrência das discussões sobre as consequências da I Guerra Mundial, especialmente devido ao uso de 
substâncias químicas. Esse olhar já se caracterizou como a visão de especialistas de áreas distintas de conhecimento, com ampla repercussão entre educadores, o que já mostrava a tendência de formação de uma interdisciplina social de natureza complexa. Assuntos diretamente relacionados com a educação ambiental, como proteção da fauna e da flora, poluição, desenvolvimento sustentável, gestão de resíduos sólidos e aquecimento global passaram a requerer explicações de diversas áreas científicas e passaram a ser incluídos também no debate político. Foi dessa constatação que surgiu a ideia de analisarmos o ambientalismo como interdisciplina e sua relação com a educação, devido à complexidade contida nessa abordagem, na perspectiva de autores como Edgar Morin (2002) e Enrique Leff (2002).

A crise ambiental afeta também a razão, o pensamento social, o conhecimento político, as práticas culturais e o comportamento humano, moldado pela educação. A relevância para a abordagem sociológica se deve ao fato de que a própria sociologia como ciência "é uma filha das crises sociais do século 19 e inicio do século 20" (SOEFFNER, 2009, p. 324). Isso explica, inclusive, as afinidades entre ambientalismo, sociologia e educação, três áreas que exercem papel-chave nos contextos de crise social, no sentido de problematização da realidade e de reinvenção de ideias e valores. Afinal, como argumenta Hannah Arendt, "em toda crise é destruída uma parte do mundo, alguma coisa comum a todos nós" (2000, p. 227), ideia se aplica diretamente ao foco da discussão aqui proposta.

Essa crise requer uma contextualização mais detalhada sobre sua evolução e redefinições, no que se refere especificamente ao escopo da análise deste artigo. Um dado contextual relevante diz respeito ao fato de que nas primeiras décadas do século XX, a ecologia ${ }^{1}$ era tratada de forma episódica e fragmentada tanto pela escola como pelos meios de comunicação e a sociedade em termos gerais. Mas com o passar do tempo, tornou-se um supertema da agenda social e educacional, especialmente após os anos de 1970, ao romper a lógica de assunto eventual da agenda pública para tornar-se problemática sociopolítica educacional com abordagem continuada, complexa e recorrente (BARROS; SOUSA, 2010). Assim, o ambientalismo passou de um espaço ermo em termos de conhecimento a um campo fértil, sincrético e híbrido de novas epistemologias e saberes.

Atualmente, os debates sobre ambiente abrangem assuntos diretamente relacionados com a educação política e ambiental e com o cotidiano do cidadão,

\footnotetext{
Cabe esclarecer que o termo inicial utilizado para se referir ao pensamento verde era "ecologia". Contudo, com o passar do tempo, passou-se a preferir "ambientalismo". Conforme Pádua (1986), o sentido do primeiro situava-se mais no campo do meio natural, enquanto o segundo passou a englobar a cultura e a sociedade. Em suma, no primeiro caso havia certa conotação de externalidade (mundo exterior), enquanto o segundo inclui o homem, a cultura, a sociedade. É nesta acepção que os dois conceitos são utilizados neste trabalho.
} 
como a coleta seletiva de lixo, o desperdício de água, a redução do consumo de energia elétrica nos domicílios, o uso de combustíveis fósseis nos automóveis etc. Contudo, essa abordagem é recente, o que justifica a necessidade de se analisar como se deu a evolução dessa temática e como os assuntos enfocados sob a ótica de uma perspectiva única de conhecimento foram adquirindo nuances de interdisciplina e de pensamento complexo, na perspectiva da educação ambiental.

Do ponto de vista histórico, o pensamento ambiental recebeu interferências diretas da agenda global, em função do contexto político e da atuação de organismos internacionais (ONU e Clube de Roma) das organizações não-governamentais, das universidades e dos partidos políticos (BARROS; SOUSA, 2010). Esses organismos internacionais e entidades sociais, desde o início, enfatizavam o aspecto educativo da temática, mesmo que não fosse do ponto de vista da educação formal. Em termos específicos, no plano da concertação política entre as nações, a Carta de Belgrado (1975) é considerada um marco na educação ambiental, com recomendações sobre a necessidade de ações educativas permanentes e continuadas para a formação cidadã no âmbito ambiental. A Conferência Intergovernamental sobre Educação Ambiental realizada em Tsibilisi (EUA), em 1977, constitui outro marco na discussão sobre a necessidade de produção de conhecimentos interdisciplinares, conforme os princípios da complexidade epistemológica. A Conferência Internacional de Tessalônica, na Grécia (1997) teve como tema "Educação e Conscientização Pública para a Sustentabilidade" e enfatizou a articulação de ideias relacionadas com sustentabilidade, educação, ética, cidadania, identidade, diversidade cultural e participação social. Em 2005 teve início a década da educação para o desenvolvimento sustentável (2005-2014), instituída pela Unesco, com o objetivo de implementar os projetos apresentados pela Agenda 21.

Diante do exposto entendendo a educação como requisito para a ação política e como mecanismo de transformação social (VARGAS, 2005; JACOBI, 2003; MOTA JÚNIOR, 2009), é que nos propusemos a analisar a educação ambiental na perspectiva política, uma vez que tanto a educação como o ambientalismo constituem campos convergentes na dimensão de construção e reprodução simbólica da realidade e de suas estruturas políticas, no sentido abrangente do termo. Além disso, a educação ambiental é entendida como instrumento de formação para a cidadania, ou seja, no sentido de formar cidadãos para atuarem na sociedade, assumindo, inclusive, a responsabilidade pelo ambiente natural, a cultura local e o meio em que vivem (CARVALHO, 1992; JACOBI, 2003; VARGAS, 2005). 
Nessa perspectiva a escola deve participar e atuar "como uma instituição dinâmica, com capacidade de compreender e articular os processos cognitivos com os contextos da vida" (JACOBI, 2003, p. 197). Mesmo assim, não basta a educação ambiental formal como disciplina curricular, mas inserida na cultura e na formação continuada, o que requer a integração de saberes e a mudança de valores. Afinal, a educação ambiental deve buscar a solidariedade, a igualdade e o respeito à diferença através de formas democráticas de atuação baseadas em práticas dialógicas. "Isso se consubstancia no objetivo de criar novas atitudes e comportamentos diante do consumo na nossa sociedade e de estimular a mudança de valores individuais e coletivos" (JACOBI, 2003, p. 197).

Uma educação ambiental que consiga atender a esse amplo escopo de atuação deve ser transversal, complexa e configurar-se como interdisciplina sociocultural e política. Isso implica, além da configuração epistêmica de interdisciplina, uma revolução endógena nas disciplinas relacionadas, atingindo também redefinições no nível de intradisciplina. Tal argumento se justifica porque a relação entre as disciplinas que envolvem conteúdos ecológicos não deve ser entendida somente no plano exógeno ou das externalidades. Tal lógica de epistemologias de integração também afeta a configuração interna de cada disciplina, provocando revisões no interior de cada uma delas. Essas revisões, em alguns casos, podem produzir efeitos mais vigorosos do ponto de vista da eficácia simbólica da ação educativa do que aquelas operadas no plano externo.

Diante desse multifacetado quadro de referência é que o ambientalismo passou a ser tomado como exemplo paradigmático da perspectiva de ampliação do olhar sociológico sobre a educação, principalmente pelo seu potencial de integrar saberes e epistemologias (no plano exógeno e endógeno das disciplinas), além de permitir problematizações complexas e transversais sobre a realidade social e política. Como resultado disso, além do campo da educação ambiental formal, inserida nas relações escolares propriamente ditas, as reflexões sobre ambientalismo foram incorporadas pelas demais configurações sociais, chegando ao nível da conversação civil, talvez uma das manifestações mais emblemáticas do potencial desse campo de saberes como educação política difusa.

A conversação civil (ECO, 2010) inclui os debates informais protagonizados pelos próprios cidadãos, sem interferência ou tutela do Estado ou de instituições e instâncias reguladoras das relações sociais e políticas. Trata-se, portanto, de práticas situadas no campo da educação difusa no seu sentido amplo. Tais práticas são derivadas da inserção dos indivíduos em relações sociais multifuncionais, a exemplo de discussões na esfera pública virtual e participações voluntárias em fóruns sociais, associações comunitárias, programas de rádio e televisão, por 
exemplo. No caso do ambientalismo, as conferências e fóruns internacionais mencionados anteriormente em muito contribuíram para o desenvolvimento da cultura da conversação civil como prática de educação política difusa.

Somado a isso se deve destacar a vocação criativa e recriativa da educação e suas práticas, na perspectiva reinvenção não só das dinâmicas educativas em si, mas também de renovação do mundo, como salienta Hannah Arendt em seu célebre livro Entre o passado e o futuro (2000). A educação cria e recria o mundo no sentido de que se constitui o elo entre o conhecimento produzido pela humanidade no passado e o potencial de saberes das novas gerações que ingressam na escola. Além disso, uma das finalidades da educação é a racionalização cultural, no sentido weberiano, ou seja, de oferecer aportes heurísticos, éticos e críticos para a interpretação da vida social. Tudo isso pode ser resumido na ideia de Petitat (2011) de que educação, cultura, invenção e reinvenção do mundo são indissociáveis, ou seja, "a educação participa diretamente da produção e da difusão do novo". Um exemplo disso são os debates e ideias inovadoras que emergiram com o ambientalismo, em sua dimensão de educação ambiental a partir da análise dos documentos produzidos pelas conferências internacionais mencionadas acima. Além disso, destaca-se a dimensão de educação política difusa, expressa no conceito de conversação civil. Passemos ao aprofundamento da dimensão política do ambientalismo, sua vertente mais vigorosa antes da abertura para o pluralismo expresso pelas retóricas conciliadoras do desenvolvimento sustentável, ou seja, a passagem do ambientalismo monossetorial para o plurissetorial.

\section{REDEFINIÇÕES POLÍTICAS DO AMBIENTALISMO: DO RADICA- LISMO À RACIONALIZAÇÃO E INTEGRAÇÃO DE SABERES}

Para a análise das redefinições e revisões políticas do ambientalismo, em sua trajetória nas últimas décadas, optamos pela perspectiva da sociologia compreensiva de Max Weber, que procura a interpretação das ações individuais a partir do sentido atribuído pelo agente social. No caso do ambientalismo isso implica avaliar a atuação social, política e educativa dos principais atores envolvidos na causa verde e os sentidos e identidades por eles construídos. Em termos mais específicos, tal opção se justifica pela inclusão da educação no escopo da análise weberiana sobre o processo de racionalização cultural do Ocidente, à luz do qual o ambientalismo deve ser compreendido. Em outras palavras, na abordagem weberiana, a educação é vista como parte do projeto amplo de racionalização das sociedades ocidentais, contribuindo para a secularização e o "desencantamento" do mundo social. 
Racionalismo para Weber é um conceito supranacional (SOUSA, 1999), assim como o ambientalismo planetário e multissetorial (racionalismo como tipo ideal). Apesar de não ter apresentado um conceito fechado de racionalização, Weber utiliza o termo em vários de seus escritos, especialmente em Economia e sociedade (1999), com o propósito de caracterizar o processo que impulsionou o desenvolvimento ocidental e uma das formas específicas de dominação legítima. Portanto, trata-se de um conceito considerado central para a compreensão de seu pensamento, além de um instrumento essencial "para se entender o desenvolvimento social, o progresso técnico das sociedades, bem como o projeto de modernidade no qual nos inserimos" (CARDOSO, 2008, p. 257). A importância do conceito reflete-se nas formulações de Weber sobre o potencial civilizador da racionalização, seja na economia, na ciência, na educação, na cultura e na política. Em sua dimensão intelectual, diretamente associada à educação, a racionalização é vista por Weber como indutora do processo civilizatório.

As reflexões de Weber sobre racionalização se complementam com a tese da secularização e desencantamento do mundo, formando uma tríade (racionalização, secularização, desencantamento) que resulta do afastamento do mundo social do universo das crenças religiosas, ou seja, do mundo encantado pelas explicações mágicas sobre a natureza e as relações humanas e sociais (PIERUCCI, 2000). À medida que avançam os processos de racionalização social por meio da ciência, da técnica, das normas jurídicas e das formas de dominação e poder, as sociedades ocidentais se afastam do mundo das explicações sobrenaturais e das relações baseadas em narrativas mitológicas e místicas. Assim, o mundo desencantado é aquele que "prescinde das escolhas e da intervenção criadora da agência social, motivada por impulsos exógenos aqueles contidos e gerados no e pelo mecanismo burocrático-administrativo que, tecnicamente, perpetua a ordem sociopolítica” (SOARES, 2000, p. 343).

A tríade supramencionada é consequência do papel que a educação passou a exercer como formadora de valores e modeladora de comportamentos sociais, suplantando a religião. Se antes as igrejas é que formavam as consciências, com o processo de secularização, as escolas é que passaram a atuar na orientação de valores e na formação da personalidade e na "desmagificação" do mundo. Os sistemas educacionais foram fundamentais na construção do projeto de modernidade cultural e essa "modernidade desencantada" é fundada no princípio da subjetividade, pois "a transição para a modernidade é um processo de internalização e de subjetivação, no qual o caminho para dentro tanto mais demora, quanto mais leva para nós mesmos - e não mais para cima, para deus" (SCHLUTCHER, 2000a, p. 18). Afinal, ao contrário da religião, o pensamento 
racional não responde de forma objetiva e imperativa o que devemos fazer e como devemos viver. É pela educação que o sujeito moderno adquire as ferramentas intelectuais e cognitivas para sua ação no mundo.

A educação, na concepção de Weber, representa a dimensão cultural do processo de racionalização ocidental, "uma vez que os fenômenos intelectuais mais significativos da história moderna foram a desilusão, a intelectualização e a racionalização do mundo", a ciência e educação afetam diretamente o significado do mundo moderno (SCHLUTCHER, 2000b, p. 60). Isso porque o conhecimento científico, ao espalhar a crença de que em princípio é possível dominar todas as coisas por meio do cálculo, quebrou o monopólio das religiões de redenção de atribuir esse significado à crença que propagam. Essa reflexão reforça a tese de que o discurso de Weber sobre o papel da ciência e sua relação com a política deixa implícito que se "trata também de um discurso sobre a educação política", uma vez que Weber defendia a autonomia das universidades para que elas não se tornassem igrejas, nem seitas, nem instituições de apoio direto ao Estado" (SCHLUTCHER, 2000b, p. 80; p. 96). Esse processo possibilitou que a educação se tornasse protagonista de narrativas sociais desvinculadas do pensamento mágico, o que nos levou à elaboração de uma prosa do mundo ${ }^{2}$ renovada e ancorada em bases racionais. Cabe reforçar que o próprio conceito de progresso, intrinsecamente associado à modernidade, decorre da própria noção de desencantamento do mundo e da consequente secularização. Percebese ainda que a educação política constitui o solo epistemológico das ideias de Weber quando ele afirma que "somos seres culturais, dotados da capacidade e da vontade de tomar atitudes ponderadas com relação ao mundo e dar-lhe significado", como observa Schlutcher (2000b, p. 63).

Para Weber a moralidade ocidental na perspectiva de necessidade de compreensão do mundo nasceu como movimentos endógenos à racionalização religiosa. Dessa forma, o ambientalismo apresenta algumas similaridades que se aproximam da moralidade e do conhecimento próprio do campo religioso, calcadas em valores como solidariedade, coletividade e comunitarismo. Por outro lado, o ambientalismo prega um discurso ascético, mas desvinculado de religião (ética intramundana) baseada nas formas pós-tradicionais de solidariedade social. Trata-se de elementos similares ao campo religioso, porém ancorados em uma moralidade secular e uma racionalidade de intregração de saberes. A educação, por sua vez, é vista como instrumento de libertação do jardim mágico das teodiceias religiosas que moldavam eticamente o mundo. $\mathrm{Na}$ modernidade a escola é que

2 Expressão utilizada por Michel Foucault em As palavras e as coisas para designar a construção de narrativas e epistémes sobre a vida social e a cultura. 
exerce tal função. Nessa perspectiva, a educação ambiental é fundamental como categoria heurística, pois a educação é abraçada pela concepção de Weber, mas livre da epistemologia que opunha ciência e religião, o que, no contexto atual, pode-se entender como conhecimento científico e saberes tradicionais sobre ecologia. Trata-se de uma concepção plural que engloba a lógica de interdisciplina e de pensamento complexo, como será abordado na sequência.

\section{O AMBIENTALISMOCOMOINTERDISCIPLINAE PENSAMENTO COMPLEXO}

Desde que a Ecologia foi reconhecida como uma ciência, a partir das contribuições do cientista alemão Ernst Haeckel, publicadas em 1869, passou a ser entendida e aceita como a ciência das relações entre os seres vivos e seu meio, concentrando-se principalmente no estudo de problemas locais, circunscritos a ecossistemas específicos, com pouca importância às diversas interações com a vida social. Posteriormente, passou-se a falar em ciências ambientais, as quais necessitariam integrar-se para formar uma ciência da biosfera, entendendo-se esta como algo mais abrangente, voltada para a globalidade da questão ecológica e sua interface com a educação, a cultura e a política. Mas, "que gênero de ciência pode explicar os vínculos complexos entre a vida e seu meio, em escala planetária?" (BOTKIN, 1992).

No âmbito das Ciências Sociais, postula-se que o ambientalismo constitui um novo quadro de referência, que contempla a dimensão política e educacional. Afinal, trata-se de um movimento que além de multidisciplinar é planetário (VIEIRA, 1995). É neste sentido que o ambientalismo passou a ser entendido como uma interdisciplina, ou seja, uma área de conhecimentos que se relaciona com diversos outros campos de saberes e com práticas educacionais, políticas e culturais.

Como já foi salientado anteriormente, durante a primeira metade do século $\mathrm{XX}$, o discurso ecológico esteve separado do pensamento político, econômico e social. Com a intensificação do debate sobre o tema passou-se a postular que o discurso ecológico é essencialmente político. Antes de se reduzir a questão a argumentos técnicos para a tomada de decisões racionais, há que se negociar alianças entre os distintos grupos sociais capazes de impulsionar as transformações necessárias. Nessa trajetória de afirmação política do ambientalismo, os estudos no âmbito das Ciências Sociais foram imprescindíveis para ampliar a própria concepção de ecologia e sua interface com a educação. Guatari (1993) referese à existência de três ecologias: a do ambiente, a das relações sociais e a da 
subjetividade humana, todas sob a égide ético-estética da ecosofia social, sendo que esta ecosofia consiste em desenvolver práticas específicas que tendem a modificar e a reinventar modos de ser e estilos de viver, seja no âmbito familiar, do contexto urbano, do trabalho, do lazer, da escola e do pensamento político.

Nessa ordem de ideias, as transformações contínuas na esfera privada e na esfera pública promovem uma relação da subjetividade humana com sua exterioridade, seja ela social, animal, vegetal ou cósmica, "que se encontra assim comprometida numa espécie de movimento geral de implosão e infantilização regressiva" (GUATARI, 1993, p.8). As formações políticas e as instâncias executivas parecem totalmente incapazes de apreender essa problemática no conjunto de suas implicações, pois se concentram na perspectiva tecnocrática, já que a abordagem limita-se ao campo dos danos industriais, "ao passo que só uma articulação ético-política - a que chamo ecosofia - entre três registros ecológicos (o do meio ambiente, o das relações sociais e o da subjetividade humana) é que poderia esclarecer convenientemente tais questões" (GUATARI, 1993, p. 8).

Por essas razões, defende o autor citado, em sintonia com o escopo analítico de Morin (1991b) que a natureza não deve ser separada da cultura e precisamos aprender a pensar 'transversalmente' as interações entre ecossistemas, mecanosfera (tudo o que compõe a vida orgânica) e universo de referências sociais e individuais, na perspectiva de um pensamento social e cultural complexo. Isso porque o chamado capitalismo pós-industrial ou capitalismo mundial integrado tende, cada vez mais, a descentrar seus focos de atenção das estruturas de produção de bens e de serviços para as estruturas produtoras de signos, de sintaxe e de subjetividade, por intermédio, especialmente, do controle que exerce sobre a educação.

Morin chama a atenção ainda para o fato de que a compreensão social da ecologia ${ }^{3}$ requer uma consciência que exige policompetências; a visibilidade que o tema adquiriu nos mostra que, ao contrário do dogma da hiper-especialização, há um conhecimento organizacional global que só ele é capaz de articular as competências especializadas para compreender as realidades complexas. A Ecologia é entendida por Morin como uma ciência aberta, que está tentando produzir uma síntese pluridisciplinar, destacando-se a contribuição de cientistas naturais e sociais de diversos campos, além de educadores e filósofos. Assim, o pensamento ecológico passou a exercer o papel de protagonista e articulador de saberes de natureza multi e interdisciplinar. Isso porque a Ecologia tem como objeto de estudo as interações entre todas as espécies de seres vivos, com o

Edgard Morin prefere o termo "ecologia" no lugar de "ambiente", por entender que expressa com mais nitidez a complexidade e a natureza de interdisciplina (MORIN, 1973; 1991a; 1991b). 
seu habitat e com o meio social, ocupando-se ainda do estudo da racionalidade (logos) desse complexo domínio sócio-ambiental. As ideias ecológicas passaram a exercer papel fundamental na valorização de outras formas de conhecimento, sobretudo os saberes empíricos, resultantes das práticas e vivências do cotidiano, diretamente relacionado com a sobrevivência do gênero humano, como é o caso do debate social recente sobre poluição e aquecimento global, por exemplo. Afinal,

O diálogo de saberes se produz no encontro de identidades. É a entrada do ser constituído por intermédio de sua história até o inédito e o impensado, até uma utopia arraigada no ser e no real, construída a partir dos potenciais da natureza e dos sentidos da cultura. $\mathrm{O}$ ser, para além de sua condição existencial geral e genérica, penetra o sentido das identidades coletivas que constituem o crisol da diversidade cultural em uma política da diferença, mobilizando os atores sociais para a construção de estratégias alternativas de reapropriação da natureza em um campo conflitivo de poder, do qual se desdobram sentidos diferenciados e, muitas vezes, antagônicos, na construção de um futuro sustentável (LEFF, 2009, p.19).

Como se observa no trecho supracitado, trata-se do engendramento de uma nova concepção simbólica e cultural, calcada em valores e sentidos nãoimediatistas; alguns até contrários à moderna ideologia econômica (capitalista) e ao individualismo. Embora não possamos ignorar que "não se pode entender a notável expansão do ecologismo fora da reciclagem em curso do capitalismo mundial [...]. O próprio estímulo ao aumento do consumo individual enfrenta sérios problemas de economias de escala nos países desenvolvidos" (BENJAMIN, 1993, p. 151). Ademais, a proteção ambiental "está se tornando a principal área de investimentos para um sistema ávido por alternativas de reciclagem e esperto demais para perder oportunidades que combinem negócios e ideologia vendáveis no mundo inteiro" (p. 152). É necessário ressaltar, portanto, que seu caráter de amálgama de vários saberes e culturas, abriu caminhos plurais para o desenvolvimento de ideias inovadoras e para a gestação de novas formas de organização dos movimentos ambientalistas, como veremos a seguir.

\subsection{DA INTERDISCIPLINA À COMPLEXIDADE}

As redefinições e reconfigurações do ambientalismo que conduziram à sua constituição como interdisciplina devem ser analisadas como essenciais para as mudanças de rumo que resultariam no pensamento social e político, nas práticas ambientalistas e nas ideias educacionais voltadas a formação da consciência cidadã. A difusão das ideias sobre pensamento complexo, a partir das 
contribuições de Edgar Morin, também deve ser considerada, uma vez que essa visão se fundamenta em uma perspectiva interdisciplinar e multirreferenciada sobre os sistemas sociais, a cultura, as identidades, a educação e a natureza, resultando em um "tecido de constituintes heterogêneos inseparavelmente associados” (MORIN, 1994). Assim, o principal argumento para considerar o ambientalismo como pensamento complexo é o fato de que o mesmo rompe com a dicotomia indivíduo x sociedade. Segundo Morin (1973), a complexidade, neste caso, deve-se, sobretudo à inclusão de outros elementos, o que resulta no seguinte esquema: espécie à indivíduo à sociedade à cultura à natureza.

Para o autor citado, existe um “ambi-sistema” bio-social e cultural que se insere em um "ambi-sistema" sócio-individual. Em outras palavras, a questão ecológicoambiental não apresenta apenas aspectos biológicos, nem apenas sociais, mas um conjunto de fatores, que forma um sistema complexo e contraditório de elementos biológicos, humanos, coletivos, individuais, culturais, simbólicos e econômicos. Aqueles que parecem puramente naturais (quando assim o são tomados) se contradizem com aqueles cujos aspectos sociais e culturais são ressaltados. Esses, por sua vez, estabelecem uma relação contraditória quando se pensa, por exemplo, nos aspectos econômicos. Enfim, é possível desenvolver uma rede de contradições entre esses fatores, dependendo do enfoque analítico. O pensamento de Morin tenta relacionar todos eles, sem construir uma hierarquia padrão.

O pensamento ecológico, portanto, surge como resultado de uma "aliança" entre política, ciência, cultura e educação, no contexto científico pós-moderno. A valorização da área de ciência, tecnologia e inovação é apontada como exemplo, uma vez que esse trinômio confirma a lei do progresso irreversível (MORIN et al., 1991b). Fenômeno esse que se enquadra na concepção moderna do avanço científico, fundado no princípio da ciência materialista, da razão leiga, da educação formal e da evolução histórica. Assim, tem uma nova arena de conhecimento (o conhecimento científico-tecnológico) que não reivindica mais a "pureza" científica tradicional. Ao contrário, esse novo campo de conhecimento aglutina e justapõe saberes de diversos outros campos, tanto teóricos como normativos e práticos.

O pensamento complexo "propõe o abandono do paradigma triunfalista de controle do real. Em seu lugar, o reconhecimento da irredutiblidade da incerteza, dos princípios da incompletude do saber e da biodegradabilidade das verdades científicas" (STROH, 1998, p. 44). As flutuações conceituais, as contradições, ambiguidades identitárias e oposições entre correntes de opinião, no âmbito do pensamento complexo, são consideradas elementos positivos, uma vez que o mesmo é movido por uma tensão permanente entre a aspiração a um saber não fragmentado e o reconhecimento da força das incertezas, 
ambiguidades e processualidades (dimensão inacabada) do conhecimento e da educação continuada.

Esse raciocínio está incluído na mesma visão de Edgar Morin (1994), para quem a complexidade é entendida como a ciência da organização dos contrários, ou seja, uma forma paradoxal de pensar a realidade e ainda um modo de tecer os fatos científicos com base não mais em dualidades, mas em paradoxos, pois a complexidade é o tecido organizador de eventos, ações, interações, retroações, determinações, acasos, que constituem o mundo fenomênico e se apresenta com os traços inquietantes do inextricável, da desordem, da incerteza, do imprevisível.

Nessa ordem de ideias, entende-se, pois a complexidade como a organização de aspectos, fatores e elementos identitários complementares, que, ao mesmo tempo, constituem opostos, ou seja, unidades que se opõem, mas que fazem parte de um mesmo sistema. Isto significa que as partes antagônicas e concorrenciais contribuem de forma positiva na organização de um sistema complexo, pois, "a complexidade reside na interrogação que podemos fazer quanto às condições, modalidades, limites e problemas colocados pelas complementaridades antagônicas e concorrenciais que organizam um sistema de investigação" (STROH, 1998, p. 47). O caráter relacional é a essência da complexidade. Segundo Morin (1994), todo sistema é fundamentado na sua substância relacional de pensamento, a exemplo da emergência do ambientalismo multissetorial brasileiro. Morin procura na complexidade cultural da sociedade contemporânea as explicações para a emergência de um pensamento ecológico, inclusive nos processos de rupturas, os quais, a seu ver, assumem o papel de "desvios inovadores", que criam as condições iniciais de uma transformação que pode eventualmente aprofundar-se - ou não.

Após a Conferência das Nações Unidas no Rio em 1992, houve uma ampliação da participação da sociedade civil em todo o mundo - o que também ocorreu no Brasil - com a emergência de novos atores sociais do ambiente, em um contexto sócio-histórico de distintas bases produtivas e de diferentes eixos de transformações sociais. Conforme Figueiredo (1996, p. 120), é neste quadro de mudanças no cenário internacional, que o ambientalismo se constitui "como força política tanto no que diz respeito à constituição de um corpo específico de valores, como a definição e agregação de atores com ele envolvidos".

A diversificação dos atores sociais está diretamente relacionada com a complexificação do ambientalismo, numa perspectiva agregadora, apesar das incompatibilidades existentes, das disputas de interesses e por visibilidade. Essa rearticulação das forças ambientais trouxe vantagens, em função da ampliação dos agentes envolvidos, da visibilidade e da ampliação da consciência ecológica, entre 
outros fatores. Esse cenário polinucleado caracteriza-se pela predominância das retóricas conciliadoras, em prol do desenvolvimento sustentável, numa perspectiva de reconciliação da ecologia com a economia. Contudo, a institucionalização dessa perspectiva ambiental reprimiu as correntes mais revolucionárias, a exemplo das vertentes ancoradas no ecossocialismo ou ambientalismo libertário e radical. Por outro lado, a perda do idealismo dos movimentos de inspiração radical pode ter sido compensado com o pragmatismo das organizações não governamentais do ambiente mais empenhadas em alianças em prol do desenvolvimento sustentável do que no confronto ideológico com o Estado e o os setores empresariais.

Pensadores como Norberto Bobbio (1992) e Eric Hobsbawn (1995) chamam atenção para a relação do ambientalismo com uma rede de outros atores sociais. Para o primeiro autor, os movimentos em defesa da natureza não devem ser compreendidos como iniciativas isoladas e autônomas, mas como parte de um conjunto de movimentos em defesa dos direitos humanos, incluindo as liberdades individuais, os direitos políticos e sociais. O ambientalismo, na visão de Bobbio se insere no âmbito dos chamados direitos de terceira geração (direitos étnicos, de gênero, de imigrantes, qualidade de vida, ecológicos etc.), ou seja, o direito relativo à natureza, no qual os sujeitos não são entendidos como indivíduos, grupos sociais, categorias profissionais ou instituições sociais. Em sua avaliação, nesses direitos de terceira geração, o sujeito é a própria humanidade. Hobsbawn complementa que esses movimentos apontam para reivindicações que exigem mudanças em toda a estrutura da sociedade e apelam para a adesão generalizada das pessoas e não apenas de categorias específicas. Os direitos ambientais são associados às reivindicações, campanhas e manifestações públicas em prol da paz, da qualidade de vida, da diversidade cultural, da integração sociocultural, do bem-estar geral da humanidade, independentemente de sua raça, religião, gênero ou nacionalidade.

Conforme a análise de Scherer-Warren (1996, p. 144), é esse aspecto de capilaridade e amplitude do ambientalismo que o impulsionou para a formação de redes inter, trans e multinacionais, com a contribuição de mais um elemento que catalisou a lógica das redes, que foi a ampliação das possibilidades da comunicação eletrônica, especialmente com a internet. Como consequência dessa capilaridade, a autora chama atenção para um modo simbólico peculiar de agir na esfera pública, com a instituição de novos códigos "criados de acordo com a ideia de uma comunidade idealizada, de uma utopia do que seria um mundo ecologicamente melhor, para a realização de uma cidadania planetária" (SCHERER-WARREN, 1996, p. 144). 
A autora citada destaca ainda um conjunto de estratégias dos atores sociais que incluem o ambientalismo em seu campo de ação: (a) parcerias com o poder público e com organizações privadas; (b) pressões institucionais; (c) intervenção na opinião pública; (d) estímulo à vigília cidadã. Na prática, todas essas estratégias se combinam. A primeira tem como meta a adesão de representantes de instituições governamentais com poder de decisão e intervenção nas políticas públicas, como conselhos municipais e prefeituras. A segunda é voltada para a alteração ou proposição de normas, leis, acordos internacionais e agendamento de debates, conferências e fóruns deliberativos sobre o assunto. A terceira prioriza a realização de protestos, campanhas, manifestos e eventos diversificados, com o intuito de ampliar a visibilidade aos temas ambientais, segundo o enquadramento das organizações ambientalistas. A última tenta prolongar o resultado das anteriores, com a instrumentalização da ação política organizada por grupos menores, a fim de cobrar a aplicação e a efetividade de medidas políticas, legislativas ou de ações governamentais. Os movimentos verdes tentam transformar os cidadãos em "fiscais da natureza" e agentes cotidianos da educação ambiental.

Sob esse prisma, o movimento ambientalista é classificado como um movimento histórico e multissetorial, vinculado às origens da ecologia política no Brasil (PÁDUA, 1996). Essa perspectiva teórica baseia-se no pressuposto de aglutinação de diversas forças sociais ao longo do tempo, transformando o movimento ambientalista em causa multissetorial e complexa, que reúne não só os ecologistas no sentido estrito do termo, mas também outros movimentos sociais preocupados com a insustentabilidade socioambiental, o crescimento populacional e a ocupação desordenada do solo urbano, a geração de tecnologias ecologicamente eficientes, a geração de energias renováveis e o debate sobre hábitos de consumo menos degradantes (VIOLA; LEIS, 1995).

Nessa visão o ambientalismo é concebido como força transformadora da história e elemento essencial à constituição de uma nova identidade cultural, devido a seu potencial para provocar reflexão na sociedade e redefinição de valores, comportamentos e identidades. Um exemplo disso é o chamado ambientalismo multissetorial complexo, que teria rompido as barreiras ideológicas e a identidade radical e permitido a constituição de uma rede com a participação de diferentes atores sociais, como movimentos políticos, sociais, empresariais e científicos, além de agências governamentais ou internacionais. Essa rede é que teria gerado as condições sociais e culturais necessárias para a difusão ampla e transversal dos valores ambientalistas, tornando a ecologia um tema simbólico horizontal, ou seja, de interesse geral (VIOLA; LEIS, 1995). 
O trabalho de Viola e Leis é avaliado por Agripa Faria Alexandre (2000) como contribuição teórica que se destaca pelo potencial analítico e singular, com larga utilização de material empírico. Entretanto, Alexandre critica a interpretação do movimento ambientalista brasileiro como um movimento histó rico e multissetorial. Em contraposição, a pesquisadora apresenta a teoria do ambientalismo político, seletivo e diferencial, com ênfase para as disputas, divergências e conflitos identitários. Conforme sua análise, a teoria do multissetorialismo pressupõe, equivocadamente, harmonia entre os diferentes atores dos movimentos ambientais, como se fosse uma pluralidade simbólica convergente. Na avaliação de Alexandre, ainterpretação do movimento histórico e multissetorial, traçada por Eduardo Viola e Ricardo Leis não consegue explicar o desenvolvimento do movimento ambientalista. Sua hipótese consiste em demonstrar que existem mais conflitos do que convergências entre os diferentes segmentos dos movimentos ambientalistas. A autora exemplifica com as oposições entre os movimentos ecoconservacionistas e os ecopreservacionistas e os conflitos entre os ecocapitalistas e os ecossocialistas (ALEXANDRE, 2000).

Apesar das críticas, Eduardo Viola e Ricardo Leis reafirmam sua tese do multissetorialismo complexo em estudos posteriores, com ênfase para a lógica da cooperação entre os movimentos ambientalistas. $O$ argumento consiste na ressalva de que embora existam no ambientalismo forças associadas ao mercado e ao Estado, deve-se registrar como um dado sumamente sugestivo "a razoável convivência, ao longo do tempo, de todas suas diversas vertentes e a predominância da cooperação por cima do conflito" (LEIS, 1999, p. 140). Assim, segundo a lógica multissetorial, a concordância é inerente ao pensamento ecocêntrico. As várias vertentes e setores do ambientalismo têm entre eles uma concordância num plano profundo, que permite aos diversos atores ser cooperativos apesar de suas diferenças. Em suma, o ambientalismo multissetorial não exclui a possibilidade de conflitos e disputas, mas põe em relevo, em perspectiva histórica, a formação de multiconvergências.

\section{CONSIDERAÇÕES FINAIS}

A configuração de interdisciplina complexa do ambientalismo, em sua interface com a educação política difusa envolve diferentes atores como cientistas, órgãos governamentais e não-governamentais, militantes, pesquisadores e educadores, além das diversas manifestações de aprendizagem social, incluindo a conversação civil, o jornalismo ambiental, entre outros. Em suma, o debate é complexo, pois incorpora diversas perspectivas e se constitui como força simbólica, cultural, política e educacional, tanto no que diz respeito à constituição 
de um corpo específico de valores como na definição e agregação de atores, práticas e interações.

Trata-se de um campo polinucleado de saberes, no qual os principais agentes e suas identidades organizam-se em núcleos que atuam como matrizes geradoras e difusoras de valores que se traduzem em ideários, lógicas, modelos de intervenção e normas que orientam a criação de novas percepções e princípios éticos que passarão a orientar as condutas. A conjunção de diferentes atores justifica-se pelo fato de que o ambientalismo é portador de valores e interesses que se sobrepõem às diferenças de gênero, etnia, religião, classe social, nível de renda e de instrução, público e privado, e de nacionalidade ou região. Dispensa os elementos corporativos, partidários ou particularistas, pois sua lógica é aglutinadora e não sectária. Assim, ampliam-se as esferas sociais de aprendizagem difusa e suas dimensões educativas e de produção e reprodução simbólica.

É necessário considerar, no escopo dos estudos sobre o tema, o potencial do ambientalismo como novo quadro social de referência para a educação e de renovação dos espaços de conhecimento que passarão a balizar os campos de alianças e negociações de sentidos, especialmente em dois campos específicos do universo educativo: a educação política e a educação ambiental, ambas vinculadas diretamente ao debate atual sobre democracia e cidadania. Essa nova configuração social está diretamente relacionada às redefinições recentes do campo ambiental, com a transição dos movimentos monossetoriais, baseados na coesão sectária, para as organizações verdes complexas, que construíram um discurso intersubjetivo transnacional e plurissetorial. Tudo isso tecido e amalgamado pela lógica da racionalização cultural weberiana e a epistemologia da complexidade proposta por Edgar Morin.

A educação, nesse cenário, é fundamental como modeladora de valores, concepções, imaginários, seja em sua dimensão política ou ambiental, visto que ambas são voltadas para a cidadania e devem ser encaradas como processos permanentes e continuados de aprendizagem política e social. Afinal, a cidadania tem a ver com a identidade e o pertencimento a uma coletividade. A educação ambiental como formação e exercício de cidadania "refere-se a uma nova forma de encarar a relação do homem com a natureza, baseada numa nova ética, que pressupõe outros valores morais e uma forma diferente de ver o mundo e os homens" (JACOBI, 2003, p. 198). Isso requer um projeto social coletivo, de modo a estimular a participação democrática na formulação de políticas públicas e nos modelos de gestão dos recursos naturais, da biodiversidade, dos espaços urbanos e rurais. Tal projeto exige a consolidação de novos paradigmas educativos. 
Vários autores entendem a educação como a ferramenta social e simbólica para formar e renovar valores, conceitos e ideias, o que, no caso do campo ambiental, possibilita a percepção dos problemas e o desenvolvimento de uma consciência favorável à mudança de atitudes e comportamentos, inclusive no plano concreto do cotidiano (DIAZ, 2002; VARGAS, 2005). Desse ponto de vista, a educação ambiental não deve ser encarada como mais uma disciplina obrigatória nos currículos escolares, com conteúdos formais, provas e outros expedientes próprios do aparato burocrático dos sistemas de ensino. Antes, deve ser concebida como formação e renovação das consciências e das condutas sociais cotidianas. Isso reforça sua abrangência como educação política difusa.

Reigota (2001) e Mota Júnior (2009) destacam o papel político da educação ambiental, com o foco na formação da consciência cidadã e na promoção de condutas e práticas cidadãs. Como se percebe essa concepção de educação ambiental como educação política pressupõe a integração de duas perspectivas, ou seja, aquela calcada na epistemologia e outra na pragmática social. A primeira está relacionada com a matriz das ideias que servem de base filosófica para os conhecimentos acerca da sustentabilidade, tais como holismo, complexidade e ética da responsabilidade. A segunda está ancorada no pressuposto de que o conhecimento ambiental resultante do aprendizado político difuso do cidadão deve ter consequências práticas nos seus comportamentos cotidianos no que se refere ao uso da água, da energia elétrica e em suas demais escolhas de consumo, por exemplo.

No próprio campo da educação ambientalé necessária uma abordagem que reitere a natureza de interdisciplina e de complexidade das temáticas ambientais, uma vez que são vários atores do universo educativo que estão envolvidos, além de diversos sistemas de conhecimentos e de campos de atuação prática. Leff (2002) reforça que a sustentabilidade será viabilizada social e culturalmente apenas se houver sistemas eficientes para mudar os valores e os comportamentos, o que depende de transformações radicais nos sistemas de conhecimento, no ensino formal e na racionalidade que rege as relações sociais, especialmente no campo do consumo. Nessa perspectiva, a educação ambiental (formal ou difusa) poderia funcionar com um antídoto à sociedade do risco, ${ }^{4}$ de modo a continuar promovendo a racionalização cultural nos termos weberianos expostos anteriormente.

\footnotetext{
4 Termo cunhado por Ulrick Beck para designar uma etapa da modernidade ou uma "segunda modernidade" que emerge da globalização e tem como consequências uma cadeia interrelacionada de riscos sociais, econômicos, políticos e ambientais, que se expressam no consumismo, individualismo, miséria, fome, violência e desastres nucleares, químicos e genéticos (JACOBI, 2003).
} 


\section{REFERÊNCIAS}

ALEXANDRE, A. F., 2000, A perda da radicalidade do movimento ambientalista. Florianópolis, Editora da Universidade Federal de Santa Catarina, 2000.

ALONSO, A.; COSTA, V.. Por uma Sociologia dos Conflitos Ambientais no Brasil. Paper apresentado no Encontro do Grupo Meio Ambiente e Desenvolvimento do Conselho Latinoamericando de Ciencias Sociais (Clacso), Rio de Janeiro, 22 e 23 de novembro de 2000.

ARENDT, H. Entre o passado e o futuro. São Paulo: Perspectiva, 2000.

BARBANTI JÚNIOR, O.. Conflitos socioambientais: teorias e práticas. Curitiba. 2006. 257f. Tese de Doutorado, 2006. Programa de Pós-Graduação em Economia. Universidade Federal do Paraná, Curitiba, 2006.

BARROS, F. L. de. Ambientalismo, globalização e novos atores sociais. Sociedade e Estado. Brasília, Universidade de Brasília, v.21, n.1, p.121-137, jan./jun. 1996.

BARROS, A. T. de; SOUSA, J. P.. Jornalismo e ambiente: análise de investigações realizadas no Brasil e em Portugal. Porto: Edições Fernando pessoa, 2010.

BAUMAN, Z.. Modernidade líquida. Rio de Janeiro: Zahar, 2001.

BENJAMIN, C.. Diálogo sobre ecologia, ciência e política. Rio de Janeiro: Nova Fronteira,1983.

BOBBIO, N.. A era dos direitos. Rio de Janeiro: Campus, 1992.

BOTKIN, D.. Qual ecologia para o século XXI? In: BARRÈRE, Martine (Org.). Terra, patrimônio comum: a ciência a serviço do meio ambiente e do desenvolvimento. São Paulo: Nobel, 1992, p.15-26.

CARDOSO, L. A.. O conceito de racionalização no pensamento de Max Weber: entre a ambiguidade e dualidade. Teoria e Debate, Belo Horizonte, Universidade Federal de Minas Gerais, v.16, n.1, jan./jun., 2008, p. 256-275

CARVALHO, I. C.. Educação, meio ambiente e ação política. In: ASCELRAD, Henri. (Org) Meio ambiente e democracia. Rio de Janeiro: Ibase, 1992, p. 32-42.

CASTRO, M. F. de. Democracia, ética e prática judicial no mundo contemporâneo: uma abordagem weberiana. In: SOUSA, Jessé (Org). A atualidade de Max Weber. Brasília: Editora da Universidade de Brasília, 2000, p. 197-233.

DIAZ, Alberto Prado. Educação ambiental como projeto. Porto Alegre: Artmed, 2002.

DOMINGUES, J. M.. A cidade: racionalização e liberdade em Max weber. In: SOUSA, Jessé (Org). A atualidade de Max Weber. Brasília: Editora da Universidade de Brasília, p. 209-234. 
ECO, U.. Cinco escritos morais. São Paulo: Record, 2010.

FIGUEIREDO, V.. Globalização, meio ambiente e novos atores sociais. Sociedade e Estado, Brasília, Universidade de Brasília, v.21, n.1, jan./jun., 1996, p.119-120.

GUATARI, F.. As três ecologias. Campinas: Papirus, 1993.

HOBSBAWN, E.. A era dos extremos. São Paulo: Companhia das Letras, 1995.

JACOBI, P.. Educação ambiental, cidadania e sustentabilidade. Cadernos de Pesquisa, São Paulo, Fundação Carlos Chagas, s/v, n.118, março, 2003, p.189-205.

LEFF, E. Epistemologia ambiental. São Paulo: Cortez, 2002.

LEFF, E, Complexidade, racionalidade ambiental e diálogo de saberes. Educação \& Realidade, Porto Alegre, Universidade Federal do Rio Grande do Sul, v. 34, n. 3, set./dez., 2009, p.17-24.

LEIS, H. R.. A modernidade insustentável: as críticas do ambientalismo à sociedade contemporânea. Petrópolis: Vozes; Florianópolis: Editora da Universidade Federal de Santa Catarina, 1999.

LIPSET, S. M. Consenso e conflito. Gradiva: Lisboa,1985.

MOTA JÚNIOR, V. D. da. Educação ambiental, política, cidadania e consumo. Interacções, Santarém, Escola Superior de Educação de Santarém, v.5, n.11, 2009, p.214-229.

MORIN, E.. Le paradigme perdu: la nature humaine. Paris: Éditions du Seuil, 1973.

MORIN, E. La méthode: les idées. Paris: Éditions Seuil. v.4., 1991a.

MORIN, E.. La pensée écologisée. In: MORIN, Edgar et al. Un nouveau commencement. Paris: Éditions du Seuil, pp.179-193, 1991b.

MORIN, E.. Introducción al pensamiento complejo. Barcelona: Gedisa, 1994.

MORIN, E.. Os sete saberes necessários à educação do futuro. São Paulo: Cortez, 2002.

PÁDUA, J. A.. Natureza e projeto nacional: as origens da ecologia política no Brasil. Rio de Janeiro: Instituto Universitário do Rio de Janeiro, 1996.

PETITAT, A.. Educação difusa e relação social. Educação \& Realidade, Porto Alegre, Universidade Federal do Rio Grande do Sul, v. 36, n. 2, maio/ago., 2011, p.365-376.

PIERUCCI, A. F.. Secularização segundo Max Weber: da contemporânea serventia de voltarmos a acessar um velho sentido. In: SOUZA, Jessé (Org). A atualidade de Max Weber. Brasília: Editora da Universidade de Brasília, 2000, p.105-162.

REIGOTA, M.. O que é educação ambiental. São Paulo: Brasiliense, 2001. 
SCHERER-WARREN, I.. Novos atores e práticas políticas ambientalistas na era da globalização. Sociedade e Estado. Brasília, Universidade de Brasília, v.21, n.1, p.139-48, jan./ jun., 1996.

SCHLUTCHER, W.. Politeísmo de valores: In: SOUSA, Jessé (Org). A atualidade de Max Weber. Brasília: Editora da Universidade de Brasília, 2000a, p.13-48.

SCHLUTCHER, W.. Neutralidade de valor e a ética da responsabilidade. COELHO, Maria F. Pinheiro et al. (Org). Política, ciência e cultura em Weber. Brasília: Editora da Universidade de Brasília, 2000b, p.55-110.

SOARES, L. E.. A racionalidade do "politicamente correto" ou: Weber errou porque estava certo. In: SOUSA, J. (Org). A atualidade de Max Weber. Brasília: Editora da Universidade de Brasília, 2000.

SOEFFNER, H-G.. A crítica da razão sociológica. Civitas, Porto Alegre, v.9, n.2, p. 324-334, maio/ago., 2009.

SOUSA, J.. A ética protestante e a ideologia do atraso brasileiro. In: SOUSA, Jessé (Org). O malandro e o protestante: a tese weberiana e a singularidade cultural brasileira. Brasília: Editora da Universidade de Brasília, 1999, p.17-54.

SOUSA, J.. Acerca do lugar da moralidade na política: Weber, Habermas e a singularidade cultural alemã. In: SOUSA, Jessé. (Org). A atualidade de Max Weber. Brasília: Editora da Universidade de Brasília, p.49-90.

SOUZA, N. M.. Educação ambiental: dilemas da prática contemporânea. Rio de Janeiro: Editora da Universidade Estácio de Sá, 2000.

STROH, P. Y.. Fitzcarraldo e a Agenda 21: desafios da sustentabilidade amazônica.1998. 223f. Tese de doutoramento em Sociologia. Programa de PósGraduação em Sociologia. Universidade de Brasília. Brasília, 1998.

VIEIRA, P. F.. Meio ambiente, desenvolvimento e planejamento. In: VIOLA, Eduardo et al. Meio ambiente, desenvolvimento e cidadania: desafios para as ciências sociais. São Paulo: Cortez, 1995, p.45-98.

VIOLA, E.; LEIS, H. O ambientalismo multissetorial no Brasil para além da Rio92: o desafio de uma estratégia globalista viável. In: VIOLA, Eduardo et al. (Org). Meio ambiente desenvolvimento e cidadania: desafios para as ciências sociais. São Paulo: Cortez, 1995, p.134-160.

VARGAS, L. A.. Educação ambiental: a base para uma ação político/transformadora na sociedade. Revista Eletrônica do Mestrado em Educação Ambiental, Natal, v.15, n.2, jul./dez., 2005, p.72-79.

WEBER, M.. A ética protestante e o espírito do capitalismo. São Paulo: Pioneira, 1989.

Texto submetido à Revista em 29.12.2015 Aceito para publicação em 13.01.2017 


\section{Mudanças climáticas: efeitos sociais sobre povos e comunidades tradicionais da Amazônia}

\section{Climate change: social effects on people and traditional communities in the Amazon}

Thereza Cristina Cardoso Menezes - Doutora em Antropologia Social pelo Programa de PósGraduação em Antropologia Social do Museu Nacional (UFRJ). Professora do Programa de Pós-Graduação de Ciências Sociais em Desenvolvimento e Agricultura (CPDA/ UFRRJ) e do Programa de Pós-Graduação em Antropologia Social - PPGAS/UFAM. E-mail: therezaccm@uol.com.br

Ana Carla dos Santos Bruno - Doutorado em Antropologia e Lingüística - University of Arizona. Pesquisadora do Instituto Nacional de Pesquisas da Amazônia na Coordenação de Sociedade, Ambiente e Saúde (CSAS/INPA) e Professora do Programa de PósGraduação em Antropologia Social - PPGAS/UFAM. E-mail: abruno@inpa.gov.br

\section{Resumo}

Este artigo busca examinar como as discussões sobre mudanças climáticas estão influenciando práticas sociais de povos e comunidades tradicionais que vivem em Terras Indígenas e Unidades de Conservação situadas na Amazônia, tendo como foco as práticas e os efeitos sociais das políticas públicas para mitigação de riscos ambientais sobre povos indígenas e tradicionais, bem como a incorporação da temática das mudanças climáticas nas agendas dos movimentos sociais que atuam na região. E por fim, como esta questão tem se traduzido em táticas diversas promovidas por organizações estatais e não governamentais dirigidas para políticas de regularização fundiária na Amazônia.

\section{Palavras-chave}

Risco. Recursos Florestais. Política de Mudanças Climáticas. Indígenas e Povos Tradicionais na Amazônia. Impactos Socioculturais. Políticas de Regularização Fundiária.

\begin{abstract}
This article seeks to examine how climate change discussions are influencing social practices of traditional peoples and communities living in indigenous lands and protected areas located in the Amazon, focusing on the practical and social effects of public policies to mitigate environmental risks on indigenous and traditional peoples, as well as incorporating the theme of climate change on the agendas of social movements operating in the region. And finally, as this question has translated into various tactics promoted by state and non-governmental organizations directed to policies of land regularization in the Amazon.
\end{abstract}

\section{Keywords}

Risk. Forest Resources. Climate Changes Policy. Indigenous and Traditional People in Amazonia. Socio-cultural Impacts. Policies of Land Regularization. 


\section{INTRODUÇÃO}

Este artigo busca refletir sobre as discussões e as práticas motivadas pela intervenção no panorama das chamadas mudanças climáticas. Propomos analisar o processo de transformação na Amazônia das intervenções motivadas pela questão e como estas estão influenciando povos e comunidades tradicionais que vivem em Terras Indígenas, assentamentos sustentáveis e Unidades de Conservação situadas na Amazônia, examinando-se como esta questão tem se traduzido cada vez mais em táticas diversas promovidas por organizações estatais e não governamentais dirigidas para políticas de regularização fundiária. Buscamos ainda analisar como os movimentos sociais se posicionam ou foram incorporados no debate desta temática na Região Amazônica.

As discussões sobre mudanças climáticas tornaram-se um dos tópicos de maior destaque na agenda do século XXI. As causas, os culpados, os riscos e perigos são temas recorrentes não só no universo científico e jornalístico, mas também passaram a fazer parte das agendas dos movimentos sociais e das políticas territoriais dirigidas para a Amazônia. Cabe ressaltar que ainda que a hegemonia discursiva sobre o tema das mudanças climáticas caiba ao mundo científico, observamos por parte dos sujeitos sociais que vivem e relacionam-se intensa e cotidianamente com a Floresta Amazônica, leituras próprias sobre a crescente imprevisibilidade do ritmo de chuvas, cheias, vazantes, bem como sua própria vulnerabilidade diante de tais mudanças.

A proposta deste texto é apontar alguns dos efeitos sociais ancorados na difusão do risco planetário acarretado pelas mudanças climáticas e como a Amazônia deveria converter-se no epicentro de intervenções para minimizálo. Esta perspectiva está hoje materializada em um conjunto muito diverso de políticas públicas que têm entre suas metas fundamentais a redução do índice de desmatamento anual na Amazônia em até $80 \%$ até $2020^{1}$. As ações voltadas para atingir esta meta têm provocado mudanças de grande envergadura no marco legal, assim como produziram novas funções de gestão, vigilância e proteção territorial a serem promovidas por povos e comunidades tradicionais na Amazônia.

Nos últimos anos, inúmeros cientistas difundiram a ideia de que as mudanças climáticas são oriundas de ações humanas inadequadas. Em 1992, na convenção-quadro realizada na Cúpula da Terra no Rio de Janeiro, a chamada ECO 92, discutia-se a necessidade de estabilizar a composição atmosférica para impedir a influência antropogênica no sistema climático sem provocar uma

1 Decreto nº 7390/2010/ Plano de Ação para Prevenção e Controle do Desmatamento na Amazônia Legal (PPCDAm) 
ruptura na economia global. E os discursos, enfaticamente, situavam como causa fundamental da emissão de grande quantidade de gás na atmosfera a retirada de carbono em excesso, principalmente do subsolo (uso de combustíveis fósseis) e das florestas tropicais em ações de desmatamento, tais como na preparação de roçados e atividades agropecuárias e madeireiras.

Segundo o relatório do Intergovernmental Panel on Climate Change (IPCC) 2007, este aquecimento seria diferenciado, pois todo planeta manifestaria seus efeitos: a) Degelo nas calotas polares; b) Mudanças nas dinâmicas e regime das chuvas, o que afeta diretamente a agricultura e o extrativismo; c) Mais ondas de calor e de frio; d) Tempestades e secas mais severas. O relatório pontuava ainda que um aumento da temperatura superior à faixa entre $2,0^{\circ} \mathrm{C}$ e $2,4^{\circ} \mathrm{C}$ seria catastrófico, teríamos uma diminuição substancial da produção agrícola mundial, milhões de refugiados ambientais, milhões de pessoas sofreriam com recorrentes e crescentes falta de água e a biodiversidade da Floresta Amazônica estaria seriamente comprometida.

Segundo Fearnside (2012), toda discussão sobre mudanças climáticas, inclusive os informes do IPCC, alertam para a probabilidade de que os problemas e os riscos sejam maiores do que os estimados. A existência do próprio fato e do seu potencial de gravidade está longe de conformar um consenso no campo científico, existindo profundos embates a respeito dos métodos e questionamentos sobre dados negligenciados em pesquisas, conclusões e estimativas futuras sobre as mudanças climáticas.

No caso da particular da Amazônia, a desertificação das florestas tem merecido grande destaque como um dos mais notórios efeitos das mudanças climáticas. Pesquisas realizadas pela NASA sobre os efeitos de duas das maiores secas já ocorridas na região em 2005 e 2010 demonstraram que estes fenômenos provocaram uma mudança representativa na paisagem. Após as secas, a floresta perderia sua capacidade de absorção de gás carbônico, o que contribuiria para o aquecimento global, formando um ciclo vicioso. Diferentemente das pesquisas que apontam o desmatamento como o principal inimigo da Floresta Amazônica, estas pesquisas indicam que as emissões de gases do efeito estufa mereceriam maior atenção.

Contrariando estas conclusões, os cientistas da Grã-Bretanha sugerem que a Floresta Amazônica pode ser menos vulnerável às secas graves decorrentes do aquecimento global do que se acreditava. Em artigo publicado na revista Proceedings of the National Academy of Sciences, a partir de pesquisas coordenadas por Yavinder Malhi, professor da Universidade Oxford, os cientistas pela primeira vez compararam simulações de Modelos Climáticos 
Globais com observações empíricas e concluíram que muitos dos modelos climáticos subestimam a quantidade atual de chuvas na Amazônia. Previu-se que a parte oriental da Amazônia, úmida durante o ano todo, teria a tendência de se transformar em "florestas sazonais", com estações secas e estações úmidas, mas sem o risco de savanização, visto que estas florestas seriam resistentes a secas ocasionais. Este estudo contraria as projeções do Painel do Clima da ONU que indicavam que a porção oriental da Amazônia poderia ser gradualmente transformada em savana. A pesquisa conclui que a melhor maneira de reduzir o risco de degradação da Amazônia seria o controle das emissões globais de gases do efeito estufa e a proteção da floresta, visto que se estima que o desmatamento pode ser responsável por cerca de $20 \%$ das emissões anuais.

Uma publicação da Nature (2012) baseada no Programa de Grande Escala da Atmosfera-Biosfera da Amazônia (LBA), indica a interdependência de fatores, humanos e naturais pressionando a borda oriental da floresta, nos estados do Pará, do Tocantins e de Mato Grosso. Mesmo considerando a capacidade de recuperação da floresta, a pressão humana proveniente da região de limite com o cerrado iniciaria o processo de savanização.

Diferentemente das previsões pessimistas sobre o impacto do aquecimento global sobre o bioma amazônico, Azis Ab’Saber (2007) foi enfático ao afirmar no Correio Brasiliense que: "É, completamente, errado afirmar que o aquecimento global ocasionará desertificação, savanização ou interrupção natural das florestas|". Segundo o autor, a Floresta Amazônica poderia mesmo tornarse ainda mais densa nos próximos anos, em virtude do aquecimento global que permitiria aumento das temperaturas médias intensificação das precipitações. Apesar de considerar o relatório do IPCC como uma ferramenta relevante de alerta, Ab `Saber percebe como um sério erro do documento o fato deste desconsiderar a influência das correntes marítimas no clima.

\section{DESMATAMENTO E MUDANÇAS CLIMÁTICAS}

Como tentamos descrever muito brevemente, não há unanimidade sobre a incidência ou risco futuro de savanização da Amazônia. No entanto, boa parte dos estudos recomenda vivamente que se tomem medidas mais efetivas para proteger o ecossistema da ação predatória do homem, visto que no Brasil o desmatamento é a principal fonte de emissões de gases do efeito estufa. Na região onde a fronteira agrícola avança em direção à floresta concentram-se os maiores índices de desmatamento. Entre agosto de 2014 a julho de 2015, percebeu-se uma inflexão, o Brasil perdeu $5.831 \mathrm{~km}^{2}$ de florestas - um aumento de $16 \% \mathrm{em}$ 
relação ao período anterior, segundo o Instituto Nacional de Pesquisas Espaciais (INPE). O Pará e o Mato Grosso lideraram em área total desmatada, porém Amazonas, Rondônia e Mato Grosso tiveram os maiores aumentos em relação ao ano anterior (54\%, 41\% e 40\%), respectivamente.

A expansão da pecuária foi a causa principal do desmatamento, seguida do corte seletivo. Dentre as novidades, em relação aos anos mais recentes, notouse o desmatamento em grandes áreas, algo considerado incomum há cerca de uma década e a concentração e o desmatamento em estados que captaram recursos do Fundo Amazônia ${ }^{2}$ para reduzir o desmatamento. Desde meados de 2017, o Fórum das Entidades Empresariais do Pará encaminhou uma carta ao presidente Michel Temer pedindo a suspensão do Fundo Amazônia justificada pela suposta obstrução que a entidade representaria aos setores produtivos do Pará e da Amazônia como um todo. Para estes setores, as organizações não governamentais prejudicariam o desenvolvimento de comunidades do interior além de impor uma tutela não solicitada.

As posturas assinaladas acima colocariam em risco um conjunto de ações em curso nos últimos anos em relação à redução do desmatamento na Amazônia. Tanto a sociedade organizada quanto o Estado se empenharam para que o desmatamento caísse da casa dos $27 \mathrm{mil} \mathrm{km}^{2}$, em 2004, para a faixa dos 5 mil, ainda que o governo federal pouco tenha se empenhado na demarcação de novas Unidades de Conservação e Terras Indígenas. Ao contrário, mudanças severas no marco legal constituem sérias ameaças para biodiversidade e sociodiversidade amazônica, como, por exemplo, a PEC 2015³, Mudanças no Código Florestal ${ }^{4}$ e

2 O Fundo Amazônia financia ações de redução do desmatamento em biomas brasileiros desde 2008. A Noruega é o maior financiador do Fundo. O Fundo Amazônia tem por finalidade captar doações para investimentos não reembolsáveis em ações de prevenção, monitoramento e combate ao desmatamento, e de promoção da conservação e do uso sustentável da Amazônia Legal. Também apoia o desenvolvimento de sistemas de monitoramento e controle do desmatamento em outros países tropicais (Disponível em: http://www.fundoamazonia.gov. $\mathrm{br} / \mathrm{pt} / \mathrm{home} /$ )

3 Proposta de emenda constitucional que delega ao Congresso Nacional o direito de demarcação de Terras Indígenas e Quilombolas

4 Dentre as mudanças no Código Florestal destacaria: a possibilidade de redução da reserva para $50 \%$ de reserva legal em estados com mais de $65 \%$ das suas áreas em reservas ambientais, desde que a redução seja autorizada pelo Conselho Nacional do Meio Ambiente. O novo texto também assegura a todas as propriedades rurais a manutenção de atividades agrossilvopastoris nas margens dos rios, desde que consolidadas até 2008, e autoriza o uso de áreas de Preservação Permanente para alguns tipos de cultivos, como maçã e café. A pecuária também ficaria permitida em encostas de até 45 grau. Agricultores com propriedade de até 4 módulos fiscais, autuados até julho de 2008, poderiam converter multas com reflorestamento, de acordo com o texto aprovado pela Câmara e estes benefícios valeriam também para os grandes proprietários rurais que desmataram até julho de 2008. Criou-se o Cadastro Ambiental Rural (CAR) autodeclaratório e realizado virtualmente que estabelece prazo para que os donos de terras registrem suas propriedades nesse cadastro. O cadastro servirá para armazenar informações ambientais de todas as propriedades rurais. Essa base de dados servirá para 
a Lei $\mathrm{n}^{\mathrm{O}}$ 11.977/09 (antes MP 759) ${ }^{5}$, entre outras.

O aumento do desmatamento costuma associar-se ao crescimento da violência na floresta. O sul do Amazonas e norte de Rondônia tem sido apontados pela Comissão Pastoral da Terra (CPT) como regiões críticas em termos de aumento da escalada na violência no campo, em decorrência dos fatores levantados acima referentes às expectativas da flexibilização legal que prometem crescimento de rebanhos, regularização fundiária desburocratizada e menor fiscalização da exploração madeireira. Dos cem municípios com maiores índices de desmatamento, 61 estão entre os que apresentam as maiores taxas de assassinatos no país, segundo levantamento realizado pela Agência Brasil, que cruzou dados do Prodes - Monitoramento da Floresta Amazônica Brasileira por Satélite com o Mapa da Violência dos Municípios Brasileiros ${ }^{6}$.

Cerca de 500 mil km² de terras que vão do leste e sul do Pará em direção oeste, passando por Mato Grosso, Rondônia e Acre compõem o chamado arco do desmatamento da Amazônia. A faixa territorial que compreende o sul do Amazonas vem se consolidando como nova área de expansão da fronteira agropecuária. Os municípios de Canutama, Lábrea Manicoré, Boca do Acre, Apuí e Humaitá concentram as maiores áreas desmatadas em função da exploração de madeira ilegal e para a criação de novas áreas de pastagens.

A análise de dados recentes de sensoriamento remoto demonstra que as Unidades de Conservação e as Terras Indígenas têm desempenhado um papel fundamental na conservação de extensas áreas contíguas de floresta, em alguns casos em áreas de expansão acelerada de frentes agropecuárias e madeireiras. No entanto, na ausência de ações efetivas para a criação de novas áreas protegidas tornam aquelas que já existem como prioritárias para a conservação e em algumas delas percebe-se um esforço em promover a utilização sustentável visando a repartição dos benefícios da biodiversidade e de outros serviços ambientais. Com este objetivo, houve nos últimos anos um grande esforço do Estado e das organizações não governamentais em promover a proteção territorial e dos recursos ambientais naturais nestes territórios por meio de ferramentas de etnomapeamentos, etnozoneamento, planos de uso e de vida, incentivo

controle, monitoramento, planejamento ambiental e econômico e combate ao desmatamento. O cadastro permite pleitear créditos agrícolas.

5 O Poder Executivo federal editou a Medida Provisória n ${ }^{\circ} 759$, de 22 de dezembro de 2016, que expressamente revogou os dispositivos daquele diploma afetos ao assunto, trazendo, também, nova disciplina da regularização fundiária rural, da liquidação de créditos concedidos aos assentados da reforma agrária e de mecanismos de alienação de imóveis da União.

6 Levantamento realizado pela Organização dos Estados Ibero-Americanos para a Educação, Ciência e Cultura (OEI), com o apoio do Ministério da Saúde (https://extra.globo.com/ noticias/brasil/municipios-mais-desmatados-sao-os-mais-violentos-664110.html) 
a participação e governança e implementação de remuneração por serviços ambientais (Programa Bolsa Verde ${ }^{7}$ ).

Os participantes do Seminário O Papel das Áreas Protegidas na Redução das Emissões Oriundas de Desmatamento, reunidos em Brasília em 2009, concluíram que a criação e a gestão eficiente das áreas protegidas em conjunto com os povos indígenas e extrativistas têm um papel crucial para reduzir as emissões de gases do efeito estufa oriundas do desmatamento e da devastação dos ecossistemas e recomendaram que todas as unidades de conservação façam parte de todas as políticas, os projetos e os programas de mecanismos de redução das emissões.

Em consonância com este esforço, em 2012, foi instituída a Política Nacional de Gestão Territorial e Ambiental de Terras Indígenas (PNGATI), com o objetivo de garantir e promover a proteção, a recuperação, a conservação e o uso sustentável dos recursos naturais das terras e territórios indígenas.

\section{MUDANÇA CLIMÁTICA, TRANSFERÊNCIA DE RENDA E CONSERVAÇÃO AMBIENTAL}

Nas últimas décadas do século XX, e sobretudo na primeira década do século XXI, observamos uma crescente discussão sobre direitos sociais e territoriais vinculadas a questões e pautas ambientais, como também uma recorrente discussão sobre a crise ambiental. Segundo Giddens (2010, p. 10), a mudança climática é a dimensão mais urgente e mais grave e profunda da crise ambiental do século XXI, porque aumenta significativamente a desertificação, a crise de recursos hídricos e a crise da biodiversidade, trazendo grandes prejuízos econômicos e afetando severamente as populações pobres do planeta.

A questão territorial e a heterogeneidade sociocultural no Brasil hoje envolvem questões que tratam não somente de ocupação e afirmação territorial, como por exemplo o reconhecimento, demarcação e homologação de terras indígenas, estabelecimentos de unidades de conservação como também a compreensão de políticas sociais e ambientais promovidas por um Estado que tem se pautado pela imposição de uma política socioambientalista que prescreve aos habitantes um dado modo de viver em consonância com princípios conservacionistas.

Estado que de diversas formas tenta transformar estes sujeitos, extrativistas e indígenas em “nativos ecológicos”. Segundo Menezes e Bruno (2012, p. 291),

O Programa de Apoio à Conservação Ambiental Bolsa Verde, lançado em setembro de 2011, que concede trimestralmente um benefício de $\mathrm{R} \$ 300,00$ ( $\mathrm{R} \$ 1.200,00$ por ano) às famílias em situação de extrema pobreza que vivem em áreas consideradas prioritárias para conservação ambiental. 
esta "ecologização" de povos e comunidades tradicionais da Amazônia ou mesmo de caçadores da África Ocidental (LEACH, 2000), sustentam-se em pressupostos românticos que estabelecem um tipo particular de humanidade indissociavelmente ligada à natureza, vivendo em perfeita harmonia com o meio ambiente. A premissa do desenvolvimento sustentável dirigido para as comunidades tradicionais da Amazônia se sustenta nesta percepção da população acima combinada a ações de uma necessária promoção do desenvolvimento econômico amparada na preservação do meio ambiente com base na exploração racional do capital de conhecimentos tradicionais acumulado.

O meio ambiente tornou-se uma gramática cada vez mais frequente para se fazer falar de conflitos sociais (LEITE LOPES, 2004) e despolitizar relações sociais e de poder. Um dos dispositivos desta operação estaria representado no imperativo do conceito de desenvolvimento sustentável, permitindo inscrever o ambientalismo dentro do campo de lutas ideológicas, econômicas e políticas. Neste contexto, habitantes de Terras Indígenas e Unidades de Conservação foram eleitos pelos ambientalistas como a vanguarda ou os bastiões da resistência contra a face mais deletéria do capitalismo: a degradação ambiental, tornandose modelos de uma sociedade alternativa capaz de interagir harmonicamente com o meio ambiente. Assim, coloca-se em marcha um "Processo Civilizatório" (ELIAS, 1993) expresso na imposição de um conjunto de normas que prescrevem uma nova crença e etiqueta expressa em um conjunto de artefatos burocráticos denominados planos de vida, de manejo, de gestão e de uso que de forma supostamente "participativa" vão difundindo determinadas modalidades de sensibilidades ecológicas.

Esta configuração que articula território, conservação e manejo sustentável na Amazônia institucionaliza uma "governança ambiental" que prevê usos racionais da natureza e uma perpétua vigilância (FOUCAULT, 2008) em relação a invasores e vizinhos o que vem alterando um modo consolidado de relacionamento de povos e comunidades tradicionais tais como indígenas, extrativistas e posseiros, que passam a experimentar com cada vez maior frequência conflitos produzidos por visões e agendas institucionais divergentes de entidades governamentais (FUNAI, ICMBIO, INCRA) alicerçadas em valores particulares sobre justiça e desenvolvimento combinados a pressupostos científicos pertinentes a suas áreas de atuação.

Tomamos exemplos coletados em pesquisas realizadas por longo período com moradores da RESEX Médio Purus, situada no município de Lábrea, ao longo do curso médio do rio Purus (Amazonas), inserida na região do arco do desmatamento da Amazônia. A unidade de conservação integra o Programa de 
Áreas Protegidas da Amazônia (ARPA), do governo federal com duração prevista de dez anos, para expandir, consolidar e manter uma parte do Sistema Nacional de Unidades de Conservação (SNUC) no Bioma Amazônia. Observamos as trajetórias dos moradores da Resex Médio Purus que são pautadas na prática atual do extrativismo, da pesca, da agricultura e da criação de pequenos animais. Compartilham de passado recorrentemente relacionado à economia gomífera e madeireira de submissão aos chamados "patrões". Em função da decadência da borracha, tanto extrativistas quanto indígenas que viviam nas diversas comunidades ao longo do médio Purus, buscaram alternativas de sobrevivência, como a coleta de castanha, a plantação de roçados de mandioca para produção de farinha e feijão de praia para consumo e comercialização.

Diante da ênfase dos discursos de analistas ambientais e demais agentes ambientalizados na necessidade de controlar desmatamentos, observamos em muitos casos que a criação de animais e, sobretudo, a abertura de novos roçados pelas famílias, tornaram-se os responsáveis pelo desmatamento na RESEX, segundo os gestores das unidades de conservação, bem como a criminalização da prática das queimadas, prática tradicional agrícola para a abertura de novos roçados. O sistema de roças, tal qual costuma ser desenvolvido por comunidades ribeirinhas, é avaliado como uma prática cultural que deve ser corrigida, pois a tradicional e frequente abertura de novas terras para roçados seria um vetor de desmatamento. As normas sobre gestão de recursos são estabelecidas no processo de discussão do Plano de Utilização, sempre respaldadas na Legislação Ambiental e constituindo o instrumento central para subsidiar a gestão de unidades de conservação. No caso da RESEX Médio Purus, a participação e acordo coletivo sobre as normas estabelecidas no Plano de Utilização foram muitas vezes mencionadas como as precondições para cadastramento e pagamento de serviços ambientais (Bolsa Verde) para as comunidades da RESEX. Se a comunidade não chegasse a um consenso e validasse o plano, incutiam-se incertezas sobre a possibilidade de inclusão dos moradores no programa de transferência de renda denominado Bolsa Verde ${ }^{8}$.

Numa conversa com a consultora que conduziu a elaboração do Plano de Utilização da RESEX Médio Purus, contratada pelo Instituto Chico Mendes para Biodiversidade (ICMBIO), um extrativista tentava explicar para a mesma, durante debate sobre os perigos e as normas corretas para aberturas de roçados

\footnotetext{
8 Segundo o site do Ministério do Meio Ambiente, “O Bolsa Verde é um programa de transferência de renda para famílias em situação de extrema pobreza que vivem em áreas de relevância para a conservação ambiental. Funciona como um incentivo às comunidades para que continuem usando, de forma sustentável, os territórios onde vivem" Só seriam cadastrados no Programa Bolsa Verde aqueles moradores já cadastrados no Bolsa Família.
} 
e extrativismo, que sua atividade não causava danos à natureza, pois em sua comunidade os plantios nas várzeas (praias de rio) predominavam em relação aos cultivos de terra firme.

A agricultura, ela não atinge assim um grande impacto, não dá um grande impacto na natureza, na floresta, na RESEX. A gente usa mais as praias... E o extrativismo, quando eu trabalhava era mais com andiroba, copaíba, não muita. A copaíba aqui a gente tem problema pra ver né!” (Extrativista e agricultor da RESEX Médio Purus)

Percebemos que há um "pacote” ambiental previamente estabelecido para ser oferecido e acatado pelas comunidades amazônicas residentes em unidades de conservação naturalmente percebidas como potencialmente predatórias e cujo potencial para a sustentabilidade deve ser induzido por meio de capacitações para a manutenção de condições ambientais ideais. Esta normatização traz consigo a criminalização das formas tradicionais de uso e ocupação do solo e recursos naturais em geral em unidades de conservação. Buscar controlar este modo de relação com o meio ambiente produz um risco para a manutenção da segurança alimentar dos moradores destas áreas. Coibir cultivos como batata-doce, cará, banana pacovã, mandioca e limitar a produção de farinha, determinando-se o tamanho máximo dos roçados ou cerceamento da abertura de novas roças e criação de pequenos animais (galinha e porcos) significa reduzir as possibilidades de manter o modo de vida tradicional que assegura o sustento familiar, tanto no que tange à alimentação, quanto na geração de renda.

\section{HIERARQUIA E CONFRONTO DE SABERES}

O que observamos a partir da forma particular de administração dos roçados da RESEX Médio Purus é que vigora um conhecimento prático, não padronizado, aberto a diferentes protocolos de experimentação (CARNEIRO DA CUNHA; ALMEIDA, 2002). Percebemos a imposição de forma hierárquica e burocrática do um conhecimento científico respaldado pela Lei difundida pelo ICMBio e por organizações não governamentais que buscam multiplicar este modelo de saber. Qualquer espaço de sinergia entre estes saberes costumava ser pouco considerado. O que se presenciou foi o científico-tutelar de um lado e do outro o saber tradicional traduzido pelos primeiros como potencialmente predatório. Segundo Berkes (2009), os cientistas e/ou agentes do Estado não confiam no conhecimento tradicional. E este conhecimento tradicional e oral dificilmente se articula ou se permite acessível ao conhecimento científico. O conhecimento tradicional costuma basear-se em pontos de vista muito diversos 
daqueles da ciência ocidental, bem como partilhar de forma muito reduzida de seu conjunto de códigos. Nos alinhamos com Maturana e Varela (1987) e consideramos que o conhecimento é um comportamento eficaz ou adequado perante um contexto específico, cremos que não deveria haver hierarquia entre saberes tradicionais e científico. Ambos deveriam ser avaliados conforme sua eficácia em dado contexto.

Vale lembrar que fora da macrorregião onde se situa a RESEX Médio Purus reina a flexibilização da legislação ambiental e da fiscalização em relação ao respeito das áreas de Reserva Legal nos empreendimentos agropecuários e madeireiros, ou para a implantação de projetos desenvolvimentistas como hidrelétricas (tal como ocorreu em Santo Antônio e Jirau) ou a repavimentação de estradas (as várias tentativas de recuperação da BR-319/ Porto Velho-Manaus). Portanto, o tratamento é absolutamente desigual em relação à aplicabilidade da lei no que tange ao desmatamento na região, vigorando a flexibilização para os mais poderosos e o rigor da lei para os menos influentes.

De acordo com Taddei (2012, p. 77), na política ambiental, especialmente em países em rápido processo de modernização como o Brasil, a linguagem particular da Ciência e Tecnologia tem sido crucial para os discursos hegemônicos. No entanto, os conhecimentos e as técnicas têm também constituido-se como importantes espaços discursivos para resistir a forças que impedem a continuidade dos modos de vida tradicionais ao impor novas modalidades desenvolvimentistas para a Amazônia. Ao perguntarmos, aos agentes sociais sobre quem agride, destroi ou desmata a floresta, confluíram explicações tais como:

Os madereiros que quebravam seringa entravam em uma área dessa aqui, destruía tanto madeira, como a seringa, que a seringa ela é uma personagem... Ela só não é o Pau Brasil, mas imitando o Pau Brasil (Extrativista da Comunidade Remanso - rio Purus, município de Lábrea)

Eu acredito que o serrador ele destrói mais do que o pescador, porque o pescador ele vive daquilo, mas na hora de ter o peixe proibido na desova, ele para de pescar e não pega aquele tipo de peixe. E os serradores, tendo que serrar pra vender, ele derruba um pau e mata mais de um pau, porque um vai caindo, vai levando os outros, e ali vai acabando com tudo, e às vezes não aproveita nem a madeira como é pra aproveitar... (Extrativista da Comunidade Praia do Santarém - rio Purus, município de Lábrea)

Estas percepções foram bastante recorrentes entre os moradores das comunidades que hoje constituem a RESEX Médio Purus e não são baseadas em fundamentos científicos sobre as causas, os riscos e os efeitos das mudanças climáticas. A maioria destes extrativistas agricultores não tiveram oportunidade 
de escolarização para além da alfabetização ou oportunidade de ter informação específica sobre a centralidade da Amazônia para a regulação do clima planetário, pois nas comunidades só há escolas muito precárias, atualmente, até a quinta série do ensino fundamental.

Nas comunidades não indígenas, as organizações não governamentais não devotam maiores esforços de capacitação. Os esforços concentram-se na capacitação ambiental para populações indígenas caracterizadas por maior alteridade radical. Quando acontecem oficinas nas unidades de conservação, estas são direcionadas para lideranças específicas convocadas pelo ICMbio, em geral extrativistas que de alguma forma já compartilham da crença do imperativo da preservação ambiental e compartilham parcialmente dos códigos científicos.

A produção desta crença se construiu de múltiplas formas, a partir de oportunidades de escolarização, da participação em projetos de viés ambientalista que recrutaram indivíduos da região ou convites para assumir cargos de representação da comunidade que tornou possível a participação frequente em eventos nacionais e internacionais, reforçando a etiqueta ambiental como regulador de conduta e os códigos científicos sobre o funcionamento do bioma amazônico como certezas inexoráveis. Este conjunto de agentes sociais tornaram-se capazes de assumir como porta-vozes e difusores da crença no desenvolvimento sustentável.

Fazer parte da RESEX e ter direito de nela viver é uma resultante da oportunidade que se abriu do ponto de vista legislativo", mas também uma construção social dos moradores a partir de uma releitura de sua saga familiar na região. Há uma memória social de exploração e insegurança territorial que estabelece uma trajetória que relaciona exploração seringalista da qual participaram seus antepassados, continua com o boom da exploração madeireira nos anos 1990 e a transformação da área em unidade de conservação em 2008.

Foi ao longo de processo de luta por segurança territorial, coroado com a criação da RESEX, que foi se produzindo novos significados, percepções e responsabilidades sobre o território que ocupavam. A proteção da floresta, tão preconizada como fundamental para conter as mudanças climáticas, foi primeiramente construída como discurso da chegada do membro da família, e depois de legitimidade e conquista de uma terra histórica e rigidamente controlada pelo poder privado de patrões seringalistas e madeireiros. Uma vez tornada terra coletiva das comunidades, a proteção da floresta impõe-se tanto

9 A RESEX Médio Purus surge como resultado de luta das comunidades e movimento social organizado durante a consulta pública para a criação de Unidades de Conservação na região do entorno da BR (Manaus-Porto Velho)/ Área sob Limitação Administrativa Provisória (ALAP). 
como instrumento de regulação da vida social imposto pelos órgãos ambientais do Estado, por meio de suas ferramentas de gestão, mas também como uma responsabilidade para com aqueles que agora passam à condição de herdeiros da terra, ou seja, filhos, netos, descendentes e partes de uma saga familiar.

Rapaz, é quase bem dizer nós mesmos. A gente não tinha aquele pensar de dizer que essa natureza podia acabar. De certo tempo pra cá, porque eu venho conversando com a comunidade, que o que nós estamos plantando hoje, e o que nós estamos preservando hoje. Vamos supor que não chegue pra nós, vai chegar pros nossos netos, nossos filhos, vamos deixar, e se nós levar como estava antes, acabando com tudo. O que nós ia deixar? Só embaúba, então acredito até que os filhos da gente, os netos, iam dizer assim: poxa o papai dizia que morava aqui tantos anos, e hoje não temos uma árvore pra fazer uma canoa, pra fazer um barraco, porque o nosso pai foi o primeiro a destruir, acabou tudo, deixou só a terra pra nós”. Então fica muito difícil. Todo mundo já começou a pensar nisso, eu comecei a conversar com a comunidade, e o povo já começaram realmente a pensar... que eu tava certo, porque eu ia morrer não ia deixar nada, quer dizer que ia morrer, ia morrer a família toda. Porque ninguém ia precisar de nada, mas é diferente, nós temos netos, nós temos filhos, nós temos bisnetos, e tudo vai precisar daquela terra, com certeza precisa da floresta também pra sobreviver como nós precisamos (Extrativista da Comunidade Maciari - rio Purus, município de Lábrea)

A respeito dos relatos acima, Taddei (2012), ao tratar da relação entre cientistas, meteorologistas no Nordeste do Brasil, menciona que os discursos científicos operam com a perspectiva e postura que não são responsáveis pelas implicações ou impactos sobre as informações que eles produzem - é um gênero discursivo abstrato e descontextualizante. Muito diferentes são os discursos dos moradores da RESEX que nomeiam precisamente os agentes sociais responsáveis pela degradação da floresta e, sobretudo, inscrevem o processo de ambientalização coletiva em um processo histórico, personalizado por pessoas e sagas familiares. De forma bastante diversa, esta região é identificada pelos cientistas como parte do "Arco do Desmatamento", ou seja, zona de intervenção prioritária. Em suma, a região é percebida como foco prioritário de políticas públicas de controle de desmatamento, uma lacuna a ser preenchida, um passivo ambiental a ser solucionado até recentemente pelos moradores de Unidades de Conservação e Terras Indígenas por meio de políticas eficazes de gestão territorial.

É importante lembrar que muitas Unidades de Conservação do estado do Amazonas são também beneficiadas pelo pagamento de serviços ambientais por meio do programa de governo do Estado do Amazonas denominado "Bolsa 
Floresta". Segundo estudo de Badr e Mattos (2010), este foi o primeiro programa brasileiro a remunerar, de forma direta, indivíduos pertencentes às comunidades residentes nas florestas pela manutenção dos serviços ambientais, tendo em vista a redução de emissões por desmatamento. O Programa Bolsa Floresta foi criado em 2007 para implementação da política de Mudanças Climáticas, Conservação Ambiental e Desenvolvimento Sustentável do Governo do Estado do Amazonas, consoante o art. 5으, II, lei n⿳丷ㅜ 3.135/2007 e tem como objetivo compensar financeira ( $\mathrm{R} \$ 1.360,00$ por família por ano) as comunidades tradicionais que conservam a floresta em pé, assumindo o compromisso do "desmatamento zero", ou melhor, "desmatamento controlado e monitorado".

O programa beneficia os moradores das Unidades de Conservação do estado do Amazonas que comprovem residência em UC estadual há pelo menos dois anos; mantenham áreas de roças com tamanho não superior àquele do ano de instituição do programa, cultivando apenas em áreas de capoeiras abertas ou em descanso e não avançando na mata primária; caso tenham filhos, que estes estejam regularmente matriculados e frequentem a escola e, finalmente, participem da Associação de Moradores da Comunidade e da implementação dos planos de uso e de gestão da Unidade de Conservação, respeitando as suas regras.

A violência simbólica explicitada, sobretudo, na Cartilha do Programa Bolsa Floresta, informa que a família que tiver desmatado área pouco maior que àquela do ano de instituição do Programa Bolsa Floresta (até 50\% a mais) recebe um cartão amarelo e deverá apresentar uma justificativa para a associação, podendo permanecer mais um ano no programa. Em caso de reincidência no desmatamento, recebe-se um cartão vermelho, que resulta na suspensão da concessão do benefício. De acordo com a cartilha, o desmatamento é monitorado anualmente in loco pela equipe da Secretaria do Meio Ambiente e Desenvolvimento Sustentável e por imagens de satélite.

\section{INDÍGENAS E MUDANÇAS CLIMÁTICAS}

Em relação aos grupos indígenas até a década de 1990, o movimento tinha como pauta das suas discussões, demandas e reivindicações, a questão da demarcação e garantia dos seus territórios, bem como o direito a um sistema de saúde e educação que respeitassem suas práticas e costumes. No entanto, a partir do ano 2000 é possível notar que outros elementos foram adicionados à pauta do movimento, uma delas sem dúvida foram "as mudanças climáticas” ${ }^{10}$. É preciso

10 Deve-se mencionar que a chamada PEC-215, proposta que passa a decisão de demarcação das terras indígenas e quilombolas do Executivo para o Legislativo, proíbe a ampliação de terras 
ressaltar que alguns elementos, como desmatamento e conservação dos recursos naturais já eram discutidos anteriormente, mas sem uma relação explícita e direta as alterações do clima.

Esta temática, indubitavelmente, constitui atualmente parte importante das agendas do movimento indígena. No estado do Amazonas, o movimento indígena conjuntamente com organizações não governamentais e o governo do estado tem desenvolvido uma série de discussões, eventos e atividades para discutir e propor ações que minimizem os efeitos e impactos das mudanças no clima. Em 2001, ocorreu o Fórum Indígena Amazônico sobre Mudança Climática, na cidade de Manaus.

Neste evento, que contou com a participação de entidades nacionais, internacionais, científicas e governamentais (Instituto Nacional de Pesquisas da Amazônia (INPA), Instituto de Proteção do Amazonas (IPAAM), IBAMA, GREENPEACE, Fundação Estadual de Política Indigenista (FEPI), Comissão Pastoral da Terra (CPT), CIMI Norte I, Museu Nacional/UFRJ, The Nature Conservancy, Projetos Demonstrativos dos Povos Indígenas (PDPI), Conselho Nacional dos seringueiros (CNS)), foram discutidas as consequências que a mudança climática poderia trazer para os grupos indígenas e agentes sociais que vivem na floresta, na bacia amazônica. No evento, muitas questões ficaram em aberto e o tema ainda era percebido como bastante complexo.

Em 2008, aconteceu o I Seminário - Impactos das Mudanças Climáticas Globais em Manaus e a Bacia do Rio Negro, realizado pelo Instituto Socioambiental (ISA), em parceria com a Secretaria Municipal do Meio Ambiente (SEMMA) e a Secretaria Estadual de Meio Ambiente e Desenvolvimento Sustentável (SDS). Neste evento, duas questões foram discutidas: “a) Que prejuízos o aumento da concentração de gases de efeito estufa na atmosfera pode trazer para a Bacia do Rio Negro, especialmente em Manaus, onde vive a maior parte de sua população? b) Como cada cidadão e os governantes podem se organizar na tentativa de reduzir essas conseqüências negativas?"

Neste, três pesquisadores do Instituto Nacional de Pesquisas da Amazônia (INPA) falaram sobre o tema. O coordenador do Escritório Central do Programa de Larga Escala da Biosfera Atmosfera da Amazônia (LBA, sigla em inglês) falou sobre os "Modelos climáticos e cenários sobre mudanças climáticas para Amazônia"; Um cientista da Coordenação de Pesquisas em Ciências Agronômicas (CPCA) discutiu sobre os "Impactos das mudanças climáticas sobre palmeiras

delimitadas e garante a indenização a fazendeiros. Este atentado aos direitos indígenas cria novos desafios ao movimento e reforça a importância do argumento de que as terras indígenas são fundamentais à estabilidade climática. 
(açaí, pupunha, tucumã, entre outras) de uso econômico"; e um pesquisador da Coordenação de Pesquisas em Biologia Aquática (CPBA), abordou a questão do "Estado atual e futuro dos recursos pesqueiros em Manaus". Notemos que neste evento, havia participação dos indígenas, no entanto estes não eram percebidos como agentes com reflexão própria sobre o tema.

Em 2009, porém observamos que os indígenas foram finalmente colocados nas mesas de discussões e agora os cientistas escutariam suas explicações, visões e conhecimentos sobre o tema. O evento foi realizado em São Gabriel da Cachoeira e foi chamado de "Mudanças Climáticas: Na visão dos Povos indígenas e Cientistas". O mesmo foi realizado pelo ISA em parceria com a FEPI, o Centro Estadual de Mudanças Climáticas (CECLIMA), a SDS e o Governo do Estado do Amazonas.

Ao observamos a organização das mesas e suas composições, sem dúvida houve uma tentativa de diálogo entre os conhecimentos indígenas e o conhecimento científico, mas ainda muito tímido. O evento ocorreu apenas em um dia e a programação estava organizada da seguinte forma: a) A mesa inicial da primeira parte da manhã era composta por autoridades - governador do estado, na época Eduardo Braga, prefeito de São Gabriel, secretária da SDS, diretorpresidente da FEPI, presidente da FUNAI e representantes da FUNAI local, general da segunda brigada de infantaria de São Gabriel, e coordenadores da Federação das organizações indígenas do Rio Nego (FOIRN) e da COIAB.

A primeira mesa, com o título "Mudanças Climáticas na Visão dos Povos Indígenas e da Comunidade Científica", tinha como moderadora a secretária da SDS e foi composta por três pajés das etnias Dessana, Tuyuca e Baniwa e dois pesquisadores do INPA. Nesta mesa, os pajés discutiram e falaram dos seus conhecimentos e perspectivas do que estava ocorrendo com o clima; $\mathrm{Na}$ segunda mesa que ocorreu no início da tarde intitulada "Mudanças Climáticas em Terras indígenas na visão dos aliados e Parceiros, as instituições (FEPI, ISA, FOIRN, COIAB e COIAM) trataram de discutir suas perspectivas e atividades que pretendiam desenvolver para auxiliar na compreensão do tema. A última mesa intitulada "Mudanças Climáticas e as políticas públicas" foi composta por representantes do CECLIMA, FUNAI, SDS, FEPI e prefeito de São Gabriel que falaram das ações e das atividades de suas instituições para minimizar os efeitos da alteração do clima. Após cada mesa, havia um momento para discussões e debates. Ao final do evento foi lançado o livro "Povos indígenas na gestão pública".

Em 2010 houve também em Manaus - uma primeira consulta pública sobre Princípios e Critérios de Redução de Emissões por Desmatamento e Degradação (REDD). Esta atividade foi uma iniciativa do Grupo de Trabalho 
Amazônico (GTA), do Conselho Nacional de Populações Extrativistas (CNS) e da Coordenação das Organizações Indígenas da Amazônia Brasileira (COIAB). Neste encontro foram realizadas oficinas para capacitar lideranças dos povos da floresta, incluindo índios, seringueiros, ribeirinhos para compreender e entender mais sobre a relação entre mudanças climáticas e REDD. Ainda entre 2010 e 2011, a COIAB com apoio da The Nature Conservancy, do Instituto de Pesquisa Ambiental da Amazônia (IPAM) e da Embaixada da Noruega realizou um curso de formação e capacitação desenvolvido pelo Centro Amazônico de Formação Indígena (CAFI) que resultou na publicação da Cartilha "Mudanças climáticas e aquecimento global na visão dos povos indígenas".

A cartilha foi elaborada durante o curso e tem como autores indígenas de diversas etnias não só do Amazonas, mas também de outros estados brasileiros. Ela está estruturada em quatro capítulos que tratam dos seguintes temas: I- O clima antes e hoje; II- O aquecimento da terra e as mudanças do meio ambiente; III- Propostas e ações para a redução do aquecimento da terra; e IV - Preparo para a participação dos povos indígenas nas ações de combate às mudanças climáticas e ao aquecimento da Terra. Este último capítulo é voltado para discussão sobre REDD (regulamentação, políticas nacionais e internacionais, marcos legais, entre outras questões). No material temos uma combinação de conceitos técnicos científicos, desenhos e explicações indígenas.

Embora a temática venha sendo discutida há mais de dez anos no estado do Amazonas, observamos que não existe um esforço significativo por parte da comunidade científica em estimular e de fato compreender como estes fenômenos são percebidos e explicados pelos indígenas: O que de fato percebem, o que está mudando, como eles explicam, como eles se apropriam desses conceitos e os reinterpretam.

Conforme assinala Taddei (2012, p. 91), para garantir que suas explicações não sejam folclorizadas, romantizadas, antimodernas, muitos indígenas para participar efetivamente da construção desse conhecimento, sobretudo, sobre REDD tem adotado formas tecno-científicas de compreensão e expressão sobre o ambiente natural o que muitas vezes significa abrir mão das suas visões de mundo específicas. Posey (2001, p. 86), ao discutir a interpretação e utilização dos conhecimentos nativos pela ciência, esclarece que áreas como, por exemplo, a etnobiologia tende a considerar o conhecimento nativo somente em relação ao que é previamente conhecido pela ciência.

Assim, investigam-se somente categorias de uso de plantas, comportamentos animais, relações ecológicas, tipos de solo e paisagens que estejam abordados no próprio sistema de conhecimento científico. As 
proposições de hipóteses inspiradas no conhecimento indígena são submetidas a uma etapa prévia de purificação (LATOUR, 2004) onde precisam ser excluídos os elementos improváveis e inacreditáveis presentes nos relatos dos informantes, o que, segundo Posey indica que "improvável" e "inacreditável" seria a inabilidade dos pesquisadores de reconhecer a "realidade" indígena de qualquer critério científico real. Um exemplo desta postura pode ser observada, no material organizado pelo Instituto Socioambiental intitulado "Manejo do mundo: conhecimentos e práticas dos povos indígenas do rio Negro - Noroeste Amazônico (CALBAZAR, 2010), que faz uma tentativa de cruzar perspectivas e conhecimentos indígenas e científicos sobre o tema.

Aqui destacaremos um texto do capítulo "Ciclos de vida e mudanças climáticas", denominado "Floresta e clima: saber indígena e ciência", escrito por um pesquisador do INPE. Neste texto, o autor fala de sua experiência com os indígenas quando participou do evento Fórum Indígena Amazônico sobre Mudança Climática' (mencionado acima) e buscou apresentar o conhecimento científico sobre o papel da floresta (fotossíntese, sequestro de carbono, entre outras questões) nas mudanças climáticas para uma plateia sem treinamento científico. (2010, p. 38). Segundo o mesmo, após ser duramente criticado pela plateia, expos e ressaltou que mesmo que o conbecimento indígena fosse reconhecido por poucos no universo cientifico, o diálogo entre os dois tipos de saberes era extremamente necessário. Assim, alinhavando narrativas Yanomami e explicações científicas, o mesmo vai "traduzindo" e explicando como a floresta interfere nas alterações do clima, mas utilizando o conhecimento Yanomami apenas quando estava em conformidade com as explicações da ciência.

Em 5 de junho de 2012, Dia Mundial do Meio Ambiente, a Presidência da República institui a Política Nacional de Gestão Territorial e Ambiental de Terras Indígenas ${ }^{11}$ (PNGATI) que teve como eixos: a proteção territorial e dos recursos naturais e a governança e participação indígena em processos relacionados à gestão de suas terras, prevenção e recuperação de danos ambientais em TI, uso sustentável de recursos naturais e fortalecimento de iniciativas produtivas indígenas. São definidas como ferramentas para a gestão territorial e ambiental de terras indígenas o etnomapeamento e o etnozoneamento e, desde a instituição do PNGATI houve uma corrida destas ações de mapeamento participativo em Terras Indígenas voltados a registrar, localizar e diagnosticar participativamente todas as áreas de relevância ambiental, sociocultural e produtiva existentes.

O Fundo Amazônia administrado pelo Banco Nacional de Desenvolvimento Econômico e Social (BNDES) aprovou o investimento de

11 Decreto nº 7.747/2012 (DECRETO DO EXECUTIVO), de 06 de maio de 2012. 
R\$ 16,4 milhões para o estado do Amazonas para desenvolver um projeto de gestão ambiental sustentável das Terras Indígenas. O programa, com prazo de 36 meses, abrange cerca de 50\% dos territórios indígenas do estado (16,2 milhões de hectares) e atinge uma população de 35 mil índios. O objetivo é reduzir as atividades exploratórias que levam à degradação dos recursos naturais com investimentos no monitoramento da região e fortalecimento institucional das associações. As TI detêm um dos menores índices de desmatamento entre as diversas categorias de áreas protegidas. No entanto, sofrem pressão sobre seus recursos naturais, especialmente em áreas limítrofes com estradas e rios de maior circulação. Dentre vários objetivos, o projeto prevê a implantação de planos de gestão ambiental e bases de monitoramento.

Tanto no caso das Unidades de Conservação como da Terras Indígenas, percebemos como recorrentemente há o controle sobre modos de vida tradicionais com a imposição de um novo conjunto de crenças e normas que estabelecem um processo civilizador mediado pela difusão de uma nova etiqueta de regulação do mundo social indígena e extrativista amazônicos, acompanhados da crescente responsabilização de povos e comunidades tradicionais pelo monitoramento e controle do desmatamento, meta da Política Nacional de Mudança do Clima. As razões para a aceitabilidade da nova condição costumam ter explicações diversas, seja a crença num ônus pela conquista da terra ou mesmo por uma associação entre dominação do patrão e dominação do Estado, entidades que se revezariam mediando e fazendo exigências para permitir o direito ao uso da terra. Historicamente, vemos se reatualizar a função antes atribuída aos indígenas de estabilizar e demarcar as fronteiras nacionais, agora reeditada para a manutenção, gestão e vigilância das fronteiras da conservação ambiental na Amazônia.

\section{REGULARIZACÃO FUNDIÁRIA: INFLEXÃO E O NOVO PAPEL DA AMAZÔNIA NO CENÁRIO AMBIENTAL}

A partir de 2009, observa-se uma inflexão em termos de políticas públicas para o desenvolvimento da Amazônia, percebe-se uma progressiva ação de investimento na autogestão territorial e desenvolvimento sustentável de povos indígenas e comunidades tradicionais para uma reorientação para a regularização territorial de terras não destinadas. O Programa Terra Legal seria o grande divisor em termos de mudança de ênfase, com o objetivo de promover a regularização fundiária de ocupações baseadas em posses mansas e pacíficas dentro de terras federais na Amazônia Legal. 
Este programa se fundamenta na no Lei 11.952, sancionada pelo expresidente Lula, em 2009. As glebas federais na Amazônia compreendem uma área que equivale a mais de um quarto do território amazônico, tendo certificado cerca de 69 milhões de hectares que permitiram a destinação das terras. A primeira forma é a destinação para fins públicos e coletivos, como terras indígenas, unidades de conservação e assentamentos da reforma agrária, usos que se sobrepõem aos privados. No início de 2016 o programa contava com mais 18 mil títulos emitidos nas áreas públicas federais, conduzindo a emissão de mais de seis mil títulos em áreas públicas estaduais.

O Programa Terra Legal constitui-se um ambicioso e ousado programa de regularização fundiária do país, visando regularizar cerca 67 milhões de hectares de terras, cerca de 8\% do território nacional. Criado em 2009 pelo Ministério do Desenvolvimento Agrário, tinha como meta dar segurança jurídica aos produtores rurais da Amazônia Legal e reforçar as políticas públicas de preservação do meio ambiente na região. Desta forma, o Programa foi descrito pelo então ministro extraordinário de Assuntos Estratégicos e coordenador do Plano Amazônia Sustentável (PAS), Mangabeira Unger, da seguinte forma: "Sem tirar a Amazônia da situação de insegurança jurídica em que se encontra, ninguém sabe quem tem o quê. Não avançaremos em nada mais."

Em 2008, a Secretaria de Assuntos Estratégicos (SAE) da Presidência da República e o International Bank for Reconstruction and Development (BIRD) realizaram, em Brasília, o Seminário Internacional “O Desafio da Regularização Fundiária na Amazônia”, que subsidiou a negociação do governo federal com os nove governadores da Amazônia Legal sobre a regularização fundiária na região. As condições convergiam para constituir a regularização fundiária como problema número um da Amazônia brasileira.

Coadunando-se com o cenário de aumento de crescimento da produção de commodities na região, o processo de destinação das terras públicas da União para a administração dos governos estaduais da Amazônia Legal foi tornando imperativo o processo de aceleração de legalização das terras públicas, por meio do repasse de recursos com a finalidade fortalecer os institutos estaduais de terras e dar a estas terras uma destinação.

Constrói-se desta forma o volume de terras a regularizar pelo Programa Terra Legal, que após inúmeras denúncias de irregularidades, sofreu uma auditoria sistematizada no Relatório de Fiscalização do Programa Terra legal, realizado pelo Tribunal de Contas da União $(2014,14)$ baseado na consulta nos dados disponibilizados no Sisterleg (Base de Dados do Sistema Terra Legal). O Programa concluiu até meados de 2014, 7.951 processos de titulação dos quais 
5.607 de áreas abaixo de um módulo fiscal (MF) totalizando 174.577 ha; 2056 processos de 1 a 4 MF totalizando a titulação de 263.429 ha e 292 processos acima de quatro MF, somando 170.947 ha titulados.

Os estados com mais títulos acima de quatro módulos fiscais situavam-se nas áreas de maior expansão da fronteira agropecuária, ou seja, Pará, Mato Grosso, Tocantins e Maranhão. Foi orçado um total de $\mathrm{R} \$ 324,5$ milhões e para atender a meta de titulações (150 mil beneficiários) entre 2011 e 2014. Mantendo-se o ritmo detectado pelo TCU seriam necessárias mais quatro décadas para se atingir as metas propostas. Em 2005, esta lei que criou o Programa Terra Legal sofreu importantes modificações no sentido de estender os limites de regularização, ampliando para 500 hectares, e, posteriormente, por meio de medidas provisórias tornadas lei, o limite estendido a 15 módulos fiscais (na Amazônia cada módulo mede 76 hectares), ou não ultrapassando 1.500 hectares, dimensão impossível de ser enquadrada como pequena propriedade familiar.

No caso da Amazônia, o efeito dessas mudanças se expressaria na disponibilização de 67,4 milhões de hectares de terras da União em condições de incorporação ao mercado de terras (12\% da região amazônica), montante reduzido a 58,8 milhões após consulta a órgãos que alegaram destinação definida de parte desta área para unidades de conservação, terras indígenas e assentamentos rurais. O saldo de terras a regularizar seria ainda maior se levada em conta, segundo dados do Ministério do Desenvolvimento Agrário (MDA), a existência de mais de 100 milhões de hectares de terra na Amazônia sob controle dos estados e gestão dos Institutos de Terras e também passíveis de regularização.

As frustrações com "lentidão no processo de regularização fundiária" na Amazônia constituíram bases para a criação do Grupo Executivo Intergovernamental para a Regularização Fundiária na Amazônia Legal (GEI). O GEI surgiu como um movimento sincronizado, catalizador de ações, a fim de definir diretrizes para acelerar o processo de destinação de terras públicas na Amazônia, nos quais se destacam as seguintes representações governamentais: Casa Civil da Presidência da República, Secretaria de Assuntos Estratégicos da Presidência da República, Ministério do Desenvolvimento Agrário, Ministério do Meio Ambiente, Ministério do Planejamento, Orçamento e Gestão e Instituto Nacional de Colonização e Reforma Agrária. A fim de acelerar a regularização fundiária, compreendeu-se a necessidade de aceitar nas reuniões do Grupo Executivo Intergovernamental, os governadores dos estados e outros órgãos e entidades da administração pública, por exemplo, coordenadores estaduais do Programa Terra Legal Amazônia. 
Durante as reuniões do GEI acordou-se sobre a flexibilização dos documentos comprobatórios necessários para regularização fundiária, resultando na simplificação e agilidade nos pareceres favoráveis à expedição de títulos definitivos. Detectaram-se assim os gargalos que "burocratizavam" a expedição de títulos definitivos, não só em termos de documentos mínimos necessários para andamento dos requerimentos de regularização fundiária, como na discussão de flexibilização de outras leis e normativas relacionadas à Lei nº 11.952.

Em 2014, ainda durante o governo Dilma Roussef, o GEI passou a adotar providências de simplificação do processo de regularização fundiária: medidas administrativas de impacto para agilizar os processos e aumento de títulos definitivos sob supervisão da Cooperação Técnica Alemã (GIZ). Aumentou o tamanho dos lotes de reforma agrária de 1 módulo fiscal para 2, e atendeu reivindicações para regularização fundiária de imóveis rurais acima de 15 módulos fiscais. Outra reivindicação era a renegociação das dívidas dos títulos antigos e a possibilidade de legalização dos processos indeferidos devido à prática de grilagem como ocorreu no sul de Lábrea (AM).

Aventamos como hipótese que as mudanças introduzidas pela chamada Medida Provisória 759 convertida em atualmente em Lei n⿳⺈ 13464/2017 estariam em consonância como o trabalho desenvolvido pelo Programa Terra Legal, especialmente quanto ao seu aspecto desburocratizante. Em entrevista com os técnicos do Programa Terra Legal, descobriu-se que a MP respondia muitas demandas apresentadas no GEI, entre as causas alegadas a possibilidade de aumentar significativamente a legalização de terras. Pode-se concluir que a chamada MP 759 é um desfecho deste movimento iniciado em 2009 e uma resultante dos acordos estabelecidos no âmbito do GEI visando criar uma "Terra Legal sem burocracia”.

Em meados de 2017, com a sanção pelo presidente da República da Medida Provisória 759/2016, produziu-se a atualização da Lei do Programa Terra Legal no 11.952/2009 e estabelecidas novas regras para a regularização de terras da União ocupadas na Amazônia Legal por meio do agora denominado Programa Nacional de Regularização Fundiária. Este novo marco legal objetiva promover o desenvolvimento da política de regularização fundiária em todo país.

Deve-se salientar que o Programa Terra Legal apresentava-se como uma política voltada para a segurança jurídica dos produtores rurais da Amazônia Legal e ao reforço das políticas públicas de preservação do meio ambiente na região. As mudanças no Código Florestal se coadunam com estas metas e traz 
como instrumento o Cadastro Ambiental Rural (CAR ${ }^{12}$ ) integrado ao SICAR, no qual deverá apresentar os dados ambientais de sua propriedade rural no Estado. O produtor rural que não se inscrever no CAR torna-se irregular, com impedimentos de licenciamento ambiental, financiamentos e obstáculos para a comercialização de sua produção.

Por pressão das organizações não governamentais por transparência total, os dados do CAR foram tornados públicos no final de 2016. A Confederação da Agricultura e Pecuária do Brasil (CNA) protocolou na Procuradoria-Geral da República, representação contra o ministro do Meio Ambiente, Sarney Filho por crime de responsabilidade e improbidade administrativa, ao determinar a divulgação pública, pela internet, de dados sigilosos do produtor rural contidos no Cadastro Ambiental Rural (CAR). Alguns dias depois o ministério retrocedeu e retirou da internet o nome das propriedades rurais.

Se anteriormente muitas ONG de perfil ambientalista se posicionavam favoráveis ao veto das mudanças no Código Florestal, atualmente estas se colocam como fiscalizadoras dos compromissos assumidos pelos produtores rurais apoiando assim o aperfeiçoamento da base técnica do CAR. De forma pejorativa, muitos produtores incomodados com a vigilância das ONG as denominam de "lobistas do CAR"13.

A análise do que vem sendo divulgado na imprensa, possivelmente por setores ruralistas, sobre a relação entre ONG e CAR é bastante intrigante, visto que reforça a ideia de que as ONG doutrinam a imprensa (A Conservation International é citada como exemplo) sobre a importância do CAR para a regularização dos imóveis rurais no Brasil e sobre a importância deste instrumento para o alcance do desmatamento ilegal zero. É sempre lembrado que as ONG se opuseram à reforma do Código Florestal por meio de seminários para jornalistas reforçando que o novo Código Florestal é um retrocesso e deveria ser vetado ${ }^{14}$.

Para os produtores o risco da divulgação pública do CAR não estaria na área a ser preservada nos imóveis rurais em Áreas de Preservação Permanente ou Reserva legal, mas nos passivos ambientais, ou melhor, na área que cabe a cada propriedade recuperar de vegetação nativa nos anos futuros. O passivo

12 O Cadastro Ambiental Rural foi criado para monitoramento, preservação e recuperação de florestas em propriedades privadas, espaços onde mais se detecta o avanço do desmatamento.

13 No encontro para a divulgação do CAR, realizado pelo ministro do Meio Ambiente estavam representantes do ISA, BVRio, IPAM, WWF, SOS Mata Atlântica, The Nature Conservancy, Friends of the Earth. Disponível em: https://www.noticiasagricolas.com.br/noticias/ meio-ambiente/183884-divulgacao-do-car-foi-acertada-com-ongs-em-outubro.html\#. WpOPNLpFxy1 Acesso em: 24 fev. 2018

14 Disponível em: http://www.codigoflorestal.com/2016/03/ongs-promovem-seminario-para. html Acesso em: 24 fev. 2018 
ambiental seria o verdadeiro interesse e motivador do controle e ação das ONG. Cabe ressaltar que a ONG The Nature Conservancy (TNC) costuma destacar sua experiência acumulada ao longo de quase uma década e está na disputa pelo cadastramento de imóveis rurais que exige habilidades em informática e conhecimento cartográfico. A representante da TNC no Brasil informou que a organização foi a primeira a implantar o CAR em grande escala no país. O projeto da TNC tem como foco os municípios que formam o arco do desmatamento na Amazônia.

\section{CONSIDERAÇÕES FINAIS}

$\mathrm{Na}$ primeira parte deste texto buscamos destacar como indígenas e comunidades tradicionais habitando áreas florestais mais preservadas e por esta razão constituíram focos para ações de promoção do desenvolvimento sustentável de agências estatais e ONG que se empenhavam no controle de desmatamento por meio do monitoramento do crescimento dos roçados, no controle da pesca predatória nos lagos e por meio do apoio destas atividades com pagamento por serviços ambientais como mecanismo de compensação para que se reduzisse a pressão sobre os recursos naturais. Destacamos ainda a dificuldade de se produzir uma sinergia entre conhecimentos científicos que frequentemente traduziam de modo folclorizado ou romantizado os conhecimentos tradicionais.

A recente e drástica mudança no marco legal da regularização ambiental e fundiária sinaliza que um estoque importante de terras formais serão disponibilizadas ao mercado para a produção rural, fechando ou dificultando muito novas possibilidades para expansão e criação de territórios indígenas e para comunidades tradicionais. Vale lembrar que as mesmas ONG que realizavam etnomapeamentos colaboram para o Cadastro Ambiental Rural e outras se empenharão nos projetos de controle e monitoramento do desmatamento e passivo ambiental em áreas cadastradas ou tituladas.

Finalmente, conforme buscamos demonstrar, houve uma mudança no eixo e objeto de debate das mudanças climáticas na Amazônia na última década. Ainda que o tema ainda esteja focado no desmatamento, os meios mudaram. Os projetos direcionados para a agricultura de baixa emissão de carbono com práticas agrícolas sustentáveis que integrem lavoura-pecuária e floresta ganham força como estratégia de combate à crise climática ${ }^{15}$. Houve mudanças nas estratégias para reduzir o desmatamento e novos grupos sociais se tornaram protagonistas deste processo.

15 O relatório completo deste estudo está dispOnível o www.Observatorioabc.com.br. 
Desde 2009 com o Programa Terra Legal e mais recentemente com a aprovação da MP 759 e a reforma do Código Florestal, os segmentos ruralistas tem alcançado vitórias importantes com estas mudanças do marco legal, transformações retoricamente dirigidas ao combate do fundiário amazônico, a segurança territorial dos produtores rurais gerando a formalização de um imenso mercado de terras. As mudanças sinalizam a nova prioridade do destino das terras públicas amazônicas: o desenvolvimento agropecuário.

O novo rumo na política territorial significa a retirada do protagonismo de indígenas e povos tradicionais do front do combate das mudanças climáticas. As ONG repercutiram esta inflexão e estão agora "de olho nos ruralistas"16, ou seja, focando suas ações no controle de ações chamadas de "integracionistas" expressas no arrendamento de suas terras para o agronegócio, por exemplo. O Ministério da Agricultura, Pecuária e Abastecimento (MAPA) em audiência no final de dezembro de 2016, no Senado afirmou que os índios "não podem ficar à margem da tecnologia e têm que ser integrados". O cenário se agrava e facilita investimentos integracionistas diante da drástica redução de recursos para a FUNAI, que teve o maior corte de recursos da última década.

\section{REFERÊNCIAS}

AB'SABER, Aziz Nacib. Entrevista concedida para a revista National Geographics, de setembro de 2007. Disponível em: < https://opiniaosocialista. wordpress.com/textos-fundamentais/aquecimento-global-opiniao-de-aziznacib-ab\%C2\%B4saber/>. Acesso em 24 fev. 2018

\section{ALUNOS INDÍGENAS, Cartilha mudanças climáticas e aquecimento} global na visão dos povos indígena. Manaus: COIAB/CAFI, 2011

BARD, F; MATTOS, F. Remuneração pela preservação da floresta em pé análise do REDD e a experiência do programa Bolsa Floresta do Estado do Amazonas. In: ENCONTRO NACIONAL DO COMPEDI, 19. Fortaleza, 2010. Anais... Fortaleza, 2010

BERKES, Fickret. Evolution of co-management: Role of knowledge generation, bridging organizations and social learning. Journal of Environmental Management, n. 90, p. 1692-1702, 2009.

BOURDIEU, P. Language and symbolic power. Cambridge, MA: Harvard University Press, 1991.

${ }_{16}$ Parafraseando o site De olho nos ruralilstas: observatório do agronegócio no Brasil (https:// deolhonosruralistas.com.br/) 
BRUNO, Ana C; MENEZES, Thereza C. C. Quando os discursos sobre mudanças climáticas modificam as agendas e afetam a vida dos sujeitos sociais - indígenas e extrativistas. In: REUNIÃO BRASILEIRA DE ANTROPOLOGIA (RBA), 29. - Diálogos Antropológicos expandindo fronteiras. Natal, 2014 Anais... Brasilia: Kiron, 2014. p. 01-12.

CALBAZAR, Aloisio (Org.). Manejo do mundo: conhecimentos e práticas dos povos indígenas do Rio Negro - Noroeste Amazônico. São Paulo, ISA: São Gabriel da Cachoeira-AM: FOIRN. 2010.

CARNEIRO DA CUNHA, Manuela; ALMEIDA, Mauro B. (Org.). A enciclopédia da Floresta. São Paulo: Companhia das Letras, 2002

CORREIO BRASILIENSE. Brasília, 20 fev. 2007.

ELIAS, Nobert. O processo civilizador: formação do Estado e civilização. Rio de Janeiro: Jorge Zahar, 1993.

FEARNSIDE, P.M. "La vulnerabilidad de la selva amazónica frente a los cambios climáticos”, em PENICHE CAMPS, F. González, E. Macías Franco, M. Guzmán Arroyo \& G. Zavala García (eds.) II Seminario Internacional sobre la Cuenca del Río Santiago: El Cambio Climático. Centro Universitario de Ciencias Económico-Administrativos (CUCEA), Universidad de Guadalajara, Guadalajara, Jalisco, México, 15-31. 2012.

FOUCAULT, Michel. Segurança, território, população. Rio de Janeiro: Martins Fontes, 2008.

GIDDENS, Anthony. A política da mudança climática. Rio de Janeiro: Zahar, 2010 .

IPCC - Intergovernmental Panel on Climate Change. Climate Change 2007: Mitigation. Contribution of Working Groups III to the Fourth Assessment Report of the Intergovernmental Panel on Climate Change. Cambridge: Cambridge University Press, 2007.

LATOUR, Bruno. Jamais fomos modernos. São Paulo: Editora 34, 2004.

LEACH, M. New shapes to shift: war, parks and the hunting person in modern west Africa. Man, v. 6, n. 4. 2000

LEITE LOPES, J. S (Coord.). A ambientalização dos conflitos sociais. Rio de Janeiro: Relume Drumará, 2004. 
MATURANA, H. R.; VARELA, F. J. The tree of knowledge: the biological roots of human understanding. Boston: Shambhala. 1987.

MENEZES, Thereza; BRUNO, Ana Carla. A floresta e sociedade: tradição e cultura. In: HIGUCHI, M. I. G.; HIGUCHI, Niro (Ed.). A floresta e suas múltiplas dimensões: uma proposta de educação ambiental. 2. ed. rev. e amp. Manaus: INPA/CNPq, 2012. p. 287-308

MENEZES, Thereza. Dois destinos para o Purus: Desenvolvimento, socioambientalismo e emergência dos povos tradicionais no Sul do Amazonas. In: MENDES DOS SANTOS, G. Álbum Purus. Manaus: EDUA, 2011.

Nature 481(7381):321-8 · January 2012. The Amazon Basin in Trasition.

Disponível em: <https://www.researchgate.net/publication/221760309_The_ Amazon_Basin_in_transition> Acesso em 09 mar.2018

NOBRE, Antonio Donato. "Floresta e Clima. Saber Indígena e Ciência", em Manejo do Mundo: Conhecimentos e Práticas dos Povos Indígenas do Rio Negro - Noroeste Amazônico. São Paulo, ISA: São Gabriel da Cachoeira-AM: FOIRN. 2010.

POSEY, Darrel. Interpretando e utilizando a realidade dos conceitos indígenas: o que é preciso aprender dos nativos? In: DIEGUES, Antônio Carlos S. e Moreira, André de Castro C. Espaços e recursos naturais de uso comum. São Paulo, Nupaub. 2001. p. 279-294

RELATÓRIO DE AUDITORIA DE CONFORMIDADE NO PROGRAMA TERRA LEGAL AMAZONIA. TCU, 2014. Disponível em: <http:// pt.slideshare.net/fullscreen/SindPFA/relatrio-de-fiscalizao-do-programa-terralegal-pelo-tcu-2014/3>. Acesso em: 24 fev.2018

SOARES FILHO et al. Redução das emissões de carbono por desmatamento no Brasil: o papel do Programa Áreas Protegidas da Amazônia (ARPA). Relatório técnico IPAM e WWF. 2009.

SUMÁRIO/RIO EXECUTIVO: Agricultura de baixa emissão de carbono: financiando a transição. Análise dos recursos ABC. Observatório ABC. Disponível em: www.observatorioabc.com.br. Acesso em: 24 fev.2018

TADDEI, Renzo. Social Participation and the politics of climate in Northeast Brazil. In: LAT'TA, Alex and Hannah WITTMAN, (Ed.), Environment and Citizenship in Latin America: Natures, Subjects and Struggles. New York, Berghahn Books. 2012. p. 77-94 
Of clouds and streams, prophets and profits: the political semiotics of climate and water in the Brazilian Northeast. 2005. PhD dissertation, Graduate School of Arts and Sciences, Columbia University, New York. 2005. 


\section{Representação descritiva comprometida com o desenvolvimento das mulheres: quais critérios importam?}

\section{Descriptive representation committed to the development of women: what criteria matter?}

Rayza Sarmento - Doutora em Ciência Política pelo Programa de Pós-Graduação em Ciência Política da Universidade Federal de Minas Gerais (PPGCP/DCP-UFMG). Professora do Departamento de Ciências Sociais da Universidade Federal de Viçosa (DCS/UFV). E-mail: yzasarmento@gmail.com

\section{Resumo}

A representação descritiva tem sido considerada uma das formas de corrigir a ausência das mulheres dos espaços eletivos da política democrática. Contudo, a literatura pouco tem discutido qual seria a representação descritiva preferível, especialmente comprometida com causas feministas. Neste trabalho apresentamos uam reflexão teórica e entendemos a representação descritiva como um instrumento fundamental para se pensar o desenvolvimento das mulheres e discutimos sobre quais parâmetros deve estar assentada tal representação, observando o cenário político brasileiro.

\begin{abstract}
The descriptive representation has been considered one of the forms of correcting the absence of women from the elective spaces of democratic politics. However, little has been discussed about what would it be the preferable descriptive representation especially committed to feminist causes. In this paper, descriptive representation is understood as a fundamental instrument to think the development of women and to discuss which parameters such representation should be based on, observing the Brazilian political scene.
\end{abstract}

\section{Palavras-chave}

Desenvolvimento. Gênero. Representação Política. Mulheres.

\section{Keywords}

Development. Representation. Women. 


\section{INTRODUÇÃO}

A familia toda passava as férias numa casa de praia em Iguape. No caminho parava num boteco pé de chinelo para tomar café com broa onde tinha um cartaz na porta: "Mulher aqui só diz três coisas:

Xô, galinha', 'Entra, menino'e 'Sim, senhor'”. Fiquei muito impressionada com isso. Outra frase que me deixou profundamente revoltada era de minha tia solteirona: "Heloneida, fique certa que mulher não tem querer". Eu tinha sete anos e resolvi que ia passar a minha vida mostrando que mulher tinha querer sim!

(Heloneida Stuardt - feminista, escritora, cearense e ex-deputada estadual)

Incluir a perspectiva de gênero para pensar o desenvolvimento humano tem sido o desafio de uma variedade de políticas públicas no plano internacional, após o reconhecimento de que ignorar tal dimensão da vida política implica não solucionar os entraves ao desenvolvimento que atingem mulheres e homens de formas diferenciadas (WALBY, 2005; WOODWARD, 2008). A abordagem das capacidades, com Sen (2001 [1999]) e Nussbaum (2000), mostrou-se um interessante caminho teórico para ultrapassar a perspectiva estritamente econômica com a qual se avaliara o desenvolvimento das sociedades e observar as diferentes dinâmicas que perpassam a vida dos sujeitos e interferem na qualidade de como vivem e sentem, almejam ou ignoram possibilidades de futuro.

Nussbaum (2000) mostrou como há fatores diretamente ligados à construção social e política do ser mulher que interferem no desenvolvimento de tal parcela da população mundial. A autora desenvolveu uma lista de capacidades básicas que deveriam ser garantidas às mulheres para o alcance do pleno desenvolvimento. Entre tais capacidades, admite-se a necessidade de as mulheres estabelecerem o que ela chama de 'controle sobre seu ambiente', tanto o material quanto o politico, e neste último serem capazes de participar efetivamente das escolhas sobre suas vidas.

A definição de tal capacidade como um dos âmbitos necessários para o desenvolvimento nos provocou uma inquietação e, mais do que buscar respostas, este texto é uma tentativa de articulação da discussão feita por Nussbaum (2000) com um tema muito caro à literatura feminista na área da Ciência Política, a representação de mulheres. Parte da literatura preocupada com a inserção das mulheres na política (ou melhor, com ausência delas) tem defendido a 
representação descritiva, como sendo o compartilhamento de características dos representados pelos representantes, o que nos parece ser uma alternativa bastante viável para corrigir as desigualdades de acesso à esfera política não só por mulheres, mas por outros grupos historicamente marginalizados (PHILLIPS, 1995; 2001).

O que discutimos, contudo, é se a simples existência de mulheres em cargos representativos, especialmente os eletivos, garante algum comprometimento com o desenvolvimento desse grupo. Ou se deveríamos estabelecer, ainda que no plano teórico, critérios para que pudéssemos definir quais representantes são preferíveis a outras, enfocando sua relação com os temas que promovam igualdade de gênero e melhoria na condição de vida das mulheres. Tal discussão tem sido feita por Suzanne Dovi (2002). A autora afirma que é possível avaliar a forma como aumento do número de representantes de grupos marginalizados melhora a condição de tais grupos, entretanto, é preciso dar um passo anterior e questionar quem seriam tais representantes, dada a pluralidade presente nos grupos sociais.

Ao entrarmos em contato com a obra de Dovi (2000), ainda que concordando com sua busca por critérios para a representação descritiva, perguntamos-nos se essa não seria uma exigência difícil de ser perseguida no quadro brasileiro de extrema ausência de mulheres na política, conforme atestam os estudos de Matos (2009). A autora apresenta uma série de variáveis que explica a pouca presença de representantes do sexo feminino e sua discussão vai muito além da falta de ambição política, comumente atribuída às mulheres. O que Matos (2009) deixa transparente ao se debruçar nas experiências de candidatas é a combinação "perversa" de fatores que colaboram para que o âmbito da política seja extremamente favorável aos homens.

Ainda diante desse cenário pouco cômodo à representação descritiva de mulheres, os dados apresentados pela autora brasileira nos levam a caminhar ao lado das proposições de Dovi (2002), na insistência acerca de parâmetros de preferências descritivas. Ao traçar os perfis e as trajetórias das mulheres candidatas analisadas em sua pesquisa, Matos (2009) observou a permanência de duas paisagens de ingresso das mulheres, típicas do legislativo brasileiro. Diz a autora:

A primeira delas refere-se ao capital político "herdado" de figuras masculinas que tenham atuação no campo político, a exemplo dos pais, maridos, tios, padrinhos etc. Nas entrevistas com as eleitas este foi um perfil preponderante (ainda que não o único). Um segundo perfil refere-se ao ativismo político. Aqui cabe menção a um elemento significativo surgido 
das entrevistas: o ativismo facilitado ou propiciado pela participação feminina em projetos, serviços e ações vinculados religiosamente (MATOS, 2009, p. 76).

Além disso, a autora também concluiu que não é possível dizer da existência de uma "sensibilidade de gênero", em função de que as candidatas não exprimiram que suas plataformas estejam permeadas por uma compreensão crítica acerca das relações de gênero ou envoltas em uma perspectiva político feminista.

O que pudemos constatar, mesmo com a legislação das cotas, é o preenchimento indiscriminado das listas ou, no máximo, o preenchimento (quando este acontece) através de um padrão de elegibilidade/perfil de carreira específico - mulheres escolarizadas e profissionais liberais - e não de todas as mulheres, de modo generalizado (MATOS, 2009, p. 79).

Os resultados apresentados por Matos (2009) sobre as formas de ingresso e ausência de uma filiação feminista nos fazem crer que as preocupações de Dovi (2009) são extremamente plausíveis. É na tentativa de pensar um tipo de representação comprometida com o desenvolvimento das mulheres que apresentaremos a seguir a discussão empreendida por Nussbaum (2000); posteriormente, a defesa da representação descritiva, para então, com Dovi (2002), discutirmos sobre o estabelecimento de critérios.

\section{COM NUSSBAUM, O GÊNERO, AS CAPACIDADES E O DESENVOLVIMENTO HUMANO}

O crescimento econômico como sinônimo de desenvolvimento humano foi um ideal dominante nas discussões teóricas e na prática de avaliação socioeconômica das sociedades industrializadas. O surgimento dos programas de bem estar social, produto do aumento da renda dos países, por vezes reafirmaram à mulher o domínio do privado e buscavam promover o desenvolvimento por meio de programas assitencialistas, tratando-as não como agentes, mas como beneficiárias do desenvolvimento. As críticas feministas ao welfare state têm mostrado como é necessário adicionar o gênero para pensar nas implicações desses regimes que são diferenciadas para mulheres e homens. Divisão sexual do trabalho, trabalho remunerado, casamento e família são questões diretamente afetadas pelas formas de provisão social do Estado

É no plano internacional, especialmente com a Conferência Mundial sobre a Mulher, em 1975, no México, que surgem as primeiras tentativas de pensar o papel das mulheres no contexto desenvolvimentista. Contudo, essa 
primeira perspectiva, conhecida como Mulher e Desenvolvimento (MED), ainda enfatizava o cuidado, a preocupação com a família e não pensava as mulheres enquanto sujeitos singulares, merecedoras de atenção específica e voz ativa para falar de suas necessidades. Assim, mesmo sendo tematizadas nessas discussões, houve uma continuidade do pensamento baseado na existência de essencialidades femininas, focado em papéis reprodutivos e domésticos, o que não provocou mudanças significativas na compreensão da relação sobre mulher e o desenvolvimento (GUZMÁN, 2001).

Na década de 1980, tal pensamento toma uma dimensão mais relacional, buscando descortinar que a subordinação das mulheres não se dá naturalmente, mas se conforma a partir da dinâmica de relações entre os sexos, inaugurando assim perspectiva de Gênero e Desenvolvimento (GED). A nova perspectiva não buscara apenas inserir as mulheres em um modelo já existente, mas construir um novo paradigma para pensar de forma igualitária as relações (GUZMÁN, 2001). O gender mainstreaming, ou transversalidade de gênero, surge como um instrumento importante para que os estados repensem a formulação de políticas com foco na igualdade ${ }^{1}$ (WOODWARD, 2008).

Woodward (2008, p. 290, tradução nossa) afirma que o conceito de gender mainstreaming se torna "muito mais sofisticado do que a categoria de mulheres biológicas sozinha e o uso do conceito de gênero é crucial na criação de políticas que melhoram a igualdade", por não somente introduzir as mulheres em uma lógica de desenvolvimento essencialmente masculina, mas discutir como as relações de gênero se criam e são mantidas dentro das políticas estatais. Walby (2005, p. 327) também assinala que o gender mainstreaming implica a "introdução de novos padrões de justiça de gênero para os seres humanos".

No plano teórico, a articulação entre igualdade de gênero e desenvolvimento ganha corpo com a obra de Martha Nussbaum (2008). A autora, a partir do que foi traduzido como abordagem das capacidades, discorre sobre quais fatores incidem diretamente a vida das mulheres e constrói uma lista de capacidades consideradas básicas para que o desenvolvimento possa ser garantido.

A abordagem das capacidades, todavia, surge e se populariza com a obra de Amartya Sen (2001 [1999]). Para este autor, a liberdade é o valor fundamental para o desenvolvimento e só será alcançado quando forem eliminados os entraves que impedem os sujeitos de optar e viver em um ambiente sadio. A obra de Sen é um marco para que o produto nacional bruto deixe de ser visto como um

Segundo Woodward (2008), o conceito de gender mainstreaming, antes de ser apropriado pela academia, surge nos relatórios dos organismos internacionais, na prática política de tentar inserir a discussão sobre igualdade de gênero no estado. 
único medidor de desenvolvimento de uma nação. Mais do que gerar riqueza, a distribuição e as oportunidades de ação e escolha devem estar garantidas aos indivíduos, os quais devem estar satisfeitos.

A ligação entre liberdade individual e a realização de desenvolvimento social vai muito além da relação constitutiva - por mais importante que ela seja. O que as pessoas conseguem positivamente realizar é influenciado por oportunidades econômicas, liberdades políticas, poderes sociais e por condições habilitadoras, como boa saúde, educação básica e incentivo e aperfeiçoamento de iniciativas (SEN, 2001, p. 19).

Para construir suas proposições teóricas, sob a perspectiva feminista, Nussbaum (2000) esclarece os pontos de aproximação e distanciamento com a obra de Sen. Para ela, mais do que emitir satisfação, a noção de capacidade precisa ser entendida a partir de uma relação complexa entre o que se deseja e o que é factível de realização. A capacidade de fazer uma escolha precisa estar conjugada à oportunidade de poder desfrutá-la.

O que torna mais marcante a discussão da autora, e está ausente nos estudos do economista, é a construção de um limiar, de um nível mínimo de garantias para que os sujeitos possam desenvolver-se ou "uma base central de princípios constitucionais que os cidadãos têm o direito de exigir de seus governos" (NUSSBAUM, 2000, p. 12, tradução nossa). Para a construção de sua lista de capacidades, Nussbaum (2000) se propõe a responder a argumentos comuns que podem fazer crer ser impossível a construção de valores universais, nos quais estão assentadas as capacidades básicas. "O objetivo é proporcionar sustentação filosófica para uma lista de princípios constitucionais básicos que devem ser respeitados pelos governos de todas as nações, com o mínimo de respeito que a dignidade humana exige", explica Nussbaum (2000, p. 5, tradução nossa).

O primeiro argumento crítico à tentativa da construção teórica das capacidades básicas enfrentado por Nussbaum (2000) é o da cultura, que, a primeira vista, pode impossibilitar a construção de um quadro universal para avaliar a vida das mulheres. A autora afirma, contudo, que as culturas são lugares de contestação e que o pluralismo, a liberdade e a diversidade não podem ser antônimos da garantia de condições básicas. A crítica incisiva feita por ela é quanto à perspectiva do relativismo cultural, a qual tende a aceitar violações das garantias básicas sob a justificativa de padrões culturais já estabelecidos.

Nussbaum (2000) usa o exemplo da cultura indiana, nas quais mulheres, tanto das tradições hindu quanto da mulçumana, tiveram suas vidas definidas pela obediência. Contudo, defende a autora, tal característica cultural não deve 
ser simplesmente negada tendo como horizonte o desenvolvimento, nem acatada de forma relativista como parte da construção cultural desse povo. Para ela, desde que sejam oferecidas outras oportunidades econômicas e políticas, a vida tradicional também pode ser uma escolha. Além disso, Nussbaum alerta para não ignorarmos as intensas contestações feitas por essas mulheres aos valores e práticas das culturas tradicionais. O relativismo cultural seria perigoso, pois "imagina homogeneidade onde há diversidade" (NUSSBAUM, 2000, p. 49, tradução nossa).

O segundo tipo de argumento que tenderia a se opor a sua lista universal traz no bojo a questão da diversidade, que nos parece bastante similar com o da cultura apresentado acima. Contra ele, a autora afirma que certas práticas constituintes da diversidade cultural só podem ser defendidas se não agridem a dignidade humana. O quadro de capacidades básicas ofereceria assim parâmetros com quais poderíamos pensar quando estamos fazendo por bem "deixar uma prática morrer" (NUSSBAUM, 2000, p. 51, tradução nossa).

O terceiro possível argumento crítico com o qual a autora dialoga diz da possibilidade de seu quadro vir a soar como uma espécie de instrumento paternalista, isto é, propondo-se a dizer às mulheres o que é bom ou não, desrespeitando assim suas capacidades de agentes. A autora corrobora a ideia de que os sujeitos são os melhores juízes para decidir sobre os rumos de suas vidas e afirma que, embora assim possam parecer, as normas universais propostas por ela não desrespeitam esse direito, mas exigem que haja pré-condições para o exercício da liberdade e da autodeterminação.

A liberdade não é apenas uma questão de ter direitos no papel, requer estar em posição de exercer esses direitos. E isso demanda recursos materiais e institucionais, incluindo a aceitação legal e social das reivindicações das mulheres (NUSSBAUM, 2000, p. 54, tradução nossa).

A tese sustentada por Nussbaum (2000) está baseada na existência de desigualdades estruturais que afetam o modo como as mulheres podem a vir a desfrutar condições de desenvolvimento e serem capazes de optar sobre o que querem ser e fazer. Tal distorção só começa a ser reparada com o estabelecimento de capacidades elementares. O papel das instituições políticas seria o de garantir esse limiar, ainda que isso não seja suficiente para a produção de justiça social daí a autora argumentar que sua abordagem é uma teoria da justiça incompleta ou parcial. A possibilidade de se pensar o desenvolvimento só se instaura quando esses patamares mínimos forem alcançados. Destarte, os itens que compõem as capacidades básicas seriam (NUSSBAUM, 2000, p. 77-80, tradução nossa): 
a) Vida: ser capaz de viver uma vida humana de comprimento normal; não morrer prematuramente.

b) Saúde do corpo: ser capaz de ter boa saúde, incluindo a saúde reprodutiva; ter saúde para se alimentar adequadamente; ter abrigo adequado.

c) Integridade corporal: ser capaz de se mover livremente de um lugar para outro; estar seguro contra a agressão, incluindo violência sexual, abuso sexual, violência doméstica; ter oportunidades para a satisfação sexual e para a escolha acerca da reprodução.

d) Sentidos, imaginação e pensamento: ser capaz de usar os sentidos, de imaginar, pensar e usar razão de forma informada e cultivada por uma educação adequada, mas não limitada à alfabetização, matemática e treinamentos científicos básicos; poder usar a imaginação e pensamento para experimentar e produzir eventos de sua própria escolha, religiosos, literários, musicais, e assim por diante; ser capaz de utilizar a mente de maneira protegida por garantias da liberdade de expressão com respeito ao discurso político e artístico e liberdade de exercício religioso; ser capaz de ter experiências agradáveis e evitar dor desnecessária.

e) Emoções: ser capaz de nos conectar a coisas e pessoas; amar aqueles que amam e cuidam de nós e lamentar a sua ausência; não ter o desenvolvimento emocional interrompido por medo ou ansiedade ou por eventos traumáticos de abuso ou negligência; apoiar essa capacidade significa apoiar formas de associação humana cruciais para o desenvolvimento.

f) Razão prática: ser capaz de formar uma concepção do bem e iniciar uma reflexão crítica sobre o planejamento da própria vida; proteção para a liberdade de consciência.

g) Afiliação: a) poder ser para e com os outros, reconhecer e mostrar preocupação com outros seres humanos, se envolver em várias formas de interação social; ser capaz de imaginar a situação do outro (proteger essa capacidade significa proteger instituições que alimentam essas formas de filiação e também proteger a liberdade de reunião e discurso político); b) dispor de autorrespeito e não humilhação; ser tratado como um ser digno; isto implica, no mínimo, proteções contra a discriminação com base em raça, sexo, orientação sexual, religião, casta e etnia.

h) Outras espécies: poder viver relacionando-se e preocupando-se com animais, plantas e o mundo natural.

i) Brincar: ser capaz de rir, brincar e desfrutar de atividades recreativas.

j) Controle sobre seu ambiente: a) político: ser capaz de participar efetivamente nas escolhas políticas que regem a vida, ter o direito de 
participação política, proteções à liberdade de expressão e associação. b) material: ser capaz de manter a propriedade (terra e bens móveis), não apenas formalmente, mas em termos de oportunidade real; e ter o direito de procurar emprego numa base de igualdade com os outros.

Nussbaum (2000) salienta que sua lista é sujeita a críticas e revisões, e principalmente, que certas capacidades tendem a ser desenvolvidas mais que outras dependendo do contexto sociocultural; todavia funcionariam como uma espécie de referência para que as sociedades pluralistas construíssem seus projetos de desenvolvimento. Também argumenta que as capacidades listadas devem ter sua importância entendida de forma separada, isto é, não se pode esperar que a forte presença de uma delas compensasse a ausência de outra. O exemplo trazido pela autora diz que não se pode defender ou almejar que a inexistência de participação política pelas mulheres seja justificada ou compensada por um grande crescimento econômico.

Contudo, ainda assim, as capacidades podem se relacionar de forma complexa, e justamente por isso, deve-se "evitar a promoção de uma em detrimento das outras" (NUSSBAUM, 2000, p. 81, tradução nossa). Para esclarecer esse ponto ela descreve que, dado o imbricamento das capacidades, não é possível, por exemplo, promover a participação política sem a alfabetização das mulheres.

É sobre a capacidade de as mulheres controlarem seu ambiente político que recaem nossas preocupações neste texto. Garantir a participação política das mulheres, bem como o direito de fazerem-se representantes, é um dos grandes focos da literatura e do ativismo feminista. Ver tal capacidade como fundamental na teoria desenvolvida por Nussbaum (2000) reafirma essa necessidade, especialmente por que no âmbito da política sempre prevaleceu o contrato sexual do qual fala Pateman (1994) e para onde o patriarcado, tão atribuído aos espaços da casa, também transborda, tornando-se público, como alerta Walby (1990).

Partindo das proposições de Nussbaum (2000) sobre a relação intercambiada que se pode estabelecer entre as capacidades, nos questionamos de que forma a prática de representação política pode ser estimulada a fim de garantir os demais itens de sua lista proposta pela autora. Para participar das escolhas que regem suas vidas, em um modelo representativo de democracia, é necessário que as mulheres se façam representadas. Mas por quem? Que tipo de representação deve estar comprometida com o desenvolvimento? 


\section{COM DOVI, A REPRESENTAÇÃO DESCRITIVA PREFERÍVEL}

A discussão sobre representação tem marcado a maioria das formulações teóricas sobre democracia. Ainda que divirjam entre si, dos modelos agregativos (cuja junção de preferências, por meio de mecanismos como o voto, é suficiente para o processo democrático) aos deliberativos (os quais consideram o intercâmbio discursivo de razões como fundamental para produção de soluções legítimas), a representação é tematizada e a necessidade de inclusão de grupos historicamente marginalizados tem permeado o debate.

A obra de Pitkin (1967), ainda na década de 1960, é considerada clássica por reunir as características básicas para, àquela época, pensar a representação nas democracias. Para autora, autorização, enquanto delegação de poder, e accountability, como prestação de contas, seriam as bases da representação. As obras mais recentes, tendo como precursora a discussão de Manin (1995) acerca das transformações da representação nas democracias atuais, têm mostrado que tais características não são mais suficientes para a compreensão da dinâmica representativa. Urbinati e Warren (2008) discutem a ampliação desses parâmetros para compreender a interação que se dá em contextos informais, em associações cívicas e movimentos sociais. Dryzek e Nieyemer (2008) também teorizam sobre um tipo de representação que independe de uma autorização explícita, cuja materialização se dá a nível discursivo.

É diante dessa pluralidade de formas de representação que emerge o debate sobre a inclusão de minorias nos espaços representativos. A década de 1990 foi marcada por uma gama de produções teóricas preocupadas com a inserção de grupos historicamente desfavorecidos, com atenção especial para as desigualdades de gênero e raça, ainda que o movimento impulsionador desse tipo de representação seja aquele ligado às causas operárias, no início do século XX, cujo resultado foi a criação dos partidos trabalhistas (PHILLIPS, 1995; 2001).

As construções teóricas sobre representação descritiva estão entre aquelas que tentam sanar a ausência de tais grupos na arena política. Dessa forma, grupos marginalizados devem ser politicamente representados por pessoas que compartilham tais características ou similaridades, não apenas no plano das ideias. Phillips $(1995 ; 2001)$ é uma defensora da política da presença. A autora, contudo, faz a importante advertência que a 'presença' por si só não basta se não estiver imbricada com as 'ideias', isto é com o conhecimento das reivindicações e opressão que marcam os grupos.

A aposta de Phillips é que o compartilhamento das demandas dos grupos pelos representantes faça estes últimos mais comprometidos com elas. A autora 
se distancia assim da crítica feita por Hannah Pitkin (1967) à representação descritiva, para quem a ênfase na similaridade deixaria obscura a atuação política, "e um aspecto valioso da representação política, a responsividade dos eleitos para com seus eleitores, é deixado de lado" (MIGUEL, 2005, p.35). Assim, ao enfatizar a mútua relação entre presença e ideias, Phillips não advoga apenas pelo mero reflexo das características dos representados no representante, mas pela construção de agendas políticas que contemplem as demandas desses grupos.

É sua tese que a ideia pode sobreviver sem a presença, isto é, pode haver defensores do feminismo mesmo em um parlamento sem mulheres, mas que tal situação é rara e limitada. São suas as palavras: "Quando a política das ideias é tomada isoladamente do que eu chamarei política de presença, ela não dá conta adequadamente da experiência daqueles grupos sociais que, em virtude de sua raça, etnicidade, religião, gênero, têm sido excluídos do processo democrático. Inclusão política tem sido cada vez mais - e eu acredito que acertadamente - vista em termos que pode ser concretizada somente por política de presença” (PHILLIPS, 1996, p. 146) (PINTO, 2010, p. 18).

Ainda que a pluralidade seja uma das bases da democracia representativa liberal, Phillips (2001) afirma que a diversidade tematizada pelos liberais traz em seu bojo a variedade de opiniões e objetivos, bem como de crenças e demais características, "que pode estar enraizada na variedade da experiência, mas é considerada desligável dela" (PHILLIPS, 2001, p. 273). A literatura política feminista tem mostrado que apenas a presença não dá conta de resolver os problemas da representação, mas descartá-la não parece ser um caminho adequado para enfrentar a dificuldade da inclusão de mulheres.

No desenvolvimento subsequente da política feminista, a questão de quem pode falar melhor por ou em nome de outro se tornou uma importante fonte de tensão, pois, já que os homens tinham sido desalojados de seu papel de falar pelas mulheres, parecia bastante óbvio que as mulheres brancas também deviam ser desalojadas de seu papel de falar pelas mulheres negras, mulheres heterossexuais pelas lésbicas e mulheres de classe média pelas da classe operária. A busca da autenticidade - ou o que Kathleen Jones vê como o beco-sem-saída da perseguição interminável da experiência que dará raízes à autoridade de alguém - torna, então, difícil para qualquer um representar uma experiência que não seja idêntica à sua própria e, levando ao extremo, torna o diálogo virtualmente impossível. A maior parte das feministas tem se oposto a esta conclusão enfraquecedora, mas os problemas de identidade raramente as movem de volta para as regiões mais puras de uma política de ideias. De fato, contribuições recentes têm reenquadrado a questão da autenticidade muito mais em termos de obtenção da igualdade de presença (PHILLIPS, 2001, p. 276). 
Ao defender a necessidade da presença, Phillips (1995; 2001) argumenta em favor da justiça, entendendo que grupos historicamente negligenciados precisam entrar na agenda política a fim de que sejam reparadas as negligências históricas sobre suas demandas. Além disso, também acredita na revitalização da democracia com a diversificação da representação.

Suzanne Dovi (2002) concorda com a necessidade de que grupos sejam representados por seus membros e reafirma a urgência do alargamento das formas e espaços de participação e representação para que tal inserção possa ser feita. Contudo, Dovi (2002) faz uma discussão extremamente importante. Dita de forma simples, a preocupação da autora, compartilhada neste trabalho, é a de que nem todas as mulheres estão preocupadas com questões relativas a esse grupo tão heterogêneo, ou não possuem uma "sensibilidade de gênero", nas palavras de Matos (2009). E ainda, que certas particularidades dos subgrupos dentro da "categoria mulheres" também precisam de representação e por vezes passam despercebidas.

A autora afirma que os teóricos da representação descritiva têm sido muito felizes em defender reformas institucionais, como cotas em listas partidárias, reservas de vagas e esquemas de representação proporcional. Entretanto, critica Dovi (2002, p. 729, tradução nossa), “a ênfase desta literatura até agora tem sido a que institui a necessidade da presença de alguns representantes descritivos, não na investigação de critérios para a identificação descritiva preferível."

Dovi (2002) afirma que os defensores da representação descritiva têm justificado sua preferência por tal modelo de duas formas, as quais colaboram para a "ausência de critérios". O primeiro é enfatizando a necessidade da autonomia, ao defender que grupos precisam ser autônomos para decidir sobre seus representantes. O segundo é acerca da contingência que, em linhas gerais, diz sobre a prática urgente de remediar a exclusão histórica. Com dois parâmetros plausíveis, as categorias para escolha ficariam em segundo plano.

A autora advoga em defesa do estabelecimento de critérios claros para que se prefiram umas a outras nesse tipo de representação. Ainda que reconheça que esses critérios podem ser usados em formas imprevistas e possivelmente prejudiciais, eles se fazem necessários em função das diferenças que atravessa tais grupos. Segundo Dovi (2002, p. 735, tradução nossa), ao não discutir critérios, a literatura ignora "os possíveis perigos e decepções de uma política de presença para a política democrática".

O primeiro critério oferecido pela autora para a escolha dos representantes preferíveis é chamado de "mutualidade". Representados e representantes devem se reconhecer mutuamente, (man) ter uma relação interativa e os primeiros 
precisam entender os segundos como 'um de nós’. A participação ativa dos grupos junto ao representante torna-se assim não apenas desejável, mas fundamental.

O segundo critério diz respeito aos subgrupos despossuídos. A expressão não está relacionada a posses privadas ou recursos, mas refere-se a grupos que são estigmatizados no processo político e não possuem representação efetiva por um conjunto de características ou "combinação de formas de opressão". Subgrupos podem sofrer opressão dentro de um grupo mais amplo em função de fatores como classe, sexualidade, localização geográfica e religião. "Os representantes descritivos preferíveis seriam aqueles que procuram estabelecer relações mútuas com subgrupos despossuídos” (DOVI, 2002, p. 735, tradução nossa).

É preciso esclarecer, contudo, que a perspectiva de Dovi não tenta essencializar os sujeitos em apenas um subgrupo, dada a construção social complexa, relacional e atravessada por uma variedade de experiências, nem buscar uma autenticidade pura. Sua preocupação é que os grupos, por vezes, se configuram em espaços em que uma dupla opressão ocorre e nesse sentido, representantes que estivessem mais sensíveis às causas que atingem subgrupos seriam preferíveis.

Mas qual a relação de tal discussão com as proposições sobre desenvolvimento humano com as quais iniciamos este texto?

A defesa de Nussbaum (2000) é que o desenvolvimento deve ser mensurado também a partir da igualdade das relações de gênero e por isso é importante que as mulheres tenham garantidas as capacidades básicas, apresentadas anteriormente. A representação política é uma das formas de buscar o cumprimento dessas garantias e a representação descritiva oferece um caminho para que questões relativas às mulheres ganhem eco na política democrática.

Entretanto, é extremamente amplo falar em mulheres. Não apenas o substantivo é plural, mas também são as opressões diversas que tal grupo tem sofrido. O que buscamos em Dovi (2002) para pensar o desenvolvimento são os critérios que fazem da representação um instrumento capaz de ser expressão das demandas dessa pluralidade, visando um reconhecimento efetivo. Os critérios da autora não são, de forma alguma, desconhecidos das discussões feitas sobre representação e é possível que pareçam até óbvios, mas seu esforço em cobrar a quebra o silêncio sobre quais representantes são preferíveis a outros pode estimular a construção de variáveis para que novos critérios sejam postos. Ainda assim, a ênfase na mutualidade com subgrupos despossuídos nos parece um caminho importante para que as desigualdades conjugadas, como as que vitimizam as mulheres, sejam tematizadas e diminuídas. 
Não defendemos que apenas as mulheres possam falar por tal grupo. Pelo contrário, quanto mais disseminada for a perspectiva feminista entre os sexos, mais se avança na construção de um mundo democrático e igualitário. Também admitimos que todas as mulheres, feministas ou não, têm o direito de concorrer democraticamente aos cargos eletivos. O que entendemos é que a vivência de diversas opressões que atingem as mulheres, especialmente aquelas entrecruzadas, dão a elas uma expertise para que possam se voltar, quando eleitas representantes, a essas demandas silenciadas. Nossa defesa é que o desenvolvimento das mulheres, considerando toda sua pluralidade, necessita de uma representação mais próxima e diretamente afetada. Assim sendo, mulheres candidatas cujas plataformas tivessem mais próximas dos subgrupos despossuídos (a exemplo das mulheres negras, lésbicas, rurais), especialmente quando fazem parte deles, seriam preferíveis às que ignoram essa complexa teia de marginalização que pode ocorrer intra-grupo.

\section{CONSIDERAÇÕES FINAIS}

De forma ainda incipiente, nossa tentativa ao longo deste texto foi discutir a relação entre representação e desenvolvimento das mulheres, entendendo ambas as dinâmicas como dependentes. É preciso garantir condições favoráveis para que mulheres possam escolher e ser efetivamente participantes da arena política. Esse controle do ambiente político é entendido por Nussbaum (2000) como uma capacidade básica. Conjecturamos que a garantia de tal capacidade, quando feita de forma próxima às demandas das mulheres, enseja maior possibilidade que as outras capacidades elencadas pela autora (liberdade para a vivência dos direitos sexuais e reprodutivos e expressão da sexualidade, para citar algumas) sejam mais bem tematizadas. Por isso, buscamos em Dovi (2002) a procura de critérios para que essa representação descritiva seja condizente com as tentativas de eliminar as diversas opressões.

\section{REFERÊNCIAS}

DOVI, S. Preferable descriptive representatives: will just any woman, black, or latino do? American Political Science Review, Washington, v. 96, n. 4, p.729-742, 2002. DRYZEK, J.; NIEMEYER, Simon. Discursive representation. American Political Science Review, Washington, v. 102, n. 4, p. 481-493, 2008. 
GUZMAN, V. La institucionalidad de género en el estado: nuevas perspectivas de análisis. Santiago: CEPAL/Unidad Mujer y Desarrollo, 2001.

MANIN, B. As metamorfoses do governo representativo. Revista Brasileira de Ciências Sociais, São Paulo, v. 29, 1995.

MATOS, Marlise. Em busca de uma teoria crítico-emancipatória feminista de gênero: reflexões a partir da experiência da política na ausência das mulheres. In: MATOS, M. (Org.) Enfoques feministas e os desafios contemporâneos: perspectiva feminista de gênero na política e nas políticas públicas. Belo Horizonte: FAFICH/DCP, 2009. p. 59-112.

MIGUEL, L. F. Impasses da accountability: dilemas e alternativas da representação política. Revista Sociologia Política, Curitiba, 25, p. 25-38, nov. 2005.

NUSSBAUM, M. Women and human development: the capabilities approach. Cambridge University Press, 2000.

PATEMAN, C. O contrato sexual. São Paulo: Editora Paz e Terra, 1994.

PHILLIPS, A. De uma política de ideias a uma política de presença? Revista Estudos Feministas, Florianópolis, v. 9, n. 1, p. 268-290 2001.

The politics of presence. Oxford: Clarendon Press, 1995.

PINTO, C. R. Jardim. Feminismo, história e poder. Revista Sociologia Política, Curitiba, v. 18, n. 36, p. 15-23, jun. 2010.

PITKIN, H. The concept of representation. Berkeley: University of California Press, 1967.

SEN, A. Desenvolvimento como liberdade. São Paulo: Cia. das Letras, 2001.

URBINATTI, N.; WARREN, M. The concept of representation in contemporary democratic theory. Annual Review of Political Science, v. 11, p. 387-412, 2008.

WALBY, S. Gender mainstreaming: productive tensions in theory and practice. Social Politics, Oxford, v. 12, n. 3, p. 321-343, 2005.

Theorizing patriarchy. Oxford: Blackwell, 1990.

WOODWARD, A. Too late for gender mainstreaming? Taking stock in Brussels. Journal of European Social Policy, Los Angeles, v. 18, n. 3, p. 289-302, 2008. 


\title{
A construção da rodovia BR-153 na fronteira e urbanização da cidade de Araguaína, Tocantins
}

\author{
The construction of the BR-153 road at the border and urbanization \\ in the city of Araguaína, Tocantins
}

Roberto Souza Santos - Doutor em Geografia pelo Instituto de Biociências, UNESP, Rio Claro, SP. Pós-doutor pela Instituto de Estudos Socioambientais - IESA - Programa de Pós-Graduação do Curso de Geografia da Universidade Federal de Goiás. Docente no Programa de Pós-Graduação em Geografia, da graduação em Geografia da UFT e integrante do Núcleo de Estudos Urbanos e Agrários (NURBA) da UFT. E-mail: robertosantos@uft.edu.br

\section{Resumo}

Os projetos de colonização e de desenvolvimento regional no Tocantins que contribuíram para o processo de urbanização foram objeto de análise deste artigo. Para esta análise fez-se um recorte temporal que é a partir da criação da rodovia Belém-Brasília. Nesta análise e abordagem verificam-se os impactos territoriais dos projetos de desenvolvimento regional desenhados no espaço urbano de Araguaina. Estes impactos territoriais se referem aos desdobramentos sociais e econômicos dos projetos de desenvolvimento no espaço urbano na fronteira. Para esta análise foram realizadas visitas de estudo de campo e uma revisão bibliográfica em livros e revistas sobre o tema pesquisado.

\section{Palavras-chave}

Processo de Urbanização. Fronteira Capitalista. Projetos de Desenvolvimento Regional. Eixo Rodoviário.

\begin{abstract}
The colonization and regional development projects in Tocantins that contributed to the urbanization process were analyzed in this article. For this analysis was made a temporal cut that is from the creation of the Belém Brasília highway. In this analysis and approach the territorial impacts of the regional development projects drawn in the Araguaina urban space are verified. These territorial impacts refer to the social and economic developments of development projects in the urban space on the border. For this analysis, field study visits were carried out at the study sites and a bibliographic review was carried out in books and journals on the researched topic.
\end{abstract}

\section{Keywords}

Urbanization Process. Capitalist Frontier. Regional Development Projects. Road Axis. 


\section{A FRONTEIRA E O PROCESSO DE URBANIZAÇÃO NO TOCANTINS}

De acordo com Diniz (2003, p. 365-6), a fronteira pioneira representa os assentamentos pioneiros marcados pela ausência de mercados de terra, grande disponibilidade de terra e trabalho, por rápido crescimento populacional via imigração. Para este autor, na perspectiva espaço-temporal, a fronteira se divide em fronteira transitória, fronteira consolidada e fronteira urbanizada.

A fronteira transitória representa os assentamentos transitórios caracterizados por economias dicotomizadas, onde convivem lado a lado os agricultores de subsistência e comerciais, sendo que estes últimos encontramse em franco processo de expansão. Com a valorização da terra, a propriedade agrícola, que se encontra atomizada na fase pioneira, começa a ser consolidada em grandes fazendas. Nestas áreas, as taxas de desmatamento são cada vez maiores. Estes fatos geram uma série de transtornos para as comunidades tradicionais que ali estavam fixadas territorialmente a algum tempo.

A fronteira consolidada é marcada por economias baseadas na agricultura comercial, concentração de terra em grandes propriedades, mercado imobiliário, presença de grandes empreendimentos agrícolas, relações de produção predominantemente capitalistas. Os imigrantes destas áreas tendem a ser os mais recentes desde que chegaram, após a instituição dos mercados de trabalho, de terra e a consolidação de pequenas propriedades em grandes fazendas de gado e de produção de alimentos. Nestas áreas, a descaracterização das comunidades tradicionais é ampliada.

As fronteiras urbanizadas fazem parte de uma herança dos embrionários núcleos urbanos criados no coração dos projetos de colonização, muito frequentes na Região Amazônica, em especial no Tocantins na região por onde passa a rodovia Belém-Brasília. Seu crescimento é condicionado pelo processo de evolução das áreas de assentamento circunvizinhas, tornando-se, portanto, entidades inseparáveis dos projetos agrícolas dos quais se originaram.

As transformações estruturais, no entorno destas fronteiras urbanizadas, intensificam os movimentos rural-urbanos, aumentando o tamanho e a complexidade dos povoados urbanos. Estes podem crescer o suficiente em organização e complexidade a ponto de se tornarem novos municípios. Esses lugares constituem centros de concentração e redistribuição de mão-de-obra, formada por ex-colonos e migrantes que não conseguiram acesso à terra. À medida que os centros ganham dinamismo, eles também tendem a receber um grupo de migrantes selecionados, oriundos de áreas urbanas, atraídos pelo 
crescente setor terciário. Nestas áreas, o desejo de adquirir terra, ainda, é um importante estímulo à imigração.

A fronteira é resultado das políticas de investimento para o desenvolvimento regional. Estas políticas de investimentos por outro lado, também oxigenam o processo de urbanização na fronteira. A Amazônia Legal foi palco de diversos projetos de desenvolvimento regional, entre os quais, podemos destacar a SPVEA. Em 1953, é criado a Superintendência do Plano de Valorização Econômica da Amazônia (SPVEA) por Getúlio Vargas. Juntamente com a criação desta superintendência criou-se também a Amazônia Legal. De 1930 até 1970, a região foi fortemente marcada pela concessão de terras na colonização oficial e doação de glebas. Nos anos 1930, as terras devolutas foram "vendidas" ou doadas às empresas colonizadoras e as áreas de colonização oficial ficaram reservadas às pessoas físicas.

A partir deste período, o poder público passa a dimensionar sua estratégia política de colonização e ocupação do território com a privatização de terras devolutas e a instalação da colonização dirigida (pública) na região. A partir dessas medidas governamentais a região passa ter atuação direta do Estado por meio da SPVEA. Em 1966, no governo Castelo Branco, a SPVEA foi substituída pela Superintendência de Desenvolvimento da Amazônia (Sudam).

A fronteira se amplia com o processo de modernização no país que começa com a chamada Marcha para Oeste, em 1943, e a intervenção direta do Estado para acelerar o deslocamento dos típicos agentes da frente pioneira sobre "territórios novos", em geral já ocupados por aqueles que haviam se deslocado com a frente de expansão. A partir de 1943, a frente pioneira que, em outras regiões se movia impulsionada pelos interesses imobiliários do grande capital, das empresas ferroviárias e da grande agricultura de exportação, como o café, no Sudeste, na Amazônia passa a depender da iniciativa do governo federal (MARTINS, 1996).

O processo de urbanização na região planejado pelas políticas públicas de investimentos juntamente com o capital nacional e internacional, como afirma Oliveira (1991), também contribuiu para o "desarranjo espacial", isto é, acentuou os conflitos sociais no campo e nos espaços urbanos. Tal processo foi planejado para dar respaldo à ocupação econômica da Amazônia e integrá-la ao contexto nacional e internacional. Este fato trouxe benefícios apenas para uma pequena parcela da população, aquelas classes sociais mais ricas e, não proporcionou o desenvolvimento social na região de forma integrada entre campo e a cidade e as classes sociais. 
As políticas territoriais estabelecidas pelos programas na Amazônia se fundamentam como uma espécie de alternativa geopolítica para a necessidade de abrandamento das tensões sociais na estrutura fundiária do sul do Brasil, colocando para os colonos a alternativa da migração para as áreas de fronteira, afirma Oliveira (1991). Os resultados das políticas territoriais destes programas são marcados pelo favoritismo, pois aí, o dinheiro público é usado para beneficiar grupos privilegiados. Cria um terreno fértil para a territorialização dos grandes monopólios na Amazônia e para a regularização fundiária, mas infelizmente as terras dos grileiros também entram nesse processo de regularização. Em outras palavras, o Estado paga o ônus e os donos dos meios de produção extraem a mais-valia como diz Karl Marx.

As políticas territoriais na Amazônia foram fomentadas a partir da criação de polos de desenvolvimento como na Zona Franca de Manaus (SUFRAMA) para estimular o processo de desenvolvimento regional, o processo de urbanização e, sobretudo, para assegurar a geopolítica territorial da região. As políticas de desenvolvimento baseadas na filosofia das teorias locacionais no Brasil foram estabelecidas a partir de programas como o Polocentro, o Polamazônia etc. Estes projetos tiveram objetivo básico de conquistar o cerrado, atingindo frações territoriais goianas e mato-grossenses cobertas pelo cerrado na área da Amazônia Legal e no Centro-Oeste.

Contribuiu para a instalação e consolidação da fronteira capitalista, nessas regiões, a implementação de obras de infraestrutura, armazenagem, estradas etc., além da pesquisa de sementes para promover o plantio de soja em grande escala no cerrado. Impôs uma nova organização territorial do cerrado, recortando-o em uma nova região, dentro do processo mais amplo da expansão do capitalismo no campo e na cidade - a fronteira capitalista.

No período do Regime Militar (1964-1985), o Brasil foi inserido em uma estratégia governamental, que objetivava integrar o país e a exploração de recursos naturais. Segundo Oliveira (1991, p. 29), a política de integração nacional compreendia as três grandes regiões geoeconômicas do país: Centro-Sul, Nordeste e Amazônia. Sob a ótica de desenvolvimento nacional, ao Centro-Sul caberia a solidificação da indústria e a modernização da agricultura, bem como o desenvolvimento do Nordeste via industrialização e a ocupação da Amazônia.

Foi um período em que o Estado propagava uma ideia de defesa às fronteiras nacionais, principalmente na Amazônia, surgindo daí a política de "Integrar para não entregar". Estratégia essa, que encobria as verdadeiras intenções do governo brasileiro, que executou por meio da Sudam, um dos maiores projetos 
de ocupação e exploração de recursos naturais da Amazônia, principalmente minérios, como o ferro e o manganês, como aponta Oliveira (1991).

$\mathrm{Na}$ década de 1970 foram criados os programas Polocentro (1975) e Polamazônia (1974), com o objetivo de possibilitar o acesso aos recursos naturais por grandes grupos econômicos, e o redirecionamento dos fluxos migratórios que partiam do Nordeste em direção ao Sudeste, para a Amazônia. De acordo com Oliveira (1991), ao cerrado estavam destinados os produtores vindos do Sul; e à Amazônia, os nordestinos. Os primeiros, devido à escassez de terras e altos preços cobrados pela parcela do solo, estavam em busca de abrir novas fronteiras para a produção agropecuária; e os últimos, em virtude das condições adversas de clima, do solo e da concentração fundiária, necessitavam de novas terras para garantir sua subsistência.

Entre os dois programas implantados na década de 1970, o Polocentro foi o que obteve melhor êxito, uma vez que serviu para a ocupação do cerrado, pela soja. Os grandes latifúndios, por meio da concentração de terras, aos poucos foram "expulsando" a população camponesa e as comunidades tradicionais, fazendo do agronegócio uma atividade bastante rentável. O Polamazônia não alcançou o seu principal objetivo, que era o de ocupação da Amazônia pelos nordestinos, pois as estradas que ligariam as regiões Nordeste e Norte, em sua maioria não foram concluídas, como é o caso da Transamazônica, e os "espaços vazios" considerados "vazios" pelo governo brasileiro, na verdade estavam ocupados por indígenas, endossando um sério conflito entre eles e posseiros e latifundiários. Apenas a exploração de recursos naturais obteve sucesso, pois, a exploração de minérios e a devastação da Floresta Amazônica alcançaram índices ainda não vistos.

Outros dois programas foram lançados no fim da década de 1970: Polonoroeste e Prodecer. O Polonoroeste visava a colonização de terras nos estados de Mato Grosso e Rondônia, através de empréstimos do Banco Mundial. Como ressalta Oliveira (1991, p. 94): “Este programa procurou, além da abertura/ pavimentação da rodovia, alimentar programas de colonização em Rondônia e de desenvolvimento e regularização fundiária em Mato Grosso”. O Prodecer tinha como objetivo a produção de commodities para o mercado estrangeiro na região de Cerrado, e foi implantado em três etapas. Primeiro em Minas Gerais, depois em Goiás, Mato Grosso, Mato Grosso do Sul e Bahia, e por último no Tocantins e no Maranhão na década de 1990.

Para que aconteça o planejado, o Estado criou programas de incentivos fiscais, de financiamentos e fomento para viabilizar o crescimento econômico. Programas como o Polonoroeste, Polocentro, Prodecer, Polamazônia, Sudam, 
etc. foram fundamentais para oxigenar os empreendimentos econômicos. Os resultados das políticas de implantação destes programas foram marcados pelo investimento de capitais nacionais e estrangeiros visando a inserção da região ao mercado internacional de commodities. Estes programas constituem verdadeiros "agentes" que promoveram e estão promovendo a modernização territorial na Amazônia e o avanço da fronteira agropecuária e urbana que se resume na fronteira capitalista nesta região.

A fronteira está ligada ao desenvolvimento urbano-industrial, ou seja, na fronteira há um processo de urbanização e paralelamente, há também o processo de industrialização. Foweraker (1992) explicita que a fronteira pioneira além de estar associada à urbanização e ao aumento das taxas de industrialização, este fenômeno caracteriza-se por existir na periferia da economia.

Muitos teóricos são unânimes em afirmar que a fronteira expressa em lócus de um notável processo de urbanização. No Brasil, a fronteira surge de fato, quando o processo de industrialização deflagrado graças à acumulação cafeeira, com isso ocorre o deslocamento do eixo central da economia para a região Sudeste a partir de 1930. Isto é, ocorre o êxodo rural de forma acentuada. Nossa sociedade se urbanizou de forma ampliada, porém, esse processo aconteceu a partir do Leste para o Oeste e do Centro-Sul para o Norte no país. Portanto, o processo de urbanização na fronteira amazônica é recente.

Geralmente, a disposição geográfica do urbano se desenvolve a partir de duas ordens que acontecem simultaneamente: a planejada e a espontânea. A primeira deriva do planejamento e investimentos feitos pela ação combinada de capitais estrangeiros, privados nacionais e públicos federais, juntamente com as políticas urbanas de desenvolvimento com objetivos pré-determinados. Faz parte desta intencionalidade os projetos de colonização e integração, a abertura de estradas, a implantação de núcleos urbanos etc. A forma espontânea se refere aos elementos não controláveis como a diferenciação evolutiva dos núcleos urbanos e o comportamento do mercado de trabalho e de terras que se desenvolvem de forma espontânea de acordo com a dinâmica da economia local e regional em que estimula a migração.

Na Amazônia, há os modelos de urbanização dos projetos baseados nos grandes empreendimentos com volumes consideráveis de recursos financeiros, portanto, planejados. O modelo de urbanização dirigido é planejado pelo Estado que se baseia nos projetos de colonização e construção de rodovias na região como a BR-153 (Belém-Brasília) e a Transamazônica. Mas há também o modelo de urbanização dirigida pela colonização particular diretamente e controlada pelas 
companhias privadas e colonizadoras com apoio do Estado em terras devolutas ou não na Amazônia.

Na década de 1970, a expansão da fronteira amazônica efetua-se num contexto urbano, condição de organização do mercado de trabalho regional e de ocupação do território. Segundo Becker (1990), a fronteira urbana é a base logística para o projeto de sua rápida ocupação. Esta ocupação não se dá de forma linear, desde a frente extrativista e agrícola até ao urbano. Machado (1990) aborda que as políticas urbanas, por meio de investimentos em infraestrutura, equipamento funcional urbano e criação de núcleos planejados, possibilitaram o uso do espaço urbano como estratégia para o povoamento regional.

O perfil das cidades na Amazônia caracteriza-se pela concentração de grandes contingentes populacionais nas cidades, carentes de bens, equipamentos urbanos, trabalho e serviços públicos adequados. Dessa forma, as cidades tradicionais, cidades da colonização, cidades espontâneas vinculadas ao garimpo ou a projetos extrativistas e as company towns ${ }^{\prime}$, são facetas complexas do processo de transformação por que passou o urbano na região (PEREIRA, 2004). É neste contexto das políticas de desenvolvimento regional, que o processo de urbanização da Amazônia se amplia e surgem novas cidades e áreas urbanas. Juntamente com as políticas de desenvolvimento regional vêm também as políticas urbanas e de incentivo ao processo de urbanização e a consequente consolidação da fronteira capitalista na região.

No Tocantins, o processo de urbanização na fronteira foi estimulado pela construção da rodovia Belém-Brasília que se constituiu no novo eixo de desenvolvimento econômico e populacional da região transformando-a em uma área de atração. E deslocou a economia e a urbanização do vale do rio Tocantins para o divisor de água de sua margem esquerda. O movimento de ocupação humana e econômica no Tocantins esta condicionada a orientação da BR-153 depois de sua construção. Um novo processo de urbanização fez com que surgem varias cidades as margens da rodovia Belém-Brasília, sendo hoje algumas delas as principais do novo estado, tais como: Gurupi, Paraíso, Guaraí, Colinas e Araguaina. Na verdade, a criação da rodovia 153 é resultado de uma política explícita de desenvolvimento e ocupação demográfica e econômica da região Norte (Tocantins e Pará) de forma planejada.

A colônia agrícola de Goiás (CANG) instalada em 1940 na atual cidade Ceres-GO e a abertura da Belém-Brasília no final da década de 1950 (1958) são

Na Amazônia a produção de energia elétrica favoreceu a implantação de grandes projetos de exploração mineral, montados em verdadeiras "company-towns" (cidades-empresas) construídas no interior da floresta. Exemplos disso, temos o Projeto Jari, no Amapá; a Mineração Rio Norte e o Projeto Grande Carajás, estes últimos no Pará. 
as primeiras entradas de uma nova política desenvolvimentista para as terras de Goiás e Tocantins. Isto é, estes projetos de desenvolvimento regional propiciaram um território fértil para a formação da fronteira urbana e agropecuário na região - a fronteira capitalista.

\section{RODOVIA BR-153 E A EXPANSÃO URBANA DE ARAGUAÍNA-TO}

No governo de Juscelino Kubitschek foi construída a rodovia BR-153, conhecida como Belém-Brasília, a principal via de escoamento da produção e acesso ao estado do Tocantins. Souza (2002, p. 353) relata que: "através da política desenvolvimentista, a expansão rodoviária era vista como uma forma de integrar geográfica e economicamente as várias regiões do país”.

É importante destacar que o Plano de Integração Nacional, outrora embasado no discurso do progresso e desenvolvimento do interior do Brasil, não se concretizou em sua totalidade. Muitas regiões da Amazônia continuam isoladas, e sofreram perdas insuperáveis em biodiversidade, devido às ocupações desordenadas, aos desmatamentos e às queimadas. A BR-153, a principal via de escoamento da produção agrícola do cerrado tocantinense ampliou o acesso à região central do Brasil, mas não a integrou totalmente ao restante do Brasil, a exemplo da região do Jalapão. Outrossim, deslocou os centros produtores que antes se localizavam às margens do rio Tocantins, para às margens da rodovia BR-153, trazendo ao isolamento às cidades ribeirinhas e tradicionais (cidades oriundas do extrativismo mineral).

Assim, a estratégia dos governos militares era permitir a exploração dos recursos naturais pelo capital estrangeiro, sem considerarem as perdas e os impactos negativos que o interior do Brasil sofreria. Pode-se dizer que obtiveram êxito, porém em relação ao desenvolvimento regional, este de fato não se concretizou totalmente. O projeto de integração nacional elaborado pelo governo do presidente Vargas, incluía a construção de uma rodovia que interligaria o Brasil do Meio-Norte ao Centro-Sul, a fim de escoar a produção de grãos e matéria-prima do interior do país.

Com a instituição de políticas de investimento para o desenvolvimento regional do Brasil, o Centro-Sul e a Amazônia passaram por um povoamento e uma ampliação de suas economias. A política de "Marcha para o Oeste", um projeto dirigido por Getúlio Vargas para a ocupação e o desenvolvimento econômico do interior do Brasil, concretizado por Juscelino Kubitschek, possibilitou a construção de Brasília e a construção de inúmeras rodovias que integraram o 
interior aos grandes centros produtores do país, como a rodovia BR-153 que atravessa o território tocantinense de Norte a Sul, conforme demonstra o Mapa 1. Mapa 1 - BR-153 (Belém-Brasília) e o rio Tocantins

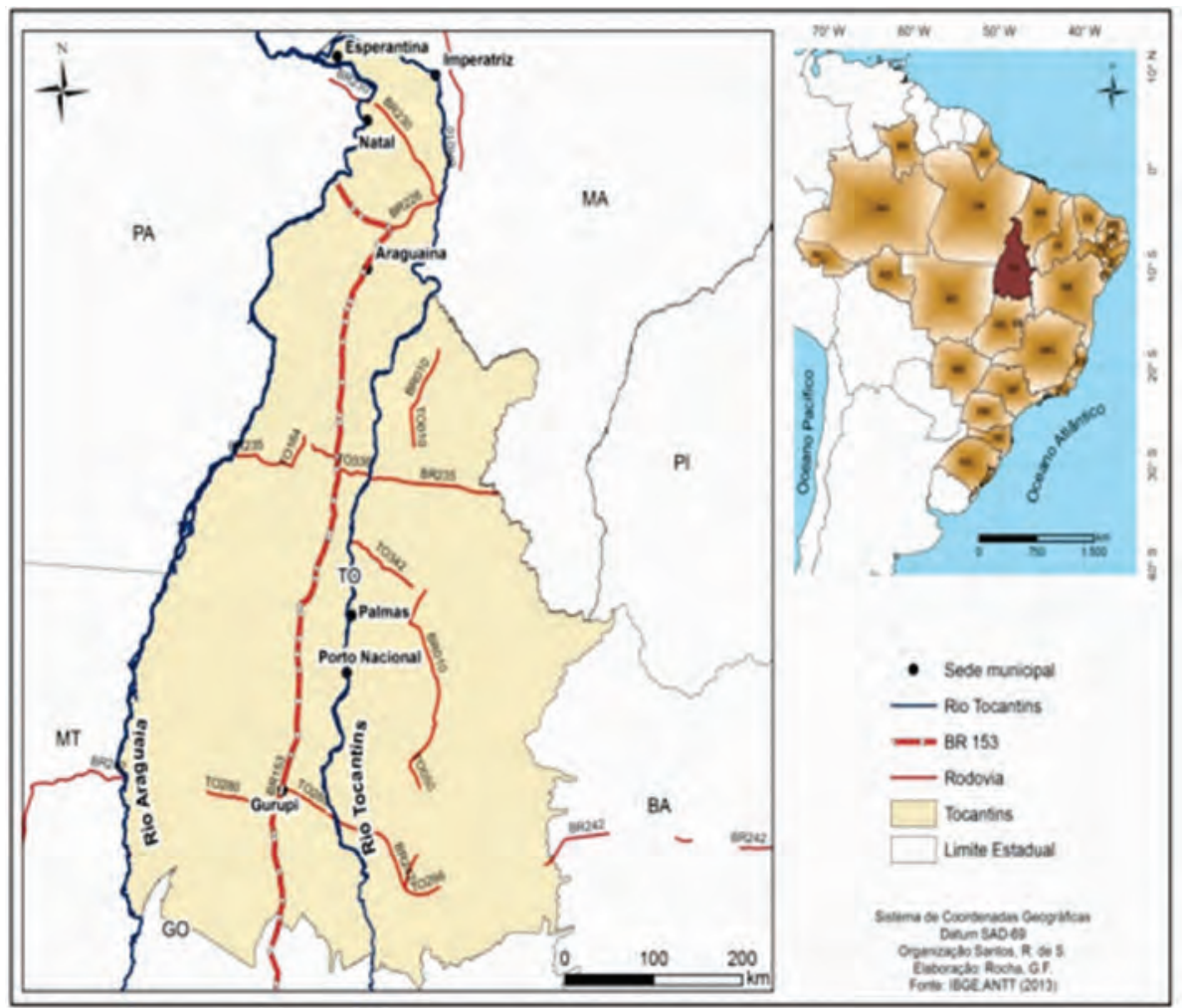

Até meados da década de 1950, o norte goiano vivia um relativo abandono em relação a outras regiões brasileiras. A falta de vias de comunicação impedia o desenvolvimento econômico e social da região, que sofreu um grande impacto com a construção da rodovia BR-153. Foi a rodovia a responsável pela dinamização das comunicações, pelo surgimento de novos núcleos urbanos e pelo crescimento de outros (VINHAL, 2009)

As rodovias têm um papel muito importante no processo de urbanização na Região Amazônica, pois são canais de penetração para o povoamento e para o desenvolvimento regional. Desde que o transporte rodoviário passou a ser priorizado pelos governos, em detrimento do transporte fluvial e ferroviário, no início da República, em 1889, as rodovias brasileiras se tornaram o principal e mais importante meio de transporte de cargas e pessoas do país. 
A construção da rodovia BR-014, como era chamada a rodovia BelémBrasília ou BR-153, compunha um plano de metas iniciado no primeiro governo de Getúlio Vargas, para a integração nacional, a partir do interior do Brasil, o que ele denominou de Marcha para o Oeste. O Plano incluía a construção de inúmeras estradas, criando eixos de ligação entre elas, às ferrovias e às hidrovias, como meio de aceleração do desenvolvimento econômico nacional. Vargas tinha consciência da necessidade sobremaneira da extração de matéria-prima e do fornecimento de produtos industrializados a essas regiões. A crítica a esse plano, mais tarde concretizado no governo de Juscelino Kubitschek, foi a entrada excessiva de estrangeiros e a intensa exploração dos recursos naturais, a partir da penetração ao interior do cerrado e da Amazônia.

A rodovia Belém-Brasília teve e tem grande importância para a expansão urbana e para o desenvolvimento da região do Tocantins, como explica Souza, (2002, p. 368):

A importância dessa rodovia para Goiás pode ser medida pelo número de novas cidades criadas após sua construção. Emergiram daí centros como Araguaína, Colinas de Goiás, Guaraí, Miranorte, Paraíso do Norte, Gurupi, Alvorada, entre outras. A Belém-Brasília ainda se constitui na principal artéria do desenvolvimento de Goiás, por onde circula grande parte de sua riqueza. Até então, a maioria dessas cidades nortenses era lugarejos estagnados em função do isolamento em que se encontravam e sem grandes perspectivas de crescimento, uma vez que o governo do Estado não possuía condições financeiras para efetuar um investimento de tamanha envergadura.

Lira também reforça esta ideia da importância da rodovia Belém-Brasília na expansão urbana das cidades e para o desenvolvimento econômico por onde a rodovia passa.

A Belém-Brasília se constituiu no novo eixo de desenvolvimento econômico e populacional da região do Tocantins, se transformando em uma área de atração e deslocando economia e urbanização do vale do Tocantins para o divisor de água de sua margem esquerda [...] (LIRA, 2011, p. 152).

Infelizmente, o plano inicial de integração regional a partir de rodovias, hidrovias e ferrovias, não foi posto em prática. O que houve foi uma clara substituição do transporte antes realizado por ferrovias e hidrovias, pelo transporte rodoviário, trazendo uma dependência muito grande do país em relação ao mercado estrangeiro, haja vista que a indústria automobilística, de peças e suplementos automotivos ainda não tinha se estabelecido no país de forma a atender a demanda. 
A construção de rodovias no Brasil, além de atender ao objetivo de integração nacional, esteve relacionada à lógica do capital estrangeiro e à implantação de indústrias automobilísticas no país, chegando-se à importação de derivados do petróleo, como a gasolina e o óleo diesel. A falta de investimentos nos setores ferroviário e fluvial de transporte fez com que o Brasil se tornasse ainda mais dependente economicamente do capital estrangeiro e provocou a decadência e o isolamento de importantes cidades que se beneficiam de outros meios de transporte, que não o rodoviário.

Esse deslocamento da economia para os eixos rodoviários causou estagnação em muitas cidades do país, a exemplo do Tocantins, as cidades que margeiam o rio Tocantins e que serviam de rota para o comércio que se estendia até o Maranhão e o Pará, perderam populações que migraram para cidades às margens da rodovia BR-153.

Ao mesmo tempo em que a rodovia Belém-Brasília fez surgir novas cidades, ela também provocou a estagnação econômico-política dos municípios ribeirinhos, porque a navegação fluvial entrou em decadência como transporte mercantil, uma vez que pela rodovia se levava menos tempo para transportar as mercadorias. Algumas cidades perderam sua importância para certos núcleos urbanos, que se desenvolveram com muita rapidez. Dessa forma, a rodovia atraiu uma grande parte da população que vivia nesses núcleos ribeirinhos para as novas cidades às margens da estrada, em busca de melhores condições de vida (SOUZA, 2002, p. 382).

Souza deixa claro que a rodovia Belém-Brasília provocou a integração econômica das cidades dinamizadas pelo transporte baseado na navegação do rio Tocantins. Valverde e Dias (1967, p. 270) reforçam a ideia de que não somente as cidades ribeirinhas perderam parte de sua população, mas nas áreas rurais sofreram um verdadeiro êxodo rural.

Não apenas as cidades localizadas na margem direita do Tocantins e que não têm acesso direto à Belém-Brasília, foram atingidas pelo desaparecimento da navegação regular do Tocantins. As áreas rurais, de estruturas arcaicas, transformaram-se em regiões de êxodo; a população rural, sem terras, sem perspectivas de melhores dias, migra em direção às áreas servidas pela rodovia ou para a bacia do médio Araguaia.

Com a construção da rodovia Belém-Brasília, houve uma aceleração do fenômeno de urbanização do norte goiano (atual Tocantins). Até o fim da década de 1950 a maioria da população residia na zona rural ou em pequenas cidades às margens do rio Tocantins, como Babaçulândia, Filadélfia e Porto Nacional, de onde se escoava a produção pela via fluvial, como expõe Valverde e Dias (1967). 
Ao contrário das cidades ribeirinhas, que entraram em um período de decadência no auge da construção das estradas de rodagem, aquelas que se localizavam às margens das rodovias sofreram um grande impulso econômico, como ocorreu com a cidade de Araguaina-TO, localizada entre os corredores dos rios Araguaia e Tocantins. Seu povoamento teve início em meados de 1876, às margens do rio Lontra, sendo emancipada em novembro de 1958. Antes de sua emancipação, o município foi conhecido como "Livra-nos Deus" e Lontra até receber o nome de Araguaína, e pertenceu a outros municípios como São Vicente do Araguaia (Araguatins), Boa Vista do Tocantins (Tocantinópolis) e Filadélfia, como afirma Gaspar (2002). O Mapa 2 ilustra a dimensão territorial e localização do município.

Mapa 2 - Localização de Araguaína-TO

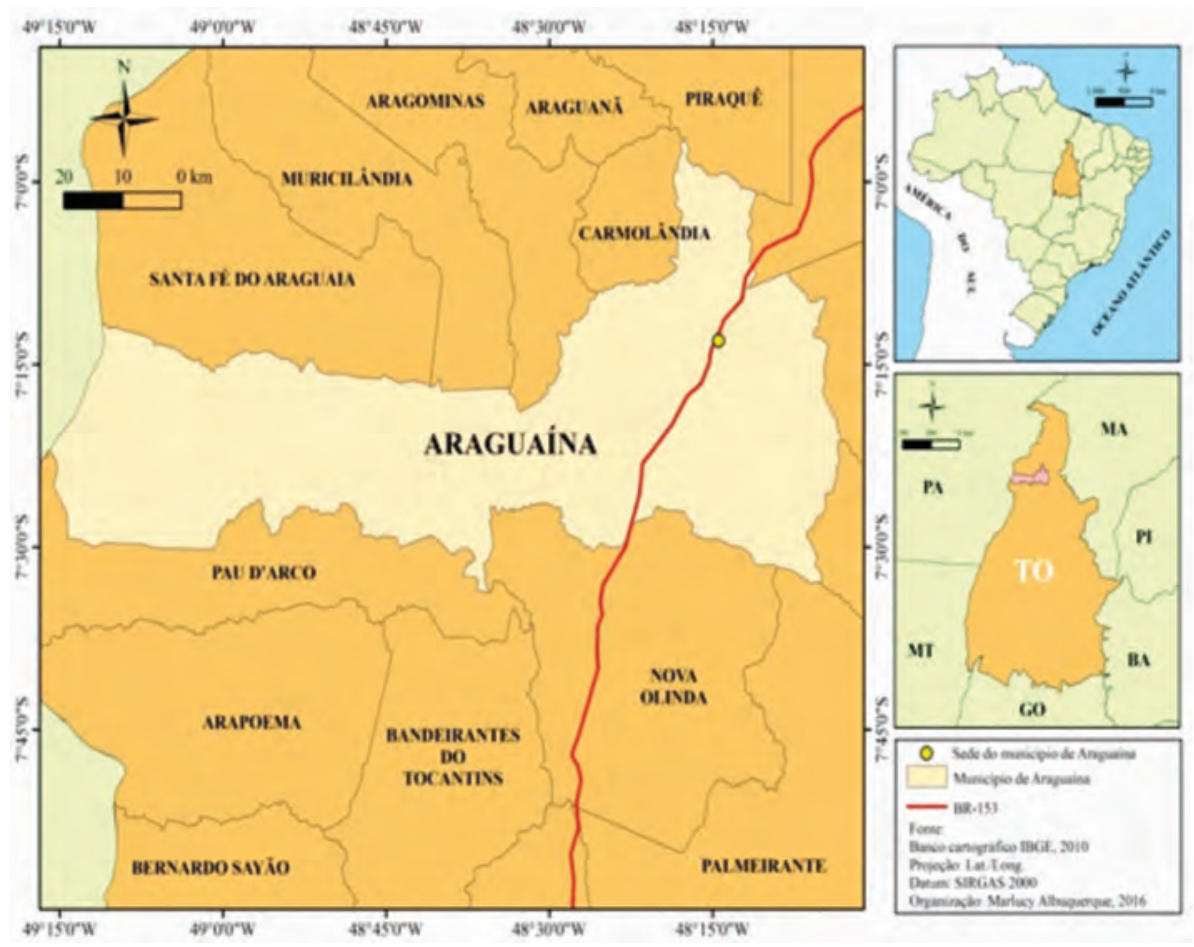

Como explica Aquino (2002, p. 333), “enquanto isso, as cidades distantes da estrada, ao mesmo tempo em que não atraíam imigrantes, por não contarem com as mesmas vantagens de suas "rivais" da rodovia, pelas mesmas razões até perdiam populações [...]." 
Até o fim da década de 1950, Araguaina não passava de um lugarejo com pouco mais de 2.000 (dois mil) habitantes, cujos limites não extrapolavam os córregos Neblina, Lava-pés e Canindé, compreendendo as ruas Cônego João Lima, $1^{\circ}$ de Janeiro, Falcão Coelho, Mangueiras, Rui Barbosa, Souza Porto e Santa Cruz, como afirma Gaspar (2002).

Após a chegada das obras da rodovia, muitos dos trabalhadores da empreiteira responsável pela abertura da estrada, passaram a residir em Araguaina, e, para atender a esse fluxo de pessoas, vários estabelecimentos comerciais foram instalados: armazéns, lojas de tecidos, barbearias e pensões, que passaram a atender também à população oriunda do campo, que antes se dirigia a outros centros urbanos, como Babaçulândia e Filadélfia.

Ao longo da rodovia BR-153 muitos estabelecimentos comerciais foram instalados com o objetivo de oferecer produtos e serviços a quem trafega pela rodovia. Na avenida Bernardo Sayão (marginal da BR-153 em seus dois sentidos), em Araguaina-TO, existem inúmeros estabelecimentos comerciais. São hotéis, postos de combustíveis, lojas de autopeças, borracharias e restaurantes, que ora se destinam a atender aos transeuntes que por ela trafegam, ora refletem a paisagem urbana da cidade. Esta paisagem urbana se apropriou da rodovia em seu traçado urbano, principalmente após a sua duplicação e a abertura de loteamentos em áreas onde se concentravam poucos bairros residenciais. Este espaço urbano reflete as contradições sociais do modo de produção capitalista, entre os quais, destaca-se o processo de segregação social.

Até a construção da rodovia BR-153, na década de 1960, a cidade não passava de um lugarejo com poucas casas, ruas sem calçamento e um comércio incipiente, cujos limites não ultrapassavam os córregos Neblina, Lava-Pés e Canindé. Após cinco anos da abertura da rodovia, devido ao impulso de ciclos migratórios vindos de diferentes regiões do país e a permanência de alguns dos trabalhadores empregados na abertura da estrada, Valverde e Dias (1967, p. 205) descrevem: "Na rua principal, perpendicular à BR-14, há casas em construção e um comércio desordenado, rústico, embora com certas lojas especializadas: casas de fazendas, barbeiro, relojeiro, até instituto de beleza”. A Fotografia 1 mostra o comércio instalado nesse período. 
Fotografia 1 - Centro de Araguaína (década de 1960)

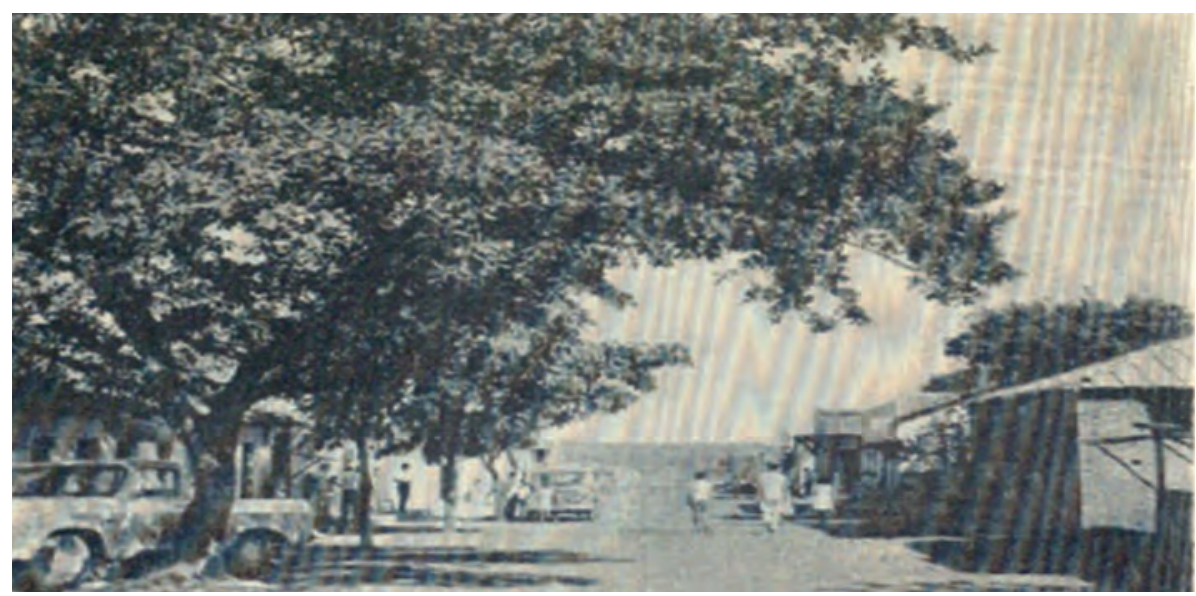

Fonte: Valverde e Dias (1967)

Nesse período, a economia de Araguaína se baseava na produção de babaçu, algodão, amendoim e arroz; e a atividade industrial era desenvolvida por uma fábrica de óleo de babaçu. A energia que abastecia a cidade era toda produzida por uma barragem construída no rio Lontra, como aponta Valverde e Dias (1967, p. 207).

Com a expansão do núcleo urbano de Araguaína uma parte da população que vivia na zona rural migrou para a zona urbana, em busca de outras atividades laborais, deixando o trabalho no campo, para se dedicarem às atividades comerciais, aumentando o índice de população urbana, assim como em Gurupi, Paraíso do Tocantins e Colinas, que emergiram com a construção da rodovia. Aquino (2002) reforça esta tese do aumento da população a partir da construção da rodovia Belém Brasília.

[...] verificam-se impulsos bastante significativos nas décadas de abertura e pavimentação asfáltica da rodovia. A estrada teve sua construção iniciada no final dos anos 50, inaugurada em 1960 e a pavimentação concluída na metade da década de 1970. Através dos Censos de 1950 e de 1980, percebe-se que a população quase triplicou nas três décadas [...] No mesmo período verifica-se também significativo incremento da população urbana (AQUINO, 2002, p. 337).

Entre as décadas de 1980 e 1990 a população do antigo Norte goiano (Tocantins) teve um crescimento normal, como aponta Aquino (2002, p. 335). No início dos anos 1990, com a recém-criação do estado do Tocantins, Araguaína assume a primeira posição com maior população e desenvolvimento econômico do estado, impulsionada pela atividade agrícola e pela pecuária. 
No início da década de 1990, o desenvolvimento da pecuária e de atividades agrícolas, impulsionadas pela recém-criação do estado do Tocantins, alavancou ainda mais a economia do município, que recebeu o título de "Capital do Boi Gordo". A expansão urbana de Araguaina extrapolou os antigos limites em menos de duas décadas, e atualmente a cidade é a segunda maior do Tocantins, com 150.484 habitantes, segundo o último censo do IBGE (2010).

Ao longo da rodovia BR-153 muitos estabelecimentos comerciais foram instalados às suas margens, no intuito de oferecer produtos e serviços às pessoas que trafegam por ela. Muitas cidades surgiram, inclusive, a partir desse comércio, que inicialmente, no período de construção e pavimentação, era vital a quem trafegava pela rodovia.

A razão do predomínio do traçado linear é a exclusiva função comercial dos núcleos. Ora, para o comércio o fator transportes é vital, pois aquêle depende sobretudo das trocas. Iam assim surgindo as lojas ao longo da estrada, gerando um Strassendorf. Em Nova Colina, por exemplo, que é um dos principais centros urbanos, no trajeto Araguaína-Miranorte, anotaram-se como atividade econômicas: beneficiamento de arroz, oficina mecânica, farmácia, restaurante, dentista, bares e posto de gasolina [...] (VALVERDE; DIAS, 1967, p. 248).

As palavras dos autores citados acima reforçam a ideia da importância da rodovia Belém-Brasília no processo de desenvolvimento regional e na expansão urbana de Araguaia e outras cidades nas imediações da rodovia.

No perímetro urbano de Araguaína existem inúmeros estabelecimentos comerciais. Eles se localizam nas margens direita e esquerda da rodovia, conhecida como avenida Bernardo Sayão. São hotéis, postos de combustível, autopeças, concessionárias, borracharias e restaurantes, que são destinados a atender tanto à população local e cidades circunvizinhas, quanto aos transeuntes que por ela trafegam. As autopeças lideram o número de estabelecimentos situados às margens da rodovia BR-153. Isso se deve a crescente procura por peças e serviços de mecânica para veículos de passeio e caminhões.

Assim como em outros municípios que se localizam às margens da rodovia, Araguaína se apropriou da rodovia em seu traçado urbano, o que pode ser constatado com a existência de inúmeros bairros em ambos os lados da BelémBrasília. Por essa razão o comércio existente na Avenida Bernardo Sayão é tão significativo à população araguainense, tanto quanto outros espaços destinados a ele, em outras áreas do seu centro urbano.

\footnotetext{
Adensamentos populacionais formados ao longo de estradas de rodagem que passam a contar com os serviços de atendimento ao fluxo rodoviário, como oficinas mecânicas, restaurantes e bares consolidando-se posteriormente em áreas urbanas (LIMA, 2010).
} 
Fazendo uma análise do processo de expansão urbana de Araguaína, é possível inferir a ele, uma íntima relação com a construção da rodovia BR-153, pois foi a partir desse canal de penetração ao cerrado e à Amazônia que os ciclos migratórios foram intensificados, ampliando a circulação de pessoas e mercadorias, e, portanto, a dinâmica comercial da região norte goiana (atual Tocantins). Desde a sua construção, a BR-153 exerce um papel atrativo econômico e demográfico para essa região.

\section{CONSIDERAÇÕES FINAIS}

A expansão urbana de Araguaina por um lado, foi motivado pela fronteira e, por outro, pela construção da rodovia Belém-Brasília. Na Região Amazônica, as vias rodoviárias têm um papel muito importante para o desenvolvimento regional e, sobretudo, para a ampliação do processo de urbanização. Pode-se notar que em todas as imediações da rodovia Belém-Brasília, o fenômeno urbano está presente. Este fato é resultado de políticas públicas de investimento com o objetivo de instalar, formar e consolidar a fronteira capitalista na região.

A fronteira capitalista desenha espaços contraditórios. No campo provoca o êxodo rural, condicionando que os camponeses migram para a cidade. Ainda no campo gera a concentração fundiária e de renda. Estas contradições no campo ampliam os conflitos sociais entre camponeses e latifundiários, e também entre latifundiários e indígenas. Nos espaços urbanos, pode ocasionar a expansão de cidades de forma desordenada. Esta expansão em tempos muito curtos, gera bairros e loteamentos sem infraestrutura e carentes de equipamentos urbanos. A especulação imobiliária é outro aspecto que gera um espaço contraditório com o fortalecimento da segregação socioespacial urbana. As cidades de fronteira, mesmo sendo muito jovens, já nascem com os velhos problemas sociais dos centros urbanos mais antigos do país.

\section{REFERÊNCIAS}

AQUINO, N. A. de. A construção da Belém-Brasília e suas implicações no processo de urbanização do Estado do Tocantins. In: GIRALDIN, Odair. (Org.). A (trans)formação histórica do Tocantins. Goiânia: Ed. UFG; Palmas: Unitins, 2002. p. 315-350.

BECKER, B. K. et al. Fronteira amazônica: questões sobre a gestão do território. Brasília: Editora da UnB, 1990. 
DINIZ, A. M. A. Migração na fronteira agrícola. AGETEO, v. 28, n. 03, set./ dez. 2003.

FOWERAKER J. A. Luta pela terra. Rio de Janeiro: Zahar Editores, 1992.

GASPAR, J. G. Araguaína e sua região: saúde como reforço da polarização. (Dissertação de Mestrado). Recife: Universidade Federal de Pernambuco, 2002.

IBGE. Censo Demográfico 2010. Rio de Janeiro, 2010.

LIMA, C. et al. Mapeamento de áreas potenciais à expansão urbana como subsídio à projeção demográfica da população na área de entorno da COMPERJ-RJ. In: ENCONTRO NACIONAL DA GEOGRAFIA, 16. Crise, práxis e autonomia: espaço de resistência e da esperança. Estado de diálogos e práticas. ENG-2010. Porto Alegre, 2010. Anais... Porto Alegre, 2010.

LIRA, E. R. A gênese de Palmas: a geopolítica de (re)ocupação territorial na Amazônia Legal. Goiânia: Kelps, 2011.

MACHADO, L. O. Urbanização e migração na Amazônia Legal: sugestão para uma abordagem geopolítica. In: BECKER, Bertha K.; MIRANDA, Mariana Helena P.; MACHADO, Lia Osório. Fronteira amazônica: questões sobre a gestão do território. Brasília-DF: Editora da Universidade de Brasília; Editora da Universidade Federal de Rio de Janeiro, 1990.

MARTINS, J. de S. Fronteiras: a degradação do Outro nos confins do humano. São Paulo: Hucitec, 1997.

MARTINS, J. de S. O tempo da fronteira. Retorno à controvérsia sobre o tempo histórico da frente de expansão e da frente pioneira. Tempo Social. Rev. Sociologia, São Paulo; USP, v. 8, n. 1, p. 25-70, maio 1996.

OLIVEIRA, A. U. de. Integrar para não entregar: políticas públicas para a Amazônia. 2a ed. Campinas: Ed. Papirus, 1991.

PEREIRA, J. C. M. Importância e significado das cidades médias na Amazônia: uma abordagem a partir de Santarém (PA). 2004. 139f. Dissertação (Mestrado em Desenvolvimento Sustentável do Trópico Úmido) - Núcleo de Altos Estudos Amazônicos, Universidade Federal do Pará, Belém, 2004.

SOUZA, S. M. Belém-Brasília: abrindo fronteiras no Norte goiano - atual Tocantins - 1958-1975. In: GIRALDIN, O. (Org.). A (trans)formação histórica do Tocantins. Goiânia: Ed. UFG; Palmas: Unitins, 2002. p. 351-394. 
VALVERDE, O.; DIAS, C. V.. A rodovia Belém-Brasília: estudo de Geografia Regional. Rio de Janeiro: Fundação Instituto Brasileiro de Geografia, 1967.

VINHAL, M. do C. B. Colinas do Tocantins: desenvolvimento e transformações ambientais. 2009. 90f. Dissertação (Mestrado em Ciências do Ambiente e Sustentabilidade na Amazônia) - Centro de Ciências do Ambiente, Universidade Federal do Amazonas, Manaus, 2009.

Agradecimentos

Pelo apoio financeiro de Pró-Reitoria de Pesquisa da Universidade Federal de Tocantins. 


\section{A habitação de interesse social no Brasil e sua expressão em Manaus}

\section{The social interest housing in Brazil and its expression in Manaus}

Elane de Azevedo Pires - Mestre em Psicologia pela Universidade Federal do Amazonas (UFAM). Especialização em Politica Social /Sistema Único de Assistência Social (UNINTER).E-mail :elane_pires@hotmail.com

Marcelo Gustavo Aguilar Calegare - Doutor em Psicologia Social pela Universidade de São Paulo (USP). Professor da Faculdade de Psicologia da Universidade Federal do Amazonas (UFAM). E-mail: mgacalegare@ufam.edu.br

\section{Resumo}

Este artigo aborda de maneira crítica as políticas públicas de habitação de interesse social no Brasil, dando foco ao caso de Manaus. Iniciamos com um breve histórico a respeito das políticas habitacionais brasileiras, revelando que a habitação no país pode ser considerada uma questão social, devido aos indicadores de déficit habitacional, o número expressivo de moradias precárias e programas de habitação de interesse social que não correspondem às expectativas dos beneficiários. Apresentando durante a discussão dados do Amazonas e Manaus, problematizamos a desigualdades no espaço urbano brasileiro, para o qual os poderes públicos têm realizado intervenções insuficientes em anos pretéritos e presentes.

\begin{abstract}
This article critically addresses public housing policies of social interest in Brazil, focusing on the case of Manaus. We begin with a brief history of Brazilian housing policies, revealing that housing in Brazil can be considered a social issue, due to the indicators of housing deficit, the expressive number of precarious housing and the programs of social interest housing that do not meet expectations of the beneficiaries. Presenting during the discussion data from Amazonas and Manaus, we problematize the inequalities in the Brazilian urban space, for which the public authorities have performed insufficient interventions in past and present years.
\end{abstract}

\section{Palavras-chave}

Habitação de Interesse Social. Moradia. Questão Social. Política Pública.

\section{Keywords}

Social Interest Housing. Housing. Social Question. Public Politic. 


\section{INTRODUÇÃO}

A falta de moradia para uma parcela da população em situação de pobreza é um problema presente em todos os países do mundo, desde os menos desenvolvidos às maiores potências mundiais. No Brasil, a questão da ausência de habitação com condições dignas e necessárias para as famílias mais pobres pode ser caracterizada por uma trajetória que perpassa as mais diversas discussões e medidas. As ações dos sucessivos governos buscaram uma saída que atenuasse os impactos gerados pelo crescimento populacional e desenvolvimento industrial, fatos que agravaram as desigualdades sociais e que deram origem ao dilema da questão social habitacional no país (SILVA, 1989).

Essa configuração do problema habitacional também se expressa no Amazonas, especialmente na cidade de Manaus, uma vez que não seguiu uma lógica diferente de outras cidades. O impacto do desenvolvimento industrial dos anos 1960 em diante causou problemas diversos no estado, como o êxodo rural e a explosão demográfica da capital (RANCIARO, 2004). A ausência de uma ação preventiva do poder público referente à ocupação territorial possibilitou que milhares de familiais ocupassem espaços inadequados para moradia, como encostas e margens de igarapés. As localidades que ao longo dos anos foram consolidadas por ocupações em Manaus dispõem de serviços públicos insuficientes, tornando a cidade com um dos maiores e piores déficits relativos do país (FUNDAÇÃO JOÃO PINHEIRO, 2013; OLIVEIRA: COSTA, 2007).

$\mathrm{O}$ agravamento da situação habitacional no país teve reflexo direto na insatisfação da população com a atuação do poder público, circunstância que levou o Estado a intervir na produção habitacional, que por longos anos ficou sob responsabilidade da iniciativa privada. Historicamente, a atuação estatal no âmbito da habitação para a população mais pobre teve início a partir de 1910, com o lançamento de programas que se propunham atenuar o déficit habitacional brasileiro, por meio do financiamento de moradias (FERNANDES; OLIVEIRA, 2010). Este tipo de iniciativa se repetiu por longos anos até a presente década, delineando-se um perfil socioeconômico para as famílias necessitadas de moradia e constituindo um desafio urbano para a habitação de interesse social.

A habitação de interesse social (HIS) é um tipo de moradia produzida para atender a necessidade de moradia de um grupo de famílias que se inserem no perfil socioeconômico de extrema pobreza a baixa renda, isto é, que possuem rendimentos de zero a três salários mínimos. Portanto, não possuem condições financeiras para obter a casa própria no âmbito do mercado capitalista, no qual os imóveis considerados adequados para moradia têm muitas vezes valores 
exorbitantes. Sendo assim, as HIS são normalmente subsidiadas pelo poder público e que também seleciona as famílias que serão beneficiárias.

Para fundamentar a discussão a respeito da HIS no Brasil e como esta se apresenta no Amazonas e, mais especificamente, em Manaus, neste artigo temos por objetivo apresentar uma revisão crítica da literatura sobre o tema, demonstrando que a habitação se configura como uma questão social devido ao número crescente de famílias que residem em locais sem condições dignas de moradia. Os vários autores que desenvolveram estudos sobre habitação contribuíram para revelar que o Brasil é um país com graves problemas na área habitacional (AZEVEDO, 2007; FUNDAÇÃO JOÃO PINHEIRO 2013; MARICATO, 1996; OLIVEIRA, COSTA, 2007) - o que se reflete também no estado do Amazonas e sua capital. Nesse sentido, apresentaremos um breve histórico das políticas habitacionais no âmbito da HIS no período de 1910 a 2014, mostrando também como estas são executadas em Manaus. Em seguida, faremos uma discussão da habitação enquanto questão social no Brasil, trazendo dados de todo país - e com destaque para Manaus - utilizados pelo governo federal a partir dos estudos da Fundação João Pinheiro, uma vez que a capital amazonense tem enfrentado graves problemas relacionados à habitação.

\section{A HABITAÇÃO DE INTERESSE SOCIAL NO CONTEXTO BRASILEIRO E EM MANAUS}

A HIS surgiu no Brasil por meio da produção de moradias operárias no governo de Marechal Hermes (1910-1914). Tais moradias consistiam em vilas proletárias destinadas aos operários residentes no bairro Marechal Hermes, no Rio de Janeiro. Como argumentam Fernandes e Oliveira (2010), a construção das vilas pode ser considerada como uma das primeiras iniciativas para o enfrentamento da questão social na área da habitação por parte do Estado no país, sendo precursoras da intervenção habitacional no período Vargas. As vilas operárias localizavam-se no centro das cidades próximas às indústrias. No entanto, esse tipo de moradia era oferecido aos trabalhadores mais qualificados das indústrias. Devido à inexistência de qualquer iniciativa que pudesse prover habitação para grande parte dos trabalhadores pobres, somado à falta de condições econômicas para pagar uma moradia digna, muitas famílias foram obrigadas a morar nos cortiços da cidade. Pertencentes à iniciativa privada e localizados no centro, os cortiços eram caracterizados por ser uma habitação coletiva, com edificações velhas e banheiro de uso coletivo. 
As vilas de Hermes foram planejadas para abrigar cerca de cinco mil pessoas, suas obras foram iniciadas no governo do Marechal Hermes, mas sua conclusão só ocorreu no governo de Getúlio Vargas, em 1941. Vargas iniciou a sua intervenção nas obras das vilas por meio do Instituto de Previdência dos Funcionários Públicos da União (IPFPU). Fernandes e Oliveira (2010) afirmam que apesar de Vargas ter dado continuidade às obras das vilas, ele reconheceu a intervenção da República Velha para amenizar a questão social habitacional. Isso contribui para que Marechal Hermes não tivesse sua atuação reconhecida no âmbito da habitação social no Brasil.

Para Bonduki (1994), outro marco a ser considerado na trajetória da HIS consiste na Lei do Inquilinato (1921-1927), que surgiu com resultado da intervenção do Estado na produção de moradias e proteção ao inquilinato, visando conquistar as massas populares que enfrentavam problemas na área habitacional. Dessa forma, tal lei preconizava o congelamento monetário dos aluguéis em virtude dos altos valores que contribuíam para agravar a crise por falta de moradia que vigorava naquele período. Assim, o Estado

assume a peculiaridade da habitação como uma mercadoria especial, onde o interesse social ultrapassa os mecanismos de mercado. Reforça, portanto, independentemente da intenção de seus idealizadores, a visão da habitação social no Brasil (BONDUKI, 1994, p. 719).

Com o objetivo de reforçar sua presença na intervenção habitacional, o Estado criou em 1933 os Institutos de Aposentadorias e Pensões (IAP), que buscavam viabilizar uma política habitacional direcionada para a classe trabalhadora (CABRAL, 2005), além de financiar, paralelamente, a habitação social e a construção civil. Os IAP construíram moradias em benefício de seus associados e tiveram uma importante intervenção reconhecida, pois construíam moradias com boa localização (BONDUKI, 1994). Apesar disso, os IAP encerraram suas atividades, pois não obtiveram retorno financeiro de seus investimentos.

De acordo com Motta (2010), a principal marca da política habitacional no período de Vargas foi a criação da Fundação Casa Popular (FCP) em 1946, sendo a primeira política nacional de habitação de fato. A FCP foi o primeiro órgão federal brasileiro na área de moradia que se propôs a centralizar a política de habitação (CABRAL, 2005). Entretanto, a FCP não dispunha dos recursos necessários para seu desempenho, além de não terem produzido moradias suficientes para atender a demanda durante seus vinte anos de existência e, assim, foi extinta em 1964 (BRASIL, 2004). 
Com o fim da FCP, em 1964, foi criado o Banco Nacional de Habitação (BNH) no mesmo ano. A iniciativa foi considerada a primeira intervenção significativa do Estado na questão habitacional. Isso contribuiu para que o governo militar alcançasse o apoio das massas populares e estruturasse uma política voltada para o setor da construção civil habitacional (BONDUKI, 1994).

$\mathrm{O} \mathrm{BNH}$ visava propiciar às classes populares a oportunidade de aquisição da casa própria. Abiko (1995 citado por LARCHER, 2005, p. 10) relembra que "O interesse social como terminologia na habitação no Brasil já era utilizado nos programas para faixas de menor renda do extinto Banco Nacional da Habitação (BNH)". O procedimento adotado para a realização de tal feito consistia em oferecer financiamentos para os agentes que executavam programas habitacionais, os quais transferiam o dinheiro para as empresas de construção. Dessa forma, o BNH deveria tornar viável a aquisição de moradias para os brasileiros, mas seu funcionamento não favorecia a compra dessas casas pelas classes desfavorecidas (VALLADARES, 1981). A alternativa encontrada pelas classes de pobres frente à ineficiência do $\mathrm{BNH}$ consistia na compra de loteamentos, que eram revendidos a preços acessíveis, de modo que os novos proprietários construíam sua própria casa. A autoconstrução resultou em inúmeras residências em condições precárias, pois as famílias não possuíam renda suficiente para investir em uma moradia com infraestrutura adequada e boa localização, em virtude dos preços de terrenos próximo ao centro serem muito caros.

Foram desenvolvidos muitos debates e propostas a fim de encontrar medidas de descentralização do BNH, mudanças no sistema de financiamento, operação e receita dos sistemas, mas nenhuma dessas alternativas foi satisfatória e o banco foi extinto em 1986. Nesse sentido, suas atribuições foram transferidas para a Caixa Econômica Federal (AZEVEDO, 2007).

Com a Constituição de 1988, passou a ser competência dos estados e municípios "a gestão dos programas sociais, e dentre eles o de habitação, seja por iniciativa própria, seja por adesão a algum programa proposto por outro nível de governo, seja por imposição Constitucional” (BRASIL, 2004, p. 10). Bonduki et al. (2003 citados por LARCHER, 2005) afirmam que a Constituição Federal de 1988 passou a atribuir ao solo urbano uma função social. Dessa forma, agregou-se a isso "o conceito de Interesse Social, que é constitucionalmente incorporado às políticas habitacionais para os setores de população de baixa renda" (LARCHER, 2005 p.10).

Durante os anos 1990, houve poucos investimentos significativos no âmbito habitacional (MOT'TA, 2010). A política habitacional foi caracterizada pela alocação das unidades construídas pelos programas populares e alternativos, 
baseados na autoconstrução, além de que a construção dessas unidades continuou privilegiando os setores populares de renda elevada (AZEVEDO, 2007). Em maio de 1990, foi lançado o Plano de Ação Imediata para a Habitação, o mais importante programa habitacional criado pelo governo Collor, que tinha como objetivo as famílias com renda de zero a cinco salários mínimos. Tal programa possuía como vertentes: "programa de moradias populares (unidades acabadas), programa de lotes urbanizados (com ou sem cesta básica de materiais) e programa de ação municipal para habitação popular (unidades acabadas e lotes urbanizados)" (AZEVEDO, 2007, p. 20).

Com vistas a dar continuidade às obras iniciadas no governo anterior, durante a gestão de Itamar (1992-1994) foram criados os Programas Habitar Brasil e Morar Município, os quais objetivavam o financiamento de moradias para a população de baixa renda (MOT'TA, 2010). Enquanto o Programa Habitar Brasil era voltado para os municípios com população superior a 50 mil habitantes, o Morar Brasil destinava-se aos municípios com menor porte, sendo que ambos possuíam as mesmas características e estavam direcionados às famílias de baixa renda e que viviam em áreas de risco (AZEVEDO, 2007).

O governo FHC (1995-2002), por sua vez, registrou sua intervenção na HIS por meio de alguns programas habitacionais: o "Programa de Conclusão de Empreendimentos Habitacionais", que buscava viabilizar a comercialização de conjuntos habitacionais; e o "Programas de Crédito Direto ao Cidadão", denominados Cred-Mac e Cred-Casa. Estes eram voltados para famílias com rendimentos de até oito salários mínimos, com fins de possibilitar a oferta de crédito para facilitar a aquisição de materiais de construção. Programas que merecem destaque também no governo de FHC são "Pró-Moradia" e o "Programa Habitar Brasil", os quais tinham como finalidade "a urbanização de áreas degradadas para fins habitacionais, a regularização fundiária e a produção de lotes urbanizados" (AZEVEDO, 2007, p. 24). Entre os programas que migraram do governo FHC para o governo Lula (2003-2010) está a Carta de Crédito, individual e associativa, além do programa Pró-Moradia, com foco na urbanização de áreas precárias.

O governo Lula estabeleceu um plano de trabalho focado para a área social, em que uma de suas principais metas era reduzir o déficit habitacional. Assim, criou-se o Ministério das Cidades, responsável por tratar de questões voltadas para o desenvolvimento urbano do país. E vinculado ao mesmo, a Secretaria Nacional de Habitação, que gerencia e faz cumprir as ações previstas na política habitacional. 
A Política Nacional de Habitação, instituída em 1994, foi considerada um instrumento significativo no avanço em termos participativos, institucionais e legais para a habitação. Assim, em 2003, é instituído o conselho das cidades e o Sistema Nacional de Habitação (SNH), que reúne os esforços dos três níveis de governo, do mercado, das cooperativas e associações populares para promoção de moradia digna.

Vale destacar que as principais providências executadas foram a implementação de ações que favorecessem a construção civil, com a diminuição dos impostos sobre os materiais de construção, direcionamento dos recursos do Sistema Brasileiro de Poupança e Empréstimo (SBPE) e do Fundo de Garantia do Trabalhador (FGTS) para a Caixa Econômica Federal, bem como aumento dos subsídios e redução da taxa de juros (BRASIL, 2010). Desse modo, o SNH passou a se articular com eixos voltados para a política de desenvolvimento urbano no país, que prevê não só a habitação como também a mobilidade urbana, a acessibilidade e o saneamento básico.

O SNH está subdividido em dois sistemas: o Sistema Nacional de Habitação de Interesse Social (SNHIS) e o Sistema Nacional de Mercado (SNM). Esses dois sistemas operam com fontes de recursos, formas e condições de financiamento diferentes. O SNHIS é voltado para atender à população de baixa renda de zero a três salários mínimos, com recursos subsidiados pelo governo para as famílias que, prioritariamente, moram em "assentamentos precários" - termo que definiremos mais adiante. E o SNM para atender a classe média com renda acima de três salários mínimos com recursos emprestados para os usuários. Para acessar os recursos do fundo e aderir ao SNHIS, os estados, o Distrito Federal e os municípios deverão tomar medidas de âmbito institucional, comprometendo-se a constituir um Fundo Local de Habitação de Interesse Social, criar um Conselho Gestor do Fundo Local e elaborar um Plano Local de habitação de interesse social. Assim, os dois estabelecem processos para a provisão de moradias em todos os segmentos sociais (BRASSIL, 2010).

A aprovação do SNHIS é considerada também uma conquista dos movimentos populares, já que seu projeto de lei foi resultado de uma mobilização nacional dos movimentos de luta por moradia e de diversas entidades. Esse projeto de lei foi apresentado no parlamento, em 19 de novembro de 1991, por organizações e movimentos populares urbanos filiados ao Fórum Nacional de Reforma Urbana, tendo sido assinado por mais de um milhão de pessoas.

Um importante instrumento criado em 2001 foi o Estatuto das Cidades, que proporcionou nova fundamentação jurídica para a efetivação do "direito à cidade", o que significa ter acesso a aparelhos comunitários (escolas, posto de 
saúde lazer, transporte etc.) - mas isto não quer dizer que de fato funcione como preconiza a lei. O Estatuto engloba a função social da propriedade, o direito à moradia e a participação popular, dispõe sobre instrumentos capazes de permitir a efetividade da função social da propriedade e a segurança da posse.

O Estatuto das Cidades pretende definir como regular a propriedade urbana, de modo que os processos que a envolvem não se constituam empecilhos ao direito à moradia para a maior parte da população. No entanto, “aplicar o Estatuto da Cidade em tal contexto, culturalmente excludente, tradicionalmente conservador, não é tarefa simples especialmente porque nessas sociedades chamadas de emergentes (...) ou periféricas, o poder político e social vem associado à propriedade patrimonial" (MARICATO, 2010, p.06).

Ainda no governo Lula foi anunciado o Plano de Aceleração do Crescimento (PAC), em que no eixo da infraestrutura urbana e social foi incluído o Programa Minha Casa Minha Vida (PMCMV), inspirado na experiência chilena de habitação. O SNH, o Estatuto das Cidades e o PMCMV foram importantes ações mantidos no governo Dilma (2010-2016). O PMCMV se expandiu e era o programa mais executado em nível nacional, tendo como principal objetivo contemplar as famílias de baixa renda com moradia digna, podendo ser organizadas por meio dos municípios, construtoras ou entidades habilitadas (BRASIL, 2010). E quanto ao governo Temer, também se manteve esse programa e se implementou o "Cartão Reforma", que se trata de um auxílio às famílias para reformarem suas casas.

O PMCMV apresenta em sua estrutura a modalidade Entidades, uma novidade não constatada em programas passados. Essa inovação possibilitou que os movimentos sociais fossem agentes efetivos na produção de moradia no país. Nesta modalidade, qualquer associação ou cooperativa que fosse legalmente regularizada poderia atuar como organizadora das famílias de baixa renda. O processo acontece da seguinte forma: a entidade apresenta os documentos de qualificação técnica e institucional para a Caixa Econômica Federal no período estabelecido em portaria. A Caixa analisa a documentação e envia o relatório para o Ministério das Cidades. A homologação do resultado é publicada no Diário Oficial da União. Se a entidade for aprovada, ela poderá atuar na gestão para construção de até 1.000 moradias.

O Fundo de Desenvolvimento Social subsidia até 95\% do valor da casa e a Caixa acompanha e fiscaliza todas as fases da obra. Para participar do PMCMVEntidades, as famílias devem atender aos seguintes critérios prioritários:

1. Ser família de baixa renda até três salários mínimos;

2. Estar inscrita no cadastro único do governo federal; 


\section{Residir em áreas de risco ou insalubres;}

4. Famílias com mulheres responsáveis pela unidade familiar;

5. Famílias que tenham em sua composição pessoas com deficiência e idosas.

Feita essa breve recapitulação de como foram delineadas as políticas públicas voltadas à resolução da questão da habitação no país, é importante entendermos como tal questão se tornou um problema também no estado do Amazonas e, especialmente, na sua capital, e quais as políticas praticadas nessa cidade. Em linhas gerais, em Manaus a apropriação do espaço e a consolidação de moradias não obedeceu uma lógica diferente de outros contextos brasileiros. A urbanização dessa cidade e, consequentemente, sua ocupação acelerada, iniciou a partir da consolidação da Zona Franca de Manaus (ZFM) nos anos 1960, como explicaremos adiante.

Após o declínio da economia da borracha na segunda década do século $\mathrm{XX}$, a população do interior do estado do Amazonas dedicava-se ao extrativismo vegetal, à agricultura e à pecuária de pequeno porte direcionada para o abastecimento da capital, além das atividades de subsistência. No entanto, esse modelo de economia era considerado fraco e insuficiente e não poderia garantir o desenvolvimento social e econômico da região. Segundo Ianni (1986), a partir de 1966 se iniciou uma nova fase de desenvolvimento extensivo do capitalismo na Amazônia, resultado da expansão acelerada das relações de produção, forças produtivas no extrativismo, agricultura e pecuária. Foi nesse contexto de inclusão da Amazônia no modelo econômico desenvolvimentista do governo militar que foi criada a ZFM, por meio do Decreto-Lei nº 288, de 28 de fevereiro de 1967. Seu objetivo era atrair interesses econômicos e financeiros com a oferta de incentivos fiscais especiais e de uma área livre para o comércio de importação e exportação de mercadorias. Essas medidas possibilitaram o desenvolvimento econômico da Amazônia ocidental, resultando no aumento da oferta de empregos, incentivo ao turismo interno e o desenvolvimento industrial agropecuário. Como a ZFM necessitava absorver mão-de-obra, muitas pessoas migraram para a capital amazonense em busca de empregos.

De acordo com Ranciaro (2004), o advento da ZFM deu notório destaque à cidade. No entanto, esta nova estruturação, somada ao crescimento do comércio de produtos importados, gerou distorções sem precedentes, dentre os quais se destacam a concentração econômica na capital amazonense e o êxodo rural acelerado. Isso inegavelmente provocou o desenvolvimento das desigualdades sociais, visto que as oportunidades de emprego não acompanharam a explosão demográfica, gerando certos problemas sociais como o crescimento populacional 
acelerado e desordenado.

Oliveira e Costa (2007) afirmam que a consolidação de moradias em Manaus se iniciou com a expansão dos conjuntos residenciais, que foram construídos por meio da iniciativa privada com subsídios oferecidos pelo Estado, via incentivos financeiros do BNH. Os conjuntos foram formados nos bairros do Japiim, Flores, Petro e Cidade Nova. As casas eram padrão e foram construídas horizontalmente, no entanto atualmente dificilmente encontram-se as casas em sua estrutura original.

Com o objetivo de amenizar o problema habitacional da cidade, foram implantados alguns programas de HIS, com a iniciativa dos poderes públicos locais, com incentivos financeiros do Governo Federal e bancos internacionais. Os programas executados mais conhecidos em Manaus são os seguintes:

- PROSAMIM - Programa Social e Ambiental dos Igarapés de Manaus. A prática do programa se caracteriza por recuperar áreas de igarapé mais próximas do centro da cidade onde residem determinado número de famílias. As mesmas são remanejadas das áreas até que sejam feitos serviços de drenagem do solo e onde são construídas novas habitações de forma verticalizada;

- Residenciais "Viver Melhor". São casas e apartamentos que foram construídos para atender às necessidades habitacionais de famílias que não possuem moradia e seguem os parâmetros de exigência do PMCMV do Governo Federal.

Há também outras iniciativas conhecidas na área da habitação como: "os conjuntos cidadãos", PMCMV-entidades e o programa "Cartão Reforma", iniciativa mais recente do governo federal criada pelo governo Temer, gerenciada pela secretaria de habitação do município. Para participar deste programa as famílias devem estar em situação de pobreza ou baixa renda e ter o título definitivo do terreno. Nesse sentido, a família recebe gratuitamente o valor de até $\mathrm{R} \$$ 9.000,00 para realizar reforma de cômodos, conserto de telhado, hidráulica, elétrica e esgoto.

\section{A QUESTÃO SOCIAL DA HABITAÇÃO NO BRASIL E EM MANAUS}

Segundo Maricato (2010), em países desenvolvidos como o Canadá, $30 \%$ da população necessitam de subsídios para resolver seus problemas de moradia, enquanto no Brasil essa estatística chega até 70\%. Em nosso país, mais de um milhão de famílias residem em assentamentos precários sem as mínimas condições de moradia. 
A questão da habitação pode ser considerada mais um entre os muitos problemas sociais urbanos do Brasil, o que reflete um século de políticas que de fato não privilegia a população mais pobre. Por muitos anos o Estado relegou a questão social da habitação atuando de forma paliativa, excludente e autoritária, visando a lucratividade e na maioria dos casos movidas por interesses secundários. Dito de forma mais direta, visando obter lucros para a máquina pública, ou por vezes com mero intuito de promoção política partidária (SILVA, 1989).

Apesar de toda luta dos movimentos populares, da legislação e dos esforços do governo federal para prover moradia digna às famílias pobres, a execução dos projetos de HIS ainda esbarra em um antigo problema do país: devido à situação agrária, ao metro quadrado dos terrenos nos centros das cidades terem valores exorbitantes e pela especulação imobiliária, grande parte das casas dos programas sociais são construídas em terrenos distantes. Isso acontece porque o recurso para execução dos programas é insuficiente para pagar um terreno mais próximo aos centros urbanos, causando a segregação espacial.

Assim sendo, as famílias que têm esperança de obter uma moradia digna são reassentadas em terras que ficam no entorno da cidade. Esses locais são caracterizados por serem distantes, por não terem aparelhos comunitários, entre outros serviços, que possam atender à necessidade dos moradores. Por isso, algumas famílias abandonam os locais da nova moradia e voltam para o seu lugar de origem, onde têm escola, padaria, posto de saúde etc. com mais fácil acesso. Para exemplificar essa realidade, basta observarmos onde estão sendo construídos os conjuntos do programa "Viver Melhor", executado pelo Governo do Estado em Manaus. O último empreendimento desse programa foi construído no bairro de Santa Etelvina, localizado próximo aos limites da cidade, muito distante do centro e de outras zonas comerciais.

De acordo com Maricato (2010), parte das grandes cidades brasileiras têm sua população morando em locais sem qualquer regularização urbanística. No sistema capitalista, o acesso à moradia obedece a meios altamente diferenciados, vinculados à lógica da produção, em que a apropriação do espaço na cidade vai sendo configurado de acordo com os interesses de classes e criando desigualdades na vida social. O salário da maioria dos trabalhadores não tem sido, em épocas passadas e atuais, suficiente para que se possa prover uma moradia digna para suas famílias, obrigando-os a criar estratégias de sobrevivência e de provisão, em geral precárias e desumanas. O alto custo dos imóveis em áreas centrais, com eficiente estrutura urbana, exclui a possibilidade de cidadãos pobres viverem nestas áreas. Desse modo, são obrigados a morar em locais distantes com pouca ou quase nenhuma infraestrutura básica. 
A ausência de opções habitacionais no Brasil, criada pelo intenso processo de urbanização, baixa intervenção do poder estatal, baixa renda das famílias, especulação de terra urbanizada e insuficiência das políticas de habitação, levaram uma grande parte da população brasileira a viver em assentamentos precários e informais. Assim, as décadas de 1980 e 1990 foram marcadas pela expansão dos assentamentos precários, agravados pela crise econômica e pelo empobrecimento da população (BRASIL, 2010).

O termo "assentamentos precários" foi incorporado pela Política Nacional de Habitação, com o objetivo de definir em âmbito nacional um conjunto de moradias urbanas consideradas inadequadas para habitação que incluem cortiços, loteamentos irregulares de periferia, favelas, assim como os conjuntos habitacionais que se acham degradados. Segundo o Ministério das Cidades (BRASIL, 2010), os assentamentos precários são porções do território urbano com dimensões e tipos variados, que geralmente seguem as seguintes características:

1. São áreas predominantemente residenciais, habitadas geralmente por famílias de baixa renda;

2. As casas são caracterizadas por possuírem inúmeras carências e inadequações, como: irregularidade fundiária, ausência de infraestrutura e saneamento;

3. Estão em locais com enormes distâncias dos centros urbanos;

4. Em sua grande parte não possuem um serviço de transporte que consiga atender a grande demanda populacional;

5. Inexistência ou deficiência de serviços públicos como: saúde, educação, lazer etc.;

6. Os terrenos podem apresentar perigos de alagamento, deslizamentos e outros tipos de risco;

7. Adensamento excessivo dos assentamentos e das edificações, insalubridade e deficiências construtivas da unidade habitacional;

8. Estão localizados em território de extrema vulnerabilidade, com predomínio de situações de violência e tráfico;

Para Maricato (2010), além da ilegalidade e dos altos índices de violência, estão presentes nesses bairros mais vulneráveis: alta taxa de mulheres chefes de famílias, maior taxa de desemprego, baixa escolaridade, renda abaixo da renda média urbana, alta taxa de mortalidade infantil, ocorrência frequente de doenças por epidemia etc. As autoridades públicas e até mesmo a polícia têm dificuldade de circular livremente por essas áreas. Além disso, o autor ressalta que "num mesmo momento histórico, estão presentes os modos de vida pré-moderno (a 
produção doméstica da moradia, a proximidade dos dejetos) convivendo com o modo de vida pós-moderno baseado na comunicação revolucionada” (p. 38).

Os assentamentos precários são classificados em "consolidados", "consolidáveis" e "não consolidáveis", conforme as definições do Ministério das Cidades (BRASIL, 2010) a seguir:

Consolidados: são assentamentos que já estão integrados urbanisticamente e dotados de infraestrutura básica, porém, não estão regularizados e seus moradores apresentam demandas específicas por programas de pós-ocupação, sociais e equipamentos e serviços públicos.

Consolidáveis: aquele que apresenta condições favoráveis de recuperação urbanística e ambiental e de reordenamento urbano, abertura ou readequação de sistema viário, implantação de infraestrutura básica, regularização urbanística do parcelamento do solo, com ou sem necessidade de remoção de parte das famílias moradoras. A realocação (remoção) pode ser necessária para eliminar situações de risco, promover o desadensamento, para executar intervenções urbanas ou, ainda, em função de restrições legais à ocupação.

Não consolidáveis: aqueles que não apresentam condições de recuperação urbanística e ambiental e de reordenamento urbano. Trata-se de núcleos comprometidos por situações de risco e insalubridade não solucionáveis, como, por exemplo, os que se localizam sob aterro sanitário, oleoduto, viário estrutural da cidade, áreas de risco, de preservação ambiental. Os núcleos "não consolidáveis" são objeto de intervenção do tipo "remoção" e reassentamento em novas áreas.

Conforme a descrição do Ministério das Cidades (BRASIL, 2010), é possível perceber que o problema da habitação não é só a falta da casa, mas possui várias dimensões relacionadas à falta de infraestrutura, saneamento básico, mobilidade urbana e regularização fundiária. $\mathrm{Na}$ ausência de uma política fundiária que favoreça os mais pobres, a ocupação de terrenos áreas de risco ou ambientalmente frágeis é a opção que muitas vezes sobra para a população que não consegue acesso aos programas públicos habitacionais.

A Fundação João Pinheiro (2013) demonstra indicadores quantitativos que revelam a realidade dos assentamentos precários no Brasil. Essas estatísticas são utilizadas oficialmente pelo Governo Federal para divulgar as necessidades habitacionais mais recentes no país. O déficit habitacional no Brasil supera 6,490 milhões de unidades e inclui moradias que são classificadas em quatro categorias, conforme as descrições a seguir: 
Domicílios precários: um conjunto de moradias que por sua situação de precariedade não tem condições de serem habitadas. Podem ser representados por aqueles domicílios que não são de alvenaria. Os materiais (taipa não revestida, madeira aproveitada, palha) utilizados possuem vida útil e oferecem risco à saúde ou são muito antigos. Também são representados por aqueles domicílios improvisados utilizados como moradia, mas que não servem para este fim, como, por exemplo, carcaça de carros abandonados, viadutos, imóveis comerciais, barracas, cavernas e outros.

Coabitação familiar: representado por famílias conviventes que têm a intenção de ter o seu próprio domicílio. São famílias secundarias que moram com uma família principal na mesma unidade habitacional. Geralmente a família principal cede ou aluga um cômodo da casa para famílias conviventes ou terceiros.

Ônus excessivo com aluguel: representado por famílias de baixa renda que não reúnem capacidade econômica suficiente para pagar aluguel. Este componente inclui as famílias com até três salários mínimos e que utilizam até $30 \%$ da renda para pagar o imóvel.

Adensamento excessivo de domicílios alugados: caracterizado por número de pessoas que utilizam o mesmo cômodo como dormitório; neste caso, foi considerado um único dormitório para o número acima de três moradores permanentes.

Portanto, o déficit habitacional é formado pelos domicílios que precisam ser repostos por serem caracterizados como precários e pela falta de domicílios que precisam ser construídos, considerando o número de famílias que não têm casa própria. Tal déficit é calculado somando os quatro componentes: domicílios precários, coabitação familiar, ônus excessivo com aluguel urbano e adensamento excessivo de domićlios alugados. Os componentes são calculados de forma sequencial e, para contar como déficit, basta que o domicílio atenda no mínimo um único critério. $\mathrm{O}$ cálculo do déficit relativo é feito dividindo o número de déficit da unidade de análise pela soma de domicílios particulares permanentes e improvisados existentes. Tal indicador "é extremamente relevante, pois é capaz de revelar as necessidades habitacionais neutralizando o efeito tamanho do município no indicador final" (FUNDAÇÃO JOÃO PINHEIRO, 2013, p. 24).

$\mathrm{Na}$ Tabela 1 são apresentados dados da estimativa do déficit habitacional levantados pela Fundação João Pinheiro (2013), com base no censo demográfico publicado pelo IBGE (2010), que apresenta as necessidades mais recentes na área da habitação no Brasil. 
Tabela 1 - Déficit habitacional absoluto e relativo

\begin{tabular}{l|r|r|r|r|r|r}
\hline \multirow{2}{*}{ Região } & \multicolumn{3}{|c|}{ Absoluto $\left(\mathbf{n}^{\circ}\right)$} & \multicolumn{3}{c}{ Relativo (\%) } \\
\cline { 2 - 7 } & Urbano & \multicolumn{1}{|c|}{ Rural } & \multicolumn{1}{c|}{ Total } & Urbano & \multicolumn{1}{c}{ Rural } & \multicolumn{1}{c}{ Total } \\
\hline Norte & 585.725 & 237.17 & 823.442 & 19,4 & 24,7 & 20,6 \\
\hline Nordeste & 1.532 .184 & 579.333 & 2.111 .517 & 13,7 & 15,6 & 14,1 \\
\hline Sudeste & 2.576 .502 & 97.925 & 2.674 .428 & 10,9 & 5,9 & 10,6 \\
\hline Sul & 685.111 & 85.639 & 770.749 & 9,0 & 6,7 & 8,7 \\
\hline Centro-Oeste & 506.006 & 54.599 & 560.555 & 13,1 & 11,5 & 12,9 \\
\hline Brasil & 5.885 .528 & 1.055 .163 & 6.490 .691 & 11,9 & 13,0 & 12,1 \\
\hline
\end{tabular}

Fonte: Fundação João Pinheiro (2013)

Os dados apontam que há um déficit habitacional de 6,490 milhões de unidades no Brasil, o que corresponde a 12,1\% de residências. Os dados da Tabela 1 demonstram que a região Sudeste concentra o maior déficit habitacional, com 2,674 milhões de unidades, o que representa 41\% do total absoluto. Em seguida vem a região Nordeste, com 1,495 milhões unidades, o que são 33\% do total absoluto. A região Centro-Oeste possui o menor déficit, com apenas 560 mil unidades. Em valores relativos, ou seja, comparando o total de déficit com o número de domicílios particulares permanentes por região, o Norte apresenta os maiores e piores resultados, isto é, 20,6\% dos domicílios da região se enquadram em algum critério de déficit. A região Sul é a que apresenta o menor déficit habitacional relativo do país, com 8,7\% (FUNDAÇÃO JOÃO PINHEIRO, 2013).

Segundo a Fundação João Pinheiro (2013), os assentamentos precários se constituem como um território com tamanhos e tipos variados, caracterizados por inúmeras carências e inadequações. Nesse sentido, pode-se afirmar que esses números não retratam a verdadeira demanda habitacional do Brasil, já que a pesquisa foi feita por unidades habitacionais distinguindo-os por categorias e não por território.

Sendo assim, não foi encontrada uma pesquisa que demonstrasse em números a quantidade de assentamentos precários nas cidades brasileiras. Assim, podemos inferir que há casas contabilizadas em assentamentos precários que foram caracterizadas como dignas para moradia, considerando que há famílias nesses territórios que possuem condições financeiras para construir uma casa com estrutura adequada para habitação. Segundo a Fundação João Pinheiro (2013), casas assentadas em locais sem asfaltamento, saneamento básico, água tratada, energia elétrica regularizada, entre outros, não são adequadas para serem habitadas. Isso nos leva a concluir que todas as casas consolidadas em assentamentos precários deveriam ser calculadas como déficit habitacional, pois 
se fossem incentivadas obras de infraestrutura em um determinado assentamento precário, as famílias teriam que ser remanejadas e novas habitações deveriam ser construídas no mesmo assentamento que fora recuperado. Desse modo, o déficit habitacional parece ser muito maior do que o divulgado nas pesquisas oficiais.

Na Tabela 2, podemos verificar o déficit habitacional por componente: domicílios precários, coabitação familiar, ônus excessivo com aluguel, adensamento excessivo de domicílios alugados. De acordo com os dados expostos, a coabitação familiar ocupa o maior número do déficit habitacional do país (39,4\% do déficit total) e o ônus excessivo com aluguel ocupa o segundo lugar nas justificativas pela falta de moradia (30,6\% do déficit). Ambos somados representam $70 \%$ do total do déficit habitacional, o que corresponde a aproximadamente 5,1 milhões de unidades. Vale ressaltar que no ônus excessivo com aluguel estão incluídas somente as famílias consideradas de baixa renda, com ganhos de 0 a 3 salários mínimos, que somam 2.124.409 milhões de famílias pobres. Além de não possuírem meios suficientes para prover o sustento de suas famílias, precisam comprometer uma boa parte de sua renda para pagar a moradia, que quase sempre pelo baixo valor são de péssima qualidade.

Tabela 2 - Déficit habitacional por componente

\begin{tabular}{l|r|r|r|r}
\hline \multicolumn{1}{c|}{ Região } & \multicolumn{1}{c|}{ Precários } & \multicolumn{1}{c|}{ Coabitação } & \multicolumn{1}{c}{ Ônus } & \multicolumn{1}{c}{ Adensamento } \\
\hline Norte & 303.261 & 352.661 & 121.893 & 45.687 \\
\hline Nordeste & 603.000 & 923.984 & 479.541 & 104.992 \\
\hline Sudeste & 175.238 & 1.165 .196 & 1067.265 & 266.729 \\
\hline Sul & 172.822 & 309.276 & 259.799 & 28.853 \\
\hline Centro-Oeste & 89.114 & 240.255 & 195.906 & 35.279 \\
\hline Brasil & 1.343 .435 & 2.991 .313 & 2.124 .409 & 481.53 \\
\hline
\end{tabular}

Fonte: Fundação João Pinheiro (2013)

Essa realidade pode ser constatada mais intensamente nas regiões Nordeste, Sudeste, Sul e Centro-Oeste, onde o número de domicílios precários é menos expressivo, mas o ônus excessivo com aluguel é alto. Os domicílios precários assumem a terceira posição do déficit habitacional total do país (19,4\%). Nas regiões Norte e Nordeste, os domicílios precários aparecem com maior percentual que nas demais regiões. Em suma, o adensamento excessivo de domicílios alugados e os domicílios precários são os menos expressivos do déficit, somando cerca de 1,8 milhões de unidades.

Por outro lado, um dado que merece destaque é a quantidade de domicílios vagos nas regiões brasileiras identificados na zona urbana ou rural, conforme 
revelado pela Tabela 3. A maioria desses imóveis se concentram em áreas centrais e, portanto, atendidas por infraestrutura e oferta de serviços urbanos. Conforme se observa, o Brasil tem 6,052 milhões de domicílios vagos. Esse valor se aproxima do déficit de 6,490 milhões de unidades. Essa aproximação dos dados nos leva a refletir se a ocupação desses domicílios vagos solucionaria o problema habitacional do país. No entanto, não foram localizados estudos que comprovem que a ocupação dos domicílios vagos poderia solucionar ou amenizar o problema do déficit habitacional.

Tabela 3 - Domicílios vagos

\begin{tabular}{l|l|l|l}
\hline \multicolumn{1}{c|}{ Região } & \multicolumn{1}{c|}{ Urbano } & \multicolumn{1}{c}{ Rural } & \multicolumn{1}{c}{ Total } \\
\hline Norte & 307.292 & 98.338 & 405.630 \\
\hline Nordeste & 1.216 .995 & 715.976 & 1.932 .971 \\
\hline Sudeste & 2.095 .381 & 352.784 & 2.448 .165 \\
\hline Sul & 654.354 & 157.141 & 811.495 \\
\hline Centro-Oeste & 382.956 & 70.944 & 453.900 \\
\hline Brasil & 4.656 .978 & 1.395 .183 & 6.052 .161 \\
\hline
\end{tabular}

Fonte: Fundação João Pinheiro (2013)

Apesar dos dados revelarem existir muitos domicílios vagos, sabe-se que é comum no Brasil a prática da especulação imobiliária e que, muitas vezes, os poderes públicos preferem assumir uma posição de neutralidade nas discussões sobre tais assuntos, pois esses imóveis, geralmente, pertencem a pessoas com alto poder aquisitivo.

Com relação ao déficit habitacional, o estado do Amazonas apresenta um dos maiores e piores resultados em nível nacional, conforme as pesquisas realizadas pela Fundação João Pinheiro (2013) e o Observatório das Metrópoles (2009). Calculou-se o déficit habitacional e a inadequação de domicílios de 5.561 municípios, conforme descrito anteriormente. Manaus está entre os cinco municípios brasileiros com maior déficit habitacional absoluto, com total de 105.587 mil unidades habitacionais, apenas atrás de São Paulo, Rio de Janeiro, Brasília e Salvador. Isso representa 22,9\% do déficit total relativo, ou seja, o maior déficit relativo do país (FUNDAÇÃO JOÃO PINHEIRO, 2013). Segundo os estudos do Observatório das Metrópoles (2009), Manaus apresenta os seguintes dados:

- 225.784 domicílios permanentes apresentam algum tipo de carência de infraestrutura, portanto são considerados inadequados para moradia;

- 104.371 domicílios apresentam serviço inadequado de abastecimento de água; 
- 167.311 domicílios apresentam problemas de esgotamento sanitário;

- 7.602 apresentam problemas para descartar seu lixo, pois inexiste coleta.

De acordo com o IBGE (2010), Manaus teve um crescimento populacional expressivo entre o período de 1991 a 2000. A população da cidade foi de 1 milhão de habitantes para 1,5 milhão. Tal crescimento populacional gerou diversas questões sociais, principalmente, na área da habitação.

Às inúmeras famílias, que não conseguiram ou não conseguem ter acesso à moradia digna, lhes restaram os espaços de florestas no entorno da cidade ou às margens dos igarapés, que foram gradativamente ocupados. Segundo Oliveira e Costa (2007), esses assentamentos precários em Manaus se formaram sem planejamento e muito rapidamente. Apenas depois de um longo período receberam infraestrutura necessária, fato que só aconteceu mediante muitas reivindicações dos moradores.

Esse processo continuou acontecendo por anos e, em 2002, por exemplo, consolidou-se em Manaus mais de 40 novos assentamentos precários que posteriormente se transformaram em bairros com infraestrutura precária. Alguns bairros que surgiram de assentamentos precários em Manaus foram os seguintes: Colônia Santo Antônio, Coroado, Compensa, Lírio do Vale, Mauazinho, Novo Israel, Santo Agostinho, Vila da Prata, Zumbi dos Palmares e parte do Tarumã (OLIVEIRA; COSTA, 2007). Alguns desses bairros são mais próximos do centro, possuem infraestrutura regular, aparelhos comunitários e são compostos por moradores de todas as classes sociais, enquanto outros, como Colônia Terra Nova, Monte das Oliveiras e Santa Etelvina, têm uma realidade bem diferente. Desse modo, os assentamentos e ocupações nas margens dos igarapés em Manaus surgiram como estratégias que as famílias pobres encontraram para ter acesso à moradia.

Em relação ao risco ambiental, as condições inadequadas de saneamento são consideradas de risco, quando comparado à proporção de domicílios nestas condições. Dentre as 39 áreas da cidade que foram estudadas pelo Observatório, nenhuma foi classificada como baixíssimo risco ou baixo risco ambiental, fato único entre todas as regiões metropolitanas estudadas. Apenas quatro áreas foram consideradas como de médio baixo risco ambiental: Japiim, Chapada, São Geraldo e Dom Pedro I. Outras 23 áreas foram classificadas nos dois grupos de maior risco ambiental, ou seja, são áreas onde mais de 60\% dos domicílios apresentam inadequação em termos das condições de saneamento. As piores situações são encontradas na Área de Expansão da Zona Rural, Jorge Teixeira, Colônia Terra Nova, Tarumã, Ponta Negra, Santa Etelvina, Monte das Oliveiras e Cidade Nova (OBSERVATÓRIO DAS METRÓPOLES, 2009). 
Em função da rápida ocupação desordenada em Manaus, há um grande número de famílias residindo em áreas inadequadas, como as margens dos igarapés e os barrancos. Segundo os dados de ocorrência do Sistema da Defesa Civil (2014), a Zona Leste da cidade apresenta o maior número de famílias residindo em área de risco e com intenso adensamento populacional (média de 6.870 hab. $\mathrm{km}^{2}$ ), além de frequentes ocorrências de fenômenos de movimentos de massa e inundações. As áreas territoriais são classificadas de acordo com os graus de risco: baixo (R1), médio (R2), alto (R3) e muito alto (R4). E somente no bairro Colônia Antônio Aleixo, foram identificadas 4.778 edificações em área de risco classificadas nos níveis R3 e R4. No mesmo local no período janeiro a julho de 2014, foram registrados sete alagações, seis desabamentos e quatro deslizamentos.

Fica evidente nos dados da Defesa Civil a ausência de condições mínimas de infraestrutura de saneamento básico por toda a cidade. Segundo o Observatório das Metrópoles (2009), quase todas as áreas de Manaus estão sujeitas a riscos ambientais decorrentes da falta de infraestrutura e de saneamento. Esse fato coloca a cidade em pior situação quanto à condição socioambiental, quando comparado a todas as outras metrópoles do país. Em suma, a capital amazonense enfrenta sérios problemas ligados às questões da habitação, que vão desde a falta de moradia para todos até os riscos decorrentes da localização das casas e da ineficiência do poder público para saná-los.

\section{CONCLUSÃO}

A HIS surgiu no Brasil como uma medida de intervenção do governo para sanar a questão social habitacional brasileira, tendo em vista ser deficiente a produção de habitações alcançáveis aos setores de baixa renda. Isso levou os vários governos a adotarem medidas e criarem políticas com o objetivo de resolver o problema habitacional. Nos anos 2000 em diante, diante dos déficits revelados pelas pesquisas e as inúmeras reivindicações dos movimentos populares, o governo Lula criou o PMCMV na tentativa de amenizar essa questão social. O governo Dilma, em sua campanha eleitoral, sinalizou mais de um milhão de moradias construídas para famílias de baixa renda através do PMCMV, no entanto, em uma rápida pesquisa constatou-se a construção de menos de 700.000 unidades. As mesmas promessas foram mantidas pelo governo Temer, mas também ainda se está longe de resolver a questão da habitação no Brasil.

Como vimos, tal movimento não foi decorrente apenas da boa vontade política, mas resultante da forte pressão de movimentos populares, que evidenciavam a insatisfação com a atuação do Estado na problemática, a qual afeta, 
sobretudo, as classes populares. Apesar da luta dos movimentos populares por habitação e ações governamentais, não se conseguiu sanar o déficit habitacional brasileiro através dos programas sociais. As estatísticas da fundação João Pinheiro demonstram evidências por todo país do quanto ainda se faz necessário investir na produção de habitações para as populações desfavorecidas. Entretanto, essas estatísticas não revelam a quantidade de assentamentos precários existentes no país, conforme a definição dada pelo Ministério das Cidades. Isto nos leva a questionar os dados oficiais e a examinar com maior profundidade o verdadeiro déficit habitacional do país, assim como a efetividade dos programas criados para favorecer a aquisição de moradias pela população de baixa renda.

No caso do Amazonas, a consolidação da ZFM trouxe perspectivas de melhoria de vida para o homem do interior e também para pessoas de outros estados do Norte que não desenvolveram uma economia de grande porte. Por isso, é comum ver em portos e rodoviárias da capital o desembarque diário de um grande número de pessoas advindas de outras regiões que chegam à capital amazonense em busca de melhores oportunidades. No entanto, o crescimento desordenado de Manaus e a falta de investimentos do poder público local resultaram na ocupação de bairros sem infraestrutura adequada e em zonas de risco. Assim, o problema não está só na falta da moradia digna, mas na falta de infraestrutura básica por toda a cidade, o que deixa a mesma no ranking das cidades que traduzem os maiores e piores números na área habitacional segundo Observatório das Metrópoles.

Os programas longe de solucionar o problema habitacional da cidade, ainda recebem inúmeras críticas das famílias beneficiarias. Por exemplo, o programa PROSAMIM, que apesar de ter melhorado o aspecto físico das margens dos igarapés próximos ao centro da cidade, para os moradores os apartamentos construídos são considerados pequenos, uma vez que as famílias em sua maioria são bastante numerosas. Em relação aos residenciais do "Viver Melhor", é comum ver nos noticiários locais denúncias referentes a problemas na obra dos apartamentos, à falta de segurança, transporte e serviços públicos próximos aos residenciais. Além do fato de todos os residenciais terem sido construídos em áreas de expansão distantes do centro da cidade. Desse modo, fica evidente que na fase de planejamento dos programas, os gestores e trabalhadores sociais não consideram o modo de vida das famílias e suas opiniões (FELIPPE, 2010).

Diante do exposto, conclui-se que Manaus, apesar de concentrar um dos polos industriais mais importantes do país e que gera bilhões de dólares, revela uma realidade complexa e contraditória com precários serviços de infraestrutura urbana, crescente ocupação em áreas de risco e intensas desigualdades espaciais. 


\section{REFERÊNCIAS}

AZEVEDO, S. Desafios da habitação popular no Brasil: políticas recentes e tendências. In: CARDOSO, L. A. (Org.) Habitação social nas metrópoles brasileiras: uma avaliação das políticas habitacionais em Belém, Belo Horizonte, Porto Alegre, Recife, Rio de Janeiro e São Paulo no final do século XX. Porto Alegre: ANTAC, 2007. p. 13-41 (Coleção Habitare)

BRASIL. Ministério das Cidades. Guia para o mapeamento e caracterização de assentamentos precários. Brasília, 2010. 82p.

Ministério das Cidades. O Estatuto da Cidade comentado. São Paulo: MC; Aliança das Cidades, 2010. 120p.

Ministério das Cidades. Política Nacional de Habitação. Brasília: 2004. (Cadernos MCidades, n. 4, 104p)

BONDUKI, N. G. Origens da habitação social no Brasil. Análise Social, v. 24, n. 127 , p. $711-732,1994$.

CABRAL, M. Habitação e questão social: análise do caso brasileiro. Scripta Nova. Revista electrónica de Geografía y Ciencias Sociales, Barcelona, v. 09, n. 194, p. 1-26, 2005.

DEFESA CIVIL DO AMAZONAS. Relatório sobre as áreas de risco da Colônia Antônio Aleixo. Manaus: DCA, 2014.

FELIPPE, Maíra Longhinotti. Casa: uma poética da terceira pele. Psicologia \& Sociedade, v. 22, n. 2, p. 299-308, 2010.

FERNANDES, N. N.; OLIVEIRA, A. C. T. Marechal Hermes e as (des) conhecidas origens da habitação social no Brasil: o paradoxo da vitrine nãovista. Scripta Nova. Revista Electrónica de Geografía y Ciencias Sociales, Barcelona, v. 14, n. 331, p. 1-17, 2010.

FUNDAÇÃO JOÃO PINHEIRO. Centro de Estatística e Informações. Déficit habitacional municipal no Brasil. Belo Horizonte: Centro de Estatísticas e Informações, 2013. 78p.

IANNI, O. Ditadura e agricultura: o desenvolvimento do capitalismo na Amazônia (1964-1978). 2. ed. Rio de Janeiro: Civilização Brasileira,1986.

IBGE - Instituto Brasileiro de Geografia e Estatística. SIS - Síntese de Indicadores Sociais. Brasília: IBGE, 2010. 
LARCHER, J. V. M. Diretrizes visando a melhoria de projetos e soluções construtivas na expansão de habitações de interesse social. 2005, 41f. Tese (Doutorado) - Universidade Federal do Paraná, Curitiba, 2005.

MARICATO, E. O estatuto da cidade periférica. In: CARVALHO, C. S.; ROSSBACH, A. (Orgs.). O Estatuto das cidades comentado. São Paulo: Ministério das cidades; Aliança das cidades, 2010. p.05-22.

Metrópole na periferia do capitalismo. São Paulo: Hucitec, 1996.

MOTTA, L. D. A questão da habitação no Brasil: políticas públicas, conflitos urbanos e o direito à cidade. 2010. Disponível em: < http:/ / conflitosambientaismg. lcc.ufmg.br/wp-content/uploads/2014/04/TAMC-MOTTA_Luana_-_A_ questao_da_habitacao_no_Brasil.pdf.>. Acesso em: 25 set. 2014.

OBSERVATÓRIO DAS METRÓPOLES. Vulnerabilidade socioambiental das regiões metropolitanas brasileiras. Rio de Janeiro: UFRJ, 2009.

OLIVEIRA, J. A.; COSTA, D. P. Conjuntos habitacionais e a expansão urbana de Manaus: Filigramas do processo de construção urbana e o papel das políticas habitacionais. Revista de Geografia da UFC, v. 06, n. 11, p. 1-13, 2007.

RANCIARO, M. M. M. A. Andirá: memórias do cotidiano e representações sociais. Manaus: EDUA, 2004.

SILVA, M. O. S. Política habitacional brasileira: frente e verso. São Paulo: Cortez, 1989.

VALLADARES, L. P. (Org.). Habitação em questão. 2. ed. Rio de Janeiro: Zahar, 1981. 196p. 


\section{Analysis of industry based on resources and institutions National Desazolves case}

\section{Análise da indústria com base em recursos e instituições caso de Desasufros Nacional}

José G. Vargas-Hernández- Research professor. Departament of Administration University center for Economic and Managerial Sciences. University of Guadalajara. E-mail: jvargas2006@gmail.com

Gabriela Sarabi González González - Maestría en Negocios y Estudios Económicos. Centro Universitario de Ciencias Económico Administrativas. Universidad de Guadalajara. E-mail: gabi.gonzalez.gonzalez2@gmail.com

\begin{abstract}
This work aims to identify the elements necessary for the operation of enterprises engaged in waste management, especially in the company called Desazolves Nacionales; as well as the importance of formal institutions to arrive to conduct their activities legally without polluting the environment. an analysis of the industry and the resources with which account, in order to take advantage of the best way to strengthen the company looking to create jobs always looking for social responsibility is made.
\end{abstract}

\section{Resumo}

Este trabalho tem como objetivo identificar os elementos necessários para o funcionamento de empresas de gestão de resíduos, especialmente na empresa chamada Desazolves nacionais; bem como a importância das instituições formais para chegar a conduzir as suas actividades legalmente sem poluir o meio ambiente. Uma análise da indústria e dos recursos com os quais conta, a fim de aproveitar a melhor maneira de fortalecer a empresa que pretende criar empregos sempre à procura de responsabilidade social é feita.

\section{Keywords}

Strategy. Institutions. Industry. SMEs. Resources.

\section{Palavras-chave}

Estratégia. Instituições. Indústria. PME. Recursos. 


\section{INTRODUCTION}

The aim of the research is to determine how resources, industry and institutions affect the operation of the National Desazolves Company, located in the State of Jalisco. First, we talk about the background it has about pollution, the importance of MSMEs and what companies defined sector of waste management. After the problem is delimited on the question how do institutions affect industry and resources for company operation within the State of Jalisco? A review of the theoretical and empirical literature on the theories studied is made. It is contextualized about where the company was born, the services performed are mentioned; the methodology to be used, the analysis of the results, and finally, are given the conclusions and recommendations on the research.

\section{BACKGROUND OF THE PROBLEM}

Companies are defined as an economic unit of production and decisions by organizing and coordinating a series of productive factors, such as labor and capital, aims to make a profit either producing and selling products or providing services in market (Andersen, 1999). The importance of small and medium (MSMEs) economics units in the global economic context is a well proven fact, not only because they represent $95 \%$ of all enterprises in most countries of the Organization for Economic Cooperation and Development (OECD), but also because they generate a high volume of employment, which exceeds more than half of private sector employment (OECD, 2000).

Latin American countries generally rank companies according to various parameters such as employees, investment in fixed assets and / or sales. In Mexico, these businesses contribute about 64\% of the total gross production, but employ only 2 out of 10 jobs, according to the National Institute of Statistics and Geography (INEGI, 2015); the growing importance of MSMEs especially in developing countries is due to their contribution to the employment and economic welfare; integrated into the enterprise, as part of the value chain, contribute to the diversification of the economy (Agyapong, 2010).

In Mexico, major obstacles and problems related to starting a business, among them are liquidity, the delegation of power, leadership of managers, finance and business continuity which can potentially cause failure of MSMEs during the first years of life (Castro, 2006). Companies dedicated to waste management and remediation services are those economic units that are dedicated to the collection, treatment and disposal of waste material both hazardous and non- 
hazardous waste; the operation of facilities for recovery of material; remediation and rehabilitation of contaminated sites; rental of portable toilets, and cleaning septic tanks (INEGI, 2015).

The importance of these companies is that according to the World Health Organization (WHO, 2014) reported that in 2012 about 7 million people died as a result of exposure to pollution because it is the health environmental risk the world's most important. If it is taken into account that has a rapid urbanization, cities face a growing demand for water and sanitation services for both households and industries.

The United Nations (ONU, 2010) mentions that they have the necessary knowledge, experience and technology to combat pollution and waste management, but it is essential to include these issues on national, regional and international agendas requiring coordination between sectors and between different local authorities and governance changes that lead to a more sustainable and equitable use of urban water resources.

\section{DEFINING THE PROBLEM AND RESEARCH QUESTION}

In 2015 the INEGI reported that the habits of consumption of natural resources and environmental degradation came close to generating 5.7\% environmental costs of gross domestic product (GDP). Mention that the amount of public sector expenditures for environmental protection was about 149 billion pesos which represented about $1.0 \%$ of GDP. In contrast, total costs consist of depletion and environmental degradation they approached the 910 billion pesos, which gave an environmental deficit of 761 billion pesos.

Companies dedicated to service waste management and waste and remediation services are vital, both in Mexico and in the State of Jalisco, as they help to fight pollution seeking to balance the effects that have in the process of industrial, agricultural and domestic activities. So, this research attempts to answer how do institutions affect industry and company resources for operation within the State of Jalisco?

\section{REVIEW OF THE THEORETICAL AND EMPIRICAL LITERATURE}

a) Theory of resources

Wernerfelt (1984) defines resources as the assets, both tangible and intangible, that are linked to the company semi-permanently as brands, own 
technological knowledge, the use of personal skills, business contacts, efficient procedures, the capital, etc. Business enterprise is defined as an administrative organization and a collection of productive resources. The overall purpose of the business enterprise is to organize the use of their "own" resources, along with other resources acquired from outside the company for the production and sale of goods and services at a profit (Mahoney, 2012); Penrose also argues that own resources are never entering the production process, but only the services that the resource can perform.

The resources lie in a set of potential services defined regardless of use, while services cannot be so defined, the service involves a function or activity; It is largely in this distinction that can be found the source of the uniqueness of each individual company. The company can be seen as a collection of productive resources where the choice of the different uses of these resources over time is determined by administrative decision. Physical resources of a company consist of material things as facilities, equipment, land and natural resources, raw materials, intermediate products, waste products and byproducts, and even stocks of finished unsold products. There are also intangible resources available in a company like unskilled and skilled, clerical, administrative, financial, legal, technical and management personnel work.

b) Industry-based theory

The industry-based theory can be defined as a group of firms producing similar goods or services together (Peng, 2012). A popular and effective in reviewing the performance of the industrial environment, the model is based on Porter's five forces (Daft, 2010) strategy.

\section{1) The threat of new competitors}

In a sector can create pressure for the establishment of organizations, which might need to hold down prices or increase their level of investment, the entry of new competitors. Also it depends largely on the amount and extent of possible obstacles, as is the cost (Daft, 2010).

\section{2) The bargaining power of suppliers}

It refers to the ability they have to raise prices and / or reduce the amount of goods and services; if the supplier industry is dominated by a few firms they may have the advantage when negotiating (Peng, 2012). 


\section{3) The bargaining power of buyers}

It can influence when having a small number of buyers leading to a strong bargaining power. They can force down prices, demand better quality or service, and increase costs for provider organization (Daft, 2010).

\section{4) The rivalry between competitors}

It refers to the intensity that has the competence. To study this area must be known if it has many competitors or are balanced, slow growth of the industry, which are storage costs and fixed costs, which is the differentiation or cost to change, the bet to the strategy and barriers to exit (Peng, 2012).

\section{5) The threat of substitute products}

It is known as the power of alternative or substitute for the services or products of the company that may be affected in costs, new technology, social trends that they affect the customer loyalty as well as other changes environmental (Daft, 2010).

Porter added in 1990 to related industries and support as affecting the competitiveness of the industry, some call them complementary defined as that firm which sells products that add value to products of the industry focal (Peng, 2012).

c) Theory of institutions

Institutions can be defined as humanly planned constraints that structure human interaction; the institutional framework is made of both formal and informal organizations that seek to govern individual behavior and of the firm. Formal institutions are those that include laws, regulations and rules, as the regulatory and coercive pillar of governments. Informal institutions include norms, culture and ethics; It gives support with training pillar referred as values, beliefs and actions of other relevant players that have influence on the behavior of individuals or focal firms; They are also supported by the cognitive pillar referring to the values and inner beliefs that assume and which also guide the behavior of individuals and firms (Peng, 2012).

The interactions between institutions and companies that reduce transaction costs are those that give way to economic activity, as institutions are not static so they are adapting and changing as will be necessary for this 
purpose require transitions institutions defined by Peng (2012) as those great and fundamental changes that are introduced to both formal and informal rules of the game that affect organizations as players spread around the world, but especially in emerging economies.

\section{CONTEXTUAL FRAMEWORK}

The state of Jalisco has an area of 80.137 square kilometers, is located in western Mexico which borders the states of Nayarit, Zacatecas, Aguascalientes, Guanajuato, San Luis Potosi, Michoacán and Colima. In addition, a considerable portion of its territory is bordering the Pacific Ocean. Jalisco's capital is Guadalajara, but today is a great metropolis, together with the municipalities of Zapopan, San Pedro Tlaquepaque, Tonalá, Tlajomulco de Zuniga, El Salto, Ixtlahuacán de los Membrillos and Juanacatlán which integrate a large conglomerate that makes Guadalajara Metropolitan Area is the most important in Mexico.

The company called National Desazolves is a micro company that has 5 years of life. It is located in the city of Zapopan, Jalisco primarily serving the metropolitan area of the state and nearby municipalities. This company has a wide range of services offered by builders and land developers, maquiladoras and food industries, shopping malls, city halls and state secretaries, as well as dwellings; between commercial activities carried out they can be listed as follows:

a) Silt removal of septic tanks, sumps absorption wells, storm drains.

b) Suction heavy mud.

c) Uncover commercial and industrial drains.

d) Preventive survey pipes.

e) Video robotized inspection.

f) Income vactor trucks and vacuum to industries and fractionators.

g) Rent of portable toilets.

h) Service hookah

\section{RESEARCH METHODS}

For this work a descriptive research on how institutions come to influence the operation of these businesses is used in the study of the case of National Desazolves for how both formal and informal institutions and industry influence the operation of these companies in the State of Jalisco, in addition to the resources that accounts. 


\section{ANALYSIS OF RESULTS}

The company has financial resources; human, organizational, physical and technological capital reputation and innovation (see Table. 1).

Table 1. Physical and intangible resources

\begin{tabular}{|c|c|}
\hline Type of resources & Resources with which accounts \\
\hline Financial & $\begin{array}{l}\text { Has a good financial situation with bank accounts. Uses bank } \\
\text { loans for investment in technological equipment. }\end{array}$ \\
\hline Human capital & $\begin{array}{l}\text { Director and operational staff are considered intangible } \\
\text { resources because of the knowledge they have to perform } \\
\text { activities. The operating staff is demonstrating good execution } \\
\text { on tasks. They do not hire employees without experience in the } \\
\text { field to avoid training time. }\end{array}$ \\
\hline $\begin{array}{l}\text { Organizational } \\
\text { architecture }\end{array}$ & $\begin{array}{l}\text { The main partnership with suppliers is the shop that repairs and } \\
\text { checks the computer constantly to not incur on higher expenses } \\
\text { in addition to make repairs quickly. }\end{array}$ \\
\hline Organizational & $\begin{array}{l}\text { There is no formal organizational structure; however, operators } \\
\text { know who to report the results of services, and technical } \\
\text { problems. }\end{array}$ \\
\hline Physical & $\begin{array}{l}\text { The geographical area where is located help and support making } \\
\text { faster tasks, the proximity of offices and the pension with } \\
\text { Treatment Plant White River Río Blanco allows the company to } \\
\text { discharge early without investing too much time. }\end{array}$ \\
\hline Technology & $\begin{array}{l}\text { Its vehicle fleet is broad for the various services it offers, besides } \\
\text { its own. Plans to renovate the team are giving according to the } \\
\text { needs that are on the market. }\end{array}$ \\
\hline Innovation & $\begin{array}{l}\text { Innovation of tangible resources is not currently performed due } \\
\text { to the degree of investment involved. On the side of intangible } \\
\text { resources, the application is very low because the technical } \\
\text { knowledge gained through some training invested in the search } \\
\text { for troubleshooting technical-operational nature. }\end{array}$ \\
\hline Reputation & $\begin{array}{l}\text { The company has a good reputation in the market that works } \\
\text { through human capital that has; It is working on positioning } \\
\text { a brand image and status in the market because it is a newly } \\
\text { established company. }\end{array}$ \\
\hline
\end{tabular}

Source: Own elaboration.

Most of the resources are physical and human capital; innovation in technology is almost nil because the equipment needed to perform the services is imported from the United States, as manufacturers are located in that country and try to imitate manufacturing equipment investment of both money is needed 
as strong capital for a company like this micro or small size is difficult to achieve, so the bargaining power of technology providers is high.

Formal institutions have broad power over these businesses, first, recourse to the Constitution of the United Mexican States, in Article 4 is established as an individual guarantee and fundamental right of everyone, enjoying an environment suitable for development and welfare thus determining the State's obligation and the powers that make it, to create the mechanisms and legal instruments that lead to the guarantee. For National Desazolves can operate needs to comply with the Regulations of the Law on Waste Management of the State of Jalisco, where the requirements that must be met before the Ministry of Roads and Transport, Ministry of Environment and Territorial Development mentioned, Intermunicipal Water system and Sewerage (see Table. 2).

Table 2. Institutions

\begin{tabular}{|c|c|c|}
\hline Institution & Granting permit & Time it takes \\
\hline $\begin{array}{lll}\text { Secretary of } & \text { Roads and } \\
\text { Transport Jalisco State } \\
\text { (Secretaria de } & \text { Vialidad y } \\
\text { Transporte del Estado de } \\
\text { Jalisco) }\end{array}$ & $\begin{array}{l}\text { Permit to allow circulation of } \\
\text { transporting waste collection } \\
\text { services special driving. }\end{array}$ & $\begin{array}{l}\text { The resolution of the } \\
\text { permit is } 15 \text { business } \\
\text { days. }\end{array}$ \\
\hline $\begin{array}{l}\text { Secretary of Environment } \\
\text { and Territorial Development } \\
\text { (SEMADET) (Secretaria de } \\
\text { Medio Ambiente y Desarrollo } \\
\text { Territorial (SEMADET)) }\end{array}$ & $\begin{array}{l}\text { Environmental License } \\
\text { for the State of Jalisco } \\
\text { and Municipalities, for the } \\
\text { collection. }\end{array}$ & $\begin{array}{l}\text { Resolution permit are } \\
45 \text { working days. }\end{array}$ \\
\hline $\begin{array}{l}\text { Intermunicipal Water System } \\
\text { and Sewerage (SIAPA) } \\
\text { (Sistema Intermunicipal de } \\
\text { Agua Potable y Alcantarillado } \\
\text { (SIAPA)) }\end{array}$ & $\begin{array}{l}\text { Permission to download non- } \\
\text { hazardous waste treatment } \\
\text { plant. }\end{array}$ & $\begin{array}{l}\text { The resolution of the } \\
\text { permit is } 3 \text { months. }\end{array}$ \\
\hline
\end{tabular}

Source: Own elaboration

Informal institutions that are present in the company are the values of teamwork, respect, care and protection of the environment; it is committed to do the job that customers want in a timely manner agreed. It should always speak the truth to consumers when they cannot perform the activity to lie and not be able to maintain the customer loyalty. Actions are being implemented to create a culture of accountability and timeliness employees. Diamond analysis of Porter manages to define what the importance of the industry is and as what happens around them influences the decisions to be taken (See table 3, below). 


\section{CONCLUSIONS AND RECOMMENDATIONS}

After analyzing the results, it can be concluded that it is necessary to have the equipment and qualified personnel. This is decisive for the company to operate efficiently and effectively, so if it is missed one of them, is missing the services provided would be deficient. The lack of experience of the operators may lead them to incur expenses for repair of equipment if it is damaged. The investment needed to a company of this type is about 1.5 million pesos and approximately 6 months that takes for granted the permits.

Table 3. Porter's Diamond analysis

\begin{tabular}{l|l|l}
\hline Force & Conditions & Actions to combat \\
\hline Threat of new entrants & High entry barriers & Are not necessary \\
\hline $\begin{array}{l}\text { Rivalry between } \\
\text { competitors. }\end{array}$ & $\begin{array}{l}\text { Differentiation in price and } \\
\text { quality of service. }\end{array}$ & $\begin{array}{l}\text { Improve services, advertising } \\
\text { and price and cost } \\
\text { improvement. }\end{array}$ \\
\hline $\begin{array}{l}\text { Threat of substitute } \\
\text { products }\end{array}$ & $\begin{array}{l}\text { Are practically nonexistent } \\
\text { for cleaning tanks, treatment } \\
\text { plants The survey of } \\
\text { housing can be performed } \\
\text { by plumber's drainage. }\end{array}$ & $\begin{array}{l}\text { They are not necessary, since } \\
\text { the cost for homes is high } \\
\text { compared to that accorded } \\
\text { the plumber. }\end{array}$ \\
\hline $\begin{array}{l}\text { Bargaining power of } \\
\text { customers }\end{array}$ & $\begin{array}{l}\text { Customers decide based } \\
\text { on price, quality and } \\
\text { implementation time of } \\
\text { services. }\end{array}$ & $\begin{array}{l}\text { Training in continuous } \\
\text { improvement. }\end{array}$ \\
\hline $\begin{array}{l}\text { Bargaining power of } \\
\text { suppliers }\end{array}$ & $\begin{array}{l}\text { Technology providers have } \\
\text { great bargaining power; } \\
\text { which they provide the } \\
\text { supplies have very little } \\
\text { bargaining power. }\end{array}$ & They are not necessary. \\
\hline
\end{tabular}

Source: Own elaboration.

Being a service that cannot be considered as a valuable, rare or difficult to imitate resource, companies seek to excel in competition based on giving a lower price and better quality service. National Desazolves intends to position itself as a separate company on quality, best performing services each time they are performed so that continuous improvement works to correct errors that have. Must work in positioning the brand to achieve to have a large market and become a larger, benefiting the community with better jobs and especially helping to fight pollution that occurs in the region on water resources. 


\section{REFERENCES}

AGYAPONG, D. Micro, small and medium enterprises' activities, income level and poverty reduction in Ghana - A synthesis of related literature. International Journal of Business and Management, 5(12):196. 2010.

ANDERSEN, A. Diccionario de economia y negocios. Madrid: Espasa Calpe, 1999.

CASTRO, A. M. PyME's Financiamiento, inversión y administración de riesgos (Vol. 2a.). México D.F., México: Sistemas de información contable y administrativa computarizados S.A. de C.V, 2006.

CONSTITUCIÓN POLÍTICA DE LOS ESTADOS UNIDOS MEXICANOS. México: Câmara de Senadores, 2015.

DAFT, R. L. Understanting the theory and design of organizations. Mason, Ohio. South - Western, Cengage Learning, 2010.

DESAZOLVES NACIONALES. Disponível em: < desazolvesnacionales.com>. Acesso em: 04 Mayo 2016.

INEGI. Censo Económico 2014. Instituto Nacional de Estadística Geografía e Informática INEGI, 2015.

MAHONEY, J. Economic Foundations of Strategy. Thousand Oaks, CA: Sage, 2012.

OCDE. OECD Small and Medium-Sized Enterprises: Local Strength, Global Reach, Organization for Economic Cooperation and Development. Disponível em: <www.oecd.org>, Acesso em: 04 Mayo 2016.

ONU, Agua y Ciudades, Hechos y Cifras. Organización de las Naciones Unidas, 2010 . Disponível em:<www.un.org> . Acesso em: 10 Mayo 2016.

OMS. 7 millones de muertes cada año debidas a la contaminación atmosférica. 25 marzo, 2014. Disponível em: <www.who.int>. Acesso em: 04 Mayo 2016.

PENG, M. W. Global Strategy. Cincinnati: Thomson South-Western, 2012.

REGLAMENTO DE LA LEY DE GESTIÓN INTEGRAL DE LOS RESIDUOS DEL ESTADO DE JALISCO EN MATERIA DE RECOLECCIÓN Y TRANSPORTE DE RESIDUOS DE MANEJO ESPECIAL. México: Cámara de Diputados, 2011.

WERNERFELT, B. A resource-based view of the firm. Strategic Management Journal, Vol. 5, p. 171-180, Apr. - Jun. 1984. 


\section{Comunidades negras no Ceará: da invisibilidade à formação dos quilombos contemporâneos}

\section{Black communities in Ceará: from invisibility to the formation of contemporary quilombos}

Leilane Oliveira Chaves - Mestre em Desenvolvimento e Meio Ambiente - Doutoranda bolsista Capes do Programa de Pós-graduação em Desenvolvimento e Meio Ambiente da Universidade Federal do Ceará. E-mail: leilane_chaves@hotmail.com

Edson Vicente da Silva - Doutor em Geografia - Professor Titular do Departamento de Geografia da Universidade Federal do Ceará. E-mail: cacauceara@gmail.com

\section{Resumo}

As comunidades quilombolas obtiveram maior visibilidade face às reivindicações de diversos segmentos sociais e principalmente do envolvimento dos quilombolas pelo direito de se autodefinirem. Esses grupos formaram-se a partir do século XVI, como forma de resistência às condições de vida e de trabalho. No presente, compreendem diferentes contextos de posse de terras por populações predominantemente negras ou de seus descendentes no país. Desta forma, buscase analisar o discurso da invisibilidade da presença negra no estado do Ceará frente ao reconhecimento de comunidades quilombolas contemporâneas. A pesquisa efetivada ancorou-se em levantamentos bibliográficos, conhecimentos empíricos, censos populacionais e instrumentos legais reunindo considerações sobre os principais conflitos que permeiam a autodefinição desses grupos. Acredita-se que o trabalho é uma importante contribuição para a visibilidade do movimento quilombola cearense.

\section{Palavras-chave}

Comunidades Quilombolas. Ceará. Invisibilidade Social. Conflitos Sociais.

\begin{abstract}
The quilombo communities have gained greater visibility in face of the claims of diverse social segments and especially the involvement of quilombolas for the right of self define. These groups were formed from the sixteenth century as a form of resistance to living and working conditions. At present, they comprise different land tenure contexts by predominantly black populations or their descendants in the country. Thus, it is sought to analyze the discourse of the invisibility of the black presence in the State of Ceará in face of the recognition of contemporary quilombo communities. The research was carried out based on bibliographic surveys, empirical knowledge, population census and legal instruments, thus gathering considerations about the main conflicts that permeate the self definition of these groups. it is believed that this work is an important contribution to the visibility of Cearás quilombo movement.
\end{abstract}

\section{Keywords}

Quilombo Comunities. Ceará. Social

Invisibility. Social Conflicts. 


\section{INTRODUÇÃO}

As comunidades quilombolas contemporâneas, a partir da mobilização de diferentes setores da sociedade inauguram um novo contexto nacional, saindo da invisibilidade em direção ao reconhecimento proporcionando a garantia de direitos legais das terras tradicionalmente ocupadas permitindo a manutenção de suas formas de vida. Com a visibilidade desses grupos criou-se uma nova demanda social, a regularização dos territórios quilombolas acirrando discussões e acarretando na inserção de novos elementos de análise territorial, como o uso dos recursos naturais para a subsistência desses grupos e melhorias nas condições de saúde, educação, trabalho, dentre outros serviços e direitos para a população quilombola.

No Brasil, já foram identificadas cerca de 2 mil comunidades quilombolas rurais, urbanas e periurbanas em diversas regiões. No estado do Ceará, em decorrência da afirmação da inexistência do negro ainda no período colonial, esses grupos, também denominados de comunidades negras rurais, até recentemente encontravam-se no anonimato. Com o passar dos anos e em virtude do posicionamento do movimento negro cearense, das comunidades negras e da sociedade civil, possibilitou-se a inserção de novos elementos na historiografia cearense, destacando a importância desses grupos na formação da identidade local.

Os procedimentos de titulação desses territórios é um dos maiores elementos geradores de discussões. No estado do Ceará, não é diferente, pois esta é uma questão presente em todos os territórios do Brasil. Outro tema que merece atenção, e que tem dificultado a autodefinição desses grupos, é a compreensão da presença das comunidades quilombolas na atualidade, não só por parte da sociedade civil, mas por instituições públicas municipais e estaduais. Na ausência desse entendimento, o que se observa, é a omissão de direitos, casos crescentes de violência, por meio de ameaças de morte e desestruturação das lideranças, comprometendo a permanência nos espaços coletivos tradicionalmente utilizados pelas populações locais.

Outro elemento que tem sido motivador de interesses divergentes é a garantia quanto ao uso dos recursos naturais, estes são limitados tanto pelos grileiros que afirmam deter os títulos da terra, como pelo poder público por meio da legislação ambiental. Muitas práticas utilizadas cotidianamente por essas comunidades têm sido consideradas ilegais, como o extrativismo vegetal com a retirada da madeira, empreendida na construção das residências e de benfeitorias nas propriedades. 
Para Almeida (2004), as terras ocupadas pelas comunidades quilombolas cumprem importante função social, pois por meio da organização comunitária esses grupos gerenciam os recursos naturais, garantindo a sua reprodução biológica e cultural. A posse coletiva favorece a família, a comunidade e a própria configuração étnica como um todo.

Nessa perspectiva, pretende-se com o presente artigo realizar uma análise e reflexão sobre o período de invisibilidade negra e seu posterior afloramento na concepção dos novos quilombos. Serão destacados os conflitos territoriais presentes nas comunidades quilombolas cearenses, envolvendo diferentes atores e interesses na apropriação e uso dos recursos naturais.

Essa reflexão baseia-se em levantamentos bibliográficos, em análise empírica e em discussões que norteiam os instrumentos legais que garantem o direito desses grupos. Assim, reuniram-se considerações amplas, mas que substanciassem os principais conflitos que permeiam a garantia dos direitos das comunidades quilombolas no estado, aprofundando a investigação no que diz respeito ao papel dos africanos escravizados na formação da sociedade cearense, a invisibilidade dos negros na historiografia local e a formação de quilombos contemporâneos.

\section{CENÁRIO ATUAL DAS COMUNIDADES QUILOMBOLAS NO BRASIL}

Assim como os índios, os africanos não aceitaram passivamente o trabalho escravo, existindo cotidianamente diversas formas de resistência, tanto individual como coletiva. "Fugindo o escravo demonstrava sua fibra rebelde, o calor de sua revolta, indiferente aos impiedosos castigos a que seria submetido quando capturado: açoites, tronco, ferro em brasa, colares de ferro, e até amputação se reincidente [...]" (GOULART, 1972, p. 28).

Algumas fugas resultaram na formação de comunidades independentes, que mais tarde receberam o nome de quilombos. Esses grupos existiram desde a época colonial até os últimos anos do sistema escravista. Moura (1981) assinala que os quilombos eram considerados um fenômeno não circunscrito a uma região específica, mas que pontilharam diversas partes do território brasileiro. A historiografia nacional relata que estes obtiveram diferentes tipos de formação, há quilombos com resistência à escravidão, há quilombos criados com a compra da terra pelos negros, há quilombos instituídos por negros livres desde a ocupação das terras pós-abolição. 
Na primeira metade do século XIX após a formulação de leis e tratados entre Portugal e Inglaterra sobre o fim do tráfico negreiro, surge a figura do africano livre. Considerado livre, porém não emancipado. Muitos escravos continuaram sendo tratados como cativos e suas condições de trabalho, moradia e alimentação se assemelhavam aos vividos no período da escravidão. O Brasil foi uma das últimas nações americana a acabar com a escravidão, entretanto esse regime de trabalho vigorou em território nacional por mais de 300 anos, haja vista que, o sistema econômico vigente durante os períodos colonial e imperial tinham como base a mão de obra escrava (FIABANI, 2008).

Muitos africanos e seus descendentes, mesmo após a abolição, preferiram continuar residindo nas comunidades de negros rurais, constituídas ainda no Período Colonial. Outros continuaram nas fazendas na condição de parceiros na produção agrícola. Ainda existiam aqueles antigos cativos que receberam terrenos de seus senhores mediante doações ou compras de pequenos lotes. Muitas dessas áreas, como ressalta Fiabani (2008), tornaram-se referência para aglomeração dos escravos livres. Na maioria das vezes, a terra era de uso coletivo, dificultando a divisão da propriedade e contribuindo para a permanência desses grupos de forma coletiva.

Graças à sua organização, os quilombos estabeleceram alianças não só com outros fugitivos, mas também com grupos indígenas, pequenos agricultores e comerciantes que contribuíam para a comercialização dos produtos agrícolas e para a manutenção desses grupos até a contemporaneidade (MATTOS, 2007).

Após o ato abolicionista, os quilombos juridicamente deixaram de existir, e até pensou-se que, com o fim da escravidão, estes grupos haviam sido diluídos socialmente. Uma vez que este segmento social não despertou interesse nem de pesquisadores e autoridades de épocas passadas, ficou invisível por um longo período. Nas décadas de 1970 e 1980, timidamente, se iniciaram os primeiros estudos acadêmicos, identificando a existência desses grupos, mas foi após a Constituição de 1988 que adquiriram uma visão pública da sua realidade nacional, desvendandose as reais condições das comunidades negras rurais (FIABANI, 2008).

Assim, com a promulgação da Constituição Federal em 1988, cujo artigo 68 do Ato das Disposições Constitucionais Transitórias (ADCT), prevê o reconhecimento da propriedade das terras aos "remanescentes das comunidades de quilombos", o debate ganha o cenário político nacional, resultando em publicações das mais diversas.

Esse reconhecimento é fortalecido com a consolidação das questões normativas nacionais, garantindo não só a titulação das terras tradicionalmente ocupadas, mas, principalmente, o direito de se identificar como pertencente a 
esse grupo. Na visão de Almeida (2004), a incorporação dessas reivindicações na legislação e nos aparatos burocráticos administrativos não significou um acatamento das suas solicitações e tão pouco na resolução dos conflitos em torno da apropriação e do uso dos recursos naturais.

$\mathrm{Na}$ atualidade esses territórios ainda são considerados espaços de interesses divergentes, implicando na coação e benefícios de outros atores sociais, comprometendo a base de sustento desses grupos, a julgar que a garantia da terra é um elemento fundamental para a manutenção das condições de vida dessas populações. Essas comunidades desenvolveram práticas de convivência com os diferentes ambientes naturais, contribuindo para manutenção da biodiversidade (INCRA, 2012).

Segundo dados do Instituto de Colonização e Reforma Agrária (INCRA), em conjunto com a Fundação Cultural Palmares (FCP) e a Secretária de Políticas de Promoção da Igualdade Racial (SEPPIR), no Brasil, somam-se mais de 3.500 comunidades quilombolas identificadas, destas, 1.200 já receberam a certidão de identificação junto à FCP e emitiram-se 154 títulos em 127 territórios, beneficiando 13.145 famílias distribuídas em diferentes estados da federação (INCRA, 2012).

No presente, infelizmente, quando transferidos para o processo de titulação, esses dados decaem vertiginosamente. A região Norte apresenta os maiores índices de territórios titulados, com 59 títulos, seguidas das regiões Nordeste com 49, Sudeste 10, Centro-Oeste 6 e Sul com 3 títulos. Dentre os estados da federação, o Pará se destaca com 55 títulos, seguidos pelo Maranhão com 33, São Paulo 6 e Bahia e Piauí, com 5 territórios cada. Esses números anualmente passam por modificações à medida que esses grupos se autoidentificam, como assegura o Decreto 4.887/03 (BRASIL, 2003).

A região Nordeste, há 49 territórios titulados, beneficiando 5.123 famílias, com destaque para o Maranhão com 2.173 e Bahia com 1.012 famílias beneficiadas. O estado do Ceará, foco do presente artigo, é composto por 184 municípios, dos quais 33 já identificaram em seu perímetro territorial a existência de comunidades quilombolas, desde 2004.

Nos últimos anos essas comunidades adquiriram maior visibilidade junto ao poder público e à sociedade civil, por intermédio da realização de inventários e de mapeamentos. Esses levantamentos vêm sendo realizados por meio de parceria das comunidades com a Comissão Estadual de Comunidades Negras Rurais do Ceará (CEQUIRCE). Essa interação possibilitou uma maior notoriedade desses grupos junto à sociedade civil, principalmente em decorrência do cenário étnicoracial do Ceará que sempre negou a presença do negro em seu território. 
É importante evidenciar, que há hoje, um novo cenário no estado do Ceará, principalmente em decorrência da tentativa de promover a desmistificação do mito da hegemonia de uma sociedade formada exclusivamente por uma população branca. Assim, almeja-se transpor o bloqueio da invisibilidade do negro no estado, para assumir garantia dos direitos dos quilombolas conquistados ao longo dos últimos vinte anos.

\section{A PRESENÇA NEGRA NO CEARÁ}

Conflitos sociais no campo não representou exclusividade de nossos tempos, mas sim uma marca do desenvolvimento e do processo de ocupação do campo no país; os grupos indígenas foram os primeiros a conhecer a avidez de terra por parte dos colonizadores. Simultaneamente à luta dos indígenas, nasceu a

peleja dos negros escravizados contra as formas de trabalho empreendidas pelos portugueses (OLIVEIRA, 1989).

A origem do elemento servil negro no Ceará surge da consolidação da ocupação da capitania, acentuando-se quando esta se torna autônoma da capitania de Pernambuco, estando livre para poder comercializar diretamente com a Metrópole (PINHEIRO, 2004). A ocupação das terras cearenses deu-se com suas fronteiras sendo rompidas pelo gado, diferenciando-se do processo ocorrido em outras áreas do Nordeste açucareiro. Caracterizado por um processo mais lento e com pouca mão-de-obra negra escravizada, contando desde o início com a força de trabalho do nativo (FUNES, 2004).

Funes (2004) esclarece que a ocupação foi se efetivando inicialmente como espaço de trabalho, atraindo um contingente de homens livres, negros e pardos, em sua maioria pobres que se deslocavam das províncias vizinhas para desempenhar atividades de vaqueiros, agricultores ou como moradores e agregados das fazendas. No segundo momento, com a crescente produção da lavoura algodoeira, ainda no século XVIII, acentuou-se uma demanda por mãode-obra, tanto livre como negra escravizada.

Neste período a quantidade de negros e pardos cativos era bastante expressiva, tendo nas vilas de Sobral (2.978), S. João Príncipe (1.856), Campo Maior (1.270) e Icó (1.507), as maiores representatividades. Mesmo com altos índices para a região, se comparada a outras localidades, a capitania do Ceará mostrou pouca expressão em quantidade de africanos, haja vista que as atividades desenvolvidas, como a pecuária e a agricultura de subsistência não demandavam um número expressivo de mão-de-obra escrava de origem africana, o que não significava a inexistência de tais grupos, como durante muito tempo foi considerado. 
Sousa (2008) manifesta a ideia de que a origem desse mito está ligada diretamente à historiografia tradicional cearense, tendo no Instituto Histórico, Geográfico e Antropológico do Ceará o seu principal legitimador. As formas como essas ideias se tornaram hegemônicas na sociedade cearense pautase na credibilidade que a instituição adquiriu naquele período. Esta era a mais importante fonte para a pesquisa histórica local, tornando-se ao longo dos anos uma referência como centro de informação histórica e geográfica. Os membros do Instituto do Ceará, ao dissertarem sobre o pioneirismo cearense no processo da abolição, enfatizaram a escala reduzida e sem grandes influências socioculturais dos africanos e seus descendentes na sociedade cearense.

Entretanto, é importante evidenciar que, assim como em outras capitanias, a mão-de-obra escrava, mesmo em quantidade inferior às existentes em outras capitanias, fez-se presente em todo o campo de trabalho, tanto no espaço rural como no urbano. Sua força de trabalho era utilizada na pecuária, na agricultura, em serviços domésticos especializados e ainda como escravos de aluguel ou de ganho.

Em termos culturais, as manifestações dos negros foram sistematicamente combatidas. Sousa (2008) esclarece que, na visão das autoridades e da sociedade de uma forma geral, essas lembranças faziam do negro uma ameaça permanente à ordem, proibindo cotidianamente seus rituais religiosos, cantorias e danças. Muitas dessas manifestações, ao longo do século XX, foram extintas e outras praticamente perderam o referencial histórico.

Ainda abordando a representatividade desses grupos, Ratts (2009) enfatiza que, em 1808, o Ceará já contava com uma população de 125.878 habitantes, sendo que desse total 19\% eram pretos, 37\% eram mulatos, 10\% eram índios e $34 \%$ eram brancos.

No século XIX, na década de 1840, a entrada de escravos na capitania do Ceará já era praticamente inexistente, em especial decorrente das primeiras proibições do tráfico negreiro. Em 1850, o Ceará passou a exportar negros cativos dentro do processo de tráfico interprovincial. Em 1883, às vésperas da extinção da escravidão no Ceará, a população cativa já demonstrava queda acentuada (FUNES, 2004).

A abolição da escravidão no Ceará permite ao cativo recuperar sua liberdade, mas vem acompanhada de uma série de medidas restritivas que mantém essa pessoa em situação inferior, excluindo-o da possibilidade de ascensão social e de direitos à cidadania. É o momento em que o negro vê legitimar sua exclusão social. É-lhe concedida à liberdade, mas nega-se o direito à cidadania. “[...] Excluído vai-se aquilombando nas periferias, nas favelas, nas frentes de expansão, 
enclausurando-se no seu mundo rural, no seu universo cultural, constituindo a sua identidade, a partir de sua historicidade" (FUNES, 2004, p. 132).

Em momentos como esse é que se percebe como os cativos escravizados e posteriormente, negros libertos são postos à margem da sociedade, fazendo desaparecer do processo histórico cearense as etnias negras e indígenas (FUNES, 2004).

O negro no Ceará até o início dos anos 1980 estava subjugado a um discurso por demais estigmatizante, ressaltando sua presença de pouca recorrência e relevância social (SOUSA, 2008). "Nesse sentido, no Ceará, a abolição precoce do elemento servil, em franco declínio a partir do final da década de 1870, decretou a "invisibilidade" do negro cearense muito mais do que a abolição da exploração escravocrata” (RIBARD, 2009, p. 97).

$\mathrm{O}$ esforço de reafirmar tal invisibilidade por parte de alguns setores da sociedade a partir do século XXI começa a sofrer alterações, principalmente, em decorrência do movimento criado pelas próprias comunidades negras na busca de reconhecimento e direitos.

\section{ONDE ESTÃO E COMO VIVEM OS QUILOMBOLAS DO CEARÁ?}

O estado do Ceará esta situado na região Nordeste e tem por limites o oceano Atlântico a norte e nordeste, Rio Grande do Norte e Paraíba a leste, Pernambuco a sul e Piauí a oeste. Sua área é de 148.825,6 km², correspondendo a 9,37\% da área do Nordeste Brasileiro e 1,7\% da superfície do território nacional (IBGE, 2011). Como em outras regiões tem em suas origens históricas a presença indígena, europeia e africana, sendo esta última empregada na lavoura de canade-açúcar, do café e da banana.

As primeiras análises dos quilombos, além de sua visão como prática criminal, datam do século XX. Ainda assim, a percepção de sua formação baseada em selvagens continuou perdurando, mas, de certa forma, estimulando pesquisadores a aprofundarem suas compreensões acerca desses grupos, não mais como bárbaros, mas sim pela óptica da resistência (CALLHEIROS; STADTLER, 2010).

Atualmente, o que conceitua essas comunidades vai além de sua formação com a fuga, buscando compreender o seu significado, abarcando os vários contextos de posse de terras por comunidades negras no País. A razão disso é que os quilombolas se definem com suporte nas suas relações com a terra, o parentesco, as tradições, as práticas culturais, dentre outros. Na visão de Schmitt, Turatti e Carvalho (2002), essa diversidade de manifestações é compreendida no 
partilhamento do território e de uma identidade e constituída sempre em relação aos outros grupos com os quais os quilombolas se relacionam.

O’Dwyer (2010) salienta que o termo quilombo refere "sobretudo, a grupos que desenvolveram práticas cotidianas de resistência na manutenção e reprodução de seus modos de vida característicos e na consolidação de um território próprio". Ainda segundo a autora, as formas de ocupação da terra não ocorrem de forma individual, predominando o uso comum e de acordo com a sazonalidade das atividades desenvolvidas, sejam elas, agrícolas, extrativistas ou quaisquer outras, tomando por base laços de parentesco e vizinhança.

Os quilombos contemporâneos espalhados por diversas localidades demonstram a representatividade que a presença africana logrou em território cearense. A manifestação de sua existência despertou para o reconhecimento de suas lutas e de suas formas de resistência no processo de formação da sociedade, "[...] que atravessaram o período colonial e imperial e que abalaram a estrutura econômica escravocrata no abolicionismo negro" (SOUSA, 2008, p. 36).

No presente, o estado do Ceará conta com 75 comunidades quilombolas, das quais 38 já possuem registro no Cadastro Geral da FCP. Ainda constam comunidades que estão em decurso de identificação, como o Quilombo da Serra dos Bastiões, município de Iracema, e comunidades que já passaram por esse momento e estão aguardando a emissão da certidão junto à FCP, sendo que ao todo são 10 (Domingos Pereira, Vila Nova, Barriguda, Batoque, Sítio Carcará, Cajueiro dos Lira, Cipoeiro, Olho d'Água, Nossa Senhora das Graças do Sítio Arapuca e Sítio Carnaúba). Além dessas comunidades que já estabeleceram algum tipo de relação com os órgãos federais, estaduais e municipais, a CEQUIRCE desenvolveu, de forma paralela, trabalhos de autodefinição com comunidades que não deram entrada junto à FCP, mas já iniciaram internamente o processo de autodefinição.

A CEQUIRCE expressa que existem 27 comunidades em decurso de identificação. Essas comunidades estão localizadas nos municípios de Araripe (2), Aurora (1), Mauriti (1), Potengi (2), Aquiraz (1), Salitre (1), São Benedito (1), Caucaia (4), Aracati (1), Milhã (2), Independência (1), Ipueiras (1), Novo Oriente (3), Parambu (4), Poranga (1) e Tamboril (1). E em dezembro de 2013 foi decretada a emissão dos títulos de propriedade, beneficiando quatro comunidades (Sítio Arruda em Araripe, Encantados do Bom Jardim e Lagoa das Pedras em Tamboril e Alto Alegre em Horizonte).

As comunidades, em sua maioria, localizam-se em áreas de difícil acesso e em condições precárias de vida. Apesar dessa fragilidade, os territórios quilombolas se estabeleceram ao longo do tempo, existindo quilombos com mais 
de 200 anos de fixação na mesma localidade. Estes criam e recriam suas formas de vida, se adaptam à natureza e à realidade que os cercam.

Esses quilombos distribuem-se geograficamente em diversas paisagens, habitando desde áreas elevadas até a depressão sertaneja assegurando formas diferenciadas de uso e ocupação do solo. A ocupação de áreas diversificadas garantiu uma diversidade cultural a essas comunidades, permitindo traçar diferentes formas de convivência com esses ambientes.

A formação de quilombos, a partir da fuga e ocupação de áreas distantes, foi bastante comum em diversas regiões do Brasil. Contudo, as condições de vida nesses sistemas ambientais se assemelham. Pressões externas, ausência de serviços básicos como agentes de saúde, educação, transporte, saneamento básico, apoio técnico ao pequeno agricultor são problemas comuns a várias comunidades.

Essa condição não é recente, pois mesmo após a abolição, as condições de vida e, principalmente, de trabalho, não foram modificadas. Fugiu da condição de escravo, mas não era totalmente livre.

Essas comunidades quilombolas não possuem documentação de posse ou propriedade da terra. Muitas delas foram cedidas pelos atuais posseiros há bastante tempo, sendo que algumas estabeleceram relações de arrendamento com os "donos" das terras. Essa prática é muito comum nas áreas rurais, onde os pequenos produtores, os arrendatários, conseguem a concessão de uma parte da propriedade agrícola, comprometendo-se, independentemente de seus rendimentos, ao pagamento, que pode ser em espécie ou em produtos, sobre seu uso.

As práticas produtivas predominantes como agricultura, extrativismo e criação de pequenos animais é a base de sustento desses grupos. Há ainda comunidades que desenvolvem artesanato e criação de peixes em tanques, mas em menor escala. Praticamente tudo o que é cultivado abastece a família e quando ocorre um excedente este é trocado ou vendido no comércio local. As residências são predominantemente de taipa e foram construídas em conjunto pelo núcleo familiar.

De acordo com o último censo realizado pelo INCRA, o estado possui em alguns de seus municípios mais de uma comunidade quilombola, como pode ser visto em Caucaia (5), Quiterianópolis (5), Tamboril (4), Salitre (2), Ipueiras (2), Monsenhor Tabosa (2), Novo Oriente (2) e Tururu (2) (INCRA, 2012).

Mesmo diante de tantos processos de autodefinição, o caminho percorrido pelo movimento quilombola cearense ainda é recente. As ideias proclamadas dão pouca expressividade a esses grupos no estado do Ceará, e fizeram com que muitas comunidades negras rurais protelassem os seus processos de identificação como quilombolas. Além disso, os conflitos advindos da questão fundiária 
também complementam esse retardamento.

Ratts (2009), ao abordar a atual conjuntura do movimento quilombola no Ceará, identifica que se encontram nessas comunidades moradores que se mantêm como agricultores e trabalhadores rurais. E que, apesar da afirmação de que no Ceará não existiam negros, essa visão passou a ser modificada a partir dos anos de 1970, com as primeiras identificações de comunidades negras rurais, e, em 1980, com a emergência do movimento negro e posterior fundação do Grupo União e Consciência Negra (GRUCON) no bairro Jardim Iracema, na cidade de Fortaleza (SOUSA, 2008).

A redescoberta dos quilombos permitiu ao movimento negro cearense realizar levantamentos e proposições de um panorama das reais condições dos moradores dessas comunidades, não só em relação aos aspectos de sua identidade, mas, também, quanto às formas de organização e condições de vida. Ainda em 1992 com a realização do Fórum de Entidades Negras do Ceará foi possível realizar um levantamento com 50 localidades com populações afrodescendentes distribuídas em todo o estado (RATTS, 2009).

Essa constante busca por legitimidade e representatividade possibilitou o despertar para uma maior organização das comunidades quilombolas contemporâneas e o início para a elaboração das comissões no plano estadual. A Comissão Estadual de Comunidades Quilombolas Rurais do Ceará (CEQUIRCE), criada em 2006, é a responsável pela articulação estadual das comunidades, possibilitando a inclusão nas discussões nacionais das particularidades pertinentes às comunidades localizadas no território.

A CEQUIRCE é uma entidade de fundamental importância na gestão dos conflitos existentes nas áreas ocupadas pelas comunidades quilombolas, não só em relação à titulação das terras, mas nas formas de uso dos recursos naturais, base para a subsistência das comunidades. Muitas práticas cotidianas como o extrativismo vegetal e os cultivos dos roçados estão sendo constantemente objetos de críticas por parte dos órgãos ambientais, penalizando criminalmente atos tradicionais das comunidades quilombolas.

Hábitos como caçar, pescar, criar animais, limpar o terreno para os roçados, retirar a madeira para a construção das residências e para cozinhar, são essenciais para o desenvolvimento sociocultural dessas comunidades. No entanto, essas práticas são consideradas como infrações ambientais, podendo ser punidas criminalmente. Ao mesmo tempo são elaborados dispositivos legais como a Política Nacional de Desenvolvimento Sustentável dos Povos e Comunidades Tradicionais que garantem a reprodução plena de suas formas de vida. 
Essas divergências e limitações ocasionam o agravamento das precárias condições de vida, expulsão das populações tradicionais e, em alguns casos, ainda uma maior degradação ambiental, à medida que ocupam novas áreas. A criminalização dessas comunidades especializou-se em diversas comunidades no estado.

Nesse contexto, a realidade destas comunidades quilombolas no Ceará, hoje, ainda carece de informações sistematizadas que possam subsidiar políticas públicas que propiciem melhores condições de vida à população remanescente.

\section{CONSIDERAÇÕES FINAIS}

$\mathrm{Na}$ historiografia cearense, durante muito tempo, propagou-se a pouca expressividade da presença negra na sociedade. Essas afirmações contribuíram para a disseminação da invisibilidade legal do negro, seja ele cativo ou livre.

A busca por visibilidade permitiu inicialmente a distinção entre quilombos coloniais e contemporâneos, possibilitando a ressemantização desse conceito, além de colaborar para avanços na legislação brasileira, garantindo não só reconhecimento nacional, mas garantias quanto à permanência nas terras tradicionalmente ocupadas. Dentre os principais instrumentos jurídicos elaborados, destacam-se a Constituição de 1988, inserindo os quilombolas na luta por igualdade e cidadania e o Decreto 4.888/03, dando o direito a esses grupos à autodefinição.

Em conclusão, na atualidade as comunidades quilombolas cearenses ainda permanecem invisíveis aos olhos do poder público e da sociedade. O direito à terra e à reprodução de sua forma de vida têm sido negligenciados e muitas vezes silenciados. As informações levantadas aqui revelam a necessidade de valorizar e resguardar os conhecimentos e práticas tradicionais vivenciadas cotidianamente por essas comunidades.

As relações de poder historicamente estabelecidas, em muitas situações, inibem o poder público de cumprir a obrigação de regularizar e titular as terras ocupadas. A morosidade na conclusão desses processos é uma delas, mas dificuldades operacionais decorrentes da má utilização dos recursos orçamentários para este fim também tem sua contribuição. Além disso, a pressão que as comunidades estão expostas na luta pelo direito à terra, em algumas situações, compromete a finalização do processo de regularização fundiária. Assim, muitas vezes os interesses dos latifundiários se sobrepõem ao direito garantido por lei aos quilombolas. 


\section{REFERÊNCIAS}

ALMEIDA, A. W. B. de. Terras tradicionalmente ocupadas: processos de territorialização e movimentos sociais. R. B. Estudos Urbanos e Regionais, Rio de Janeiro, v. 6, n. 1, p. 9-32. 2004.

BRASIL, Constituição (1988). Constituição da República Federativa do Brasil. 27. ed. Brasília: Câmara dos Deputados, 2007.

. Decreto n⿳o 6.040, de 07 de fevereiro de 2007. Diário Oficial da União, Brasília, 08 de fevereiro de 2007, Seção 1, p. 316.

. Decreto $\mathrm{n}^{\mathrm{O}} 4.887$, de 20 de novembro de 2003. Diário Oficial da União, Brasília, 21 de novembro de 2003, Seção 1, p. 4.

CALLHEIROS, F. P.; STADLER, H. H. C. A identidade étnica e poder: os quilombos nas políticas públicas brasileiras. Rev. Katál, Florianópolis, v. 13, n. 1, p. 133-139, jan/jun. 2010.

FIABANI, A. Os novos quilombos: luta pela terra e afirmação étnica no Brasil (1988 - 2008), 2008. 275f. Tese (Doutorado em História) - Centro de Ciências Humanas, Universidade do Vale do Rio dos Sinos, São Leopoldo, 2008.

FUNES, E. A. Negros no Ceará. In: SOUZA, Simone de; GONÇALVES, Adelaide (Org.). Uma nova história do Ceará. Fortaleza: Demócrito Rocha, 2004. p. 103-13).

GOULART, J. A. Da fuga ao suicídio: aspectos de rebeldia dos escravos no Brasil. Rio de Janeiro: Conquista, INL, 1972.

IBGE. Cidades@: 2011. Disponível em: <http://www.ibge.com.br/cidadesat/ topwindow.htm?1>. Acesso em: 12 jan. 2016.

INCRA. Quilombolas. 2012. Disponível em <http://www.incra.gov.br/ estrutura-fundiaria/quilombolas >. Acesso em: 01 fev. 2016.

MATTOS, R. A. Histórico e cultura afro-brasileira. São Paulo: Contexto, 2007.

MOURA, C. Os quilombos e a rebelião negra. São Paulo: Brasiliense, 1981.

O'DWYER, E. C. Terras de quilombo no Brasil: direitos territoriais em construção. In: ALMEIDA, A. W. B. (Org.). Territórios quilombolas e conflitos. Manaus: UEA, 2010. p. 42-49. 
OLIVEIRA, A. U. de. A Geografia das lutas no campo. São Paulo: Contexto, 1989.

PINHEIRO, F. J. Mundos em Confrontos: povos nativos e europeus na disputa do território. In: SOUZA, S. de; GONÇALVES, A. et al. (Org.). Uma nova história do Ceará. Fortaleza: Demócrito Rocha, 2004. p. 17-55.

RATTS, A. Traços étnicos: espacialidades e culturas negras e indígenas. Fortaleza: Museu do Ceará/SECULT, 2009.

RIBARD, F. A corte real dos reis de congo: territórios festivos negros em trânsito (Fortaleza - 1871/1900). In: HOLANDA, C. R. (Org.). Negros no Ceará: história, memória e etnicidade. Fortaleza: Museu do Ceará/SECULT/Imopec, 2009. p. 95-110.

SCHMITT, A.; TURAT'TI, M. C. M.; CARVALHO, M. C. P. de. A atualização do conceito de quilombo: identidade e território nas definições teóricas. Ambiente \& Sociedade, São Paulo, v. 5, n. 10, p. 129-132, $1^{\text {o }}$ sem. 2002.

SOUSA, A. V. C. Afro-cearenses em construção: discursos identitários sobre o negro no Ceará. Fortaleza: Demócrito Rocha, 2008. 


\title{
Dinâmicas da agricultura familiar com cultura do dendezeiro no município de Moju, na Amazônia paraense
}

\section{Dynamics of family agriculture with oil palm crops in the municipality of Moju, Amazon region of the state of Pará, Brazil}

\begin{abstract}
João Santos Nabum - Mestre em Planejamento do Desenvolvimento pelo Núcleo de Altos Estudos Amazônicos (NAEA/UFPA). Doutorado em Geografia pela Unesp-Rio Claro. Professor da Faculdade de Geografia e Cartografia e do Programa de Pós-Graduação em Geografia da UFPA. E-mail: prof.joaonahum@gmail.com
\end{abstract}

Cleison Bastos dos Santos - Doutorando pelo Programa de Pós-Graduação em Geografia (PPGEO), da Universidade Federal do Pará. Professor de Geografia da Secretaria Municipal de Educação de Moju e da Secretaria Executiva de Educação do Estado do Pará - 3ª URE. E-mail: cleisongeo@gmail.com

Ana Cláudia Alves de Carvalho - Doutoranda em Geografia pelo Programa de PósGraduação em Geografia (PPGEO), da Universidade Federal do Pará. E-mail: carvalho_ anaclaudia@yahoo.com.br

\section{Resumo}

Analisamos a dinâmica da agricultura familiar do dendê no espaço rural de Moju, estado do Pará. Interpretamos os traços estruturais dessa modalidade produtiva e suas implicações no lugar. Para tanto, revisitamos literatura e legislação concernente ao tema, bem como realizamos trabalho de campo onde entrevistamos produtores, representantes das associações produtoras das comunidades e das empresas integradas a cadeia produtiva. $\mathrm{Na}$ primeira parte caracterizamos em largos traços a expansão da dendeicultura na aurora do século XXI, decorrente do Programa Nacional de Produção e Uso do Biodiesel e Programa de Produção Sustentável de Óleo Programa de Produção Sustentável de Óleo de Palma no Brasil; na segunda os traços gerais dos projetos de agricultura familiar associados às empresas no Moju, destacando-se a experiência da Agropalma.

\section{Palavras-chave}

Agricultura Familiar. Dendeicultura. Amazônia. Agropalma.

\begin{abstract}
We analyzed the dynamics of oil palm family agriculture in the rural area of the municipality of Moju, state of Pará, Brazil. The structural traits of this production modality and their implications in the region were interpreted. To that end, we reviewed the literature and legislation on the subject, besides carrying out field work by interviewing producers and representatives of production associations of the communities and companies involved in the productive chain. In the first part, we characterize in general lines the expansion of oil palm farming in the dawn of the $21 \mathrm{st}$ century caused by the National Program of Biodiesel Production and Use and the Program of Sustainable Palm Oil Production in Brazil. The second part brings an overview of family agriculture projects associated with companies in Moju, in particular the experience of Agropalma.
\end{abstract}

\section{Keywords}

Family Agriculture. Oil Palm Farming. Amazon. Agropalma. 


\section{INTRODUÇÃO}

Interpretamos a chegada da dendeicultura na microrregião de ToméAçu, na Amazônia paraense, tal como um evento reorganizador da paisagem, da configuração territorial, da dinâmica social, enfim do espaço geográfico ou território usado (NAHUM; MALCHER, 2012). Desde então, temos demarcado um período geográfico do dendê (CARVALHO; NAHUM, 2014), possibilitado por pesquisas acerca das condições edafoclimáticas necessárias e propícias ao cultivo em grande escala da palma do dendê; por um conjunto de ações governamentais tais como o Plano Nacional de Produção e Uso de Biodiesel (PNPB) e o Programa de Produção Sustentável de Óleo de Palma no Brasil (PPSOP) que propõem alternativas à matriz energética alicerçada no combustível fóssil e integrar o agricultor camponês à cadeia produtiva do agronegócio na Amazônia; por fim, estimulado pela voracidade do mercado de commodities de óleo de palma, que encontrou seus limites físicos e territoriais no continente asiático, por isso expande-se para África e América Latina.

É grande a rentabilidade produtiva do dendezeiro (Elaeis guineensis Jacq) comparada com outras oleaginosas. Essa palma possui a maior produtividade, com rendimento entre 4 a 6 toneladas de óleo/ha/ano, correspondendo a 1,5 vezes a produtividade do óleo de coco, a 2 vezes a do óleo de oliva e mais do que 10 vezes a do óleo de soja, superado apenas pelas algas, que tem produtividade anual entre 50 a 150 toneladas por hectares (SILVA, 2015). A produção dos cachos tem início a partir dos 3,5 anos após o plantio, chegando ao ápice entre 7 e 15 anos. Do ponto de vista econômico sua vida útil é de 25 anos, com rendimentos superiores a 25-28 toneladas de cachos por ha/ano. Dois tipos de óleo são extraídos dos frutos da palma, sendo o mais valioso o do palmiste, proveniente da amêndoa ou endosperma e o produto comum é o óleo decorrente do esmagamento da polpa ou mesocarpo (RIVAL; LEVANG, 2014).

Teses, dissertações, publicações especializadas, jornais, dentre outros, em uníssono exaltam as virtudes da palma africana que prodigiosamente tão bem se adaptou ao solo amazônico. Sublinham que seu cultivo seria capaz de promover o desenvolvimento sustentável, recuperando ambientalmente, economicamente e socialmente áreas degradas pela pecuária. O cultivo do dendezeiro geraria empregos e renda para o agricultor familiar, que não terminaria seus dias praticando cultivos de pouco rendimento econômico. Este, dada sua disposição para o trabalho, organização familiar e a baixa escolaridade poderia ser absorvido para trabalhar nos campos de dendezeiro, seja na produção direta em sua propriedade ou nas empresas (FURLAN JÚNIOR et al., 2006; CASTRO; LIMA; SILVA, 2010; 
SUFRAMA/FGV, 2003; SILVA, 2006; SEMEDO, 2006; EMBRAPA, 2006). No entanto, tão importante quanto ressaltar as potencialidades econômicas, ambientais e sociais do dendezeiro, é compreender sobre as metamorfoses no modo de vida do lugar onde esse agronegócio se expande.

Centramos a análise sobre um aspecto comum nos lugares onde se estabelece a monocultura, qual seja, o que significa para o agricultor familiar tornarse produtor de dendê. Analisamos as relações entre dendeicultura e agricultura familiar no município de Moju, estado do Pará, a partir do projeto de produção familiar criado pela associação entre o Estado brasileiro e capital nacional e internacional. Para tanto, revisitamos literatura e legislação concernente ao tema, bem como realizamos trabalho de campo onde entrevistamos produtores, representantes das associações produtoras das comunidades e das empresas integradas a cadeia produtiva. A situação geográfica em foco é o espaço rural de Moju, berço da dendeicultura empresarial, onde ela é mais dinâmica e diversificada. Dentre as empresas, normas e unidades produtoras familiares de dendezeiro, privilegiamos a prática do Grupo Agropalma, por ser pioneiro no processo, com experiência de 16 anos e um nível de enraizamento e abrangência amplo; sendo protótipo para os projetos de empresas como Marborges S.A., Biopalma S.A. e Belém Brasil Bioenergia S.A. Na primeira parte caracterizamos em largos traços a expansão da dendeicultura na aurora do século XXI, decorrente do Programa Nacional de Produção e Uso do Biodiesel e Programa de Produção Sustentável de Óleo Palma no Brasil; na segunda discorremos sobre os projetos de agricultura familiar de dendezeiro associados às empresas no Moju, destacando-se aqueles associados a Agropalma.

\section{O TERRITÓRIO PARA O DENDÊ}

O espaço rural da Amazônia paraense é marcado pela dendeicultura (NAHUM; SANTOS, 2013), cuja dinâmica deve ser entendida a partir de um processo de reorganização da matriz energética europeia, que tem por meta desenvolver fontes alternativas às fósseis (ALTVATER, 2010; GIDDENS, 2010; HOUTART, 2010). Segundo Lima e Castro (2010, p. 50), “a Comunidade Europeia (ou União Europeia) é o maior produtor mundial de biodiesel e tem apresentado uma posição bastante firme na substituição de combustíveis fósseis por fontes renováveis, em sua matriz energética". A divisão internacional do trabalho configura um circuito global de produção de matéria-prima para o biodiesel, que tem na Ásia, na África e na América Latina áreas privilegiadas nisso. Mas é por meio do Plano Nacional de Produção de Uso do Biodiesel, lançado em 
2004, que o Estado brasileiro propõe política para o biodiesel, criando condições financeiras e normativas para expansão da palma africana no trópico úmido.

$\mathrm{Na}$ década de 1980, o município de Moju foi o primeiro a ter empreendimento voltado para a dendeicultura, referimo-nos a extinta Reflorestadora da Amazônia S.A. (REASA). A dendeicultura desde então se expande nos municípios de Acará, Moju, Tailândia, Tomé-Açu e Concórdia do Pará, pertencentes à microrregião de Tomé-Açu, no estado do Pará, onde a cadeia produtiva do dendezeiro é mais estruturada. A chegada das empresas Amapalma, na década de 1990, Guanfeng e Biopalma, em 2009 e 2010 respectivamente, e da Belém Brasil Bioenergia (BBB), em 2011, colocaram Moju, segundo os dados oficiais do Instituto Brasileiro de Geografia e Estatística, na terceira posição em quantidade produzida de Cachos de Frutos Frescos (CFF) no estado do Pará, com 141.151 toneladas, atrás apenas do município de Acará, com 195.000 toneladas, e de Tailândia, com 405.055 toneladas ${ }^{1}$.

O Zoneamento Agroecológico do Dendezeiro para as Áreas Desmatadas da Amazônia Legal (EMBRAPA, 2010) e o Decreto nำ 7.172, de 7 de maio de 2010, que aprova o zoneamento agroecológico da cultura da palma de óleo, identificaram no Moju, entre áreas preferenciais e regulares para o cultivo do dendê, 4.012,69 km²; aproximadamente 44\% do total do município, que, segundo o IBGE, é de $9.094,135 \mathrm{~km}^{2}$. Sob os pilares da técnica e da ação política reedita-se a ideologia do espaço vazio, tal como na época dos Planos de Desenvolvimento da Amazônia (NAHUM, 2012), áreas antropizadas e subaproveitadas economicamente, propícias às frentes de expansão do dendê.

Em relação à mão-de-obra, a expansão da dendeicultura encontra apoio e cumplicidade do sindicato dos trabalhadores rurais, das secretarias municipal e estadual de agricultura, bem como da federação dos trabalhadores na agricultura do estado do Pará. Além do que, a histórica simbiose entre movimentos sociais e partidos políticos acentuada no início do século XXI, fez com que muitas lideranças dos movimentos sociais no campo na Amazônia se elegessem vereador, deputado, senador, secretário de estado ou fossem incorporadas em alguma parte do organograma governamental e reproduzissem essa política de estado, o que silenciou qualquer discurso alternativo, crítico ou contestatório à dendeicultura como vetor do desenvolvimento territorial rural. Estão dadas, portanto, as condições políticas para a emergência da monocultura como pensamento único, espécie de discurso competente, lacunar (CHAUÍ, 1990), mas atacando problemas históricos da agricultura familiar, quais sejam, custear, produzir, distribuir e comercializar a preço de mercado. Isso é claro no Decreto n⿳⺈ 5.297,

Disponível em: https://cidades.ibge.gov.br/. Acesso em: 02 mar. 2018. 
de 6 de dezembro de 2004, onde no Art. $2^{\circ}$ fica instituído o selo "Combustível Social", que será concedido ao produtor de biodiesel que:

I - promover a inclusão social dos agricultores familiares enquadrados no Programa Nacional de Fortalecimento da Agricultura Familiar - PRONAF, que lhe forneçam matéria-prima; e

II - comprovar regularidade perante o Sistema de Cadastramento Unificado de Fornecedores - SICAF.

$\int 1^{\circ}$ Para promover a inclusão social dos agricultores familiares, o produtor de biodiesel deve:

I - adquirir de agricultor familiar, em parcela não inferior a percentual a ser definido pelo Ministério do Desenvolvimento Agrário, matéria-prima para a produção de biodiesel;

II - celebrar contratos com os agricultores familiares, especificando as condições comerciais que garantam renda e prazos compatíveis com a atividade, conforme requisitos a serem estabelecidos pelo Ministério do Desenvolvimento Agrário; e

III - assegurar assistência e capacitação técnica aos agricultores familiares (BRASIL, 2004).

Enquanto discurso competente (CHAUÍ, 1990), a expansão dos dendezais aparece como exemplo de paradigma do capitalismo agrário capaz de promover o agricultor tradicional à condição de empreendedor familiar, nos moldes europeus (ABRAMOVAY, 2012). Reedita-se a ideologia da fronteira, bem como a representação de Amazônia como fronteira agrícola (LÉNA; OLIVEIRA, 1992; D'INCAO, OLIVEIRA, 1994; AUBERTIN, 1988; MARTINS, 1997; CARDOSO, MULLER, 2008; NAHUM, 2012). Em 2004, tínhamos o dendezeiro cultivado pela "Agropalma, Marborges, Dentaua e Palmasa restringiam-se aos municípios de Moju, Acará, Tailândia, Santo Antônio do Tauá e Igarapé-Açu” (NAHUM; SANTOS, 2015, p. 2). Segundo dados da EMBRAPA², a área colhida de dendê no Brasil que em 2004 era de 87.542 mil/ha, em 2016 expande-se para $142.246 \mathrm{mil} / \mathrm{ha}$, aproximadamente $61,5 \%$.

Ainda segundo a EMBRAPA, em 2004, o Pará tinha $45.96 \mathrm{mil} / \mathrm{ha}$ de dendezeiro, em 2016 são 99,4 mil/ha, aproximadamente 46,2\%. Em 2017 essa atividade era desenvolvida pela Biopalma, Archer Daniels Midland (ADM), Agropalma, Denpasa, Dentaua, Marborges, Yossan, Palmasa, Guanfeng do Brasil, Belém Bioenergia Brasil, dentre outras, distribuídas pelos municípios de Abaetetuba, Acará, Aurora do Pará, Baião, Bujaru, Cametá, Castanhal, Capitão Poço, Concórdia do Pará, Garrafão do Norte, Igarapé-Açu, Irituia, Mãe do rio, Mocajuba, Moju, São Domingos do Capim, Tailândia e Tomé-Açu (Figura 1).

2 Disponível em: https://www.embrapa.br/agropensa/producao-agricola-municipal. Acesso em: 04 mar.2018. 
Figura 1 - Empresas dendeicultoras em município do estado do Pará em 2017

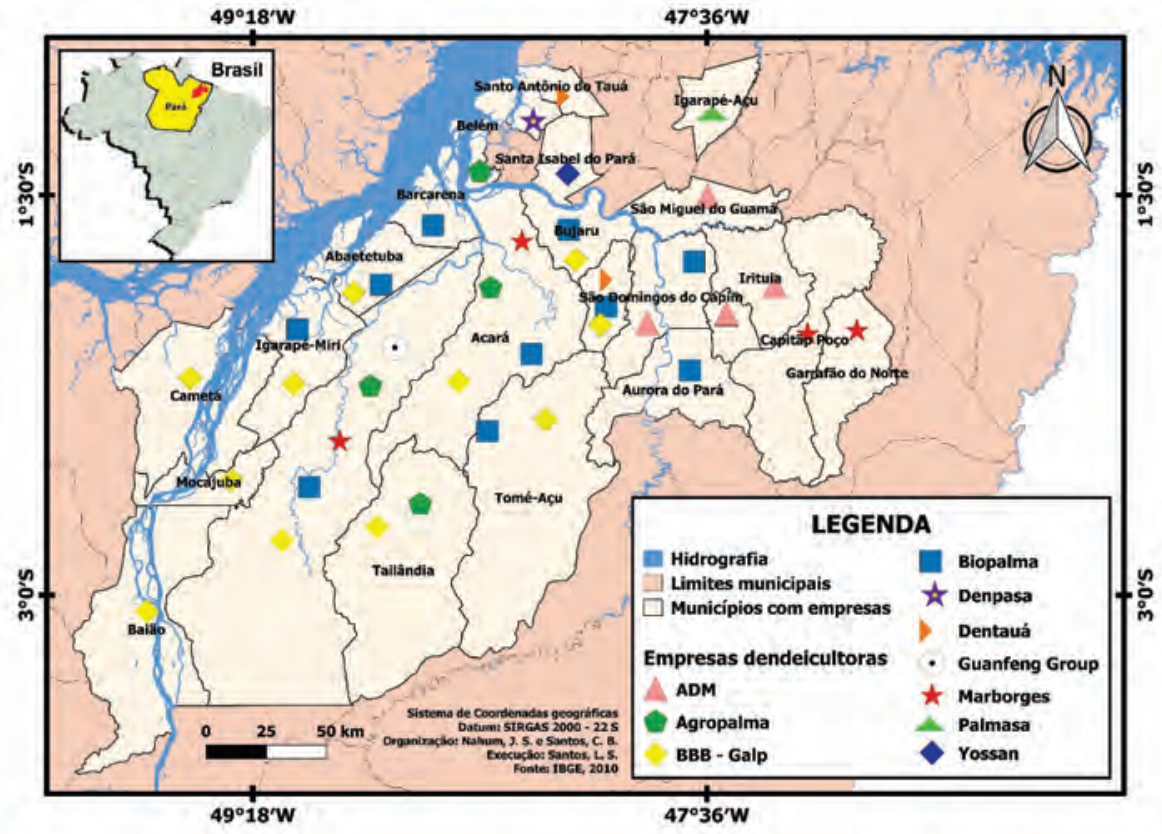

Fonte: IBGE, organizado pelo Grupo de Pesquisa Dinâmicas Territoriais do Espaço Rural na Amazônia (GDEA).

Neste período formam-se territórios do dendê possibilitados por políticas estatais associadas aos interesses empresariais. De modo que os dendezais das empresas constituem um recurso por meio do qual reinventam as condições materiais de existência dos lugares sob sua influência. $\mathrm{O}$ tamanho e quantidade dos pontos dependem da envergadura e natureza do capital acionado para transformar extensas terras em território do dendê. Todavia, nem toda empresa de dendê tem condições políticas, econômicas e espaciais para construir seu território-rede (NAHUM; SANTOS, 2013). No estado do Pará conhecemos quatro caminhos pelos quais as empresas adquirem terra e produzem o dendê: compra, arrendamento, associação com produtor familiar e aquisição da produção de produtores particulares. Tem prevalecido a aquisição por compra de áreas antropizadas predominantemente, mas não somente, pela extração de madeira, precursora da pecuária extensiva e de fazenda que tem na renda da terra seu principal instrumento de valorização. Somente na microrregião de Tomé-Açu, no nordeste paraense, a Biopalma tem 87 propriedades no seu nome, abrangendo mais de 134 mil hectares, onze no Moju. 
No Moju, na modalidade arrendamento temos 510 hectares do Sr. Altino Coelho, arrendados pela Agropalma; além das fazendas Vitória, com 705 hectares, e Primavera, com 810 hectares arrendadas pela Belém Brasil Bioenergia. As empresas pagam ao proprietário pelo uso de suas terras para cultivar o dendezeiro, geralmente os contratos são de 25 anos, período de vida econômica útil da palma. Ratifica-se, desse modo, na Amazônia paraense do século XXI a renda da terra, "considerada como preço pago pelo usa da terra", tal como exposta por Smith (1996, p. 185), no século XVIII. Na modalidade produtores independentes de dendê, que vende a produção para as empresas, temos as propriedades dos senhores Domingos Lima, com 34 hectares, Hitofume Kimura, com 580, e José Wanderley, com 2.221, totalizando 2.835 hectares. Quanto às áreas de plantio próprio, temos a Marborges, com 6.250 hectares, a Biopalma, com 9.328, e a Agropalma, com 4.954 (SANTOS, 2015).

\section{A AGRICULTURA FAMILIAR DE DENDÊ}

Os agricultores familiares a que nos referimos são proprietários ou não da terra que dedicam 10 hectares à produção de dendê seguindo acordo contratual da empresa e sob financiamento do Banco da Amazônia S.A. A Marborges, a Agropalma, a Belém Brasil Bioenergia e a Biopalma são empresas que desenvolvem projetos de agricultura familiar de dendê. Segundo os dados levantados na pesquisa, a modalidade soma 266 famílias, sendo cinco projetos associados com a Marborges; 155 com a Agropalma; e 106 com a Biopalma, totalizando 2.660 hectares de plantio de dendê. Quanto aos projetos integrados à Belém Bioenergia, segundo o setor agrícola da empresa, há em Moju 181 projetos familiares com dimensões de 7, 8, 9 e 10 hectares.

A comunidade do Arauaí é englobada pela dinâmica do dendezeiro no ano de 2002, quando o Grupo Agropalma, a prefeitura Municipal de Moju, o Instituto de Terras do Estado do Pará (ITERPA), a Empresa de Assistência Técnica e Extensão Rural (EMATER), a Secretaria de Agricultura do estado do Pará (SAGRI), o Banco da Amazônia S.A. (BASA) juntamente com os colonos da comunidade, implantaram o pioneiro "Projeto de Agricultura Familiar com Cultura de Dendê".

Segundo o responsável pela implantação do projeto de agricultura familiar, em entrevista concedida a Cruz (2006, p. 127), "a motivação que levou a empresa a estabelecer essa parceria com os pequenos produtores foi a preocupação com as populações ribeirinhas que vivem próximas as áreas de projeto da empresa". No entanto, ainda segundo o autor, em entrevista com o responsável da SAGRI 
no projeto de agricultura familiar, este informou que "o projeto já vinha sendo desenvolvido pelo Governo do Estado do Pará no município de Concórdia do Pará, mas devido a uma série de problemas foi abandonado, daí surgindo à necessidade desenvolvê-lo em outro local" (CRUZ, 2006, p. 127-129). Foi dentro deste contexto, que a Agropalma se interessou e criou condições para implantação do projeto piloto no município de Moju.

O projeto foi pensado em três etapas e envolveu agricultores que criavam, cultivavam, extraíam e produziam tão somente para reprodução da unidade produtiva familiar. O projeto de agricultura familiar do dendê forma-se quando o Estado cria um projeto de assentamento destinado ao cultivo da palma, a empresa proporciona o saber/fazer da cultura do dendê, o Banco disponibiliza linha de crédito e o agricultor entra com força de trabalho. Tudo pensado para a dendeicultura se constituir renda complementar às atividades tradicionais desenvolvidas nos sítios.

A primeira iniciou em 2002, na comunidade do Arauaí, com o plantio de 500 hectares, distribuídos em lotes de 10 hectares para cada família, num total de 50 famílias. A segunda, em 2004, na comunidade da Soledade, também localizada no alto Moju, com 500 hectares destinados para 50 famílias e a terceira, no ano de 2005, novamente na Comunidade do Arauaí, denominado Arauaí II, com o plantio de 500 hectares, distribuído em lotes de 10 hectares destinados para 50 famílias. Totalizando 1.500 hectares para 150 famílias. O projeto foi estendido, em 2006, para o Projeto de Assentamento, Calmaria II, do Instituto de Colonização e Reforma Agrária (INCRA), localizado nas proximidades do km 65, da rodovia PA-150, com uma área de 210 hectares destinados para 35 famílias, cada uma com 6 hectares (BASA, 2012).

Os agricultores dos projetos I e III da comunidade do Arauaí trabalham na terra na condição de assentados da reforma agrária, que tem a titulação coletiva, isto é, podem usar a terra, mas não tem a titulação individual da mesma. Isso foi possível quando, segundo Pinto et al. (2009):

O governo do estado do Pará através do Decreto no 1.198 , de 23 de agosto de 2004, em seu Art. 1ㅜ, considerando entre outras coisas, que compete ao poder público estimular os empreendimentos idôneos e contribuir para o desenvolvimento econômico e social da região, reserva à Associação do Desenvolvimento Econômico do Ramal do Arauaí, uma área de terras medindo 2.714 ha 23 a e $96 \mathrm{ca}$ (dois mil e catorze hectares, vinte e três ares e noventa e seis cantares). No Art. $2^{\circ}$ diz que "a área de terras previstas no Art. $1^{\circ}$ não poderá ser objeto de qualquer operação que importe na sua transferência a terceiros, sob qualquer hipótese", portanto a área foi doada à Associação, sendo que cada lote seria "arrendado" as famílias 
participantes do projeto para utilizarem 10 hectares com dendê. Sendo que, caso alguma família abandonasse ou não tratasse o lote corretamente de acordo com as recomendações agronômicas do profissional responsável pela área, o mesmo poderá ser repassado para outra família que tenha interesse em assumir a atividade e o financiamento bancário, fato que ocorreu com apenas 6\% (seis por cento) dos lotes durante os 8 (oito) anos de existência do projeto I (PINTO et al., 2009, p. 32).

Inicialmente o projeto organizou-se de modo a cada família receber 10 hectares para cultivar 160 plantas por hectare, somando 1.600 plantas por lote e, mais 2 hectares, um para construção de estrada e outro para plantio de subsistência. A área destinada à cultura de subsistência, posteriormente, não foi incentivada pela empresa, o que causou desconfiança dos agricultores. Isso porque a família envolvia-se desde o começo no preparo dos lotes, mas a palma começa a produzir no terceiro ano. Neste hiato de tempo entre plantio/colheita/ venda os agricultores temiam pelo sustento da família, o que lhes causavam apreensão e desconfiança.

Isso foi sanado por meio do crédito viabilizado pelo Banco da Amazônia que repassou o financiamento do Programa Nacional de Fortalecimento da Agricultura Familiar (PRONAF), concedendo linha de crédito às famílias no valor de $\mathrm{R} \$ 16.107,18$, com juros de 3\% ao ano, carência de três anos e desconto de $40 \%$ da dívida se fosse paga até o dia do vencimento. Dentro do financiamento, foi garantido aos participantes do projeto o valor de 2 dois salários mínimo (cujo valor do salário em 2004 era de $\mathrm{R} \$ 260,00$ ) a cada dois meses durante os três primeiros anos para custear o sustento da atividade até o início da produção dos cachos. Estamos diante de uma linha de crédito precursora do PRONAF-Eco, em 2010, comum aos projetos do dendê que se desenvolvem a partir do Plano Nacional de Produção e Uso do Biodiesel.

O Grupo Agropalma atua no projeto fornecendo as mudas do dendezeiro e proporcionando a infraestrutura inicial para o lote, bem como assistência técnica. Por meio de contrato, a empresa compromete-se a comprar a produção por um período de 25 anos, tempo economicamente útil do dendezeiro, fixando o valor em 10\% do preço Free On Board (FOB) do óleo bruto no porto de Roterdã. Ainda financia os fertilizantes utilizados pelos agricultores num total de $\mathrm{R} \$ 7.000,00$ ao ano, sendo descontados $25 \%$, desse valor, do que o agricultor tem a receber da matéria-prima entregue à empresa; também são descontados 25\% do valor do cultivo do agricultor para ressarcimento do financiamento bancário, introduzido para reduzir o risco de inadimplência do financiamento. 
As obrigações dos produtores são basicamente duas: a) a venda de toda a produção para a empresa durante os 25 anos estabelecidos no contrato; b) os tratos culturais, ou seja, a gestão do plantio. Os primeiros três anos do plantio exigem tratos culturais intensivos como, por exemplo, o coroamento (rebaixo) uma vez por ano, que consiste em eliminar a vegetação que circunda a palma, evitando a competição com as mesmas; a podagem, consiste na retirada de folhas não saudáveis ou danificadas na planta uma vez por ano; a adubação duas vezes ao ano por conta da especificidade do solo amazônico e a aplicação de herbicida uma vez ao ano para as prevenções e os combates das pragas e outras doenças que acometem o dendezeiro (MÜLLER, 1980). O período de colheita do fruto abrange em média 17 dias de trabalho por mês, dado que a palma de dendê produz todos os meses do ano, tendo uma diminuição de produtividade no período do verão.

Os agricultores devem seguir as normas estabelecidas no contrato pela empresa, e caso descumpram alguma cláusula, podem sofrer sanções do grupo. Os agricultores que conseguem desempenhar bons tratos culturais, ou seja, uma boa gestão dos plantios é acrescida $8 \%$ sobre o valor pago pela tonelada. Segundo Alves (2008), quem atrasar a colheita por 60 dias, as atividades de poda e roçagem por mais de 12 meses ou a adubação por mais de 30 dias terá seu contrato cancelado.

O projeto desenvolvido na comunidade do Arauaí seguiu a racionalidade empresarial globalizada da Agropalma onde, segundo Santos (2006):

cada gesto e cada resultado deve se previsto de modo a assegurar a maior produtividade e a maior rentabilidade possível [...] as técnicas a serviço da produção, da armazenagem, do transporte da transformação dos produtos e da sua distribuição, respondem ao modelo mundial e são calcadas em objetivos pragmáticos, tanto mais provavelmente alcançados, quanto mais claro for o cálculo na escola e na sua implantação. É desse modo que se produzem nexos estranhos à sociedade local [...] (SANTOS, 2006, p. 304-305).

A presença da monocultura e a introdução do mesmo ritmo de produção empresarial, ampliou a carga de trabalho dos agricultores familiares, que além da gestão dos lotes de dendê, precisam reservar tempo para os cultivos de subsistência nos sítios (NAHUM; SANTOS, 2017). Para Pinto et al. (2009), a diversidade do tamanho e composição familiar da comunidade pode ocasionar o sobretrabalho e/ ou a contratação de trabalho assalariada:

No projeto encontramos discrepância entre as famílias, por exemplo, uma composta por somente uma pessoa - o produtor - trabalhando quase que 
diariamente para manter o lote produtivo. Outras compostas por 9 (nove) membros, sendo que destes, 6 (seis) trabalham rotineiramente. $\mathrm{O}$ fato de algumas serem pequenas e contarem com pouca mão de obra no período de safra, acarreta na contratação de trabalhadores diaristas (PINTO et al., 2009, p. 36).

A quantidade de frutos frescos colhidos é determinada principalmente pelo tamanho e a composição da família e, o mais importante, pela intensidade do trabalho. No caso da unidade familiar onde há falta de braços disponíveis para movimentar a lavoura isso é solucionado com a ajuda de parentes ou de vizinhos da comunidade. Fizemos um trabalho de campo em março de 2016 na comunidade e de dezesseis famílias entrevistadas, apenas duas disseram ter trabalhado com mutirão no lote. A quase ausência dessa característica da agricultura camponesa se explica pela preocupação que as famílias têm em cumprir os tratos culturais estabelecidos pela empresa, visto que nos três projetos há cinco técnicos fiscalizando diariamente o trabalho dos agricultores.

Do exposto acima, temos um cenário propício para a introdução da mão-de-obra assalariada nos lotes dos produtores. A contratação de trabalho assalariado reduz o ganho da família produtora, pois são contratados em média dois trabalhadores por lote. A contratação explicar-se em função: a) do receio na aplicação dos produtos químicos nas 1.600 plantas de um lote; b) da família numerosa, mas com filhos ainda em fase escolar; c) da família relativamente numerosa, mas com filhos que não possuem habilidade suficiente para desempenhar as tarefas com rapidez necessária; e c) de famílias com poucos filhos. Assim, o que define a entrada do trabalho assalariado no interior da unidade produtiva é a quantidade de braços familiares disponíveis ao cultivo do dendezeiro.

O projeto gerou empregos e aumentou a renda dos agricultores familiares da comunidade. No ano de 2011 os produtores do projeto I receberam pela venda de sua produção, uma receita total de $\mathrm{R} \$ 2.656 .640,00$ equivalente a uma renda anual de $\mathrm{R} \$ 53.132,80$ por família, ou seja, $\mathrm{R} \$ 4.427,73$ por família, aqui faltam os descontos nos insumos, equipamentos e outros (BASA, 2012). Assim, puderam adquirir bens que outrora não possuíam, por exemplo, motos, televisores, geladeiras, e outros eletroeletrônicos. Outra mudança diz respeito ao tipo da moradia e da escola, que no passado na sua maioria eram de madeira, atualmente, são erguidas de alvenaria.

No entanto, nem todos os participantes do projeto conseguem conciliar o trabalho nos lotes de dendezal com a manutenção de suas propriedades, os sítios, como nos explica “seu” Jefith Abreu, do Projeto I: "Muitos de nós abandonemos 
nossos plantios, ficamos quase que exclusivo no dendê. Porque é muito serviço" ("Seu" Jefith, em entrevista pessoal, em 17 de setembro de 2013). esta dificuldade foi confirmada por “dona” Maria, em entrevista ao Repórter Brasil (2010):

Quando eles trazem o adubo, temos obrigação de aplicar. Se não fizer o que eles mandam, se não passar veneno ou podar, eles seguram o nosso dinheiro no banco. Aqui tem cinco fiscais (técnicos da empresa) que ficam controlando tudo", diz a agricultora. Sua família é uma das que não mantiveram as roças de culturas alimentares "porque não dá para fazer as duas coisas ao mesmo tempo (REPÓRTER BRASIL, 2010, p. 20).

No contexto do PNPB foram implantados dois novos projetos de dendê familiar no município de Moju, o Projeto III, também conhecido como Arauaí II, em 2005, e o Projeto Dendê Familiar IV, localizado no Projeto de Assentamento Calmaria II, na comunidade Água Preta, em 2006. A comunidade do Arauaí recebe pela segunda vez o Projeto Agricultura Familiar com Dendê III. Ele foi configurado na comunidade em 2005, abrangendo 50 famílias com 10 hectares de dendezeiros financiados na linha de crédito Pronaf D, sendo destinado para cada família cerca de $\mathrm{R} \$ 26.864,76$ (BASA, 2012).

O Projeto Dendê Familiar IV foi introduzido nos lotes dos assentados do Projeto de Assentamento Calmaria II, em 2006. O PA Calmaria II está localizado nas proximidades do quilômetro 65, da PA-150, na comunidade Água Preta, destinado a 35 famílias, cada uma com seis hectares. A linha de financiamento foi o FNO/Pronaf A. As 35 famílias receberam recursos na ordem de $\mathrm{R} \$ 12.255,75$. O prazo total foi de 10 anos com carência de cinco anos e juros de 1,5\% a.a. As instituições envolvidas no projeto foram a FETAGRI, o Sindicato dos Trabalhadores Rurais de Moju e entidades associativas do PA Calmaria II, o INCRA-PA, o MDA/PA, a SECTAM (hoje SEMA), o IBAMA, o BASA e o Grupo Agropalma (BASA, 2012; INCRA).

A empresa Agropalma, no ano de 2013, acrescentou mais nove projetos, sendo cinco no Arauaí, em Moju, e quatro no PA Calmaria II, no Acará. O PA Calmaria II possui $70 \%$ do seu território no município de Acará e 30\%, em Moju. A pesquisa apontou, com base em dados da EMATER, que os plantios dos assentados não se localizam em Moju, mas no Acará. Desse modo, há uma diferença entre o território jurídico, ou seja, a área de localização do plantio e o território do dendê, que corresponde ao território pertencente ou controlado pelas empresas. Atualmente, as áreas de plantio de dendezeiro na modalidade familiar vinculado ao Grupo Agropalma estão localizadas em dois municípios. No total, são 192 famílias, sendo 35 trabalhando 6 hectares no Projeto de Assentamento Calmaria II no município de Acará, totalizando 210 hectares, e 
157 famílias manejam 10 hectares cada uma, perfazendo 1.570 hectares, na região do Alto Moju, no município de Moju, perfazendo, 1.780 hectares plantados com a cultura do dendezeiro na modalidade familiar.

$\mathrm{Na}$ agricultura familiar do dendê a terra e o trabalho são comandados por determinações do capital. A unidade produtiva inserida nos programas tem a possibilidade de cultivar dendê consorciado com mandioca, melancia, feijão, por exemplo, mas somente no primeiro ano de plantio da palma, quando as raízes ainda não estão completamente desenvolvidas e permite o plantio de culturas que não são de raízes profundas. Entretanto, provavelmente, faltaria energia física ao agricultor para essas atividades, visto que a mesma foi utilizada no empreendimento do dendê. Assim, a pluriatividade característica da unidade familiar camponesa, provavelmente, tende a ceder espaço para a especialização produtiva, predominando o que Bernstein (2011) chama de mercantilização da sobrevivência, ou seja, "[a] mercantilização é o processo pelo qual os elementos de produção e reprodução social são produzidos para troca no mercado e nele obtidos e que os sujeita às suas disciplinas e compulsões" (BERNSTEIN, 2011, p. 125).

Esse projeto exemplifica a apropriação do território pelo capital dendeicultor, sem apropriação da terra, nem contratação de força de trabalho. Melhor que isso, ele usa terra e força de trabalho alheios, condição criada pela política de estado que cede terra aos agricultores, desde que numa parte dela eles cultive dendê. O estado, por meio do PRONAF Eco e do Banco da Amazônia S.A., estabelece as condições normativas e creditícias para financiamento dos recursos. E a empresa tem a gestão do território, isto é, regula seus usos por meio da equação tempo, trabalho e ciclo da cultura do dendê, emergindo uma rotina de trabalho que desconsidera o modo de vida do lugar.

As unidades familiares associadas aos projetos de agricultura familiar de dendê não perdem a propriedade jurídica da terra, tampouco as pessoas tornam-se assalariados das empresas; em suma, continuam proprietárias da terra enquanto meio de produção e força produtiva e sua força de trabalho não é vendida à empresa. Porém, quem determina e comanda os usos dessa terra são as empresas; a terra, por meio de contratos entre partes juridicamente iguais e em comum acordo, transformou-se em território usado pelo dendê. Igualmente a força de trabalho de todos que adentram os campos é treinada, comandada e utilizada exclusivamente para a cultura da palma africana. Portanto, o território usado, isto é, a área e seus usos, são utilizados na reprodução do capital dendeicultor, sobretudo quando assinam contrato com o Grupo Agropalma e com o banco. Cria-se, por esse meio, laço de dependência territorial entre os projetos de agricultura familiar, a empresa e o banco, posto que, não é apenas a 
agroindústria do dendê que expropria os rendimentos dos camponeses o capital financeiro também o faz pela dependência destes ao crédito bancário e seu constante endividamento.

Ainda que tenhamos agricultores familiares trabalhando com o dendê, isso não é suficiente para afirmar que o trabalho na cultura e processamento do dendê foi o que lhes atraiu; não induz a afirmar que a segurança salarial oferecida pelas empresas dendeicultoras atrai os agricultores tradicionais. O processo é mais complicado. Compreendemos que não é o projeto de agricultura familiar do dendê o que atrai os agricultores camponeses, mas a ausência de política de estado para as comunidades rurais camponesas direciona o agricultor camponês para reprodução de um modo de vida que não é o seu (NAHUM; BASTOS, 2014). Senão vejamos, o agricultor tradicional não dispõe de alternativa produtiva com o mesmo suporte institucional capaz de se configurar como alternativa ao dendê. Nenhuma linha do PRONAF recebe tanto apoio e incentivo do Estado e do capital quanto o PRONAF ECO, sobretudo no que se refere a garantia de compra do produto a preço de mercado e monitoramento de todas as fases do processo produtivo, a começar pelo piqueteamento da área, treinamento para coleta e mesmo carregamento da produção até a agroindústria. Mesmo as organizações representativas dos camponeses, agricultores familiares e trabalhadores rurais carecem de propostas alternativas à dendeicultura enquanto pensamento único para o desenvolvimento rural, geração de emprego e renda. Movimentam-se no mesmo campo político que reivindica a inclusão da agricultura familiar nos projetos de dendê como única política de estado para o meio rural. Portanto, assistimos, isto sim, a continuidade de um longo processo de formação de um campo sem camponeses, lentamente gestado por um Estado que secundariza política agrária que prime pela reprodução do modo de vida do campesinato tradicional.

As políticas propostas até aqui são desenvolvimentistas e produtivistas, concebem o campo como um espaço econômico, um espaço para produção e não um espaço para viver. Um exemplo é o PRONAF, cuja meta é transformar o camponês tradicional em empreendedor rural. Provavelmente isso explica os movimentos migratórios, pois no meio rural o território é viabilizado pelo Estado para a reprodução do capital, que se apropria de espaços construídos por comunidades e campesinato tradicionais, que mantem com a terra uma relação de pertencimento, berço onde cultivam, criam, extraem e produzem as condições necessárias à produção de seu gênero de vida.

Busca-se nos territórios do dendê emprego e renda, abandona-se a unidade produtiva familiar, forma-se um campo sem camponeses, posto que 
estes se metamorfoseiam, paulatinamente, em trabalhadores para o capital (WANDERLEY, 2009). Esse movimento acentua processos anteriormente existentes nestes espaços rurais tais como a crise na produção familiar de alimentos, envelhecimento do agricultor familiar, enfraquecimento da pluriatividade, dependência e subordinação dos lugares à dinâmica das empresas, enfraquecimento dos movimentos sociais e das lutas pela reforma agrária, dentre outros que são objeto de investigação, análise e interpretação da geografia rural e dos movimentos sociais. Foge aos limites deste texto elucidar como, porque, quando e onde a dendeicultura aprofunda tais processos.

\section{CONSIDERAÇÕES FINAIS}

O espaço rural contém múltiplas possibilidades, sobretudo se concebido numa perspectiva territorial, consideradas a configuração espacial e as dinâmicas sociais que usam o espaço, territorializando ações. Espaço caracterizado pelo uso da terra, como principal força produtiva e meio de produção, por diferentes e divergentes grupos e classes sociais, uns concebendo-o eminentemente como setor produtivo da economia, outros como lugar singularizado por seu modo de vida, o campo é palco, produto e condicionante de lutas entre classes sociais para territorializar seus interesses, isto é, seus usos do território.

Em se tratando do espaço amazônico paraense, desconfiamos do boom do dendê que promete sustentabilidade ambiental, rentabilidade econômica, inclusão social de agricultores familiares, soberania e segurança energética e alimentar, sem que se esclareça para quem e como. Trata-se isto sim de mais um capítulo da questão agrária na Amazônia, onde as virtudes de um produto (drogas do sertão, borracha, manganês, ferro, bauxita, energia e gado) mostram-se insuficientes para assegurar espaços menos desiguais e mais justos. Forma-se isto sim verdadeiros processos de desenvolvimento de comunidades rurais, campos descampesinizados, espaços mais e mais esquizofrênicos, posto que organizados segundo comandos exógenos e não daqueles que cotidianamente os vivem.

A adesão aos projetos de agricultura familiar de dendê desencadeou mudanças na sua condição espacial. Na condição de agricultor camponês as necessidades da família determinavam o ritmo e a intensidade do trabalho no roçado. Igualmente a família comandava e controlava o processo produtivo. No lote do dendê, embora exista a presença do trabalho familiar, o comando e o controle da produção, bem como o ritmo do trabalho são determinados pela temporalidade do mercado mundial, que tem na empresa seu representante local. O agricultor integrado ao projeto não tem o uso do território, pois não 
decide sobre a natureza e a finalidade do trabalho, bom como da reprodução das relações de produção, não decide como e o quê plantar nas entrelinhas do dendê; tampouco pode escolher para quem vender sua produção e a que preço vender, porque estão "presos" pelas normas do contrato, do mercado e da empresa. Nessa condição, os agricultores apenas executam tarefas determinadas pela empresa, assemelhando-se a um trabalhador para o capital sem torná-lo um operário (WANDERLEY, 1985).

Os projetos de agricultura familiar do dendê manifestam o avanço da cultura com ritmo, finalidade e comando do trabalho dados pela comercialização do óleo de palma nos mercados de commodities. Tais projetos configuram-se como principais fontes de renda e reprodução das famílias, o que levou Nahum e Santos (2015) a sustentar que nos lugares em torno de onde se pratica a monocultura do dendê se reproduz um espaço rural sem camponês; mais que isso, os camponeses ao se integrarem aos projetos de agricultura familiar acentuam processos de descampesinização, tornando-se agricultores do dendê.

Muda-se a paisagem, a configuração espacial e a dinâmica social dos camponeses da comunidade do Arauaí e em torno. Esses lugares, tal como outros no município de Moju até o último quartel do século XX, eram marcados por sítios enquanto espaços da vida, unidade na diversidade de atividades e trabalho na rotina da roça, vivificada pela família ou mesmo pela solidariedade dos mutirões ritmados pelos ciclos naturais e neles os roçados de mandioca. Propagandeado como solução para a precariedade estrutural em que viviam os camponeses, o projeto de dendê familiar configura-se como estratégia do Estado brasileiro para que a empresa dendeicultura use o território, isto é, a área e a força de trabalho, sem que para isso tenha que adquirir terra e assalariar trabalhadores.

Ancorado num discurso de geração de emprego, renda e inclusão social, o projeto amplia a capacidade de consumo dos agricultores. O grande atrativo do projeto é que ele ampliar o poder de compra do agricultor integrado. Nesta situação emerge a enigmática figura do agricultor integrado à produção de dendê, que não é nem capitalista, pois que a lógica de sua unidade produtiva não é a reprodução do capital, nem é assalariado, posto que não é força de trabalho contratada pela empresa, tampouco continua camponês, visto que se alterou a natureza do trabalho, e, por conseguinte a paisagem, a configuração espacial, a dinâmicas social, enfim o território usado ou espaço geográfico enquanto quadro da sua vida. Lembrando Chayanov, podemos dizer que no lote de dendê o ritmo de trabalho não é definido pela equação trabalho versus necessidades camponesas. Longe disso, o calendário agrícola desenvolvido reduz o camponês à condição de produtor de fruto fresco colhido, matéria-prima sem qualquer 
valor agregado, atrativa tão somente pela voracidade do mercado de palma, pelas vantagens econômicas e técnicas oferecidas aos agricultores comparadas às demais culturas.

A dendeicultura não é a solução, nem é a causa dos males que afligem o espaço rural nas áreas antropizadas. É preciso superar a tradição política que subordina o desenvolvimento da Amazônia à ascensão e queda de um produto no mercado mundial, que deposita todas as esperanças ou mesmo amaldiçoa determinado produto; política que se regozija ao dizer "nossos minérios", "nossa floresta", "nossas riquezas" ou mesmo que repete o mito do desenvolvimento em muitos adjetivos, regional, sustentável, territorial, participativo. Esquecendo-se de perguntar quem usufrui das riquezas, sejam elas essências florestais, borracha, madeira, minérios, energia hidroelétrica e dendê. Dendê para quem? Dendê por quê? Dendê para quê?

Portanto, é preciso perguntar quem ganha com a dendeicultura, pois tão importante quanto ressaltar as potencialidades econômicas, ambientais e sociais do dendê, faz-se necessário refletir sobre quem usufrui dos dividendos dessas potencialidades, ou seja, quem fica com a renda da terra e se beneficia do território; refletir sobre os impactos no modo de vida do lugar onde o agronegócio do dendê se implanta e expande, isto é, sobre o que significa passar da condição de lavrador para agricultor de dendê ou de outro modo, de camponês tradicional para agricultor familiar do dendê, trabalhador para o capital.

\section{REFERÊNCIAS}

ABRAMOVAY, R. Paradigmas do capitalismo agrário em questão. São Paulo: Edusp, 2012.

ALTVATER, E. O fim do capitalismo como o conhecemos. Uma crítica radical do capitalismo. Rio de Janeiro: Civilização Brasileira, 2010.

ALVES, R. N. B.; CARDOSO, C. E. L. Sistemas e custos de produção de mandioca desenvolvidos por pequenos agricultores familiares do município de Moju, PA. Belém, Embrapa Amazônia Oriental. 2008.

AUBERTIN, Catherine (Org.). Fronteiras. Brasília: Editora da UNB, 1988.

BASA. "A experiência do Banco da Amazônia com projetos integrados de dendê familiar". Revista Contexto Amazônico. Ano 5, n. 22, 2012. Disponível em: http://www.bancoamazonia.com.br/images/arquivos/institucional/biblioteca/ boletim/contexto_amazonico_22.pdf. Acesso em: 04 mar. 2018. 
BERNSTEIN, H. Dinâmicas de classe da mudança agrária. São Paulo, Unesp, 2011.

BRASIL. Decreto n. 5.297, de 6 de dezembro de 2004, Dispõe sobre os coeficientes de redução das alíquotas da Contribuição para o PIS/PASEP e da COFINS [...]. Disponível em: http://www.planalto.gov.br/ccivil_03/_Ato2004-2006/2004/ Decreto/D5297.htm. Acesso em: 02 mar. 2018

CARDoso, F. H.; MÜLLER, G. Amazônia: expansão do capitalismo. Rio de Janeiro: Centro Edelstein de Pesquisas Sociais, 2008 .

CARVALHO, A. C. A. de C; NAHUM, J. S. Período do dendê na Amazônia paraense. In: NAHUM, J. S. (Org.). Dendeicultura e dinâmicas territoriais do espaço agrário na Amazônia Paraense. Belém: GAPTA/UFPA, 2014. p. 13-40.

CASTRO, A. M. G. de; LIMA, S. M. V; SILVA, J. F. V. Complexo Agroindustrial de Biodiesel no Brasil: competitividade das cadeias produtivas de matérias-primas. Brasília: Embrapa Agroenergia, 2010.

CHAUÍ, M. Cultura e democracia. São Paulo: Editora Cortez, 1990.

CHAYANOV, A. V. Sobre a teoria dos sistemas econômicos não capitalistas. In: SILVA, J. G.; STOLKE, V. (Org.). A questão agrária. São Paulo: Brasilense, 1981. p. $133-163$

CRUZ, B. E. V. da. Territorialização e organização espacial do Grupo Agropalma. 2006. Dissertação (Mestrado em Geografia) - Instituto de Filosofia e Ciências Humanas, Universidade Federal do Pará, Belém, 2006.

D'INCAO, M. A; SILVEIRA, I. M. da (Org.). A Amazônia e a crise da modernização. Belém: MPEG, 1994.

EMBRAPA. Zoneamento agroecológico do dendezeiro para as áreas desmatadas da Amazônia legal. Rio de Janeiro, Embrapa, 2010.

Embrapa Amazônia Oriental e o Agronegócio do Dendê no Pará.

Belém: Embrapa, 2006. Disponível em: https://www.embrapa.br/busca-depublicacoes/-/publicacao/394940/a-embrapa-amazonia-oriental-e-o-agronegociodo-dende-no-para Acesso em: 04 mar. 2018.

FURLAN, JÚNIOR et al. Biodiesel. Porque tem que ser dendê. Belém: EMBRAPA/ PALMASA, 2006.

GIDDENS, A. A política da mudança climática. Rio de Janeiro: Zahar Editora, 2010 .

HOUTART, F. A agroenergia. Solução para o clima ou saída da crise para o capital? Petrópolis: Vozes, 2010. 
LÉNA, P; OlIVEIRA, A. E. de. Amazônia. A fronteira agrícola 20 anos depois. Belém: CEJUP, 1992.

LIMA, S. M. V, CASTRO, A. M. G de. Agronegócio do biodiesel e suas matérias primas. In: CASTRO, A. M. G. de; LIMA, S. M. V; SILVA, J. F. V. (Org.). Complexo Agroindustrial de Biodiesel no Brasil: competitividade das cadeias produtivas de matérias-primas. Brasília: Embrapa Agroenergia. 2010. p. 47-112

MAPA. Anuário estatístico da agroenergia Brasília. 2010. Disponível em: http:/ / www.agricultura.gov.br/assuntos/sustentabilidade/agroenergia/pasta-anuarioestatistico-da-agroenergia/anuario-estatistico-da-agroenergia. Acesso em: 04 mar. 2018.

MARTINS, J de. S. Fronteira. A degradação do outro nos confins do humano. São Paulo: Editora HUCITEC, 1997.

MÜLLER, Antônio. A cultura do dendê. Belém, EMBRAPA-CPATU, 1980.

NAHUM, J. S. Região e representação: a Amazônia nos planos de Desenvolvimento. Biblio 3W revista bibliográfica de geografía y ciencias sociales, Universidad de Barcelona, v. XVII, n. 985, 2012. Disponível em: http://www.ub.edu/geocrit/b3w985.htm. Acesso em : 04 mar. 2018.

NAHUM, J. S; BASTOS, C. S. Dendeicultura e descampesinização na Amazônia paraense. Campo-Território: revista de geografia agrária, v. 9, n. 17, p. 469-485, abr. 2014. Disponível em: http://www.seer.ufu.br/index.php/campoterritorio/ issue/view/1113. Acesso em: 05 mar. 2018.

NAHUM, J. S; MALCHER, A. T. Dinâmicas territoriais do espaço agrário na Amazônia: a dendeicultura na microrregião de Tomé-Açu (PA). Confins [Online], v. 16, 2012. Disponível em: http://confins.revues.org/7947?lang=pt. Acesso em: 05 mar. 2018.

NAHUM, J. S.; SANTOS, C. B. Do sítio camponês ao lote de dendê: transformações do espaço rural na Amazônia paraense no século XXI. Revista NERA, Presidente Prudente-SP, v. 20, n. 37, p. 54-76, maio/ago. 2017. Disponível em: http://revista. fct.unesp.br/index.php/nera/issue/view/312. Acesso em: 05 mar. 2018.

O boom do dendê na microrregião de Tomé-Açu, na Amazônia paraense. Confins [Online], v. 25, nov. 2015. Disponível em: http://journals. openedition.org/confins/10536. Acesso em: 05 mar. 2018.

Impactos socioambientais da dendeicultura em comunidades tradicionais na Amazônia paraense. ACTA Geográfica, Boa Vista, Ed. Esp. Geografia Agrária, 2013. Disponível em: http://revista.ufrr.br/index.php/actageo/ issue/view/117/showToc. Acesso em : 05 mar. 2018. 
PINTO, G. Pompeu et al. Avaliação do projeto de agricultura familiar com dendê para fabricação de Biodiesel - Moju/PA, 2009. Monografia (Especialização em Produção de Biodiesel) - Universidade Federal do Pará/Universidade Federal Rural da Amazônia, Belém, 2009.

REPÓRTER BRASIL. Agricultura familiar e o programa nacional de Biodiesel: retrato do presente, perspectivas de futuro. Centro de Monitoramento de Agrocombustíveis, 2010. Disponível em: http://reporterbrasil.org.br/documentos/ AgriculturaFamiliar_Biodiesel2010.pdf. Acesso em: 05 mar. 2018.

RIVAL, A.; LEVANG, P. La palma de la controversia: La palma aceitera y los desafíos del desarrollo. Bogor, Indonesia: CIFOR, 2014.

SANTOS, C. B. Dendeicultura e comunidades tradicionais: uma análise do município de Moju. Belém: Itacaúnas, 2015.

SANTOS, M. A natureza do espaço. Técnica e tempo. Razão e emoção. São Paulo: Edusp, 2006.

SANTOS, M.; SILVEIRA, M. L. O Brasil. Território e sociedade no início do século XXI. São Paulo: Editora Record, 2001.

SEMEDO, I. O mercado de energia renovável: viabilidade econômica do dendê na agricultura familiar do Baixo Sul-Bahia. 2006. Dissertação (Mestrado em Economia) - Universidade Federal da Bahia, Salvador, 2006

SILVA, J. S de. Produtividade de óleo de palma na cultura do dendê na Amazônia oriental: influência do clima e do material genético. 2006. Dissertação (Mestrado em Fitotecnia) - Universidade Federal de Viçosa, Viçosa-MG, 2006.

SILVA, Maia, Ricardo Ramos da. Biodiesel no Brasil: análise de custo-benefício. Curitiba: Appris, 2015.

SMITH, A. A riqueza das nações. Investigação sobre sua natureza e suas causas. São Paulo: Editora Nova Cultural, 1996.

SUFRAMA/FGV. Potencialidades regionais. Estudo da viabilidade econômica do dendê. Manaus, 2003. Disponível em: http://www.suframa.gov.br/publicacoes/ proj_pot_regionais/dende.pdf. Acesso em: 05 jun. 2018.

WANDERLEY, M de. N. B. O mundo rural como um espaço de vida. Reflexões sobre a propriedade da terra, agricultura familiar e ruralidade. Porto Alegre: Editora da UFRGS, 2009.

O camponês: um trabalhador para o capital. Cadernos de Difusão de Tecnologia, Brasília, v. 2, n. 1, p. 13-78, jan./abr., 1985.

Texto submetido à Revista em 07.11.2016 Aceito para publicação em 27.09.2017 


\section{Mudanças socioambientais no uso da terra em Altamira, Amazônia oriental}

\section{Environmental changes in land use in Altamira, Eastern Amazon}

Maristela Marques Silva - Mestre em Agroecossistemas - UFSC, Doutora em Ciências Agrárias - UFRA, docente da Universidade Federal do Pará/UFPA. E-mail: stela@ufpa.br

Francisco Assis Oliveira - Doutor em Hidrologia e Manejo de Ecossistemas. Instituto de Ciências Agrárias (ICA), Universidade Federal Rural da Amazônia (UFRA). E-mail: francisco.oliveira@ufra.edu.br

Antônio Cordeiro Santana - Doutor em Economia Rural, docente da Universidade Federal Rural da Amazônia (UFRA), Instituto Socioambiental e Recursos Hídricos (ISARH). E-mail: acsantana@superig.com.br

\section{Resumo}

Este estudo tem como objetivo analisar as principais mudanças no uso da terra e caracterizar os principais fatores que influenciam estas mudanças a partir de um estudo de caso no "Projeto de Assentamento Assurini", uma área representativa dos sistemas de produção agrícolas do município de Altamira, no Estado do Pará. Foram entrevistadas 50 famílias que residem no assentamento no período de outubro de 2012 a julho de 2013. As análises dos dados foram realizadas através da estatística multivariada, com análise fatorial e a análise de agrupamentos, utilizando 15 variáveis ligadas aos sistemas de produção. Os resultados indicaram que a criação de bovinos, o cultivo de cacau, aspectos ambientais, outras fontes de renda e as culturas anuais são os principais fatores que determinam as mudanças no uso da terra. Constatou-se, ainda, a diminuição das áreas de floresta primária, diminuição das áreas com cultivos anuais e o crescimento da dependência das famílias de outras fontes de renda.

\section{Palavras-chave}

Agricultura Familiar. Floresta Primária. Bovinos. Cacau. Culturas Anuais.

\begin{abstract}
This study aims to analyze the major changes in land use and characterize the main factors influencing these changes from a case study in "Settlement Project Assurini", a representative area of agricultural production systems in the municipality of Altamira, in the State of Pará. We interviewed 50 families living in the settlement from October 2012 to July 2013. Data analyzes were performed using the multivariate analysis, with factor analysis, and cluster analysis using 15 variables related to production systems. The results indicated that the cattle, cocoa farming, environmental, other sources of income and annual crops are the main factors that determine the changes in land use. It was found also decreased in the areas of primary forest, decrease in areas with annual crops and the growing dependence of the families of other sources of income.
\end{abstract}

\section{Keywords}

Family Farming. Primary Forest. Cattle. Cocoa. Annual Crops. 


\section{INTRODUÇÃO}

O uso da terra, em geral, tem sido considerado um problema ambiental local. No entanto, as ações humanas estão alterando o ambiente terrestre a taxas sem precedentes em todo o mundo, impulsionadas pelo avanço de cultivos agrícolas, pastagem e expansão das áreas urbanas, tornando-se um problema global à medida que tem habilitado os humanos a se apropriar dos recursos naturais do planeta, utilizados de forma não racional e causando impactos irreversíveis aos ecossistemas (FOLEY et al., 2005).

As mudanças no uso da terra são intensas em todo o mundo, mas, particularmente, na Amazônia brasileira, esse processo tem atraído atenção nos últimos trinta anos devido ao desmatamento acelerado, resultado de ocupação desordenada por meio de programas de desenvolvimento baseados em eixos de desenvolvimento, que resultaram na construção de estradas como a Rodovia Transamazônica (BATISTELLA; MORAN, 2005; BRONDIZIO, 2014). O município de Altamira, no estado do Pará, foi uma das áreas centrais do Programa Integrado de Colonização (PIC) e sofreu mudanças drásticas em sua estrutura produtiva, passando de uma região que tinha sua base econômica no extrativismo de produtos da floresta, para uma economia baseada em atividades agrícolas, direcionadas para o mercado.

As formas de uso da terra no município de Altamira acompanharam as etapas que ocorreram na região da Transamazônica como um todo. $\mathrm{Na}$ fase inicial de ocupação, que envolveu o período de 1972 a 1978, a base produtiva da região foram as culturas anuais (arroz, milho, feijão e mandioca), subsidiadas com crédito a juros baixos (CASTELLANET et al., 1998). As culturas perenes foram introduzidas na região a partir de 1976, destacando-se a pimenta-do-reino, que recebeu incentivos fiscais do Banco do Brasil, e o cacau, incentivado pelo Programa Procacau (SABLAYROLLES; ROCHA, 2003).

Essa etapa durou aproximadamente dez anos. No entanto, no final da década de 1980, ocorrem problemas fitossanitários, queda dos preços e dificuldades com a comercialização, causando o declínio das culturas perenes em toda a região da Transamazônica. Tal declínio favoreceu o desenvolvimento da pecuária na região, principalmente nos pequenos e médios estabelecimentos (TOURRAND et al., 1998). Durante o processo de ocupação, vários fatores têm influenciado as mudanças de uso da terra na região. Brondizio (2009) destaca que o efeito da idade da família, os efeitos periódicos como flutuações na migração, diferentes políticas de crédito, inflação, entre outras, são determinantes para tais mudanças. 
Atualmente, Altamira entra novamente no cenário nacional com a implantação de uma das principais obras de infraestrutura do Programa de Aceleração do Crescimento (PAC) com a construção do Complexo Hidrelétrico do Xingu, o que resultou em impactos ambientais, sociais e econômicos para a região como um todo (CORRÊEA, 2016). A partir deste contexto, este estudo tem como objetivo analisar as principais mudanças no uso da terra e caracterizar os principais fatores que influenciam estas mudanças em sistemas de produção familiares. Para entender essas mudanças foi realizado um estudo de caso no Projeto de Assentamento Assurini, uma área próxima à sede de Altamira, considerada um polo de produção agrícola e que possui relações econômicas, sociais e ambientais importantes para o município.

\section{MATERIAIS E MÉTODOS}

\section{1 ÁREA DE ESTUDO}

A área conhecida como Projeto de Assentamento Assurini localizase próxima à sede do município de Altamira. A primeira frente de ocupação da área começou na margem direita do rio Xingu, na época do Segundo Ciclo da Borracha, na década de 1940, com a migração de famílias nordestinas para explorar o látex da borracha, sendo intensificada na década de 1960, com o surgimento do extrativismo de pele de animais silvestres e coleta de castanha (PACHECO et al., 2009).

No final dos anos de 1970, tais famílias começaram a reivindicar, junto ao INCRA, a regularização fundiária e em 1981 foi iniciada a demarcação das primeiras áreas ocupadas pelas famílias (PACHECO et al., 2009).No entanto, a área só foi oficializada pelo INCRA em 1995, na categoria de Projeto de Assentamento (PA), devido às políticas de regularização das ocupações já existentes que haviam sido iniciadas em meados da década de 1990. O assentamento possui uma área de $32.140,15 \mathrm{~km}^{2}$ e conta com 574 domicílios ocupados e 1.453 habitantes (IBGE, 2010).

A pesquisa foi desenvolvida de outubro de 2012 a julho de 2013, sendo entrevistadas 50 famílias que residem em 04 localidades no Projeto de Assentamento Assurini. Estas localidades foram escolhidas por estarem bem distribuídas ao longo da área do assentamento e serem de fácil acesso, pois se localizam nas margens ou próximas da rodovia Transassurini (Figura 1). 
Figura 1 - Localização das propriedades no Projeto de Assentamento Assurini, Altamira - Pará

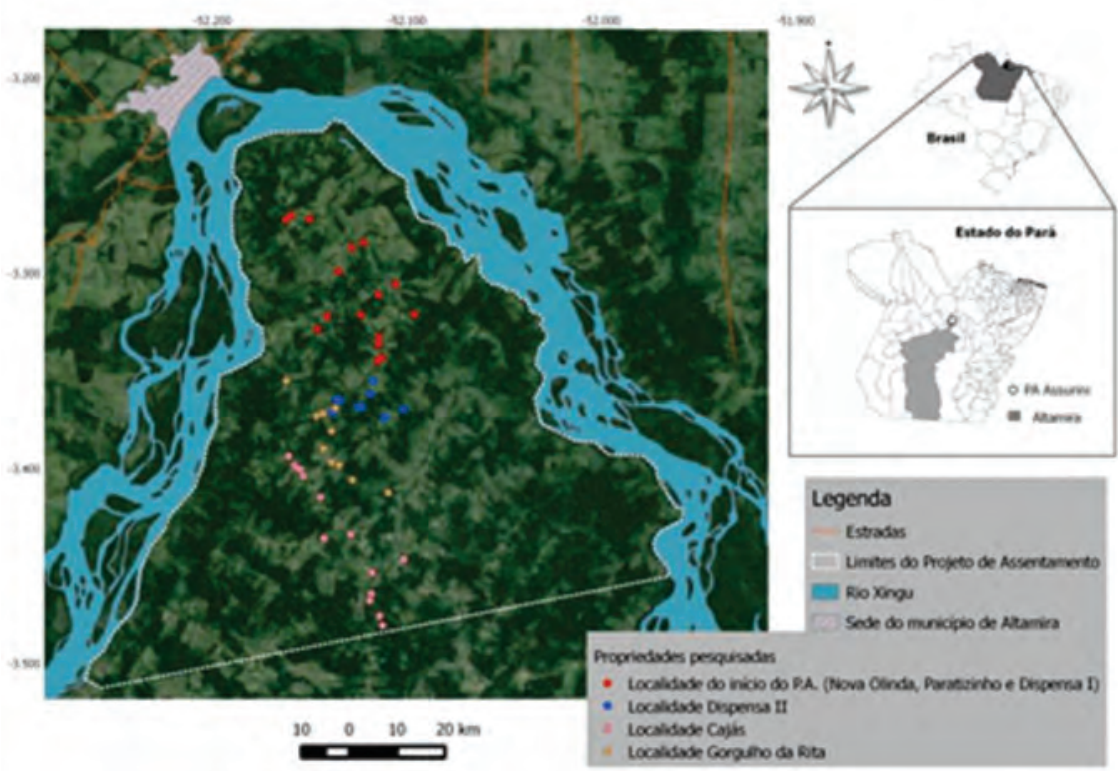

Fonte: Elaborado por M. J. M. PEREIRA

\subsection{COLETA E ANÁLISE DOS DADOS}

As informações foram obtidas por meio de entrevistas semiestruturadas onde foram abordados aspectos relacionados ao histórico de vida das famílias, caracterização dos sistemas de produção, mudanças nas práticas de manejo e principais formas de uso da terra no assentamento. Além das entrevistas, foram realizadas visitas nas parcelas cultivadas com o objetivo de conhecer as áreas e verificar o meio natural das propriedades estudadas.

Para entender as mudanças no uso da terra predominantes na área de estudo, utilizou-se da estatística multivariada com base na análise fatorial e na análise de agrupamentos. As informações foram obtidas por meio de questionários estruturados, o qual continha questões a respeito do sistema de produção, das formas de uso da terra, da renda das atividades, dos custos de produção e das limitações dos sistemas de produção desenvolvidos na região.

As variáveis que foram utilizadas na análise são as seguintes:

X1 - Tamanho da propriedade (TP) - ha

X2 - Área de floresta primária (AFP) - ha

X3- Área de floresta secundária (AFS) - ha 
$\mathrm{X} 4$ - Cabeças de bovinos $(\mathrm{CB})-\mathrm{n}^{\circ}$

X 5 - Mão-de-obra familiar (MOF)

X 6 - Renda do Gado (RG) - R\$

X 7 - Renda da cultura do cacau (RCC) - R\$

$\mathrm{X} 8$ - Rendas de culturas anuais e outras produções (ROP) - R \$

X 9 - Renda obtida com aposentadoria (RA) - R\$

X 10- Renda obtida com empregos (RE) - R\$

X 11-Custo manutenção da pastagem (CMP) - R \$

$\mathrm{X} 12$ - Custo com vacinas e sal mineral (CVS) - R\$

X13 - Custo na aquisição de insumo (CAI) - R\$

$\mathrm{X} 14$ - Custo com tratos culturais do cacau (CTC) - R\$

X15 - Custos com culturas anuais e outras produções (CCA) - R\$

A análise fatorial, de modo geral é utilizada para estudar a estrutura das interrelações entre um grande número de variáveis, definindo um conjunto de variáveis que são fortemente interrelacionadas, denominadas de fatores. Esses grupos de variáveis (fatores), que são altamente relacionados, são considerados como representantes das dimensões dentro dos dados (HAIR et al., 2009). Conforme Hair et al. (2009), um modelo de análise fatorial na forma matricial, é definido pela equação 1 :

$$
X=\alpha F+\varepsilon
$$

\section{Em que:}

$\mathrm{X}=$ é o $\mathrm{p}$-dimensional vetor transposto das variáveis observáveis, denotado por $\mathrm{X}=(\mathrm{x} 1, \mathrm{x} 2, \ldots, \mathrm{xp})^{\prime} ; \mathrm{F}=$ é o q-dimensional vetor transposto de variáveis não observáveis ou variáveis latentes chamadas de fatores comuns, denotado por, $\mathrm{F}=(\mathrm{f} 1, \mathrm{f} 2, \ldots, \mathrm{fq})$ ', sendo que $\mathrm{q}<\mathrm{p} ; \varepsilon=$ é o p-dimensional vetor transposto de variáveis aleatórias ou fatores únicos, $\varepsilon=(\mathrm{e} 1, \mathrm{e} 2, \ldots, \mathrm{ep})^{\prime} ; \alpha=$ é a matriz $(\mathrm{p}, \mathrm{q})$ de constantes desconhecidas, chamadas de cargas fatoriais. No modelo de análise fatorial pressupõe-se que os fatores específicos são ortogonais entre si e com todos os fatores comuns. Normalmente, $\mathrm{E}(\varepsilon)=\mathrm{E}(\mathrm{F})=0$ e $\operatorname{Cov}(\varepsilon, \mathrm{F})=0$.

Os fatores serão identificados por meio da técnica da raiz latente, que parte do princípio de que qualquer fator individual deve explicar a variância de pelo menos uma variável para que seja mantido para interpretação. Cada variável contribui com um valor 1 do autovalor total. Com efeito, apenas os fatores que têm raízes latentes ou autovalores maiores que 1 são considerados significantes e os demais fatores, com autovalores menores do que 1, são considerados insignificantes e descartados (SANTANA, 2007). 
Para facilitar a interpretação dos fatores é realizada uma rotação ortogonal pelo método Varimax, que procura minimizar o número de variáveis fortemente relacionadas com cada fator, permitindo obter fatores mais facilmente interpretáveis. Para identificar a adequação do método à amostra de dados, foi utilizado o teste de Kaiser-Meyer-Olkin Measure of Sampling Adequacy (KMO), que se baseia no princípio de que a inversa da matriz de correlação se aproxima da matriz diagonal, comparando as correlações entre as variáveis observadas. Os valores do teste variam de 0 a 1 e os valores de KMO abaixo de 0,50 indicam a não adequabilidade da análise. Foi também aplicado o teste esferecidade de Barllet, que fornece a significância estatística de que a matriz de correlação tem correlações significantes com pelo menos uma das variáveis (HAIR et al., 2009).

Para entender como os principais fatores identificados na análise fatorial fazem parte do modo de vida das 50 famílias, realizou-se a análise de agrupamentos por meio do método hierárquico, com as mesmas variáveis usadas na análise fatorial. Todas as análises estatísticas foram realizadas utilizando o Programa Estatístico Statistical Package for Social Science (SPSS), versão 20.

\section{RESULTADO E DISCUSSÃO}

\subsection{CARACTERIZANDO O USO DA TERRA NO ASSENTAMENTO}

Entre as famílias que participaram deste estudo, os homens possuem idade no intervalo de 29 \pm 79 anos, com média de 55 anos, e as mulheres, idades de $26 \pm 74$ anos, com média de 50 anos. O número de filhos por família varia de $1 \pm 11$ filhos, com o número médio de 4,7. No entanto, nota-se uma grande mobilidade de jovens e adultos na área do assentamento, já que apenas 27\% dos filhos moram com a família na área; 44\% moram em Altamira; 19\% moram na área do assentamento, mas em outras propriedades; e 10\% moram em outras cidades.

Por estar localizada muito próxima à sede do município, na área do assentamento ocorre uma grande mobilidade de pessoas, que se intensificou a partir da construção do Complexo Hidrelétrico de Belo Monte, em Altamira. Assim, 14\% (n.7) das famílias informaram que os filhos saíram recentemente do assentamento para trabalhar em empresas prestadoras de serviços ou no consórcio construtor da obra em Altamira. 
As primeiras famílias que chegaram ao assentamento na década de 1970, dedicaram-se exclusivamente ao plantio das culturas anuais por meio do sistema de corte e queima, com destaque para o cultivo de mandioca (Manihot esculenta Crantz) para produção de farinha, que era o principal meio de subsistência dessas famílias. Com a venda da farinha, as famílias conseguiram recursos para continuar investindo em outros cultivos como o arroz (Oriza sativa L.), o milho (Zea mays L.) e o caupi (Vigna unguiculata (L.) Walp).

A partir de 1990 inicia-se o processo de organização da comunidade em torno de reivindicações a respeito da melhoria da infraestrutura do assentamento, como a abertura da estrada e a construção de escolas, culminando com o processo de regularização do assentamento realizado pelo Instituto Nacional de Colonização e Reforma Agrária (INCRA), em 1995. Logo em seguida, é realizada a abertura da rodovia Transassurini que percorre toda área do assentamento.

Essas mudanças no assentamento influenciaram diretamente as formas de uso da terra, resultando em um novo direcionamento nas atividades agrícolas, notadamente o surgimento dos primeiros plantios de pastagem, por meio da implantação dos primeiros financiamentos através do Fundo Constitucional de Desenvolvimento da Região Norte (FNO).

A partir do ano 2000 foram introduzidos os primeiros cultivos de cacau e de hortaliças. Essas atividades foram favorecidas pela abertura da estrada, o que facilitou o transporte dos produtos para serem comercializados na Feira do Produtor na sede do município. Neste período também foram introduzidos os primeiros Sistemas Agroflorestais (SAF), por intermédio de uma iniciativa do Projeto Roça Sem Queimar ${ }^{1}$, tendo o cacau o como espécie principal, geralmente associada com espécies florestais ou frutíferas de valor econômico na região.

No entanto, a partir da implantação da atividade pecuária, ocorrem mudanças significativas na estrutura produtiva do assentamento e os cultivos anuais começam a dar espaço para pastagem, resultando em mudanças nas áreas cultivadas no assentamento (Figura 2).

O Projeto Roça Sem Queimar foi uma iniciativa realizada pela Fundação Viver Produzir e Preservar, com o apoio do Ministério do Meio Ambiente, implantada na Região da Transamazônica a partir do ano 2000, que visava buscar alternativas de preparo de área sem o uso do fogo. 
Figura 2 - Demonstrativo da área média cultivada pelas famílias nos anos de 2000 e de 2013 no Projeto de Assentamento Assurini, em Altamira - Pará

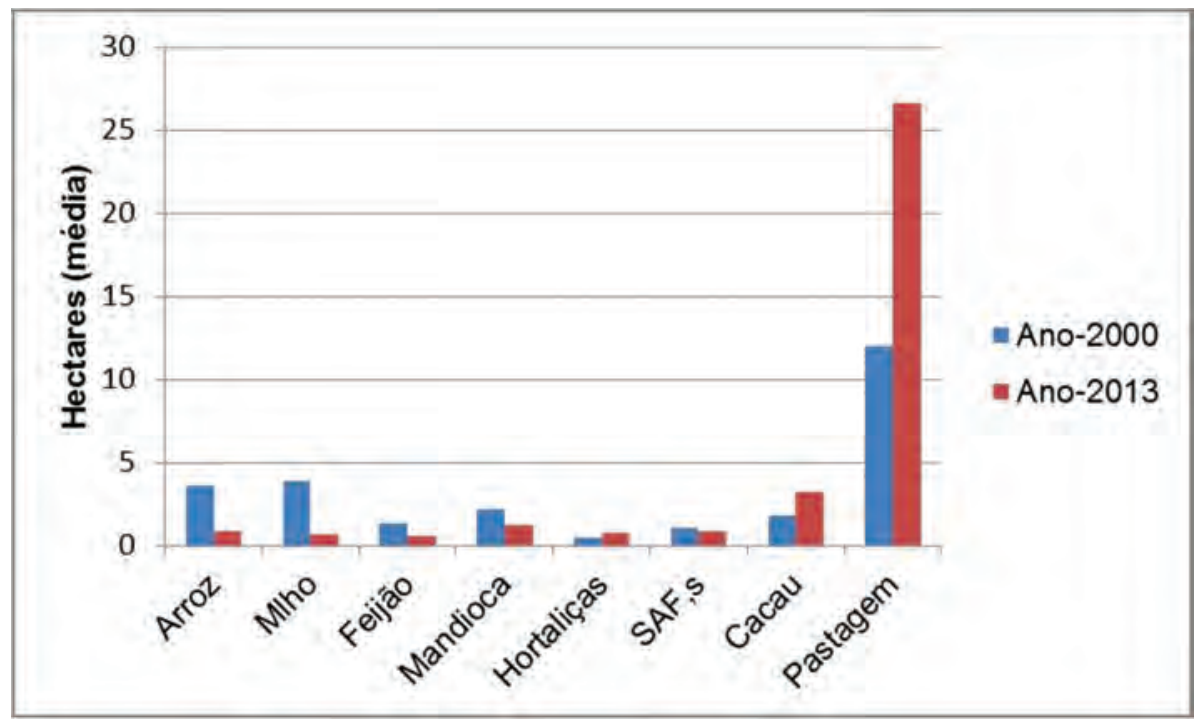

Fonte: Elaborado pelos autores

Como se nota, no período de treze anos houve uma redução nas áreas cultivadas com os cultivos anuais e uma expansão das áreas cultivadas com cacau e pastagem, indicando a expansão da pecuária na área do assentamento.

\subsection{FATORES QUE INFLUENCIARAM AS MUDANÇAS DE USO DA TERRA NO ASSENTAMENTO}

Para identificar os principais fatores que influenciam as formas atuais de uso da terra no assentamento foi utilizada a análise fatorial, a partir da organização das variáveis envolvidas no sistema de produção.

O resultado do teste KMO foi de 0,586; o do teste de Bartlett foi de 452.638, significante a 1\%; e o valor do Determinante foi de 3,75, demonstrando a adequação da amostra à análise fatorial. Esses resultados indicam que as variáveis são correlacionadas e que a solução do modelo é a mais adequada, portanto, a amostra de dados se adequa à aplicação do modelo de análise fatorial (SANTANA, 2007). Por intermédio do critério da raiz latente, foram definidos cinco fatores envolvidos no sistema de produção (Tabela 1). 


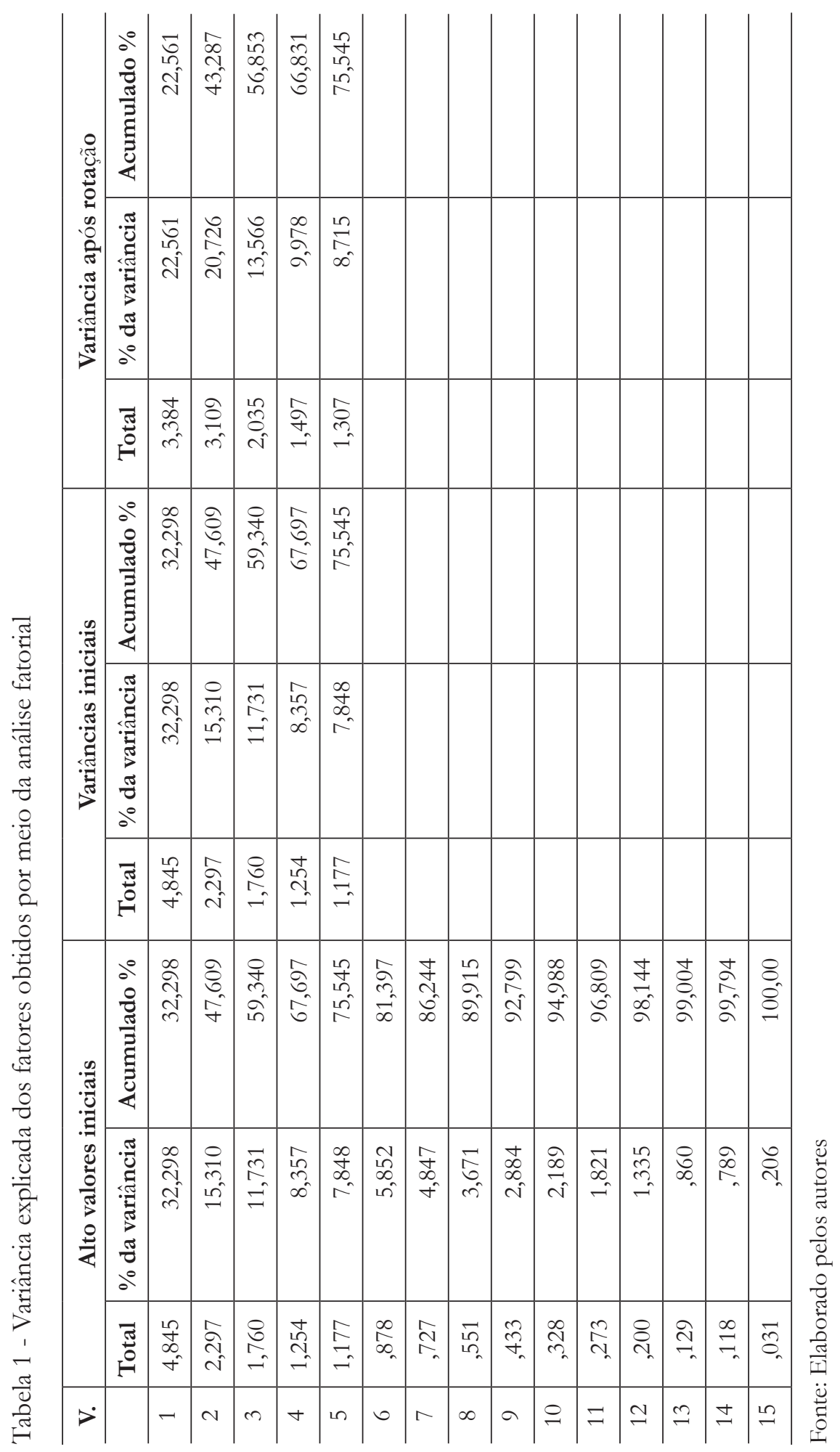


Os fatores identificados na análise explicam $75,54 \%$ da variância total, indicando uma boa representatividade da variância total dos dados. Foram identificadas, ainda, as variáveis que compõem cada fator e colocada a comunalidade correspondente a cada variável. A comunalidade representa a proporção da variância captada pelos fatores para cada indicador, ou seja, o poder de explicação destes fatores em relação a cada variável (Tabela 2). A escolha das variáveis que formam cada um dos fatores ocorreu verificando-se as cargas fatoriais de cada variável, da esquerda para direita e ao longo de cada linha, elegendo-se a carga fatorial de maior valor absoluto (SANTANA, 2007).

Tabela 2 - Matriz de cargas fatoriais rotacionadas

\begin{tabular}{|c|c|c|c|c|c|c|}
\hline \multirow{2}{*}{ Variáveis } & \multicolumn{5}{|c|}{ Fatores } & \multirow{2}{*}{$\begin{array}{l}\text { Comu- } \\
\text { nalidade }\end{array}$} \\
\hline & FPP & FPC & FAAM & FOR & FCAO & \\
\hline $\mathrm{N}^{\circ}$ de cabeças de bovinos (CB) & 827 & 140 & 222 & 167 &,- 088 & ,789 \\
\hline Mão-de-obra familiar (MOF) & ,722 &,- 119 &,- 1.15 &,- 159 & 114 & ,587 \\
\hline $\begin{array}{l}\text { Custo com manutenção da } \\
\text { pastagem }(\mathrm{CMP})-\mathrm{R} \$\end{array}$ &, 734 & ,414 & ,301 & ,064 &,- 017 & 805 \\
\hline $\begin{array}{l}\text { Custo com vacinas e sal mine- } \\
\text { ral (CVS) - R\$ }\end{array}$ & ,791 & ,414 & ,301 & 064 &,- 017 & ,743 \\
\hline Renda do gado $(\mathrm{RG})-\mathrm{R} \$$ &, 588 & ,487 & , 194 & 207 &,- 184 & ,698 \\
\hline $\begin{array}{l}\text { Renda da cultura do cacau } \\
\text { (RCC) - R } \$\end{array}$ & ,008 & ,917 & ,078 & ,047 &,- 004 & 850 \\
\hline $\begin{array}{l}\text { Custo com tratos culturais do } \\
\text { cacau (CTC) - R\$ }\end{array}$ &,- 040 & ,912 & ,228 & ,038 &,- 009 & ,888 \\
\hline Custo na aquisição de insumo & ,301 & ,768 &, 010 & ,093 &, 074 & 694 \\
\hline $\begin{array}{l}\text { Área com floresta secundária } \\
(\mathrm{AFS}) \text { - ha }\end{array}$ &,- 357 &,- 474 & ,245 & ,020 & ,280 & ,491 \\
\hline $\begin{array}{l}\text { Área de floresta primária } \\
(\mathrm{AFP})-\mathrm{ha}\end{array}$ & ,076 & ,097 & 900 &,- 154 &,- 067 & ,852 \\
\hline Área da propriedade (AP) - ha & ,374 & ,118 & ,879 & ,062 &,- 049 & ,934 \\
\hline $\begin{array}{l}\text { Renda obtida com aposenta- } \\
\text { doria (RA) - R\$ }\end{array}$ & ,140 &,- 100 & ,045 & 859 & ,117 & ,784 \\
\hline $\begin{array}{l}\text { Renda obtida com empregos } \\
\text { (RE) - R\$ }\end{array}$ & ,073 &,- 300 & , 166 &,- 782 & ,055 & ,738 \\
\hline
\end{tabular}

Fonte: Dados da pesquisa

Em relação às comunalidades obtidas, destacam-se as variáveis: área da propriedade $(0,934)$, custo com tratos culturais do cacau $(0,888)$, área de floresta primária $(0,852)$ e renda da cultura do cacau $(0,850)$, demonstrando que essas variáveis são significantes para determinação dos fatores. As variáveis área de 
floresta secundária $(0,491)$ e mão-de-obra familiar $(0,587)$ apresentaram valores baixos, indicando que essas variáveis tiveram uma menor contribuição na determinação dos fatores.

O primeiro fator, denominado de produção pecuária (FPP), explicou $31,439 \%$ da variância total, composto pelas seguintes variáveis: cabeças de bovinos (CB), mão-de-obra familiar (MOF), custo manutenção da pastagem (CMP), custo com vacinas e sal mineral (CVS) e renda do gado (RG).

O segundo fator, denominado produção de cacau (FPC), explicou 15,31\% da variância total dos dados, sendo formado pelas seguintes variáveis: renda da cultura do cacau (RCC), custo com tratos culturais do cacau (CTC), custo na aquisição de insumo (CAI) e área com floresta secundária (AFS)

O terceiro fator, denominado de aspecto ambiental (FAAM), explicou $11,73 \%$ da variância total dos dados, sendo formado pelas seguintes variáveis: área de floresta primária (ha) e área da propriedade (ha).

O quarto fator, denominado outras fontes de renda (FOFR), explicou $8,35 \%$ da variância total dos dados, sendo formado pelas variáveis: renda obtida com aposentadoria (RA) e renda obtida com empregos (RE).

O quinto fator, denominado produção de culturas anuais e outras produções (FCAO) explicou 7,848\% da variância total dos dados, formado pelas seguintes variáveis: custos com culturas anuais e outras produções (CCAOP), rendas de culturas anuais outras produções (ROP).

\subsection{GRUPOS DE FAMÍLIAS COM CARACTERÍSTICAS SIMILARES DE USO DA TERRA NO PROJETO DE ASSENTAMENTO ASSURINI}

O principal resultado da análise de agrupamento é a formação de grupos ou tipos, a partir dos valores obtidos na análise fatorial, com características similares. Foram formados cinco grupos, que se agruparama partir de características similares de uso da terra dentro do assentamento. Os grupos foram denominados a partir das variáveis mais marcantes que se delinearam em cada grupo e organizados em ordem a partir do número de famílias que compôs cada grupo. Para aprofundar e facilitar a caracterização de cada grupo, e destacar os pontos marcantes e as diferenças entre os grupos, foi organizada uma tabela que sintetiza as principais características de cada grupo (Tabela 3). 


\begin{tabular}{|c|c|c|c|c|c|}
\hline 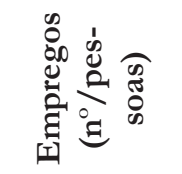 & in & 1 & in & $N$ & $r$ \\
\hline 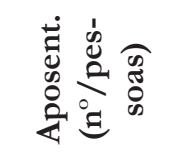 & $\nabla$ & $\stackrel{\vartheta}{2}$ & 1 & $\underset{I}{I}$ & 1 \\
\hline ن & $\stackrel{0}{\rightarrow}$ & $\sigma_{0}$ & $\stackrel{n}{\sim}$ & - & $\vec{i}$ \\
\hline 己્తુ & $\stackrel{n}{m}$ & $\begin{array}{l}\infty \\
i\end{array}$ & $\tilde{\mathrm{d}}$ & $\stackrel{\overbrace{}}{\sim}$ & $\begin{array}{l}\stackrel{R}{0} \\
0\end{array}$ \\
\hline 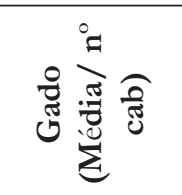 & $\stackrel{\circ}{\curvearrowright}$ & ป & in & in & $\bullet$ \\
\hline 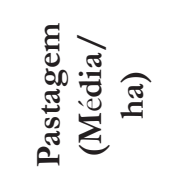 & $\stackrel{\text { F }}{f}$ & $\hat{\sim}$ & $\stackrel{\sim}{\sim}$ & $\stackrel{\circ}{\sim}$ & $\infty$ \\
\hline 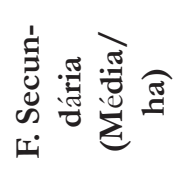 & $\sim$ & $a$ & $\infty$ & $a$ & 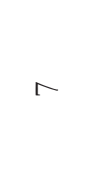 \\
\hline 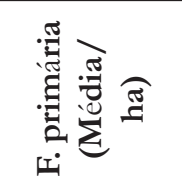 & $\vec{m}$ & nి & ले & $\widetilde{\curvearrowright}$ & ป \\
\hline 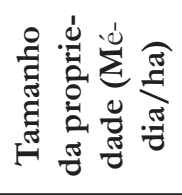 & $\grave{\infty}$ & 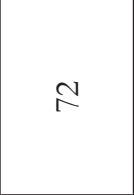 & $\stackrel{\infty}{\sim}$ & กิ & $\stackrel{\infty}{+}$ \\
\hline$\stackrel{0}{0}_{0}^{0}$ & 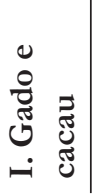 & 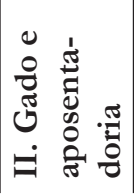 & 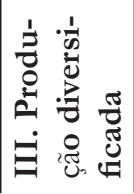 & 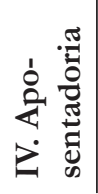 & 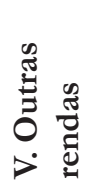 \\
\hline
\end{tabular}


Os cinco grupos serão descritos com suas principais características produtivas a seguir:

\section{Grupo 1 - Famílias com criação de bovinos e cacau}

Esse grupo é formado por $24 \%$ das famílias (n.12) entre as quais predomina a criação de bovinos como a atividade principal e cuja outra atividade importante é o cultivo de cacau. Em relação às culturas anuais, neste grupo apenas cinco famílias haviam plantado a cultura do milho em 2013 e oito famílias estavam cultivando a mandioca na época da realização da pesquisa.

\section{Grupo 2 - Famílias com criação de bovinos e aposentadoria}

Esse grupo é formado por $20 \%$ das famílias (n.10), sendo que em nove famílias dois membros da família já estão aposentados. Além da aposentadoria, as outras fontes de renda são a criação de bovinos e pequenas áreas com cultivo de cacau. Neste grupo, as áreas de cultivo são reduzidas e na maior parte dos casos apenas o casal reside no lote, pois os filhos moram em outros locais no assentamento ou em Altamira.

\section{Grupo 3 - Famílias com produção diversificada}

Este grupo, formado por $20 \%$ das famílias estudadas (n.10), possui áreas com a cultura do cacau, cultivos anuais, produção de hortaliças, fruticultura em pequena escala e a criação de bovinos.

Entre os cultivos anuais, destacam-se a cultura da mandioca para venda in natura em supermercados e feiras livres de Altamira. As culturas do milho e do feijão também são verificadas em áreas menores do que um hectare e são destinadas principalmente ao consumo da família. Destacam-se seis famílias que trabalham na produção de hortaliças e algumas espécies frutíferas, as quais comercializam diretamente na Feira do Produtor em Altamira.

\section{Grupo 4 - Famílias de aposentados com pouca produção agrícola}

Esse grupo é formado por 18\% das famílias (n.9). Nele, a principal fonte de renda é a aposentadoria. As áreas de cultivo são pequenas e destinadas ao consumo da família e as áreas de pastagens encontram-se em processo de degradação, com uma média de cinco cabeças de gado por propriedade.

\section{Grupo 5 - Famílias dependentes de outras rendas}

Esse grupo é formado por $14 \%$ das famílias (n.7). Aqui, a principal renda vem de atividades desenvolvidas fora do sistema de produção. Neste grupo, 
um dos membros da família possui outra fonte de renda, fora da agricultura. Consequentemente, as áreas destinadas à produção agrícola e a criação de gado são reduzidas.

\subsection{CARACTERIZAÇÃO DOS PRINCIPAIS FATORES IDENTIFICADOS NA ANÁLISE FATORIAL}

\section{a) Fator - Produção Pecuária}

As variáveis ligadas à produção pecuária explicaram $31,43 \%$ da variância dos dados. A importância da atividade para a sustentabilidade econômica das famílias é bastante diferenciada, pois existem famílias que possuem apenas cinco hectares com pastagens, com $4 \pm 5$ cabeças de bovinos, assim como existem famílias que possuem mais de 70 hectares com pastagem e 150 cabeças de bovinos. Apesar dessa variação, a análise fatorial comprovou a importância dessa atividade nos cinco grupos definidos na análise de agrupamentos.

Em todos os grupos delineados na análise de agrupamento, a criação de bovinos está presente. Nos grupos I, II e III (Tabela 3), a criação de bovinos tem uma maior participação na renda das famílias, já nos grupos IV e V, a atividade faz parte do sistema de produção, mas as principais fontes de renda vêm de outras atividades.

A presença da criação de bovinos em todos os grupos está relacionada ao acesso ao crédito, pois $96 \%$ (n.46) das famílias que participaram deste estudo tiveram acesso a algum tipo de crédito, com destaque para o Fundo Constitucional de Desenvolvimento da Região Norte (FNO), que financiou 56\% (n.28) das famílias; seguido pelo Programa de Crédito Especial para Reforma Agrária (PROCERA), com 14\% (n.7); e pelo Programa Nacional da Agricultura Familiar (PRONAF-A), que financiou 12\% (n.6) das famílias.

Acrescente-se que Poccard-Chapuis (2003) afirma que a tendência de expansão da pecuária na região da Transamazônica estaria ligada à emergência de mercados consumidores locais, que sustentariam o preço e garantiriam o acesso ao mercado dos produtos da pecuária, destacando que em outros locais da Amazônia o consumo local é pequeno, uma vez que a maior parte da produção é comercializada para outros estados.

A expansão da pecuária na região teve como consequência direta uma pressão maior sobre o ambiente, refletida pela diminuição da área de florestas primárias dentro das propriedades. Segundo Brondizio et al. (2002), houve um aumento do desmatamento na região da Transamazônica, em 1996, associado à baixa inflação e ao retorno aos incentivos de crédito como o FNO. Esse fator é 
agravado pela baixa capacidade de suporte das pastagens na região, assim como o baixo nível tecnológico dos sistemas de produção desenvolvidos na região da Transamazônica (TONI, 2003).

Uma série de estudos vêm apontando para os impactos diferenciados de práticas agrícolas nos desmatamentos na região da Transamazônica, associado às atividades ligadas à criação de bovinos um impacto maior no desmatamento do que cultivos comerciais ou de subsistência e a expansão do desmatamento em áreas de assentamento (BRONDIZIO et al., 2002; BRONDIZIO, 2009; GODAR et al; 2012; MORAN; BRONDIZIO: BATISTELLA, 2008; ALENCAR et al., 2016).

\section{b) Fator - Produção de Cacau}

As variáveis relacionadas ao sistema de produção do cacau explicaram $15,31 \%$ da variância dos dados. Apesar de o cultivo ser desenvolvido em pequena escala, em todos os grupos definidos na análise de agrupamentos existem áreas cultivadas com cacau. Atualmente, 68\% das famílias (n.34) que participam deste estudo estão cultivando a cultura do cacau, com cultivos que variam de $0,5 \pm 15$ hectares, com uma média de 3,20 hectares cultivados.

As áreas cultivadas com cacau no assentamento são pequenas quando comparadas com a área média cultivada nos municípios da região da Transamazônica, que é de 15 hectares (MENDES, 2000). Entretanto, representam o esforço das famílias em buscar cultivos que tenham um melhor acesso aos mercados locais e regionais e que tragam menos impactos ambientais.

\section{c) Fator - Os aspectos ambientais}

As variáveis relacionadas aos aspectos ambientais explicaram 11,73\% da variação dos dados e são compostas por: área da propriedade e área de floresta primária. No momento de ocupação do assentamento, as famílias demarcavam áreas em torno de $50 \pm 80$ hectares. No entanto, atualmente as áreas são bastante diversificadas, pois muitas famílias venderam o direito de posse, assim, o tamanho das propriedades estudadas varia de $10 \pm 165$ hectares, com uma média de 70,8 hectares.

As áreas de florestas primárias possuem tamanhos que variam de $10 \pm 72$ hectares, com uma média de 30,76 hectares. A quantidade de floresta primária que ainda existe na área de estudo está condicionada pelas estratégias de uso da terra e as opções tecnológicas nos sistemas de produção. Em relação às áreas de floresta secundária, 86\% (n.43) das famílias possuem florestas secundárias com dimensões de $1 \pm 32$ hectares, com um estoque médio de 7,7 hectares por propriedade. 
No momento de ocupação do assentamento, os agricultores implantaram suas roças ou pastagens sem levar em conta o que estava previsto no Código Florestal $^{2}$ para ser deixado como Reserva Legal e, atualmente, a maioria das famílias desmataram áreas a que tinham direito para implantar suas roças. Nos grupos I e II, as famílias já utilizaram as áreas de floresta primária previstas no Código Florestal e as florestas remanescentes nas propriedades fazem parte da Reserva Legal (Figura 3).

Figura 3 - Comparação entre áreas da propriedade, floresta primária, secundária e áreas cultivadas nos cinco grupos identificados no Projeto de Assentamento Assurini, Altamira - Pará

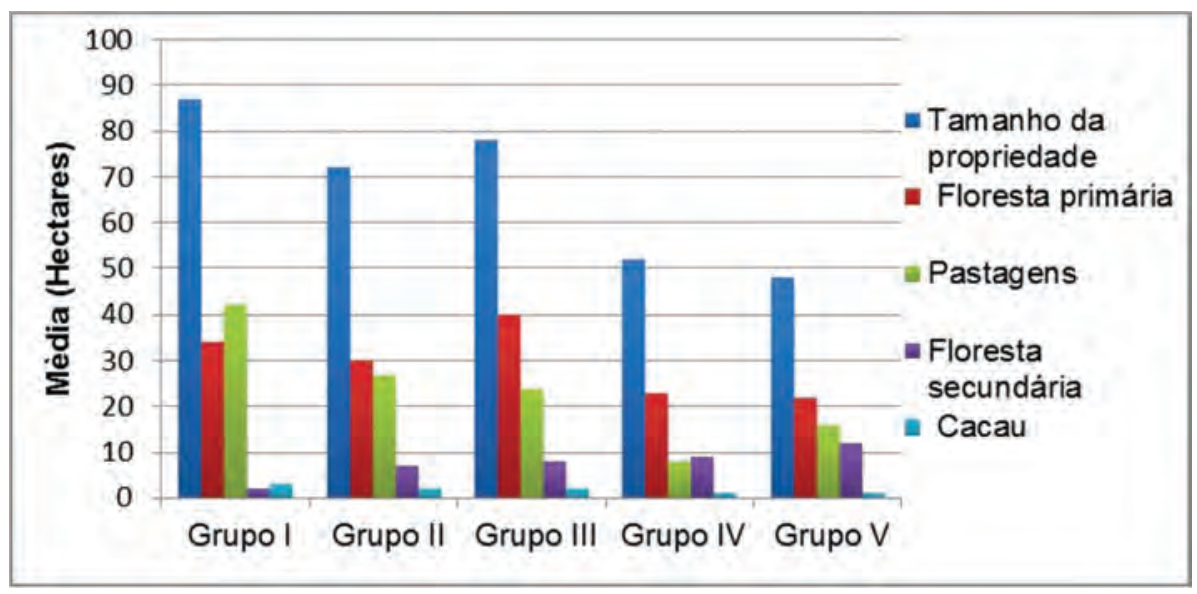

Fonte: Elaborado pelos autores

Nos demais grupos a relação está mais balanceada, com destaque para o grupo III, que é formado pelos agricultores diversificados, que possuem uma área de floresta primária maior. Ressalta-se que a diminuição das áreas de floresta primária foi citada por $60 \%$ das famílias como uma das principais limitações que impedem a continuidade dos cultivos anuais com a mesma frequência que se faziam nos primeiros anos de ocupação do assentamento.

d) Fator - Outras Fontes Renda

As variáveis relacionadas a outras fontes de renda explicaram 8,35\% da variância dos dados e estão compostas pelas variáveis: outras fontes de renda,

2 Segundo o código Florestal de 1965, Lei 4.771, vigente no momento de ocupação do assentamento, as áreas de reserva legal seriam de 50\% do imóvel rural. O novo Código Florestal, Lei $\mathrm{n}^{\circ}$ 12.651/2012,estabelece, no artigo III, que a Reserva Legal é de 80\% do imóvel rural. No entanto, no Estado do Pará, a Lei Estadual No 7.243, de 9 de janeiro de 2009, institui o Zoneamento Econômico Ecológico das áreas de influencia da BR-163 e Rodovia Transamazônica, que regulamentou em áreas consolidadas a reserva legal de 50\% do imóvel rural. 
recursos da aposentadoria, bolsa família e outros empregos. Entre as famílias que participam deste estudo, 46\% (n.23) obtêm renda da aposentadoria. Basicamente, a aposentadoria é a principal fonte de renda para os grupos II e IV, com a diferença de que, no grupo II, as famílias possuem também a renda da criação de bovinos, enquanto no grupo IV a aposentadoria é a principal renda da família (Figura 4).

Figura 4 - Outras fontes de renda e aposentadoria nos cinco grupos identificados no Projeto de Assentamento Assurini, Altamira- Pará

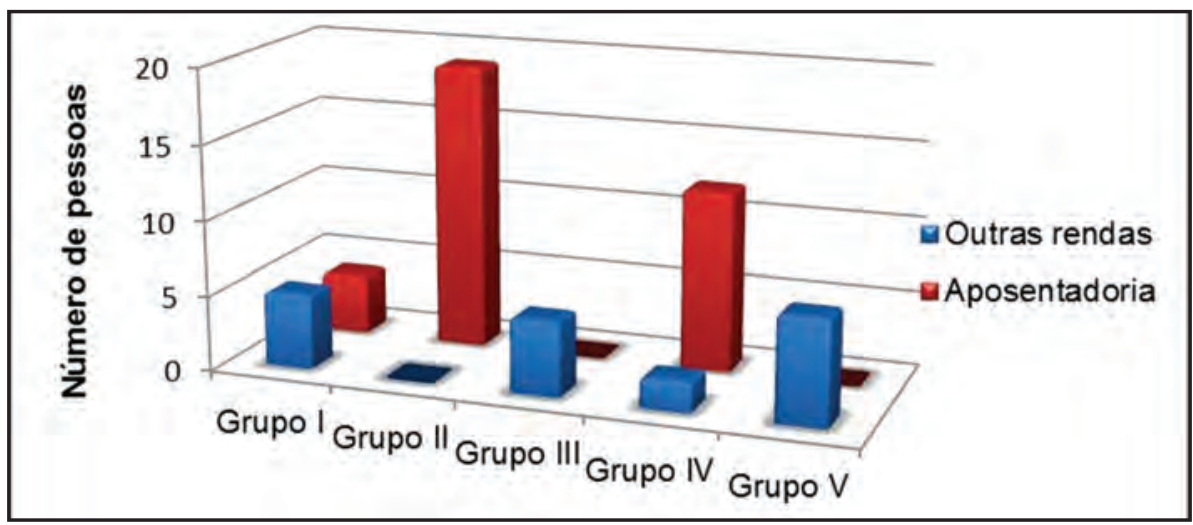

Fonte: Elaborado pelos autores

Em relação às outras fontes de renda, 44\% (n.22) das famílias desenvolvem algum tipo de atividade remunerada fora da agricultura e $22 \%$ (n.11) recebem auxílio do programa Bolsa Família. A importância das atividades não agrícolas foi comprovada por meio da análise de agrupamentos, demonstrando que, em quatro grupos I, III, IV e V, pelo menos um dos membros da família realiza atividades não agrícolas (Figura 4). Esse crescimento das atividades não agrícolas demonstra as limitações que a agricultura tem enfrentado na região como um todo.

Esta realidade é um fenômeno que vem ocorrendo no âmbito de unidades familiares de outras regiões do Brasil e vem sendo denominada pelos cientistas sociais de pluriatividade agrícola. Schneider et al. (2006) definem pluriatividade como um fenômeno que se caracteriza pela combinação das múltiplas inserções ocupacionais das pessoas que pertencem à mesma família, ocorrendo em situações em que os membros que compõem as famílias domiciliadas nos espaços rurais combinam atividades agrícolas com outras formas de ocupação, em atividades não agrícolas.

As atividades não agrícolas mencionadas pelas famílias são bastante variadas, mas as principais estão ligadas a empregos ofertados pela Secretaria Municipal de Educação, como por exemplo: professor, vigilante, merendeira e serviços gerais. 
Existem também agentes de saúde e outros profissionais liberais. A participação do poder municipal e federal, com a prestação de serviços básicos, contribuiu para que surgissem oportunidades de empregos no próprio assentamento.

\section{e) Fator - Produção de culturas anuais e outras produções}

Este fator impactou em 7,84\% na variância dos dados, sendo composto pelas variáveis relacionadas à renda e aos custos com as culturas anuais e outras produções. Na variável outras produções foram agregadas atividades como a produção de hortaliças e venda de outros produtos, como frutas originadas dos sistemas agroflorestais e galinha caipira, que são produzidos em pequenas proporções.

As culturas anuais são cultivadas por 50\% (n.25) das famílias que participaram deste estudo, com uma área média por família de 1,03 hectares. As famílias, em sua maioria, informaram que praticamente não cultivam mais arroz devido aos custos com mão de obra e por não terem mais área de floresta primária disponível para plantar, sendo priorizados os cultivos de milho e da mandioca, que obtém bons resultados quando plantados em áreas de floresta secundária.

Os cultivos anuais revelam retração quando comparados com a fase inicial de ocupação. Entretanto, ainda persistem no assentamento. A persistência dos cultivos anuais na região da Transamazônica já foi identificada em vários estudos realizados. Walker et al. (1998) e Homma (1998), na década de 1990, indicaram a importância das culturas anuais nos sistemas de produção para a subsistência das famílias. Em estudo mais recente, em três municípios da região, Rocha e Almeida (2013) constataram que grande parte das famílias não cultivam mais arroz, mas a maioria ainda realiza cultivos de feijão, milho e mandioca, confirmando a importância dessas culturas para os sistemas de produção da região.

Em nosso estudo, a falta mão-de-obra familiar foi identificada como fator limitante, pois a maioria dos filhos não mora com a família. Outro fator mencionado foi a idade média dos chefes de família, que passa de cinquenta anos. Em outros estudos, aspectos relativos à mão-de-obra e à composição familiar já haviam sido identificados como propulsores de mudanças em relação ao uso da terra na região da Transamazônica (BRONDIZIO, 2009; ROCHA, 2016). Essas limitações têm sido uma barreira para manutenção dos cultivos anuais no assentamento, pois essa atividade demanda mão-de-obra significativa para realizar o manejo, que envolve desde o preparo de área até a colheita.

Outra questão que tem limitado a expansão das áreas de cultivos está ligada ao acesso das famílias a serviços como assistência técnica e outras políticas públicas. Desde a ocupação do assentamento, a assistência técnica foi 
ocorrendo de forma pontual, por meio da atuação da Empresa de Assistência Técnica e Extensão Rural (EMATER), com ações direcionadas para programas específicos como a implantação de projetos de crédito como FNO, PROCERA e PRONAF-A. Além da concessão de crédito, apenas 30\% das famílias que participaram deste estudo receberam assistência em outras atividades como a produção de hortaliças e o cultivo do cacau.

\section{CONSIDERAÇÕES FINAIS}

As mudanças no uso da terra que se delinearam no assentamento foram moldadas a partir de um conjunto de fatores, que envolvem desde suas experiências com atividades agrícolas, até aspectos exógenos, ligados àspolíticas públicas e a conjuntura regional. A análise fatorial identificou a ampliação efetiva da criação de bovino e do cultivo do cacau ea diminuição das áreas com cultivos anuais, alémdo crescimento da dependência das famílias de outras fontes de renda, como a aposentadoria e os empregos no assentamento.

Apesar das limitações relacionadas aos aspectos produtivos e ambientais, a produção agrícola em pequenas proporções está presente em todos os grupos, demonstrando que existe potencial para ampliar e diversificar a produção, com a expansão dos cultivos de hortaliças e da produção de frutíferas. No entanto, a baixa produtividade dos cultivos e a falta de opções de renda podem levar as famílias a venderem os seus lotes e a se mudarem para a sede do município, resultando em uma concentração de terras na área do assentamento.

\section{AGRADECIMENTOS}

Às famílias do Projeto de Assentamento Assurini que participaram desta pesquisa, compartilhando informações a respeito de suas vivências e desafios nas várias etapas de ocupação do assentamento. À Fundação Amazônia de Amparo a Estudos de Pesquisa no Estado do Pará (FAPESPA), pela bolsa de doutorado que possibilitou a realização da pesquisa.

\section{REFERÊNCIAS}

ALENCAR, A.; PEREIRA, C.; CASTRO, I.; CARDOSO, A. SOUZA, L.; COSTA, R.; BENTES, A. J.; STELlA, O.; AZEVEDO, A.; GOMES, J.; NOVAES, R. Desmatamento nos Assentamentos da Amazônia: histórico, tendências e oportunidades. Brasília: IPAM, 2016. 93p. 
BATISTELA, M.; MORAN, E. F. Dimensões humanas do uso e cobertura das terras na Amazônia: uma contribuição do LBA. Acta Amazônica, Manaus, n. 35, v. 2, p. 249-257, 2005.

BRONDIZIO, E. S. Análise inter-regional de mudança do uso da terra na Amazônia. In: MORAN, E. F.; OSTROM, E. (Org.). Ecossistemas Florestais: interação homem-ambiente. São Paulo: EDUSP, 2009. p. 289-326.

BRONDIZIO, E. S.; MCCRCKEN, S. D.; MORAN, E. F.; SIQUEIRA, A. D.; NELSON, D.R.; RODRIGUES-PEDRAZA, C. The colonist footprint: towards a conceptual framework of deforestation trajectories among small farmers in frontier Amazônia. In: WOOD, C.; PORRO, R. (Ed.). Land use and deforestation in the Amazon. Gainesville, Fl, USA: University Press of Florida, 2002. p.133-160.

BRONDIZIO, E. S. Abordagens teóricas e metodológicas para o estudo de mudanças no uso da terra. In: VIEIRA, I. C.; TOLEDO, P. M.; SANTOS JUNIOR, R. A. O. Ambiente e Sociedade na Amazônia: uma abordagem interdisciplinar. Rio de Janeiro: Garamond. 2014. p. 149-178.

CASTELlANET, C.; SIMÕES, A.; CELESTINO FILHO, P. Diagnóstico preliminar da agricultura familiar na Transamazônica: indicações para pesquisa e desenvolvimento. Belém: EMBRAPA. Documentos 105. 1998. 48p.

CORRÊA, S.R. M. Neodesenvolvimento e conflitos sociais: o caso da hidrelétrica de Belo Monte. Novos Cadernos NAEA, Belém, v. 19, n. 3, p. 233-254, 2016.

FOLEY, J. A.; DEFRIES, R.; ASNER, G. P.; BARORD, C.; BONAN, G.; CARPENTER, S. R.; CHAPIN, F. S.; COE, M. T.; DALY, G. C.; GIBBS, H. K.; HELKOWSKI, J. H.; HOLLOWAY, T.; HOWARD, E. A.; KUCHARIK, C. J.; MONFREDA, C.; PATZ, J. A.; PRENTICE, I. C.; RAMANKUTTY, N.; SNYDER, P. K. Global consequences of land use. Sience, v. 309, n. 5735, p. 570-574, 2005.

GODAR, J.; TIZADO, E. J.; POKORNY, B.; JOHNSON, J. Tipology and characterization of amazon colonist: a case study along the Transamazon Highway. Human Ecology, n. 40, p. 251-267, 2012.

HAIR, J. R.; ANDERSON, R. E.; TATHAM, R.L.; BLACK, W.C. Análisemultivariada de dados. 6. ed. Porto Alegre: BOOKMAM, 2009. 688 p. HOMMA, A. K. Redução dos desmatamentos na Amazônia: política agrícola ou ambiental. In: HOMMA, A.K. O. (Org.). Amazônia: meio ambiente e desenvolvimento agrícola. Belém: EMBRAPA-CPATU, 1998. p. 119-143. 
IBGE - Instituto Brasileiro de Geografia e Estatística. Censo 2010. Disponível em: <http://www.ibge.gov.br/cidadesat/topwindow.htm>. Acesso em: 14 abr. 2014.

Censo Agropecuário. 2006. Disponível em: <http://www.ibge.gov. br/cidadesat/topwindow. htm>. Acesso em: 14 jun. 2012.

INPE - Instituto Nacional de Pesquisas Espaciais. Monitoramento da Floresta Amazônica por satélite. No período de 1997 a 2010. 2013. Disponível em: <http://www.inpe.br/prodes/>. Acesso em: 2013-03-29.

INPE - Instituto Nacional de Pesquisas Espaciais; Embrapa - Empresa Brasileira de Pesquisa Agropecuária. Levantamento de informações de uso e cobertura da terra na Amazônia. Sumário Executivo. 2011.

MENDES, F. A Cacauicultura na Amazônia Brasileira: potencialidades abrangência e oportunidades de negócios. Movendo Idéias, Belém, v. 5, n. 8, p. 53-61, 2000.

MORAN, E. F.; BRONDIZIO, E. S.; BATISTELLA, M. Trajetórias de desmatamento e uso da terra na Amazônia Brasileira: uma análise multiescalar. In: BATISTEllA, M.; MORAN, Emílio. F; ALVES, Diógenes. S. (Org.) Amazônia: natureza e sociedade em transformação. São Paulo: EDUSP, 2008, p. $137-180$.

PACHECO, P.; NUNES, W. ; ROCHA, C.; VIEIRA, I.; HERRERA, J. A.; SANTOS, K.; SILVA, T.; CAYRES, G.. Acesso a terra e meio de vida: examinando suas interações em três locais no Estado do Pará. Belém: CIFOR, 2009. 74 p.

PARÁ. Lei Estadual nº 7243, de 9 de janeiro de 2009. Dispõe sobre o Zoneamento Ecológico- Econômico da área de influência das Rodovias BR-163 (SantarémCuiabá) e BR-230 (Transamazônica) no Estado do Pará - Zona Oeste. Diário Oficial do Estado do Pará, Belém, 20 jan. 2009. Disponível em: <http:// www.mma.gov.br/port/conama/processos/606CC34C/Lei_7.243_ZEEBR163_09jan09.pdf.>. Acesso em: 5 dez. 2014.

POCCARD-CHAPUIS, R. Seguindo o caminho do gado numa estrada de colonização: cadeias produtivas bovinas e viabilidade de agricultura familiar na Transamazônica. In: TOURRAND, J. F.; VEIGA, Jonas. B. Viabilidade de sistemas agropecuários na agricultura familiar na Amazônia. Belém: EMBRAPA-CPATU, 2003. p. 325-353. 
ROCHA, C. G. S.; ALMEIDA, J. Lógicas de reprodução social, trajetórias produtivas e gestão do meio natural de agricultores familiares no Sudoeste do Pará, Brasil. Novos Cadernos NAEA, Belém, v. 16, n. 1, p. 149-172, 2013.

ROCHA, C. G. S. Reprodução social e práticas socioprodutivas de agricultores familiares do Pará. Jundiaí-SP: Ed. Paco, 2016. 257 p.

SABLAYROLLES, P.; ROCHA, C. G. Desenvolvimento sustentável da agricultura familiar na Transamazônica. Belém: AFATRA, 2003. 300 p.

SANTANA, A.C. Índice de desempenho competitivo das empresas de polpas de frutas no Estado do Pará. Revista de Economia e Sociologia Rural. Rio de Janeiro: v. 45. n. 3, p. 749- 775. 2007. Disponível em: <www.scielo.br/pdf/resr/ v45n3/a09v45n3.pdf>. Acesso em: 29 maio 2011.

SCHNEIDER, S.; CONTERATO, M. A.; KOPPE, L. R.; SILVA, C. C. Pluriatividade e as condições de vida dos agricultores familiares do Rio Grande do Sul. In: SCHNEIDER, S. (Org.) Diversidade da agricultura familiar. Porto Alegre: Editora da UFRGS, 2006. p. 137-165.

TONI, Fabiano. A conquista do FNO-especial pelos agricultores da Transamazônica e seus efeitos sobre a pecuarização da agricultura familiar. In: TOURRAND, J. F.; VEIGA, J. B. (Org.) Viabilidade de sistemas agropecuários na agricultura familiar na Amazônia. Belém: EMBRAPA-CPATU, 2003. p. 413-425.

TOURRAND, J. François; V., J. B.; QUANZ, D.; FERREIRA, L.A.; SIMÃO NETO, M. Produção Leiteira em área de Fronteira Agrícola da Amazônia: o caso do município de Uruará-Pará. In: HOMMA, A.K. O. (Org.) Amazônia: meio ambiente e desenvolvimento agrícola. Belém: EMBRAPA-CPATU, 1998. p. 346-365.

WALKER, R. T.; HOMMA, A.K.; SCATENA, F. N.; NEVES, A. C. P.; SANTOS, A. I. M.; CONTO, A., J.; PEDRAZA, C. D. R.; FERREIRA, C. A. P.; OLIVEIRA, Pedro, M.; CARVALHO, R. A. A evolução da cobertura do solo nas áreas de pequenos produtores na Transamazônica. In: HOMMA, A. K. O. (Org.) Amazônia: meio ambiente e desenvolvimento agrícola. Belém: EMBRAPACPATU, 1998. p. 321- 343. 


\section{Agricultura de corte e queima e alternativas agroecológicas na Amazônia}

\section{Slash and burn agriculture and agroecological alternatives in the amazon}

Anna Karyne Costa Rego - Mestre em Ciências Florestais pela Universidade Federal Rural da Amazônia/UFRA, Programa de Pós-Graduação em Ciências Florestais. Professora da Universidade Federal Rural da Amazônia/UFRA. E-mail: anna.kcosta@hotmail.com.

Osvaldo Ryohei Kato - Doutor em Agricultura Tropical pela Universitat Goettingen, Alemanha. Pesquisador A na Embrapa Amazônia Oriental. E-mail: osvaldo.kato@ embrapa.br

\section{Resumo}

Esse artigo tem por objetivo apresentar a principal forma de uso do solo pelos agricultores da Amazônia, bem como as alternativas de produção baseadas nos princípios agroecológicos por meio de levantamento bibliográfico. A expansão da agricultura e da pecuária é identificada como a principal causa do desmatamento na região devido ao corte e a queima da vegetação como principal forma de preparo de áreas para o cultivo. Essa prática consiste em derrubar e queimar a vegetação para a implantação de cultivos agrícolas por dois ou três anos, posteriormente a área é deixada em pousio para o restabelecimento da vegetação secundária e para que o solo retome sua capacidade produtiva. No entanto, com o crescimento populacional e a necessidade de geração de alimentos, essa prática tornou-se insustentável devido apresentar períodos de pousio cada vez mais curtos. Com isso, o desenvolvimento de novas formas de cultivo sustentável tornou-se necessário.

\section{Palavras-chave}

Uso do Solo. Agricultura. Desmatamento. Cultivo Sustentável.

\begin{abstract}
This article aims to present the main form of land use by farmers in the Amazon, as well as production alternatives based on agroecological principles through a literature review. Agriculture is identified as the main cause of deforestation in the region due slash and burn of vegetation as the main form of land preparation for farming. This practice consists in slashing and burning vegetation for the deployment of crops for two or three years, posteriorly the land is leave at fallow to the secondary vegetation establishment and soil recapture their productive capacity. However, with population growth and the need to generate food this practice became unsustainable due presents fallow periods increasingly shorter. Thus, the development of new forms of sustainable crop has become necessary.
\end{abstract}

\section{Keywords}

Land Use. Agriculture. Deforestation. Sustainable Farming. 


\section{INTRODUÇÃO}

Nas décadas de 1960 e 1970, os Planos de Desenvolvimento da Amazônia (PDA) foram direcionados para favorecer a implantação de grandes projetos agrícolas e pecuários (FEARNSIDE, 1997). Nesse mesmo período, começaram a serem criados os projetos de colonização na região, com o objetivo de integrar economicamente essa região ao restante do país (SANTOS, 2008). Os projetos de colonização atraíram milhares de famílias de pequenos produtores para a Amazônia (SANTOS, 2008). Boa parte dessa população é de agricultores com estabelecimentos de pequeno e médio porte (agricultura familiar) com até 200 ha (HURTIENNE, 2005) que ao longo dos anos têm praticado o corte e a queima da vegetação para o estabelecimento de cultivos agrícolas e pastos.

A expansão da agricultura e da pecuária na Amazônia tem sido considerada a principal causa do desmatamento na região (CATTANEO, 2002). Entre as consequências desse processo de expansão da fronteira agrícola e ocupação da região, destaca-se a aceleração do desmatamento e da pobreza rural (MMA, 2000). Os planos de expansão da agricultura na Amazônia preconizavam a adoção de insumos modernos nos sistemas de produção, nos moldes da revolução verde (SANTOS, 2008).

Esse artigo tem por objetivo apresentar a principal forma de uso do solo pelos agricultores na Amazônia, a agricultura de derruba e queima, bem como as alternativas de produção baseadas nos princípios agroecológicos por meio de levantamento bibliográfico. Em primeiro lugar, é feita uma abordagem sobre uso da terra pela agricultura e impactos ambientais causados. Em seguida, é dada atenção especial aos estudos que analisam alternativas de produção sustentável e as transformações nas formas de uso do solo. Por fim, são apresentados sistemas de produção exitosos que vêm sendo utilizados como alternativas à forma tradicional de cultivo, a fim de promover sua sustentabilidade por meio de tecnologias de baixo impacto e fonte de renda para os agricultores da Amazônia.

\section{AGRICULTURA DE CORTE E QUEIMA NA AMAZÔNIA}

Entre as diversas formas de uso do solo na Amazônia, destaca-se a agricultura de subsistência, praticada por agricultores em pequena escala, por meio do corte e queima da floresta primária ou secundária para fins agrícolas (FREITAS et al., 2013). Este sistema produtivo é o que prevalece na região, para formação de roças (OLIVEIRA et al., 2007), onde se alterna períodos de cultivo e de pousio, quando a vegetação secundária (capoeira) se desenvolve por meio de 
rebrotas de tocos, raízes e sementes que sobrevivem ao corte e à queimada, para após algum tempo, ser transformada em fertilizante para o próximo período de cultivo (KATO et. al., 2014).

Essa prática busca suprir as necessidades nutricionais das culturas com os nutrientes acumulados na vegetação secundária (MARCOLAN; LOCATELLI; FERNANDES, 2009). No entanto, a queima da vegetação propicia a perda de nutrientes retidos na biomassa (KANASHIRO; DENICH, 1998). Essa forma de cultivo interrompe a reciclagem e os nutrientes que seriam adicionados gradativamente ao solo, pela decomposição da matéria orgânica, passam a ficar disponíveis de uma só vez, nas cinzas sobre a superfície do solo (MARCOLAN; LOCATELLI; FERNANDES, 2009). A agricultura de corte e queima torna-se insustentável na medida em que são feitas repetidas queimadas, o que reduz o tempo de pousio entre os cultivos (DENICH; KANASHIRO; VLEK, 1999). Este sistema de cultivo necessita de pousios longos (sete a dez anos) para ser sustentável em termos produtivos (KATO, O. et al., 2014).

A sustentabilidade desse sistema de cultivo é baseada na fertilidade natural dos solos, que foi colocada em risco pela intensificação do processo de ocupação da Amazônia (MIRANDA; RODRIGUES 1999). As queimadas constantes representam uma contínua extração de nutrientes minerais e redução da matéria orgânica do solo a qual leva à degradação do solo e ao declínio da produtividade, além de provocar alterações no comportamento hídrico e fotossintético de espécies componentes da vegetação, emissão de gases do efeito estufa e riscos de incêndios acidentais (HOLSCHER et al., 1997). Além disso, é considerada a principal fonte de desmatamento (ARCO-VERDE; AMARO, 2012).

Neste contexto, os agricultores familiares são prejudicados com a perda de produtividade agrícola, e na maioria das vezes não dispõem de recursos financeiros suficientes para a recuperação da fertilidade do solo da propriedade, ficando impossibilitados de obter renda a partir da atividade agrícola. Com isso, muitos agricultores acabam migrando para novas fronteiras agrícolas.

Tendo em vista a redução da capacidade produtiva do solo ocasionada pela prática de corte e queima, é necessário o uso de novos sistemas produtivos de alimentos onde a produção seja feita de forma diversificada e sustentável.

\section{TRANSIÇÃO PRODUTIVA E A AGROECOLOGIA}

O processo de modernização da agricultura causou efeitos danosos, em particular, no mundo rural e sobre a sociedade de forma geral. O processo de mecanização do campo provocou sérios danos ambientais (JESUS et al., 2011; 
FONTES et al., 2013; FREITAS et al., 2014), como: destruição das florestas, erosão dos solos (FREITAS et al., 2014), além da contaminação dos alimentos e sérios conflitos sociais no Brasil, o aumento da concentração da posse de terra, concentração da pobreza nas áreas rurais, o êxodo rural e o desemprego (FREITAS et al., 2014). Esse modelo de agricultura afetou diretamente os centros urbanos, o modo e a qualidade de vida da sociedade, além de criar dificuldades para a geração de renda das populações (FONTES et al., 2013), colocou em risco os ecossistemas (FONTES et al., 2013) e a perdas de solos (JESUS et al., 2011).

Há vários anos a sociedade busca estabelecer estilos de agricultura que sejam menos danosos ao meio ambiente e capazes de manter os recursos naturais, assegurar maior longevidade produtiva, tentando fugir do estilo convencional de agricultura que passou a ser hegemônico a partir dos novos descobrimentos da química agrícola, da biologia e da mecânica ocorridos a partir do final do século XIX (CAPORAL; COSTABEBER, 2007).

$\mathrm{Na}$ busca e construção de novos conhecimentos, surge a Agroecologia, de modo que seus princípios passam a contribuir para o estabelecimento de um novo caminho para a construção de agriculturas de base ecológica e sustentáveis (CAPORAL; PAULUS; COSTABEBER, 2009). A Agroecologia nasceu, como novo enfoque científico, capaz de dar suporte a uma transição a estilos de agriculturas sustentáveis e, portanto, contribuir para o estabelecimento de processos de desenvolvimento rural sustentável (JESUS et al., 2011).

Além de produzir sem agrotóxicos a Agroecologia trabalha com o manejo ecológico dos agroecossistemas priorizando a manutenção contínua da fertilidade dos solos. Encontra-se destinada à subsistência e a qualidade de vida do produtor rural e de sua família, não deixando de lado a inserção dos seus produtos num mercado que é cada vez maior e atua com relações mais solidárias (FREITAS et al., 2014).

Tem-se confundido a Agroecologia com um modelo de agricultura (CAPORAL; PAULUS; COSTABEBER, 2009). Também é comum confundir Agroecologia com a simples adoção de determinadas práticas ou tecnologias agrícolas ambientalmente mais adequadas ou com uma agricultura que não usa agrotóxicos ou, simplesmente, com a substituição de insumos (ALTIERI; ROSSET, 2002).

A agroecologia, segundo Altieri (1989), é definida como ciência ou disciplina científica que apresenta uma série de princípios, conceitos e metodologias para estudar, analisar, dirigir, desenhar e avaliar agroecossistemas, com a finalidade de permitir a implantação e o desenvolvimento de estilos de agricultura com maiores níveis de sustentabilidade. 
Segundo Caporal e Costabeber (2007), a agroecologia é capaz de realizar a transição dos atuais modelos de desenvolvimento rural e de agricultura convencional, para estilos de desenvolvimento rural e de agriculturas sustentáveis. Isso ocorre por ela ser uma ciência que por meio de seus princípios e conceitos, é capaz de gerar metodologias para a superação do modelo da revolução verde, por meio do resgate, valorização e novas formas de se fazer agricultura (FONTES et al., 2013).

A adesão ao enfoque agroecológico não supõe pleitear ou defender uma nova "revolução modernizadora", mas sim uma ação dialética transformadora, como já vem ocorrendo ao longo de um horizonte temporal. Este processo modernizador, parte do conhecimento local, respeitando e incorporando o saber popular e buscando integrá-lo com o conhecimento científico, para dar lugar à construção e à expansão de novos saberes socioambientais, alimentando assim, permanentemente, o processo de transição agroecológica (CAPORAL; PAULUS; COSTABEBER, 2009).

A agroecologia proporciona as bases científicas para apoiar o processo de transição para uma agricultura "sustentável" nas suas diversas manifestações e/ou denominações (ALTIERI, 1989). Para Nunes da Silva et al., (2009), os processos de transição agroecológica constituem-se em desafios para a sustentabilidade das regiões rurais. A transição agroecológica não implica somente numa maior racionalização econômico-produtiva com base nas especificidades biofísicas de cada agroecossistema, mas também numa mudança nas atitudes e valores dos atores sociais em relação ao manejo e conservação dos recursos naturais (COSTABEBER, 1998).

Gliessman (2001) distinguiu três níveis fundamentais no processo de transição para agroecossistemas mais sustentáveis. O primeiro nível diz respeito ao incremento da eficiência das práticas convencionais para reduzir o uso e consumo de inputs externos caros, escassos e daninhos ao meio ambiente. O segundo nível da transição se refere à substituição de inputs e práticas convencionais por práticas alternativas. A meta seria a substituição de insumos e práticas intensivas contaminantes e degradadoras do meio ambiente por outras mais benignas sob o ponto de vista ecológico. Neste nível da transição a estrutura básica do agroecossistema seria pouco alterada, podendo ocorrer, então, problemas similares aos que se verificam nos sistemas convencionais. $\mathrm{O}$ terceiro e mais complexo nível da transição é representado pelo redesenho dos agroecossistemas, para que estes funcionem com base em um novo conjunto de processos ecológicos. 


\section{SISTEMAS PRODUTIVOS BASEADOS NOS PRINCÍPIOS AGROECOLÓGICOS}

\subsection{MANEJO DE CAPOEIRA: SISTEMA DE CORTE E TRITURAÇÃO COMO ALTERNATIVA AGROECOLÓGICA}

A necessidade de se buscar práticas sustentáveis que substituam o corte e a queima da capoeira no preparo da área estimulou o desenvolvimento de iniciativas de transição do modelo convencional de agricultura para formas mais sustentáveis (CORRÊA, 2011). O manejo da capoeira é um bom exemplo: antes tratado sob a lógica de corte e queima e, hoje, com possibilidades de incorporação de uma nova tecnologia capaz de triturar a biomassa aérea dessas vegetações (SAMPAIO; KATO; NASCIMENTO E SILVA, 2008). O empenho da comunidade científica em buscar novas tecnologias de produção resultou no sistema de plantio direto na capoeira ou tecnologia de corte e trituração da capoeira sem queima, desenvolvido pela Embrapa Amazônia Oriental em parceria com as universidades alemãs de Göttingen e de Bonn (KATO, M. et al., 1999; KATO, O. et al., 2007).

Segundo Sampaio, Kato e Nascimento e Silva (2008), o sistema agrícola cultivado com a técnica de corte e trituração da capoeira está associado a duas inovações tecnológicas: enriquecimento de capoeira - plantio de leguminosas arbóreas de crescimento rápido visando diminuir o período de pousio e acumular biomassa na vegetação de pousio (BRIENZA JÚNIOR et al., 2000) e a trituração de capoeira - que consiste na trituração da biomassa aérea da vegetação de pousio (capoeira) para reduzir a perda de nutrientes, adicionar matéria orgânica e formar uma cobertura morta do solo (KATO, O; SECCO, N. 2004).

Os estudos baseados no corte e na trituração da capoeira apontam tendências de aumento da matéria orgânica do solo favorecendo o restabelecimento de níveis desejáveis de fertilidade do solo, ainda que sejam utilizadas pequenas doses de fertilizantes nos primeiros anos de implantação do sistema para suprir a carência de nutrientes nessa fase (KATO, M. 1998; GAMA, 2002; COELHO et al., 2004).

Esse sistema proporciona a recuperação gradual do solo pela oferta de nutrientes e carbono por meio da reciclagem de nutrientes das camadas profundas para a superfície e fornecimento de matéria orgânica pela deposição da folhagem, melhorias nas propriedades químicas e físicas do solo, oferta de serviços ambientais e flexibilização do calendário agrícola (TRINDADE et al., 2011).

Para Marcolan, Locatelli e Fernandes (2009), o preparo da área usando a técnica de corte e trituração da vegetação poderá, além de reduzir a poluição 
ambiental e os riscos de incêndios acidentais, evitar as perdas de nutrientes acumulados na biomassa e proteger o solo contra os efeitos da lixiviação e da erosão, reduzindo os gastos com adubação e melhorando os atributos físicos, químicos e biológicos do solo.

No manejo com a vegetação secundária triturada, os resíduos vegetais são mantidos na superfície do solo, enquanto que, no sistema com a queima da vegetação secundária, o solo fica exposto à degradação pelo impacto das gotas das chuvas e pela ação do fogo, diminuindo a estabilidade do solo e como consequência ocorre a diminuição da qualidade estrutural do solo, proporcionando aumento da densidade e da resistência à penetração (MARCOLAN; LOCATELLI; FERNANDES, 2009).

Souza et al. (2011), verificaram que o sistema de manejo com corte e trituração da capoeira propiciou condições favoráveis ao desenvolvimento radicular na camada mais superficial do solo, com menor resistência à penetração, em relação ao manejo de derruba e queima da capoeira.

Os agroecologistas argumentaram durante anos que os novos modelos de agricultura que a humanidade vai precisar no futuro imediato devem ser enraizados na lógica ecológica da agricultura de pequena escala tradicional, que representa formas já estabelecidas, bem sucedidas e adaptáveis de agricultura (ALTIERI, 2004). No sistema sem queima, as vantagens são bastante nítidas e aos poucos o sistema de manejo da capoeira tradicional de corte e queima vem sendo substituído pela moderna prática de corte e trituração, porém de forma lenta e reticente (SAMPAIO; KATO; NASCIMENTO E SILVA, 2007).

$\mathrm{Na}$ Região Amazônica, particularmente, as alternativas tecnológicas ao uso do fogo disponíveis hoje têm se mostrado promissoras, embora seus resultados ainda sejam incipientes, principalmente porque não têm sido incluídas em políticas de uso da terra e nos instrumentos econômicos de financiamento à produção (PEREIRA; VIEIRA, 2001; SÁ et al., 2006).

\subsection{SISTEMAS AGROFLORESTAIS COMO ALTERNATIVA DE PRODUÇÃO SUSTENTÁVEL}

\subsubsection{Definição e classificação dos sistemas agroflorestais}

A definição dos sistemas agroflorestais, tipos e manejos são resultantes de diversas pesquisas e práticas, o que inclui processos de sucessão ecológica, conceitos de sustentabilidade e agroecologia (ALVES, 2009). 
São muitas as definições sobre sistemas agroflorestais (SAF), entre as quais, pode-se citar as de Nair (1989) e Medrado (2000). Nair (1989) define os sistemas agroflorestais como sistemas de produção nos quais árvores são associadas com espécies agrícolas e/ou animais, podendo apresentar vários arranjos em espaço e tempo. Para Medrado (2000), são sistemas de manejo sustentado da terra que aumenta o seu rendimento, combinando o plantio de espécies florestais com cultivos agrícolas e/ou animais, simultânea ou consecutivamente, de forma definida, na mesma unidade de terreno, envolvendo práticas de manejo de acordo com a população local.

A classificação dos sistemas agroflorestais varia de acordo com a composição, condição, situação e propósito ou função a que se determina a atividade (SILVA, 2013). No entanto, a classificação mais utilizada está relacionada com a natureza dos componentes, podendo, os SAF serem classificados em silviagrícola, quando envolve o consórcio de espécies arbóreas e culturas agrícolas; silvipastoril, quando o consórcio envolve espécies arbóreas e animais; e agrossilvipastoril quando o consórcio se dá entre espécies arbóreas, culturas agrícolas e animais (MARTINS, 2013).

\subsubsection{Vantagens de produzir através de SAF}

Estes sistemas apresentam inúmeras vantagens, seja do ponto de vista ecológico, econômico e social, por serem considerados sustentáveis, visto que contribuem para a qualidade do meio ambiente; gerando renda aos agricultores e por integrarem homens e mulheres em suas atividades, possibilitando a participação de todos no processo produtivo (VIEIRA et al., 2008).

Para Engel (1999), o objetivo principal dos SAF é otimizar o uso da terra, conciliando a produção florestal com a produção de alimentos, conservando o solo e diminuindo a pressão pelo uso da terra para produção agrícola. ArcoVerde (2008) apresentou como objetivos dos SAF a contribuição para a segurança alimentar e o bem-estar social e econômico dos produtores rurais, particularmente aqueles de baixa renda, assim como para a manutenção dos recursos naturais. Paludo e Costabeber (2012) observaram os princípios agroecológicos dos SAF e constataram que eles têm por objetivo harmonizar os agroecossistemas com os processos dinâmicos dos ecossistemas naturais.

Em comparação aos sistemas convencionais de uso do solo, os SAF apresentam como principal vantagem o aproveitamento mais eficiente dos recursos naturais obtido através da otimização do uso da energia solar pelas plantas devido à estratificação dos componentes, pela ciclagem de nutrientes, 
pela manutenção da umidade do solo e pela proteção do solo contra erosão (ALVES, 2009).

A combinação de árvores com cultivos anuais ou pastagens fazem com que os SAF tenham o potencial de diminuir a degradação do solo, diversificar a renda, diminuir a pressão sobre as áreas florestais remanescentes (SMITH et al., 1998), produzir várias culturas ao mesmo tempo e minimizar o risco de perdas (VANDERMEER, 1989).

Os sistemas agroflorestais proporcionam a melhoria da estrutura e da fertilidade dos solos e promovem uma maior eficiência na ciclagem de nutrientes promovida pelas raízes dos componentes arbóreos, arbustivos e herbáceos (ALVES, 2009). A utilização de diferentes espécies proporciona um melhor aproveitamento da área, aliando interesses conservacionistas e econômicos.

Com o aumento da biodiversidade no sistema de produção, os sistemas agroflorestais podem ser considerados uma boa alternativa para utilização de recursos que aumentam a produtividade, proporcionando maior nível de sustentabilidade, (LAMÔNICA; BARROSO, 2008). Alves (2009) observou que a diversidade é fundamental para a estabilidade biológica e econômica em todos os modelos de SAF.

Segundo Noronha (2008) e May e Trovatto (2008) estes sistemas têm demonstrado enorme potencial para produzir sustentavelmente grande diversidade vegetal e até animal. Assim, poer meio dos SAF obtém-se uma importante ferramenta para a agricultura familiar no combate à pobreza rural, na garantia da segurança alimentar e na conservação dos recursos naturais.

A condição de sustentabilidade nesses sistemas deve está vinculada tanto às necessidades, anseios e possibilidades do produtor, como às exigências agroecológicas das espécies a serem combinadas e às limitações do ambiente (SILVA, 2014). Nesse sentido, pode-se afirmar que a condição efetiva de sustentabilidade é determinada pela integração de fatores condicionantes da biologia, economia e ecologia que favoreçam sua adotabilidade pelos agricultores (SILVA, 2014). Abdo, Valeri e Martins (2008), consideram os sistemas agroflorestais como uma opção interessante e extremamente viável para o pequeno produtor (ABDO; VALERI; MARTINS, 2008). No entanto, o agricultor deve escolher uma variedade de espécies adaptadas à região e promover uma boa interação entre elas (ABDO; VALERI; MARTINS, 2008).

Nesse sentido, a sustentabilidade pode ser entendida como a consequência direta do desempenho de sistemas tecnicamente bem formulados, economicamente viáveis e ambientalmente adequados. 
Silva (2014) estabelece que para os fatores biológicos e ecológicos, devem prevalecer as seguintes premissas: foco nas espécies a serem associadas e no ambiente; adequação à condição agroecológica; completaridade entre os componentes do sistema e conservação do ambiente produtivo (água, solo, microclima).

\subsubsection{SAF como Mecanismos de Desenvolvimento Limpo (MDL)}

As mudanças climáticas causadas pelas alterações nas concentrações de Gases do Efeito Estufa (GEE) na atmosfera, provocadas principalmente pela queima de combustíveis fósseis e pela mudança no uso do solo, tem estimulado a busca por alternativas que objetivam a mitigação dos efeitos do clima sobre a população e promovam o desenvolvimento sustentável (OLIVEIRA, 2013).

A Rio-92, o Protocolo de Quioto, as convenções sobre o clima, a comunidade científica, os governos e a sociedade civil organizada buscam ferramentas para harmonizar o desenvolvimento econômico com responsabilidade socioambiental (OLIVEIRA, 2013). O protocolo de Quioto, em vigor desde 2005, trouxe à comunidade global o conceito de Mecanismo de Desenvolvimento Limpo (MDL), um dos três mecanismos de flexibilização desenvolvidos como proposta de recompensar, financeiramente, os países que adotem práticas sustentáveis de uso dos recursos naturais com o objetivo de reduzir as emissões de carbono (OLIVEIRA, 2013).

O mecanismo de Redução de Emissão por Desmatamento e Degradação Florestal (REDD) é a ligação de mecanismos legais, ações governamentais e de tecnologias de exploração e produção que visam a redução das emissões de carbono provenientes do desmatamento e da degradação florestal por meio de incentivos positivos ou compensações financeiras (OLIVEIRA, 2013).

Entende-se o Código Florestal Brasileiro como mecanismo legal ou de comando/controle e como MDL, pode-se citar os sistemas agroflorestais (IPCC, 2007 apud OLIVEIRA, 2013). As práticas de florestamento, reflorestamento, manejo florestal e redução do desflorestamento surgem como MDL (OLIVEIRA, 2013).

No Protocolo de Quioto, os SAF são classificados como um Mecanismo de Desenvolvimento Limpo (NEPSTAD et al., 2010). Os SAF possuem elevado potencial para sequestro de carbono e a mitigação da emissão dos GEE (MUTUO et al., 2005).

Motta et al. (2000) destacaram que os sistemas agroflorestais são promissores à recuperação das áreas degradadas, alteradas, de reserva legal e de 
áreas de preservação permanentes, além do Mecanismo de Desenvolvimento Limpo (MDL) e a introdução dessas áreas em novos ciclos produtivos. O uso dos SAF para a restauração de passivos florestais, Áreas de Preservação Permanente (APP), Reservas Legais (RL), dentre outros, podem apresentar vantagens econômicas pelos retornos produtivos das culturas agrícolas nos primeiros anos, enquanto as árvores recompõem a paisagem (AMADOR, 2003; SABOGAL et al., 2006).

Segundo a legislação anterior - Lei no 4771, de 15 de setembro de 1965 (BRASIL, 1965), não era permitido o cultivo de quaisquer sistemas de produção em Área de Preservação Permanente (APP) e Reserva Legal (RL), sendo permitido apenas o manejo agroflorestal sustentável em Reservas Legais de pequenas propriedades rurais, o que restringia significativamente o perímetro agricultável de tais propriedades.

Com a publicação da Lei n 12.651, de 25 de maio de 2012, que institui o novo Código Florestal (BRASIL, 2012), essas definições mudaram. Ficou definido que pequenas propriedades rurais podem utilizar plantios de sistemas agroflorestais em suas APP e RL, desde que esses sistemas sejam submetidos a planos de manejo sustentáveis aprovados pelo órgão estadual do meio ambiente responsável.

\subsubsection{Sistemas agroflorestais na Amazônia: o caso de Tomé-Açu}

A região Norte do Brasil, que ocupa quase metade do território do país e detém a maior extensão de florestas quentes e úmidas do mundo, apresenta grande concentração e diversidade de SAF, que são, na maior parte, estabelecidos e manejados por meio do conhecimento popular socialmente importante, porém com baixo nível técnico (SILVA, 2013).

O uso de sistemas agroflorestais na Amazônia surgiu como uma opção sustentável, com possibilidade de auxiliar na redução do desmatamento, uma vez que quebra o ciclo da agricultura migratória, a qual, em função de períodos de pousio muito curtos para a recuperação dos solos, aumenta a pressão sobre as áreas de floresta primária (SMITH et al., 1998). Ferreira et al. (2009) realizaram uma pesquisa com cinquenta agricultores familiares e identificaram que nas áreas de adoção dos SAF o número de áreas preparadas através do sistema tradicional, de corte e queima, foi reduzido.

Com diversas finalidades e arranjos, os SAF têm sido trabalhados e incentivados como estratégias para o fortalecimento das unidades produtivas locais, buscando a melhoria da renda familiar (CALVI, 2009). 
A prática de SAF não é novidade, pois já era utilizada por comunidades indígenas, caboclas e ribeirinhas, para fins de subsistência, porém, os colonizadores europeus somente perceberam a sua importância muito tempo depois (BARROS et al., 2009).

Entre os diversos tipos de sistemas agroflorestais nas regiões tropicais são destacados os sistemas taungya, silvipastoris, quintais agroflorestais e os sistemas multiestratificados comerciais, sendo estes dois últimos bastante praticados na Amazônia (VIEIRA et al., 2007).

Os quintais agroflorestais são muito comuns na Amazônia (SILVA, 2013). Van Leeuwen e Gomes (2001) denominam os quintais agroflorestais como pomar caseiro. Dependendo da região, esses sistemas de produção podem receber outras denominações como terreiro, quintal, sítio, pomar doméstico ou horta caseira e miscelânea (VAN LEEUWEN; GOMES, 2001). Os quintais geralmente apresentam em sua composição árvores de muitas espécies diferentes, boa parte frutífera, a área varia entre 0,2 e 2,5 hectares, normalmente dentro do pomar é mantida uma pequena criação de aves (galinhas e patos). Para Noda S., Noda H. e Martins (2001), os quintais equivalem aos SAF multiestratificados encontrados nas propriedades dos agricultores familiares de terra firme da Amazônia Central.

Os SAF multiestratificados são praticados na Amazônia brasileira desde a década de 1970 pelos agricultores japoneses em Tomé-Açu, PA. Os primeiros sistemas agroflorestais implantados no município foram inseridos pelos agricultores nipo-brasileiros como estratégia de diversificação da produção e da redução dos riscos do monocultivo. Esses sistemas de produção surgiram a partir da busca por novas alternativas produtivas, em função da disseminação da fusariose (Fusarium solani f. sp. piperis) nos plantios de pimenta-do-reino (Piper nigrum L.), que surgiu em 1957 e passou a devastar os monocultivos de pimenta a partir da década de 1970, e da queda de preços decorrente da expansão desordenada dos plantios (HOMMA, 2004). A busca por novas alternativas econômicas fizeram com que sistemas consorciados, em rotação e sequencial, com cultivos perenes e anuais fossem adotados, com o objetivo de aproveitar áreas antes, durante e depois do plantio da pimenta-do-reino (HOMMA, 1996).

Barros et al. (2011) afirmam que a busca por novas alternativas de produção permite que os sistemas agroflorestais implantados em Tomé-Açu apresentem grandes perspectivas de expansão na região, visando a ocupação de áreas desmatadas, assim como a recuperação de áreas degradadas.

O município tem se destacado pela tradição do uso de sistemas agroflorestais com diferentes composições de espécies, formas e tamanhos, conforme o objetivo do agricultor, tornando-se um modelo base de produção 
diversificada, denominada atualmente como Sistema Agroflorestal de Tomé-Açu (SAFTA) (MATSUNAGA; HIRAMIZU, 2016).

O SAFTA permite a inclusão de uma diversidade de culturas, desde as anuais, semiperenes e florestais, gerando uma produção eficaz, desde o primeiro ano do sistema e ao longo dos anos, logo, obtém-se uma melhor distribuição de renda e trabalho durante o ano e ao longo dos anos, otimizando o uso da terra, o que contribui para o desenvolvimento sustentável das terras agrícolas da região (MATSUNAGA; HIRAMIZU, 2016). Os sistemas agroflorestais praticados em Tomé-Açu representam um caminho para um futuro melhor para a terra e para os trabalhadores que a utilizam para produzir (TAFNER JÚNIOR; SILVA, 2012).

Os SAF do município de Tomé-Açu têm no cacau e no cupuaçu as duas culturas perenes consideradas principais na rentabilidade dos sistemas e a pimenta do reino aparece na maioria das propriedades devido à tradição no cultivo e pelos altos rendimentos em curto prazo, mesmo enfrentando fases de declínio com preços mais baixos (MENDES, 2003). Segundo Barros et al. (2009), os SAF do município são formados, basicamente, por cultivos de pimenta-doreino, cacau, açaí e cupuaçu, combinados entre si e/ou com espécies frutíferas e florestais. Couto (2013) identificou que 90\% dos SAF de Tomé-Açu apresentam a pimenta-do-reino em seu arranjo, da mesma maneira que o cupuaçu e o açaí, o cacau está presente em $81 \%$ das propriedades. A mesma autora observou que os sistemas foram implantados a partir do monocultivo de pimenta já existente, sendo introduzidas ao longo do tempo as demais espécies frutíferas e florestais.

Segundo Carvalho (2008), a produção em SAF na Amazônia vem se desenvolvendo por meio de organização de pequenos produtores de base familiar, em associações ou cooperativas de produtores, geralmente localizados em áreas de difícil acesso e pouca infraestrutura.

Em Tomé-Açu não é diferente, pois no município existem diversas associações de produtores rurais (COUTO, 2013), com destaque para a Cooperativa Agrícola Mista de Tomé-Açu (CAMTA) e a Associação de Produtores e Produtoras de Agricultura Familiar do Município de Tomé-Açu (APPRAFAMTA).

A CAMTA desempenha um importante papel no desenvolvimento do município com a agroindustrialização da produção agrícola, além disso, oferece assistência técnica aos agricultores cooperados e não cooperados, mas que podem se tornar fornecedores da CAMTA. Assim, todos os agricultores conseguem produzir em maior quantidade e de forma eficiente.

A APPRAFAMTA foi fundada a exemplo da CAMTA, pelos agricultores familiares da comunidade de Santa Luzia, situada na zona rural do município, os 
quais passaram a adotar as experiências exitosas com SAF associados com novas alternativas de produção, beneficiamento e comercialização (COUTO, 2013).

\section{CONSIDERAÇÕES FINAIS}

A agricultura de corte e queima é a forma de cultivo predominante nos estabelecimentos agrícolas familiares na Amazônia. Por muito tempo, sua prática foi tratada como um sistema sustentável tendo em vista a rápida disponibilização de nutrientes para o solo e consequentemente a alta produtividade. No entanto, nos últimos anos, muitos estudos têm apontado os impactos negativos causados por essa prática, entre eles, a emissão de gases do efeito estufa e a redução na capacidade produtiva devido à diminuição no tempo de pousio, ocasionado pelo aumento populacional e pela necessidade de geração de alimentos. Com isso, novas formas de produção baseadas nos princípios da sustentabilidade surgiram, entre elas, o corte e trituração da capoeira e os sistemas agroflorestais.

Espera-se que as práticas de corte e trituração da capoeira e os sistemas agroflorestais sejam amplamente difundidos, a fim de proporcionar a utilização de áreas já desmatadas e abandonadas, utilizar as áreas para produzir mais e por mais tempo e diminuir a pressão sobre as áreas de floresta, para que possamos ter uma agricultura baseada no tripé da sustentabilidade, economicamente viável, socialmente justa e ambientalmente correta.

\section{REFERÊNCIAS}

ABDO, M. T. V. N.; VALERI, S. V.; MARTINS, A. L. M. Sistemas agroflorestais e agricultura familiar: uma parceria interessante. Revista Tecnologia \& Inovação Agropecuária, São Paulo, v. 1, n. 2, p. 50-59, 2008.

ALTIERI, M. A. Agroecologia: princípios e estratégias para a agricultura sustentável na América Latina do século XXI. 1989. Disponível em: <http:// webcache.googleusercontent.com/search?q=cache:tkI4-gAyqfcJ:comunidades. mda.gov.br/o/899012+agroecologia $+\mathrm{e}+$ revolu $\% \mathrm{C} 3 \% \mathrm{~A} 7 \% \mathrm{C} 3 \% \mathrm{~A} 3 \mathrm{o}+$ verde\&c $\mathrm{d}=21 \& \mathrm{hl}=\mathrm{pt}-\mathrm{BR} \& \mathrm{ct}=\mathrm{clnk} \& \mathrm{gl}=\mathrm{br}>$. Acesso em: 08 jan. 2016.

ALTIERI, M. A; ROSSET, P. Agroecologia versus substituição de insumos: uma contradição fundamental da agricultura sustentável. In: ALTIERI, M. A. Agroecologia: bases científicas para uma agricultura sustentável. Guaíba: Agropecuária, 2002. p. 321-346. 
ALTIERI, M. A. Linking ecologists and traditional farmers in the search for sustainable agriculture. Frontiers in Ecology and Environment. University of California, Berkeley, v. 1, n. 2, p. 35-42, 2004.

ALVES, L. M. Sistemas Agroflorestais (SAF's) na restauração de ambientes degradados. Programa de Pós-graduação em Ecologia Aplicada ao Manejo e Conservação de Recursos Naturais (PGECOL). UFJF, Juiz de Fora, MG, 2009. $18 \mathrm{p}$.

AMADOR, D. B. Restauração de ecossistemas com sistemas agroflorestais. In: KAGEYAMA, P. Y. et al. (Org.). Restauração ecológica de ecossistemas naturais. Botucatu: Fundação de Estudos e Pesquisas Agrícolas e Florestais, 2003. p. 333-340.

ARCO-VERDE, M. F. Sustentabilidade biofísica e socioeconômica de Sistemas Agroflorestais na Amazônia Brasileira. 2008. 209 f. Tese (Doutorado). Curso de Pós-graduação em Ciências Florestais, Universidade Federal do Paraná, Curitiba, 2008.

ARCO-VERDE, M. F; AMARO, G. Cálculo de Indicadores Financeiros para Sistemas Agroflorestais. Boa Vista, RR: Embrapa Roraima, 48p. 2012.

BARROS, A. V. L. de.; HOMMA, A. K. O.; TAKAMATSU, J. A.; TAKAMATSU, T.; KONAGANO, M. Evolução e percepção dos sistemas agroflorestais desenvolvidos pelos agricultores nipo-brasileiros do município de Tomé-Açu, estado do Pará. Amazônia: Ciência \& Desenvolvimento. Belém, volume 5, p. 121-151. 2009.

BARROS, A. V. L.; HOMMA, A. K. O.; SANTANA, A. C.; ARCO-VERDE, M. F.; MENDES, F. A. T. . Sistemas Agroflorestais Nipo-brasileiros do Município de Tomé-Açu, Pará: Formação e Percepção. In: HOMMA, A. K. O.; FERREIRA, A. DA S.; FREITAS M. C. DA S.; FRAXE, T, DE J. P. (Org.). Imigração Japonesa na Amazônia: Contribuição na agricultura e vínculo com o Desenvolvimento Regional. 1. ed. Manaus: Editora da Universidade Federal do Amazonas, 2011, p. 305-337.

BRASIL. Lei no 12.651, de 25 de maio de 2012. Diário Oficial da República Federativa do Brasil, Poder Executivo, Brasília, DF, 25 de maio. 2012. Lei no 4.771, de 15 de setembro de 1965. Diário Oficial da República

Federativa do Brasil, Poder Executivo, Brasília, DF, 15 de set. 1965. 
BRIENZA JÚNIOR. S.; DENICH, M.; FÖLSTER, H.; VLEK, P. L. G. Fallow vegetation enrichment with leguminous trees in the eastern amazon of Brazil: Trees performance. German-Brazilian Workshop on Neotropical Ecosystems Achievements and prospects of cooperative research Hamburg, $3-8$, p. 935-938, set. 2000.

CALVI, M. F. Fatores de adoção de sistemas agroflorestais por agricultores familiares do Município de Medicilândia, Pará. 2009. 122f. Dissertação (Mestrado) - Pós-Graduação em Agriculturas Amazônicas, Universidade Federal do Pará, Belém, 2009.

CAPORAL, F. R.; COSTABEBER, J. A. Agroecologia: alguns conceitos e princípios, 1. ed. Brasília: MDA/SAF/DATERIICA, 2007. 24 p.

CAPORAL, F. R.; PAUluS, G.; COSTABEBER J. A. Agroecologia: uma ciência do campo da complexidade. Brasília. 2009, 111 p.

CARVAlHO, O. M.; SILVA NETO, J. M.; CARVALHO, E. M.; PEREIRA, S. A. A Nova Economia Institucional - NEI e os Sistemas Agroflorestais - SAFs: um estudo com duas organizações agroflorestais na região amazônica. Palestra. In: XLVI Congresso da SOBER - Sociedade Brasileira de Economia, Administração e Sociologia Rural. Rio Branco - AC, 2008. Disponível em <http://www.sober.org.br/palestra/9/785.pdf>. Acesso em: 27 fev. 2016.

CATTANEO, A. Balancing agricultural development and deforestation in the Brazilian Amazon. Washington: IFPRI, 2002. 146p.

COELHO, R. F. R.; OLIVEIRA, V. C.; CARVALHO, C. J. R.; SÁ, T. D. de A. Fluxo de nitrogênio e fósforo pela deposição de liteira em sistemas de produção agrícola de corte/queima e corte/trituração/manejo de capoeira, na Amazônia oriental. In: CONGRESSO BRASILEIRO DE SISTEMAS AGROFLORESTAIS, 5., 2004, Curitiba. Anais... Colombo: EMBRAPA, p. 559-561. 2004.

CORRÊA, M. J. P. Levantamento da flora espontânea na cultura do feijão-caupi sob manejo de capoeira triturada no município de Santa Luzia do Paruá - MA. Cadernos de Agroecologia. v. 6, n. 2, 2011. 5 p.

COSTABEBER, J. A. Acción colectiva y procesos de transición agroecológica en Rio Grande do Sul, Brasil. Córdoba, 1998. 422f. (Tese de Doutorado) Programa de Doctorado en Agroecología, Campesinado e Historia, ISEC-ETSIAN, Universidad de Córdoba, España, 1998. 
COUTO, M. C. de M. Beneficiamento e comercialização dos produtos dos sistemas agroflorestais na Amazônia, Comunidade Santa Luzia, ToméAçu, Pará. 2013. 138f. Dissertação (Mestrado em Agriculturas e Desenvolvimento Sustentável) - Universidade Federal do Pará, Belém, 2013.

DENICH, M.; KANASHIRO, M.; VLEK, P. L. G. The potential and dynamics of carbon sequestration in traditional and modified fallow systems of the Eastern Amazon region, Brazil. In: LAL, R.; KIMBLE, J. M.; STEWART, B. A. (Ed.) Global climate change and tropical ecosystems. Boca Raton: CRC, 1999. p. 213-229.

ENGEL, V. L. Sistemas agroflorestais: conceitos e aplicações. In: Introdução aos Sistemas Agroflorestais. Botucatu: FEPAF, 1999. 70 p.

FEARNSIDE, P. M. Limiting factors for development for agriculture and ranching in Brazilian Amazonian. Revista Brasileira de Biologia, v. 57, n.4, p. 531-549. 1997.

FERREIRA, J. H. O.; KATO, O. R.; FREITAS, A.; GREVINELL, J. G.; PISSATTO, M. Sistemas agroflorestais na agricultura familiar como alternativa para diversificação da produção e redução de queimadas no Nordeste Paraense. In. CONGRESSO BRASILEIRO DE SISTEMAS AGROFLORESTAIS, 7., 2009. Anais... EMBRAPA, 2009.

FONTES, M. A.; RIBEIRO, G. T.; SIQUEIRA, E. R.; SIQUEIRA, P. Z. R.; RABANAL, J. E. M. Sistema agroflorestal sucessional como estilo produtivo para agricultura familiar em território de identidade rural, em Sergipe, Brasil. Revista Brasileira de Agroecologia, v. 8, n. 2, p. 112-120, 2013.

FREITAS, J. L.; SANTOS, E. S.; LIMA E SILVA, R. B.; SILVA, T. L. Comparação e análise de sistemas de uso da terra de agricultores familiares na Amazônia. Biota Amazônia, Macapá, v. 3, n. 1, p. 100-108, 2013.

FREITAS, J. P. de.; MEDEIROS, M. C. S.; SILVA, J. A. L.; FREITAS, F. E. de; NETO, M. F. da S. Agroecologia como alternativa para mudanças de um estilo de agricultura convencional para uma agricultura de base familiar: o caso do assentamento Santo Antonio no município de Cajazeiras-PB. CAMPOTERRITÓRIO: Revista de Geografia Agrária, v. 9, n. 17, p. 436-468, abr. 2014.

GAMA, M. A. P. Dinâmica do fósforo em solo submetido a sistemas de preparo alternativos ao corte e queima no Nordeste Paraense. 2002. $96 f$. Tese (Doutorado) ESALQ, Piracicaba, 2002. 
GLIESSMAN, S. R. Agroecologia: processos ecológicos em agricultura sustentável. Porto Alegre: Editora UFRGS, 2001. 653 p.

HOLSCHER, D.; MOLLER, M. R. F.; DENICH, M.; FOLSTER, H. Nutrient input-output budget of shifting agriculture in Eastern Amazonia. Nutrient Cycling in Agroecosystems, 47, p. 49-57, 1997.

HOMMA, A. K. O. Dinâmica dos sistemas agroflorestais: o caso da Colônia Agrícola de Tomé-Açu, Pará. Revista Instituto de Estudos Superiores da Amazônia, v. 2, p. 57-65, 2004.

Modernization and technological dualism in the extractive economy in Amazonia. In: PÉREZ, M. R.; ARNOLD, J. E. M. (Ed.) Current issues in nontimber forest products research. Bogor, Indonesia: Cifor/ODA, 1996. p.5981.

HURTIENNE, T. Agricultura familiar e desenvolvimento rural sustentável na Amazônia. Novos Cadernos NAEA, Belém: NAEA/UFPA, v. 8, n. 1, 2005. $71 \mathrm{p}$.

JESUS, P. P.; SILVA, J. S.; MARTINS, J. P.; RIBEIRO, D. D.; ASSUNÇÃO, H. F. Transição agroecológica na agricultura familiar: relato de experiência em Goiás e Distrito Federal. CAMPO-TERRITÓRIO: revista de geografia agrária, v. 6, n. 11, p. 363-375. fev., 2011.

KANASHIRO, M.; DENICH, M. Possibilidades de utilização e manejo adequado de áreas alteradas e abandonadas na Amazônia brasileira. Brasília, DF: MCT/CNPq, 1998, 157 p.

KATO, M. S. A. Fire free land preparation as an atlernative to slash-andburn agriculture in the Bragantina region: crop performance and Phosphorus dynamics. Göttingen: Cuvillier, 1998. 144 p.

KATO, M. S. A.; KATO, O. R.; DENICH, M.; VLEK, P. L. G. Fire free alternatives to slash-and-burn for shifting cultivation in the eastern Amazon region: The role of fertilizers. Field Crops Research, Amsterdam, v.62, n.23, p. 225-237. 1999.

KATO, O. R.; SECCO, N. B. Intensificando o cultivo em sistemas agroflorestais sucessionais. In: CONGRESSO BRASILEIRO DE SISTEMAS AGROFLORESTAIS, 5. Ilhéus, Anais... Ilhéus: CBSA. Documentos, 98, p. 111 113. 2004.

KATO, O. R.; KATO, M. do S. A.; CARVALHO, C. J. R. de; FIGUEIREDO, R. de O.; CAMARÃO, A. P.; SÁ, T. D. de A. Plantio direto na capoeira: uma 
alternativa com base no manejo de recursos naturais. In: WADT, P. G. S. (Org.). Sistema plantio direto e controle de erosão no Estado do Acre. Rio Branco: Embrapa Acre, 2007. p. 79-111.

KATO, O. R.; VASCONCELOS, S. S.; FIGUEIREDO, R. O.; CARVALHO, C. J. R.; SÁ, T. D. A.; SHIMIZU, M. K. Agricultura sem queima: uma proposta de recuperação de áreas degradadas com sistemas agroflorestais sequenciais. In: LEITE, L. F. C.; MACIEL, G. A.; ARAÚJO, A. S. F. (Ed.). Agricultura Conservacionista no Brasil. Brasília: Embrapa, 2014. p. 189-216.

LAMÔNICA, K. R.; BARROSO, D. G. Sistemas agroflorestais: aspectos básicos e recomendações. Manual Técnico 7. Niterói - RJ, 2008. 15 p.

MARCOLAN, A. L.; LOCATELLI, M. FERNANDES, S. R. Atributos químicos e físicos de um Latossolo e rendimento de milho em diferentes sistemas de manejo da capoeira. Comunicado Técnico 352, Embrapa, Porto Velho - RO, 2009, p. 6.

MARTINS, S. V. Recuperação de áreas degradadas: como recuperar áreas de preservação permanente, voçorocas, taludes rodoviários e áreas de mineração. 3. ed. Viçosa: Aprenda Fácil, 2013. 264 p.

MAY, P. H.; TROVATTO, C. M. M. Manual agroflorestal para a Mata Atlântica. Brasília: MDA/SAF, 2008. 196p.

MATSUnAGA, A. T.; HIRAMIZU, N. H. Análise sócio econômica e de produtividade de um sistema agroflorestal multiestratificado no Município de Tomé-Açu/PA. 2016. 43f. Trabalho de Conclusão de Curso (Graduação em Engenharia Florestal) - Universidade Federal Rural da Amazônia, 2016.

MENDES, F. A. T. Avaliação de modelos simulados de sistemas agroflorestais em pequenas propriedades cacaueiras selecionadas no Município de Tomé-Açu, no Estado do Pará. Informe GEPEC, v. 7, n. 1, 2003. 19p.

MEDRADO, M. J. S. Sistemas agroflorestais: aspectos básicos e indicações. In: GALVÃO, A. P. M. (Org.). Reflorestamento de propriedades rurais para fins produtivos e ambientais: um guia para ações municipais e regionais. Brasília: Embrapa Comunicação para Transferência de Tecnologias; Colombo, PR: Embrapa Floresta. 2000. p. 269-312.

MMA - Ministério do Meio Ambiente. Agricultura Sustentável. Brasília, 2000. 157 p. 
MIRANDA, P. S.; RODRIGUES, W. Sistema Agroflorestal "agricultura em andares." Belém: UFPA, NUMA, POEMA, 1999. 102 p.

MOTTA, R. S. FERRAZ, C.; YOUNG, C. E. F.; AUSTIN, D.; FAETH, P. O mecanismo de desenvolvimento limpo e o financiamento do desenvolvimento sustentável no Brasil. Rio de Janeiro: IPEA, 2000. 51 p. Disponível em: <http:/ /www.ipea.gov.br>. Acesso em 15 mar. 2016.

MUTUO, P. K.; CADISCH, G.; ALBRECHT, A.; PALM, C. A.; VERCHOT, L. Potential of agroforestry for carbon sequestration and mitigation of greenhouse gas emissions from soils in the tropics. Nutrient Cycling in Agroecosystems, v. 71, p. 43-54, 2005.

NAIR, P. K. R. Agroforestry systems in the tropics. Dordrecht: Boston: Kluwer Academic Publishers. ICRAF. 1989, 664 p.

NEPSTAD, D.; STICKLER, C. M.; CATTANEO, A.; JOHNS, T. Brazil's emerging sectoral framework for reducing emissions from deforestation and degradation and the potential to deliver greenhouse gas emissions reductions from avoided deforestation in the Amazon's Xingu river basin. California, EUA: Electric Power Research Institute, 2010. 158 p.

NORONHA, A. F. B. Agricultura familiar, extensão rural e sistemas agroflorestais: a experiência do CAV no Alto Jequitinhonha. 2008. $119 f$. Dissertação (Mestrado em Administração) - Universidade Federal de Lavras, Lavras - MG, 2008.

NODA, S. do N.; NODA, H.; MARTINS, L. L. U. Utilização e apropriação das terras por agricultura familiar Amazonense de Várzeas. In: DIEGUES, A. C; MOREIRA, A. de C. C. (Org.). Espaços e recursos naturais de uso comum. São Paulo: Núcleo de Apoio à Pesquisa sobre Populações Humanas e Áreas Úmidas Brasileiras, 2001. p. 181-204.

NUNES DA SILVA, J.; MATTTOS, J. S.; DINIZ, P. C. O.; VASCONCELOS, G. O. S. Transição Agroecológica em Assentamentos Rurais: o processo inicial no assentamento Chico Mendes III/PE-Brasil. Revista Brasileira de Agroecologia, v. 4, n. 2, p. 3022-3025, nov. 2009.

OLIVEIRA, D. M. Q. de. Avaliação econômica de sistemas agroflorestais no Nordeste Paraense: os sistemas agroflorestais como instrumento de política pública de desenvolvimento socioeconômico e ambiental regional. 2013. 162 f. Dissertação (Mestrado em Ciências Ambientais) - Universidade Federal Rural da Amazônia, Belém, 2013. 
OLIVEIRA, J. S. R.; KATO, O. R.; OLIVEIRA, T. F.; QUEIRÓZ, J.; CARDOSO, R. Agricultura familiar e safs: produção com conservação na Amazônia Oriental, nordeste paraense. In: CONGRESSO BRASILEIRO DE SISTEMAS DE PRODUÇÃO. Agricultura familiar, políticas públicas e inclusão social. 2007. Anais... Fortaleza: Embrapa Agroindústria Tropical, 2007.

PALUDO, R.; COSTABEBER, J. A. Sistemas agroflorestais como estratégia de desenvolvimento rural em diferentes biomas brasileiros. Revista Brasileira de Agroecologia, v. 7, n. 2, p. 63-76, 2012.

PEREIRA, C. A.; VIEIRA, I. C. G. A importância das florestas secundárias e os impactos de sua substituição por plantios mecanizados de grãos na Amazônia. Interciência, v. 26, p. 337-341, 2001.

SÁ, T. D. A.; KATO, O. R.; CARVALHO, C. J. R.; FIGUEIREDO, R. O. Queimar ou não queimar? De como produzir na Amazônia sem queimar. Revista USP, São Paulo, v. 72, p. 90-97, 2006.

SABOGAL, C. Silvicultura na Amazônia Brasileira: avaliação de experiências e recomendações para implementação e melhoria dos sistemas. Belém: CIFOR, 2006, 190 p.

SANTOS, J. C. Sustentabilidade socioeconômica e ambiental de sistemas de uso da terra da agricultura familiar no estado do Acre. 2008. 182f. Tese (Doutorado) - Universidade Federal de Viçosa, Viçosa, MG, 2008.

SAMPAIO, C. A.; KATO, O. R.; NASCIMENTO E SILVA, D. Corte e trituração da capoeira sem queima como alternativa de uso da terra, rumo à sustentabilidade florestal: o caso Tipitamba em Igarapé-Açu/Pará. In: ENGEMA - Encontro Nacional Sobre Gestão Empresarial e Meio Ambiente, 9, 2007, Curitiba, PR. Anais... Curitiba, PR, 2007.

SAMPAIO, C. A.; KATO, O. R.; NASCIMENTO E SILVA, D. Sistema de corte e trituração da capoeira sem queima como alternativa de uso da terra, rumo à sustentabilidade florestal no nordeste paraense. RGSA - Revista de Gestão Social e Ambiental. v. 2, n. 1, p. 41-53.Jan. - Abr. 2008.

SILVA, I. C. Sistemas agroflorestais, conceitos e métodos. Itabuna: SBSAF, 2013. 308 p.

SILVA, I. C. Sistemas Agroflorestais no Brasil: Aspectos Conceituais e Conjunturais. In: GIMÉNEZ, A. M.; BOLZÓN, G. I. (Org.). Educación e Investigación Forestal Para un Equilibrio Vital: Cooperación Binacional Brasil Argentina. 1. ed. Córdoba (Argentina): Brujas, v. 1. 2014. p. 197-215. 
SMITH, N. DUBOIS, J. C. L.; CURRENT, D.; LUTZ, E.; CLEMENT, C. Experiências Agroflorestais na Amazônia Brasileira: Restrições e oportunidades. Programa Piloto para a Proteção das Florestas Tropicais do Brasil, Brasília, Brasil, 1998. 146p.

SOUZA, C. M. de A.; FREITAS, F. dos S.; CARVALHO, C. J. R. de; VASCONCELOS, S. S.; KATO, O. R. Atributos físicos do solo em sistemas agroflorestais sequenciais no município de Igarapé-Açu, Pará. In: CONGRESSO BRASILEIRO DE SISTEMAS AGROFLORESTAIS, 8. Belém, 2011. Anais... Belém: SBSAF; Embrapa Amazônia Oriental; UFRA; CEPLAC; EMATER; ICRAF, 2011.

TAFNER JÚNIOR, A. W.; SILVA, F. C. Atuação da Cooperativa Agrícola Mista de Tomé-Açu (CAMTA) no Mercado Promovendo o Cooperativismo e a Sustentabilidade na Amazônia. In: ENCONTRO NACIONAL DA ASSOCIAÇÃO NACIONAL DE PÓS-GRADUAÇÃO E PESQUISA EM MEIO AMBIENTE E SOCIEDADE, 6. Belém, 2012. Anais... Belém: ANPPAS, 2012.

TRINDADE, E. F. DA S.; KATO, O. R.; CARVALHO, E. J. M.; SERAFIM, E. C. DA S. Disponibilidade de fósforo em solos manejados com e sem queima no Nordeste paraense. Amazônia: Ciência \& Desenvolvimento, Belém, v. 6, n. 12, p. 7-19. jan./jun. 2011.

VANDERMEER, J. The Ecology of Intercropping. Cambridge: Cambridge University Press, 1989.237 p.

VAN LEEUWEN, J.; GOMES, J. B. M. O pomar caseiro na região de Manaus, Amazonas, um importante sistema agroflorestal tradicional. Brasília: INPA, 2001. Disponível em: < http://www.inpa.gov.br/cpca/johapomar.html>. Acesso em: 18 fev. 2016.

VIEIRA, T. A.; ROSA, L. S.; VASCONCELOS, P. S. S.; SANTOS, M. M.; MODESTO, R. S. Sistemas agroflorestais em áreas de agricultores familiares em Igarapé-Açu, Pará: caracterização florística, implantação e manejo. Acta Amazônica, Manaus, v. 37, n.4, p.549-558, 2007.

VIEIRA, T. A.; ROSA L. S.; MODESTO, R. S.; SANTOS M. M. Gênero e Sistemas Agroflorestais: O Caso de Igarapé-Açu, Pará, Brasil. Revista Ciências Agrárias, Belém, n. 50, p. 143-154, jul./dez. 2008. 


\section{Aprendizagem experiencial na formação de gestores socioambientais}

\section{Experencial learning in formation of leaders in social and environmental management}

Walterlina Brasil - Doutora em Ciências Socioambientais pelo Núcleo de Altos Estudos Amazônicos, Universidade Federal do Pará (NAEA-UFPA). Docente do Núcleo de Ciências Humanas, Universidade Federal de Rondônia (UNIR). Pesquisadora no Grupo de Estudos e Pesquisas em Educação Superior. E-mail: walterlina.brasil@gmail.com.

Solange Arrolho - Doutora em Aquicultura pelo Centro de Aquicultura da Universidade Estadual Paulista (UNESP). Professora da Universidade do Estado de Mato Grosso (UNEMAT).E-mail: solarrolho@yahoo.com.br

Berenice Simão - Mestre em Desenvolvimento Regional e Meio Ambiente pela Universidade Federal de Rondônia (UNIR). E-mail: berenicesimao@yahoo.com.br

\section{Resumo}

Trata-se da experiência proporcionada durante um curso de Pós-Graduação Lato Sensu para formação de lideranças na gestão socioambiental, onde se estabeleceu como base metodológica a Aprendizagem Experiencial, nos termos de Freire (1987), Lizeo (2003) e Kolb (1984). O artigo analisa o uso dessa abordagem no curso, e quais contribuições oferecem àqueles que se disponham a efetivar formação de gestores socioambientais. Anota-se que o curso foi estruturado com base na teoria de sistemas socioecológicos complexos, buscando contribuir com a formação de lideranças para a Amazônia brasileira. Este marco teórico é importante porque está associado à escolha metodológica para a formação oferecida, convertendo-se no eixo da proposta que abre espaço para experiências oferecidas a partir da Aprendizagem Experiencial. A análise pode subsidiar outros processos semelhantes, aperfeiçoados com base na reflexão sobre $o$ método para a aprendizagem e identificando a efetividade dessa prática na formação profissional.

\section{Palavras-chave}

Aprendizagem Experiencial. Gestão Socioambiental. Formação de Lideranças. Pós-Graduação.

\begin{abstract}
This article demonstrates the experience provided during a Lato Sensu Post-Graduation course for the formation of leaders in social and environmental management, where the Experiential Learning was established as a methodological basis, according to Freire (1987), Lizeo (2003) and Kolb (1984). Moreover, it analyzes the use of this approach within the Course, and the respective contributions to those who are willing to carry out the training of socio-environmental managers. It is noted that the course was structured based on the theory of complex socioecological systems, seeking to contribute to the formation of leaderships for the Brazilian Amazon. This theoretical framework is important because it is associated with the methodological choice for the training, becoming the axis of the proposal that broadens for Experiential Learning experiences. The analysis can support other similar processes, refined based on reflection on the method for learning, and identifying the effectiveness of this practice in vocational training.
\end{abstract}

\section{Keywords}

Experiential Learning. Environmental Management. Leadership training. Graduate Course. 


\section{INTRODUÇÃO}

O artigo contribui com os estudos sobre o uso de ferramentas metodológicas que abarcam a aprendizagem experiencial. Com este propósito e dentro do tema da conservação da Amazônia brasileira, registra e analisa a experiência do Curso de Especialização em Gestão Colaborativa de Sistemas Socioecológicos Complexos na Amazônia brasileira realizado em Mato Grosso, na cidade de Cotriguaçu, no período de 2010 a 2013. O curso teve como objetivo a formação de lideranças para gestão ambiental.

A aprendizagem experiencial foi central na proposta de condução do curso, uma vez que as mediações pedagógicas mais gerais tornaram-se cada vez mais interdependentes nas ações do grupo, quer sejam quando relacionadas ao planejamento e conteúdo, quer sejam quando relacionadas aos enfoques e intercâmbios de informação e comunicação. A execução do curso envolveu o critério de participação e colaboração entre os indivíduos para o sucesso do resultado e, disto, o quanto eram capazes de gerar estratégias de aprendizagem entre grupo e indivíduos (e vice-versa) cada vez mais consolidadas.

Assim, a aprendizagem experiencial se mostrou essencial como uma parte da formação. Portanto, aprofundar análises relacionadas ao seu uso permite avaliar o potencial dessa abordagem em situações formativas semelhantes e inferir quanto aos possíveis aprimoramentos, conforme o caso.

Com este interesse, apresentamos o resultado do exercício realizado nesta experiência de curso. Neste caso, porém, realçamos que a aprendizagem experiencial possui íntima relação com a percepção do que se compreende como gestão colaborativa, como veremos adiante. Também um resumo da proposta pedagógica, quanto à aprendizagem experiencial para o curso onde foi aplicado, é apresentado ao esclarecermos a compreensão de "Ciclo de Aprendizagem".

Em síntese, a hipótese de trabalho consiste em verificar se o Ciclo se apresenta no curso de forma progressiva, quando foi incorporando estratégias de planejamento participativo e estruturas de cogestão interna - são componentes centrais na abordagem experiencial - seria previsível que é permitido ao grupo construir uma compreensão própria quanto a limites e possibilidades da gestão colaborativa que foi concebida como tópico para reflexão permanente no processo do curso. Portanto, quando o conteúdo propõe criar situações para aquisição de instrumental teórico-prático e experiencial, a abordagem de aprendizagem experiencial pretendeu orientar o olhar do cursista sobre os grupos humanos envolvidos em conflitos relacionados ao uso e à conservação dos recursos naturais, alinhando-se a uma visão sistêmica do ambiente. Este efeito pretendido 
dependeria bastante do repertório de experiências dos cursistas e da disposição destes em colaborar.

Assim, o contexto da aprendizagem experiencial evoca a natureza e o conteúdo do projeto desenvolvido. O curso foi realizado de 2010 a 2013 e subdividido em quatro módulos presenciais, com etapas intermediárias de estudos e atividades on-line. A proposta e a implementação justificaram-se, entre outros aspectos, com a intenção de "enfrentar o desafio de conciliar conservação ambiental e desenvolvimento socioeconômico na Amazônia envolvendo diferentes áreas disciplinares, atores sociais e arranjos institucionais" (Projeto, página online do curso, 2011). Não trataremos das conclusões registradas pelos participantes do curso a respeito dos conceitos de aprendizagem experiencial e colaboração envolvidos no exercício do Módulo 3 (Brasil, W. 2012, Plano de Aplicação), porque isto se distancia dos objetivos aqui descritos. Durante o exercício, assumimos a postura de observador participante, e, desta posição, obter a coleta e realizar a análise dos dados.

Realizar um curso com um público diversificado e buscar a integração entre experiências individuais e aprendizagens coletivas, abriu espaço para reflexão sobre o resultado proporcionado, considerando a base metodológica de o projeto ser orientada para a aprendizagem experiencial. Segundo a proposta, os "participantes [eram] representativos de uma diversidade de áreas disciplinares e de experiências práticas na Amazônia, e que por isto [possibilitavam] a troca de experiências e a potencialização dos processos de aprendizagem, reflexão e aplicação dos conteúdos e métodos do curso" (Projeto, página online do curso, 2011).

Por estes dois princípios - a concepção teórica que orienta e seleciona o conteúdo em conjunto com a definição metodológica para execução - os quatro módulos visaram conduzir a identificação dos atributos, variáveis e história do sistema analisados em razão do conteúdo, ao mesmo tempo em que cada um dos envolvidos no processo poderia avançar em sua autoaprendizagem. A partir desta última reflexão, se davam acertos quanto ao planejamento e não o inverso, como usual.

No módulo 3 os grupos de trabalho convergiram para dois enfoques: questões conceituais e questões metodológicas, respectivamente. Neste sentido, o conceito de colaboração é fundamental, pois é ele que vincula conteúdo e metodologia. Por isto, a questão a ser discutida neste artigo é: em que medida e sob qual percepção dos sujeitos acerca das próprias experiências, o desenvolvimento da colaboração acontece nos processos formativos? E como se constituem como aprendizagem experiencial? 
Foi durante o planejamento e execução do módulo 3 (março 2012), que os participantes do curso assumiram de maneira mais evidente o protagonismo quanto à autoaprendizagem, como parte do conteúdo do curso. Isto confirmou as preocupações voltadas para entendimento da perspectiva metodológica, levemente sinalizada nos módulos anteriores. Os objetivos foram definidos de modo a explicitar a vinculação entre colaboração, aprendizagem experiencial e formação, como se observa no transcrito (BRASIL, 2012, Plano de Aplicação, destaques nossos):

[...] [os objetivos do Módulo 3 são]:

-Avançar no entendimento teórico-metodológico sobre a interface entre resiliência, colaboração e gestão.

-Fechar os trabalhos dos projetos de aplicação e integrar os resultados num exercício de cenários;

-Ligar a nossa experiência individual e do grupo com processos de gestão participativa/colaborativa na Amazônia;

-Sair do campo teórico e revisar aplicações práticas da nossa abordagem;

-Aprofundar conceitos ligados aos atributos nos projetos de aplicação;

-Sistematizar a nossa aprendizagem, em 3 níveis, desde o início do curso;

-Planejar uma atividade ou processo de interação com atores locais no módulo $[\ldots]$

Diante dos objetivos, pareceu-nos conveniente tomar como registro para discussão da efetividade do ciclo de aprendizagem durante a realização do módulo 3 porque este momento do curso envolveu as tarefas para execução de um estudo específico relacionado à compreensão do conceito de colaboração e construir uma ponte em relação aos grupos de atores que compunham as experiências de campo.

\section{CONCEITOS E ABORDAGENS}

O curso foi baseado na teoria de sistemas socioecológicos complexos. Segundo essa teoria, a composição do mundo em um grande sistema ecológico (recursos naturais) e social (humano) pode ser compreendido em vários subsistemas como, por exemplo: recursos hídricos, florestais, cidades e até pequenas comunidades. Estudam-se, nesta teoria, as ações do homem perante os recursos naturais e sua interação com o meio ambiente frente às intervenções de desenvolvimento econômico e os desafios de conservação e adaptação do sistema (OSTROM, 2009). 
A governança de sistemas que envolve o uso comum dos recursos não se explica exclusivamente em razão da escassez, gestão, influência de decisões comunitárias ou de governo, mas, em grande medida, da capacidade dos atores em se envolver na gestão e compreender os processos para não esgotar os recursos, reconhecer conflitos e tomar decisões racionais. São as características dos sistemas, seus atributos e os diferentes regimes em que se manifestam que promovem, internamente, resiliência e revisão dos limites do uso e os conflitos a serem tratados para sobrevivência do sistema.

\subsection{APRENDIZAGEM EXPERIENCIAL, COLABORAÇÃO E GESTÃO COLABORATIVA}

Consideramos o conceito de aprendizagem experiencial por estar ligado ao processo formador no âmbito da atuação dos indivíduos inseridos no contexto do curso, suas interações, percepções, compartilhamentos, atitudes e disponibilidades para aprendizagem colaborativa em razão de uma gestão colaborativa. Tais envolvem decisões e escala superiores à própria condição desses indivíduos, vistas no conjunto das atividades do curso, mas também a partir dos avanços compreendidos em torno da aprendizagem.

Um dos pilares para o desenvolvimento de estratégias de aprendizagem foi a acepção de Kolb (1984). Em síntese, Kolb (1984, p. 38) define aprendizagem como resultado da transformação da experiência e estabelece quatro etapas para este processo que podem ser sintetizadas no chamado "Ciclo de Aprendizagem Experiencial". Envolvem a experiência concreta, observação reflexiva, conceitualização abstrata e a experimentação ativa, buscando que o sujeito procure obter a visão sobre os efeitos relativos ao próprio comportamento de aprender, enquanto aprende.

De fato, Kolb procura estabelecer uma compreensão sobre a experiência como base da aprendizagem em adultos. Trata aspectos quanto ao significado dessas aprendizagens, os dilemas que podem ou não ser superados em relação aos estilos de aprendizagem envolvidos e modificar o comportamento, de modo a adquirir significado em torno da própria aprendizagem. A abordagem experiencial considera que o indivíduo precisa querer aprender para que efetivamente a aprendizagem ocorra. Para tanto, é preciso identificar quais dispositivos são disparados quando o indivíduo se confronta com os conteúdos a serem aprendidos. No curso, os aspectos relacionados ao repertório a ser disponibilizado ou acessado entre os cursistas é previsto durante a composição da turma e considerando-se os cursistas também atores experientes cuja memória e 
história pessoal evocará experiências a serem verificadas, questionadas e trocadas de forma autônoma e interessada para que o processo que está sendo oferecido seja ressignificado. Não sendo considerado isto, o curso torna-se objeto em si, longe de ser objetivo coletivo.

Nesta experiência, a gestão socioambiental é o desafio formador, a partir de lideranças que possuem elementos teóricos quanto à complexidade dos sistemas socioecológicos e atores envolvidos nos dilemas da gestão colaborativa. É preciso aproximar as expectativas dos cursistas frente aos desafios formadores contidos na proposta do curso e a rede de significados a ser tecida pelos indivíduos. Ou seja, nos termos de Kolb (1984), se a experiência é transformada, a aprendizagem ocorre.

Os estudos sobre Kolb no Brasil enfatizam este aspecto da aprendizagem de adultos em processos de profissionalização. Conforme Pimentel (2007), a teoria da aprendizagem experiencial desenvolvida por Kolb é importante ser conhecida e incorporada no Brasil porque são poucas as contribuições das teorias do desenvolvimento que envolvem a relação da profissionalização em adultos e a aquisição do conhecimento. A proposta de Paulo Freire (1987; 1996), por exemplo, envolve em grande medida aspectos políticos da mediação docente em ambiente escolarizado e a consciência política promovida pelo diálogo, do que, necessariamente, identificar quais processos internos mobilizam a aprendizagem. De fato, no curso analisado, tanto o engajamento cognitivo com base na abordagem experiencial, quanto o entendimento da dimensão dialógica, com base na abordagem freireana, são complementares para avançar na concepção de colaboração, complexidade e os dilemas da gestão socioambiental.

Mas detendo-nos no conjunto das condições impostas pelas características que cursos de formação possuem, outro dado nessa concepção, é o uso da noção de mapas ou modelos mentais. Esse conceito durante o curso foi usado para explicar, justificar ou exemplificar como os indivíduos assumem determinada posição, constroem os interesses e interpretam suas relações do mundo. No estudo de Lizeo, há também uma referência a estes aspectos. Entretanto, a autora propõe uma posição para revelar estes "mapas". Segundo ela, entre a experiência concreta e a observação reflexiva há um gap, que é ocasionado por conta dos ajustes entre a experiência e a estrutura reflexiva do sujeito. A intermediação se daria a partir do uso do entendimento que deveria ser usada para operar no processo de compreensão do ambiente e da percepção das pessoas sobre o ambiente e sobre si mesmas, dentro dele ou como parte dele.

O que o indivíduo sabe ou compreende é o que ele estabelecerá na rede de estruturas que compõem o mapa conceitual. Lizeo propõe uma adaptação 
ao Ciclo de Aprendizagem em relação ao mapa conceitual e observação dos aspectos individuais no processo, mediante a inclusão da noção de Loop.

Os loops são os avanços que um grupo "se permite" a partir das reações às propostas de interação que são realizadas. Na condução da experiência, podemos inferir ou destacar processos sob os quais os indivíduos se disponibilizam para aprender. A aprendizagem em grupo reflete níveis de interdependência, confiança, compartilhamento e autonomia. Um grupo, quando aprende, não reflete o acúmulo de aprendizagem dos indivíduos, mas do acúmulo de conhecimento que pode gerar em conjunto. Um passado comum e um futuro desejado fazem parte da nuance por compor e instrumentalizar um grupo. Daí a importância de entender o Ciclo de Aprendizagem Experiencial pautada no grupo.

Desse ponto de vista, é importante identificar que existem outras extrapolações relacionadas à interação individual e coletiva nos processos de aprendizagem. No campo da psicologia social é crescente o interesse por aprendizagens que podem assumir impactos amplos e coletivos no campo do pensamento e da linguagem, especialmente quando partem do plano individual (MARKOVÁ, 2006). A psicologia organizacional acompanha esta onda, estando cada vez mais ocupada com as ferramentas para compreensão das estruturas humanas na sociedade (SIQUEIRA et al., 2008), assim como a administração, gestão e aprendizagem organizacional, no âmbito da discussão sobre as competências (RUAS; ANTONELLO; BOFF, 2005). Porém, essas questões não foram exploradas com o foco e/ou a partir experiência nem para o propósito do curso, dado parecerem secundárias, excessivamente acadêmicas ou de baixo impacto em relação ao conteúdo formativo proposto (BRASIL, W. Notas de Curso, 2011-2013). Abordagens sobre teorias de aprendizagem são bastante úteis, mas não é possível destacar todas como se tratássemos da aprendizagem em si. De fato, se tratou do registro de um processo de aprendizagem em específico, sem menção a outras possibilidades.

Sobre o Ciclo de Aprendizagem Experiencial, Lizeo (2003, p. 23) o define como "[...] um processo contínuo de reflexão e ação baseadas na compreensão compartilhada e ancoradas na experiência conjunta, tendo como resultado a geração de novos conhecimentos e de insights". Coletivamente, os membros do grupo refletem sobre os resultados de suas ações (Experiência Conjunta) por meio da Conversação Reflexiva baseada no diálogo e na discussão produtiva. A qualidade da reflexão dos membros sobre os resultados de suas ações dependerá dos Mapas Cognitivos Coletivos do grupo, incluindo sua base de conhecimento e seus modelos mentais. 
A partir da reflexão os membros do grupo desenvolvem em conjunto um Plano de Ação, que os orienta nas tomadas de decisão e na solução de problemas (Implementação da Ação). Os resultados de suas ações servem como base para futuras experimentações, completando o ciclo de aprendizagem em grupo. Entretanto, há limitações que podem ocorrer dentro do ciclo experiencial que envolvem grupos. Várias são as razões que vão desde a condução do grupo, até a disponibilidade de tempo para as tarefas, conflitos de interesses, expectativas e disponibilidade de recursos. A figura a seguir, proposta por Lizeo (2003), posiciona tais limitações dentro do Ciclo.

Figura 1 - Ciclo de Aprendizagem Experiencial em Grupo e suas limitações

\section{Ambiente}

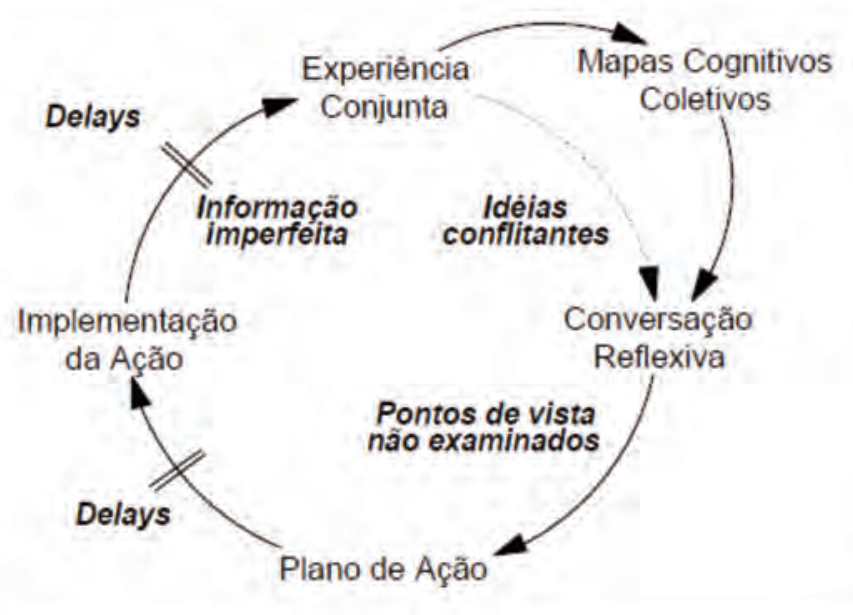

Fonte: Adaptado em Lizeo (2003, esquema 2.5 e 2.7, p. 24 e 40)

As limitações do ciclo experiencial podem incidir em ciclos incompletos. Isto significa não aprendizagem como grupo. Alguns dos elementos que contribuem para um ciclo incompleto são: ideias conflitantes, que fazem os indivíduos reativos à oposição de um pensamento em particular, exigindo negociações que, por vezes, conduzem à conformação resignada do grupo. Tensão relacionada a pontos de vista, onde a prevalência de um ponto de vista depende da posição ou imposição de um comando ou ideia específica em relação ao grupo. Delays ou "atrasos" entre a designação de tarefas, o tempo de execução ou a responsabilização do grupo em torno destas. Em um nível mais específico ou profundo, o delay vem acompanhado com informação imperfeita, quando restringe a informação a certos aspectos em lugar de outros ou a certos indivíduos em detrimento do grupo. 
Em toda a proposta do curso, as indicações propostas nas contribuições teóricas atribuídas à análise de sistemas socioecológicos complexos são que o reconhecimento da não linearidade se estabelece em função, principalmente, da possibilidade de identificar quais elementos poderiam ser constantes ("resiliência de que", no sistema) e quais diferentes atores, com diferentes interesses, em algum momento, podem convergir. Do ponto de vista da teoria freireana, a convergência não seria necessariamente fruto de um diálogo.

Assim, embora não analisemos a pedagogia de Paulo Freire com sincronia ou não à teoria de Kolb ou vice-versa, há, no conceito de diálogo, em ambos, o apelo em torno da reflexão constante sobre e em torno das ideias que conflitam em um grupo ou o reconhecimento prévio dos riscos ao diálogo, em razão da produção de informação imperfeita.

\section{METODOLOGIA}

Para o desenho da metodologia, consideramos a oportunidade de analisar a interação entre o conhecimento "em formação" de natureza acadêmica e vivencial, articulado em parte pela motivação e pela formalidade (cumprimento de tarefas e produtos dos cursistas), com a oportunidade de aprendizagem experiencial.

Por conhecimento "em formação" entendem-se os conteúdos mobilizados para a execução e movimento (processo) disponível para novas aprendizagens durante o curso. Os acessos à formação ocorrem por meio do desenho pedagógico coerente com o fundamento teórico e os objetivos a serem atingidos.

A hipótese geral de trabalho foi que os participantes do curso que estavam mobilizados para o conhecimento (no caso os cursistas e os organizadores) também possuíam relações internas (intra-grupo) e características pessoais que constituíam (ou "construíram") a dinâmica da ação grupal relacionada à própria aprendizagem e aos resultados do curso (BRASIL, 2012). Assim, poderiam, na verdade, gerar mais delays do que sofrer a influência de loops durante o processo de reflexão relacionado à aprendizagem experiencial.

Diante disto, a principal pergunta foi: qual a efetividade do uso de uma técnica didática e pedagógica como uma aprendizagem experiencial em relação a uma atividade que considera a natureza e a construção dessas relações de aprendizagem em grupo? 


\subsection{A OBSERVAÇÃO PARTICIPANTE COM EMPREGO DE REGISTRO DE FALA}

No processo metodológico empregamos a técnica da observação participante associada à coleta de fragmentos de fala. Isto significou que os registros da pesquisa cumpriam também a função de aprendizagem reflexiva das autoras ${ }^{1}$. O espaço para coleta dos dados foi indicado a partir da realização de uma atividade denominada Painel de Atores e Discussão de Cenário, cujas compreensões seriam registradas visualmente através do Mural de Conceitos. Neste último registro (o Mural) foram registrados os insights do grupo, conforme ocorrências nas discussões.

A etapas de trabalho passaram a ser:

1. Realização de atividade prática (painel, mesa, campo) de modo que o grupo tivesse um relato de experiência que envolvesse mobilização e participação de grupos.

2. Registro das reflexões do grupo em torno da percepção relacionada ao modo de como estes atores fazem a leitura do "caso" a partir da compreensão que tivessem sobre participação.

3. Indicação por parte do grupo da percepção sobre a participação, considerando os conteúdos do módulo como mobilizadores do pensamento sobre participação.

4. Registro coletivo da compreensão do grupo. Foi realizada uma dinâmica para mobilizar os participantes a revisar a construção do diálogo sobre participação ocorrido no módulo.

5. Exposição geral da experiência no momento do módulo e submissão à crítica dos participantes.

Estes itens de 1 a 4 foram cumpridos obtendo-se, mediante registro da percepção conceitual, o que o sobre a colaboração e foram orientadas em torno de fragmentos de fala. A técnica do fragmento de fala já havia sido experienciada pelo grupo na atividade de diagnóstico do sistema, desenvolvido no módulo 1, aplicada a diversos atores sociais. O uso da técnica foi precedido de conversas informais sobre os objetivos da atividade, do projeto de aplicação em evidência e das metas da observação (BRASIL, W. 2012).

A coleta durante o Módulo 3 seguiu focada especialmente nos "atos de

\footnotetext{
"Originalmente os dados registrados foram utilizados para análise dos diversos conceitos e procedimentos associados à colaboração e a gestão colaborativa a partir do ponto de vista do ator, sem desprezar que também está presente o ponto de vista de quem intervém e interage com este ator" (BRASIL, 2012).
} 
palavra" expostos em relação à oralidade, sem entrar na voz, timbre, tons e outros elementos que constituem os modos da fala e sem adentrar no ritmo interno da palavra. Neste sentido, as palavras foram transcritas, sem marcas ou ênfases específicas relacionadas a linguagem ou uso pelos sujeitos.

\subsection{BASE ANALÍTICA}

Durante a observação participante, as autoras produziram os registros analíticos. Foram capturadas as falas que fossem produzidas durante a exposição dos convidados na atividade do Painel de atores, discutindo a experiência do Zoneamento Econômico Ecológico do Estado do Mato Grosso. Também foram destacados registros durante a atividade relacionada a metodologia de construção de Cenários, uma vez que, em ambos os casos, o foco era a reflexão em torno de tópicos onde emergissem indícios dos conceitos relacionados à participação, que era o mote para mobilizar os debates do grupo.

Os dados da coleta foram postos como frases. As frases, quando compostas, assumem explicativamente sua concepção filosófica (SOUZA E SILVA; KOCH, 1989, p. 11), em torno de um conjunto de palavras que compõem um sentido comunicativo (Dicionário de Filosofia, verbete FRASES. http:// www.defnarede.com/f. btml), com estrutura própria e distintiva da proposição que contem pensamento literal em frases declarativas (Dicionário de Filosofia, verbete PROPOSIÇÃO. http:/ / www. defnarede.com/f.html).

A meta do trabalho foi coleta de percepções dos cursistas e, conforme a viabilidade de integração destes na discussão, produzir uma reflexão sobre como tal percepção reflete na adoção do conceito de colaboração relacionada à gestão. Os cursistas não atuaram como coletores dos fragmentos de fala. Este procedimento assegurou isenção do registro, para que houvesse a possibilidade de saltar dos registros de fala para a construção de um conceito de colaboração advindo do grupo.

O destaque de proposições à luz da compreensão filosófica foi constituído a partir da etapa da análise do grupo, quando se produziu "sínteses de sentido" a partir de palavras-chave e que sofreram as críticas do grupo, de modo a produzir definições que os representassem quanto ao entendimento que tinham a partir do que ouviram, falaram e registraram.

As interpretações dadas pelo grupo às atividades desenvolvidas, sob coordenação das autoras, permitiram classificar os fragmentos de fala em proposições. Feito este exercício, a análise recorreu às definições que fossem razoáveis ao campo disciplinário - no campo científico - aos quais essas 
construções pudessem remeter. Ou seja, para o conjunto das interpretações produzidas pelo grupo, buscou-se a sua "convergência" no campo interpretativo a partir da Sociologia, da Psicologia, da Linguagem ou da Filosofia.

Um dado importante, gerado pela condução do curso, é que a decisão de interpretar os resultados obtidos na atividade deveria ser posterior ao exercício do módulo 3, mas não foi realizado o exercício de validação em grupo dos registros no módulo 4, quando os registros já haviam assumido a forma de relatório, apesar do argumento alguma conclusão deveria ser a partir do material disponibilizado na atividade do módulo 3.

Este fato foi crucial para que tivessémos elementos capazes de fazer refletir e considerar como e em que medida a aprendizagem experiencial influencia ou é influenciada por fatores externos e como se constitui a participação e apreensão das condições de aprendizagem dos sujeitos. Assim, a análise dos resultados foi orientada pela decisão de classificar os passos cumpridos no exercício em razão do Ciclo de Aprendizagem, exposto no item de análise dos resultados.

Foram previstas duas atividades dentro de um Plano de Trabalho (denominado Projeto de Aplicação), para observação participante - pelas autoras - durante uma atividade do Módulo 3 voltada a discussão do conceito de colaboração Painel de Atores e Palestra sobre Cenários. Aqui, dizemos exclusivamente sobre o Painel de Atores por envolver a construção do Mural de Conceitos pelos Cursistas considerando a realização do Painel.

A função das observadoras, além do natural envolvimento nas atividades por também serem cursistas, foi de auxiliar os registros gerais na realização das tarefas e coordenação posterior das análises.

\subsection{ANÁLISE DOS RESULTADOS}

O interesse analítico do resultado do exercício foi objeto de registro específico e partir da presença da fala. Aqui transportamos as etapas do exercício para os elementos da abordagem experiencial, baseados nos conceitos de loop e gap apresentados na discussão teórica. Dentro de uma perspectiva da aprendizagem experiencial, inserida no ciclo de aprendizagem em grupo, cada etapa da coleta a análise obedeceu a seguinte forma: 
Figura 2 - Ciclo de Aprendizagem Experiencial, limitações e localização das atividades desenvolvidas pelo estudo

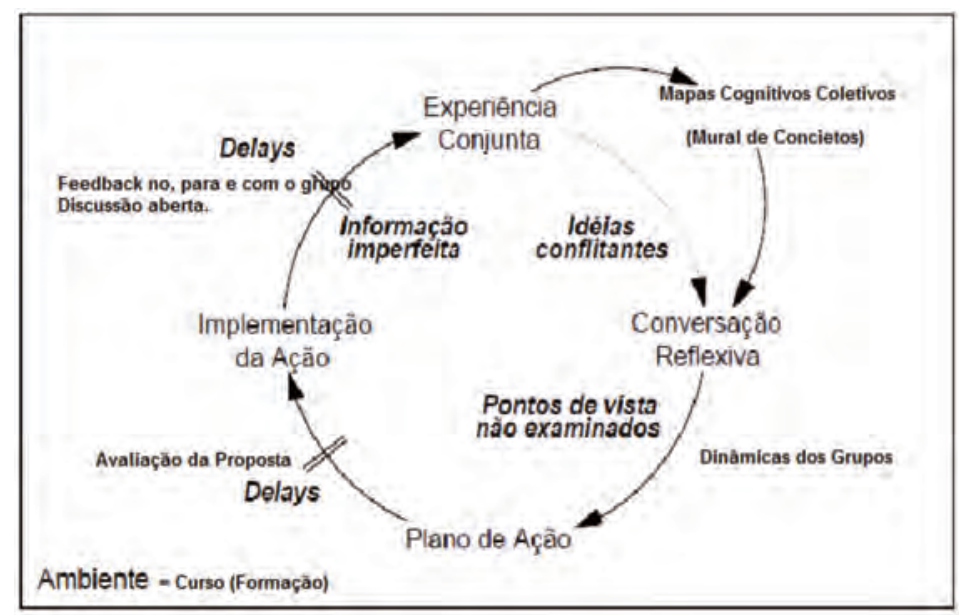

Fonte: Adaptado de Lizeo

Verificamos o histórico do curso e observamos que a principal medida de registro reflexivo foi a construção dos diários de aprendizagem, que no terceiro módulo assumiram a denominação de scrap books. Para este processo, os proponentes e coordenadores das atividades buscaram indicá-lo como um espaço de registro intimista, voluntário, espontâneo e arbitrário de anotações sobre insights, memórias e reflexões por parte do cursista. Outra estratégia, mais coletiva, foi a adoção do monitoramento que consistia no grupo revisar aprendizagens a partir da observação participante em sub-grupos que produziam feedback livres para os cursistas no início da atividade.

Figura 3 - Ciclo de Aprendizagem Experiencial

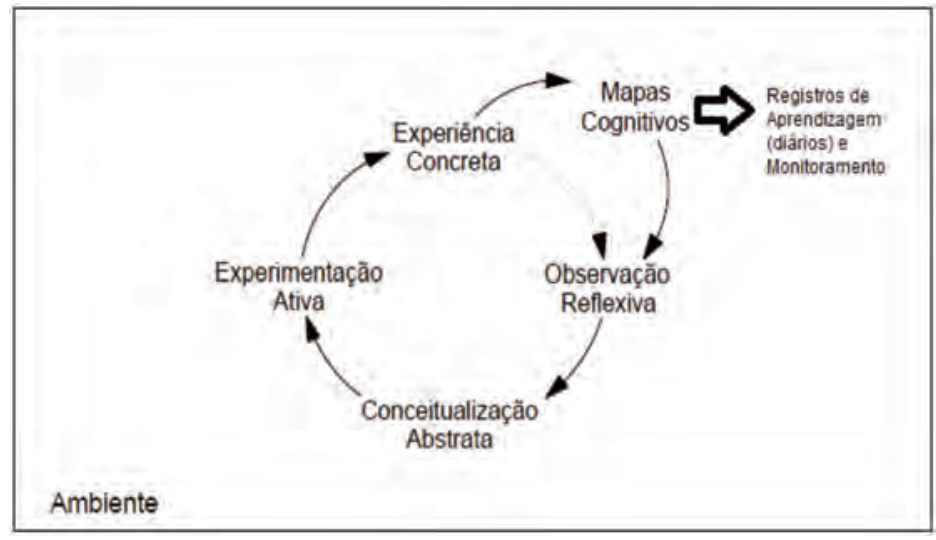

Fonte: Adaptado em Lizeo (2003, esquema 2.2, p.24) 
Consideramos as etapas do Ciclo Experiencial em Grupo com suas limitações e identificamos o processo em que o grupo desenvolveu a atividade proposta. Para cada tarefa e resultado alcançado, procuramos verificar como o grupo se comportou e quais fatores podem ser considerados em cada uma das etapas.

\subsubsection{Observação do Painel de Atores e Mural de Conceitos do Grupo}

O Painel de Atores ocorreu com representantes envolvidos na gestão de recursos naturais, no âmbito das políticas macro-sistêmicas de Mato Grosso, trocando experiências sobre o Zoneamento Socioeconômico e Ecológico (ZSEE) no estado. Assim, a atividade "Mural de Participação" teve como mobilizador o Painel de Atores relacionado à experiência do ZSEE, mas não se referiu exclusivamente a esta atividade. Ou seja, o Painel de Atores constituiu-se a atividade mobilizadora, mas sua abrangência em torno do Mural (Conceitual) sobre participação, buscou movimentar no grupo de cursistas a percepção sobre o que é participação e como este grupo expressa a percepção que possui, a como processos participativos podem ocorrer, tendo em conta um conceito para tratar a participação.

Toda a produção das análises ocorreu em forma de tempestade de ideias e debate livre. Os registros ocorreram "na hora", com correções "em tempo". Também os registros ficam disponíveis e visíveis para o público durante todo o decorrer das atividades do curso. Cada observadora anotou nas exposições orais expressões e exemplos que pudessem remeter ao grupo o que seria "participar".

Ao final do dia, as observadoras conversavam procurando construir um entendimento e destacar quais exemplos observados poderiam ser expostos para o grupo de modo a favorecer mais o debate sobre o conceito em questão e alimentar o painel. Também dessas conversas com quais sínteses iniciais poderiam ser produzidas e disponibilizadas no Mural. Isto também convenceu as autoras a produzir uma memória metodológica deste aspecto do curso, resultando no relatório.

\section{RESULTADOS E DISCUSSÃO}

Conforme apresentado anteriormente, nossa metodologia consistiu em analisar a experiência em torno do ciclo de aprendizagem em grupo, adaptado de Kolb (1984) por Lizeo (2003). Para o propósito deste artigo, algumas observações de Lizeo devem ser reforçadas. Em primeiro lugar, este ciclo não tem valor em 
si mesmo. Ele representa a necessária intermediação da pessoa em relação as suas experiências no mundo. Durante o Curso, os participantes não tiveram contato intensivo com a dimensão teórica de Kolb. Entretanto, foi assumida esta condição pedagógica no desenho do curso, combinada com princípios da educação de adultos em Paulo Freire (1987), sendo estudado e discutido dentro das atividades apenas o segundo autor.

Especialmente nos módulos 3 e 4 atuar "dentro" do ciclo de aprendizagem passou a ser crucial inclusive para o processo de planejamento, escolha dos conteúdos, sequência de abordagem e estratégias de registro. Nós entendemos então que uma reflexão importante seria exatamente entender a dimensão e a prática do ciclo de aprendizagem na atividade em grupo. Essa atividade possui especial relevo se considerarmos que o objetivo consistiu fundamentalmente em contribuir para construção coletiva e experiencial de um conceito.

A partir dessa abordagem e de acordo com análise dos registros no desenvolvimento das tarefas dentro do processo de coleta, podemos apresentar cada um dos quatro passos do ciclo.

\section{Passo 1 - Experiência Conjunta $=>$ Reflexão Conversação Reflexiva}

Idéias Conflitantes $\Leftrightarrow$ Mural de Conceitos

O Mural de Conceitos sobre o entendimento de participação foi a ferramenta proposta. A partir do mural da participação, o grupo indicaria qual o entendimento sobre um conceito de colaboração estava revelado em torno do que e como ele próprio se organizava e tomava suas decisões.

O grupo rejeitou o processo de inferência por "votação", entendendo que esse critério era uma limitante da reflexão pretendida e não havia segurança se o resultado visual no final auxiliaria ou não no resultado. Essa rejeição, porém, não se tornou um fator que remeteria ao resultado. Esteve indicado no planejamento que, a cada dia, deveria obter-se uma visão geral do conjunto pelos participantes. Isto se daria a partir da observação do processo, ocasionando uma validação para o grupo, a partir da exposição de uma síntese de modo a ir compondo o mural.

\section{Passo $2-$ Conversação Reflexiva $=>$ Plano de Ação}

\section{Pontos de Vista não-examinados $\Leftrightarrow$ Dinâmica dos Grupos}

Apesar do planejamento, das iniciativas prévias das formas de exposição e disponibilidade de conteúdo, todas as atividades previstas foram ajustadas. $\mathrm{O}$ painel foi adaptado em suas atividades iniciais e também na previsão de execução dentro da agenda do curso. Durante a exposição metodológica para o uso do mural, a pergunta do painel esteve focada em "Participação". Os cursistas 
entenderam que associar colaboração/participação em uma única questão ou abordagem a tornaria mais complexa a reflexão do que inviabilizaria o foco em cada uma das questões. O conteúdo gestão colaborativa passou, portanto, a assumir o sinônimo (ou ideia) de gestão participativa.

O grupo rejeitou o processo de inferência por "votação", entendendo que esse critério era uma limitante da reflexão pretendida e não havia segurança se o resultado visual (final) auxiliaria no resultado. Utilizou-se com maior ênfase as afirmações dos convidados do que dos membros dos grupos.

\section{Passo 3 - Plano de Ação => Implementação da Ação}

Delays ou mudanças $\Leftrightarrow$ Avaliação da Proposta

O Mural de Conceitos remetia às práticas dos cursistas como subgrupos e indivíduos dentro do curso. Devido à lacuna entre o tempo de aprovação e execução para incursão nos dados gerais e instrumentos de pesquisa, não foi possível construir um instrumento de coleta sincrônico com o planejamento, instalação e atividades dos Planos de Aplicação em coerência com a rotina dos cursistas e do curso. Assim, esta abrangência relacionada às práticas não foi possível, limitando o espaço de aprendizagem a uma oportunidade técnica com poucas possibilidades de feedback dos subgrupos internos a partir de suas experiências próprias, como sendo atores efetivamente interessantes para o grupo e envolvidos nas respectivas atividades por eles mesmos aprovada.

\section{Passo 4 - Implementação da Ação => Experiência Conjunta}

Informacão Imperfeita ó Feedback no, para e com o grupo. Discussão Aberta.

O grupo não indicou a recepção da informação, nem proveu feedback aberto sobre o tema. A análise ficou a critério da coordenação da atividade, por exigência do percurso. Seria metodologicamente mais consistente, se os prosseguimentos de análise pelo grupo, diante dos dados organizados pela observação, pudessem ser por eles mesmos criticados e qualificados de forma mais intensa.

Um paradoxo aparente - dado que não foi aprofundado - é que a análise de grupo sobre a compreensão conceitual que detinham e as contribuições externas dos convidados, encontraram as mesmas categorias, isto é a percepção ideológica, política ou técnica. Entretanto, assumindo aspectos mais amplos quando relacionados as proposições que formaram maioria no grupo, ao se tratar da participação em relação a construção de Cenários obteve-se uma ênfase na abordagem técnica. Quando no tema do Zoneamento Socioecológico de Mato Grosso, obteve-se a ênfase na abordagem política. 
Não é possível atribuir esse paradoxo exclusivamente a noção de informação imperfeita, mas é provocativa a ideia de que essas distinções merecem aprofundamento em razão dos compromissos teóricos e técnicos propostos pelo projeto do curso. Ficou evidente um gap de tempo para tratar desse assunto.

\section{CONCLUSÕES}

Exercícios como este demonstraram ser bastante produtivos, desafiadores e úteis se queremos aprofundar quais perspectivas pedagógicas que envolvam aprendizagens significativas e que se consolidem em razão de um propósito coletivo. Entretanto, no caso estudado, a análise da experiência demonstrou ser um processo incompleto do com ciclo de aprendizagem em grupo. De fato, pode haver aprendizagem, mas certamente não se referiu ao grupo. Talvez as subdivisões que se formam ou ao plano individual. O que leva a ponderar entre as decisões entre quem é o grupo e quem são os indivíduos que lideram ou interessam a ele.

Embora não tenha este propósito, estamos seguras que as propostas para registro reflexivo contidas nos diários ou scrap-book e no monitoramento coincidem com a visão de que a experiência e a observação precisam de um suporte "prático" para criar uma ponte e gerar consciência, de modo a que a conceitualização abstrata não se estabeleça ante uma ameaça de vazio e divagação permanente. Portanto, adaptando da proposta de Lizeo, consideramos que as atividades de aprendizagem experiencial e que a superação do gap é dada a partir do uso dessas ferramentas. Entretanto, esta tarefa se esvaziou durante o curso e, já no quarto módulo, não foi mais adotada de forma sistemática.

O sucesso dessas ferramentas atuarem por meio dos mapas cognitivos é discutível no plano geral do curso. Como dissemos foram abordagens en pasant, e as estratégias de avaliação eram privadas e direcionadas à gestão do curso. Apesar disto, este entendimento (presença de ferramentas) é útil para identificar qual ou como o processo reflexivo foi estimulado neste grupo, a partir da atividade que analisamos.

Em alguns momentos no transcurso da atividade, as perguntas relacionadas aos objetivos da proposta de observação participante no Plano de Aplicação, foram conduzidas no sentido de esperar o desenlace das circunstâncias do que serem levadas para o debate do grupão. Isto ocorre dada a dimensão conflituosa na própria natureza do Curso de Especialização, tanto em relação a visões sobre o conteúdo que se apresentavam como demandas, quanto para serem inseridas, avaliadas ou apropriadas. Os produtos gerados pelo curso contabilizam e 
demonstraram como, quanto e com quem os indivíduos preferiam ou optaram por interagir e, talvez, aprender.

Para poder analisar a emergência dos conceitos nos grupos, eles deveriam ser tratados como "percepções". E as categorias utilizadas, em conformidade com a dimensão teórica que pudessem ser defendidas durante a explicação e a escolha do grupo, na atividade. A compreensão determinou que participação, colaboração e gestão seriam expressões que envolveriam mais a percepção e experiência dos indivíduos, do que confrontos teóricos. Demonstrou o ambiente para rejeição do debate em torno do campo sob o qual os conceitos estão sendo propostos. A aprendizagem empírica desligava-se do aprofundamento teórico previsto para o curso em torno da teoria dos sistemas socioecológicos complexos.

A disseminação dos resultados e dos passos seguintes previstos na atividade consistiu em disponibilizar o relatório ao grupo de cursistas. A ideia era permitir o aprimoramento e/ou validação. Também houve a previsão de proporcionar um estudo acerca da colaboração - participação no estudo teórico, mas esta segunda sugestão não foi viabilizada. Transferida para o Módulo 4 também não pode ser executada. A sugestão foi definir as categorias que surgiram em relação ao conceito a partir do referencial de quem realizou o estudo. O Grupo se organizou e se mobilizou em direção aos proprios campos e subtemas.

Os conteúdos e as conclusões desta experiência e do grupo não puderam ser efetivamente tratados nas discussões do curso, por diversas razões legítimas e outras nem tanto. Nestas razões incluimos estarmos todos tateando sobre o tema bem como o reconhecimento dos limites do próprio curso quanto a sua condução ou conteúdo. Também convem lembrar as observações de Moon (2004) de que nem sempre a escrita sobre a aprendizagem experiencial consegue alcançar a profundidade de como e quando os sujeitos aprendem, mas talvez fiquem presos ou a como fazer o ciclo funcionar ou a verificar se o ciclo funciona. Faltaram-nos mais ferramentas.

A base da eficácia do ciclo é o diálogo. Um dado a este respeito é que na proposta do Curso, o diálogo foi integrado especialmente com base nas contribuições de Paulo Freire (1987; 1996), entretanto, com seu conteúdo "politizador" minimizado uma vez que a ação de aprendizagem estava justificada na palavra e no diálogo entre as pessoas, sem inferir sobre a condição ideológica que as posições e a palavra dos sujeitos guardavam. O que torna esta contribuição limitada e, em certos aspectos, discutível como veremos adiante.

A literatura sobre Paulo Freire enfatiza que o maior impacto de sua teoria é o reconhecimento de uma relação clara entre a existência de um opressor e um oprimido e que, por isto, são "não iguais" e não dialogam (BARRETO, 2004), 
dado que há impossibilidade de diálogo com quem usa de uma vantagem clara sobre alguém destituído de um bem cultural que, no caso de Paulo Freire (1987; 1996), refere-se à escolarização ou, no caso de atores e gestão, informação. Em outras circunstâncias pode-se admitir a existência um "diálogo" entre "não iguais" com foco na negociação, que foi por onde o curso pretendeu encaminhar o conceito de Freire, ao tratar de distintos atores e interesses.

De fato, os Ciclos de Aprendizagem funcionaram como mobilização cognitiva e vinculação eventual entre os indivíduos, o que se mostrou suficiente para demonstrar que a formação não enfrentou os dilemas da incursão na realidade em razão das práticas sociais. Isto torna essa experiência dependente de uma teoria de liderança que considere a participação/colaboração tanto como um conceito, quanto uma atitude. Em situações similares, nota-se que é necessário priorizar quais os compromissos formadores para obter articulações que gerem comunicação e pensamento articulado efetivo, reduzindo ou avaliando os eventos que geram os loops circunstanciais e produzam gaps de interesse e manipulação na própria aprendizagem. Entretanto, não há dúvida de que Kolb possui uma contribuição fundamental em propostas formadoras dessa natureza, caso sejam explicitas e incorporadas no grupo e/ou em um projeto.

\section{REFERÊNCIAS}

BARRETO, V. Paulo Freire para educadores. São Paulo: Arte \& Ciência, 2004. BRASIL, W. O projeto de aplicação. Curso de Especialização em Gestão Colaborativa. Porto Velho, RO, 2012. Disponível em <https://docs.google. $\mathrm{com} /$ viewer? $\mathrm{a}=\mathrm{v} \& \mathrm{pid}=$ sites\&srcid $=Z$ ZGVmYXVsdGRvbWFpbnxjdXJzb 3NlbWVudGV8Z3g6NzMyMTUwYmQ5ZmIxMGY1ZA> Acesso em 09 jan. 2013.

Conceitos e percepções de colaboração: bricolagens à reflexão sobre o tema gestão colaborativa. 2012. Monografia de Conclusão de Curso. Porto Velho, RO, 2012. Disponível em: <http://wwwacademia.edu/3569347/ Conceitos_e_Percepcoes_de_Colaboracao._Bricolagens _a_Reflexao_sobre_o_ Tema_da_Gestao_Colaborativa_2012_> Acesso em: Acesso em 09 jan. 2013.

FREIRE, P. Pedagogia da autonomia: saberes necessários à prática educativa. São Paulo: Paz e Terra, 1996.

Pedagogia do oprimido. 17. ed. Rio de Janeiro: Paz e Terra, 1987. 
KOLB, D. A. Experiential Learning. Experience as the Source of Learning and Development. Englewood Cliffs, NJ: Prentice Hall, 1984. Disponível em: <http:/ / academic.regis.edu/ed205/kolb.pdf> Acesso em: 13 jul. 2011.

LIZEO, E. Um modelo dinâmico de aprendizagem em grupo. 2003. $163 f$. Tese (Doutorado em Administração de Empresas) - Escola de Administração de Empresas de São Paulo, Fundação Getúlio Vargas, São Paulo, 2003.

MARKOVÁ, I. Dialogicidade e representações sociais: as dinâmicas da mente. Petrópolis-RJ: Vozes, 2006.

MOON, J. A handbook of reflective and experiencial learning. theory and practice. London: RoutledgeFarm. (PDF). 2004. Disponível em: < http:// perpustakaandeajulia.weebly.com/uploads/1/8/2/6/18261275/a_handbook_ of_reflectiv e_and_experiential_learning_-_theory_and_practice.pdf $>$ Acesso em: 13 jul. 2011.

MORIN, E. Introdução ao pensamento complexo. Tradução: Eliane Lisboa. 3. ed. Porto Alegre: Sulina, 2007.

OSTROM, E. A general Framework for Analyzing Sustainnatility of SocialEcological Systems. Science, 324, p. 419-422, 2009.

PIMENTEL, A. A teoria da aprendizagem experiencial como alicerce de estudos sobre desenvolvimento profissional. Estud. Psicol., Natal, v. 12, n. 2, p.159168, 2007. http://dx.doi.org/10.1590/S1413-294X2007000200008. Disponível em: <http://www.scielo.br/pdf/epsic/v12n2/a08v12n2.pdf>. Acesso em: 9 jul. 2013.

RUAS, R.; ANTONELLO, C. S.; BOFF, L. H. (Org.). Os novos horizontes da gestão: aprendizagem organizacional e competências. Porto Alegre: Bookman, 2005.

SOUZA E SILVA, M. C. P. de; KOCK, I. G. V. Línguística Aplicada ao Português: Sintaxe. São Paulo: Cortez, 1989.

SIQUEIRA, M. et al. Medidas do comportamento organizacional. ferramentas de diagnóstico e de gestão. Porto Alegre: Bookman, Artmed, 2008. 


\section{RESENHA}

PIZARRO, Ana. Amazônia: as vozes do rio: imaginário e modernização. Trad. Rômulo Monte Alto. Belo Horizonte: Editora da UFMG, 2012.

Cesar Mauricio de Abreu Mello - Doutorando em Desenvolvimento Socioambiental pelo Programa de Pós-Graduação em Desenvolvimento Sustentável do Trópico Úmido (PPGDSTU/NAEA/UFPA).E-mail: mello.cesar@gmail.com

Juliana Azevedo Hamoy - Mestranda em Desenvolvimento Socioambiental pelo Programa de Pós-Graduação em Desenvolvimento Sustentável do Trópico Úmido (PPGDSTU/NAEA/UFPA. E-mail: julianahamoy@gmail.com

Leonard J. Grala Barbosa - Mestrando em Desenvolvimento Socioambiental pelo Programa de Pós-Graduação em Desenvolvimento Sustentável do Trópico Úmido (PPGDSTU/NAEA/UFPA). E-mail: leograla@gmail.com

De constituição singular e possuidora de pluralidade cultural, de biodiversidade inimaginável e detentora de imensos recursos naturais, a Amazônia foi, e ainda é, cobiçada mundialmente. Durante muitos anos, a história da região foi contada unicamente pelas vozes dos conquistadores, que lhe atribuíam visões que iam de inferno verde a paraíso tropical, sempre dependendo da lente e dos interesses com que era observada.

A fim de suprimir essa ótica singular, Ana Pizarro busca incluir neste processo, outros interlocutores na construção histórica, social e cultural da região. Eles representam a multiplicidade de vozes outrora apagadas, e surgem a partir de uma nova perspectiva crítica latino-americana. O resultado deste esforço é o livro Amazonía: el río tiene voces: imaginario y modernización, publicado pelo Fundo de Cultura Econômica do Chile, em 2009 e traduzido para o português em 2012 com o título "Amazônia: as vozes do rio: imaginário e modernização”, pela Editora da Universidade Federal de Minas Gerais. 
A publicação marca, portanto, uma alternativa que utiliza outras vozes para abordar a história da Amazônia por meio de sujeitos distintos. Segundo a autora, também professora da Universidade de Santiago do Chile, o livro foi encorajado por múltiplas razões, sendo a mais importante de todas, a necessidade de colocar em evidência uma área geográfica-cultural ainda pouco conhecida nos estudos culturais do continente, o que claramente destoa da sua importância no destino do continente sul-americano e do mundo.

Os recursos materiais incorporam ao livro uma abundância de narrativas de viagens, crônicas, fotografias, gravuras, cartas e textos escritos por personagens partícipes da construção histórica analisada pela autora - do século XVI à atualidade - e que acabam por conformar o imaginário sobre esta área cultural, reproduzindo um discurso europeu. Para a autora, uma das principais características da região é que a Amazônia foi construída com um pensamento exterior ao seu, tal como apontava Said (2007) a respeito da construção da ideia de Oriente por seus colonizadores também europeus.

Tal construção é representada nas vozes dos barões do caucho, alicerçadas nos ideais de pátria, progresso e civilização. A autora se apropria das produções intelectuais da época para fazer surgir, por meio de testemunhos escritos, da memória, dos mitos e da literatura de cordel, as vozes que denunciam as atrocidades praticadas no percurso da exploração da borracha, momento onde traz à tona as vozes dos nordestinos e indígenas conhecidos como "trabalhadores da borracha".

Seguindo uma narrativa histórica, com certa linearidade, a autora inicia com um relato do século XVI que destaca a importância que os rios, notadamente o Amazonas, têm na vida da região, impactando a população local e os viajantes europeus, “[...] numa geografia de águas que, quando não invade tudo, se faz pressentir a sua volta, em sua permanência, em seu ritmo. São discursos de uma nação de águas" (p. 18).

Lembra a autora que a região possui formas culturais peculiares, com um universo mítico gigantesco e que as "culturas de selva tropical" passam, recentemente, por uma renovação do olhar cultural sobre ela, em função: a) do surgimento de uma concepção mais ampla de cultura; b) dos resultados dos impactos ambientais e sociais decorrentes dos processos de superexploração dos recursos naturais e; c) a necessidade de defesa da região em razão das "ameaças externas", o que proporciona uma aproximação dos oito países que estão sob a sua influência para a criação de uma posição harmônica da região em torno do seu desenvolvimento. 
Em continuidade, Pizarro reafirma a condição da composição discursiva do território amazônico, colocando em evidência que a oralidade e os escritos da Amazônia, provindos de diferentes momentos históricos, criaram uma imagem parcial, um discurso dos dominadores. A criação desta imagem discursiva não era "inocente", partia de um ponto de vista e de um fazer histórico determinado. Somente a partir do século XIX é que vozes locais começaram a dar pluralidade à imagem amazônica, vindo a se intensificar a partir do século XX. A autora finaliza o primeiro capítulo reafirmando a importância da dualidade paraíso e inferno, expressas na relação do homem com a natureza, para a formação da ideia de Amazônia.

O segundo capítulo é dedicado às crônicas de viagens que aconteceram entre meados do século XV e início do XIX. Graças à escrita, esses discursos ganharam permanência, visibilidade e popularidade. A autora aponta que em função da dificuldade de penetrar na densa muralha de selva, "A Amazônia é ocupada, primeiramente, pela imaginação fantasiosa do conquistador e, posteriormente, pelo imaginário moderno dos naturalistas" (p. 38). Das inúmeras viagens realizadas, Pizarro destaca três pelo significado que cada uma teve na construção e na instalação de três figuras centrais do imaginário: as Amazonas, o Eldorado e o Maligno.

A primeira viagem apresentada é a do espanhol Francisco de Orellana, narrada por Frei Gaspar de Carvajal com tom fantástico e épico. Este relato é moldado pela fome, pelo excesso de privações e sofrimentos que suportaram durante a travessia. Teve a primazia de apresentar ao mundo ocidental o universo privilegiado da natureza e a multiplicidade da riqueza da Amazônia, pautando as descobertas para a coroa espanhola.

Nesta expedição, que se inicia por volta do ano 1541 nas proximidades da cidade de Quito, Francisco de Orellana e cinquenta e sete homens partem em busca de um mítico "País da Canela". Nessa aventura, que inclui ataques de indígenas e a impossibilidade de retorno, a empreitada se transforma na busca do Eldorado, um lugar coberto de ouro. $\mathrm{Na}$ mesma epopeia, é narrado o encontro com um dos mitos centrais da história da região, as Amazonas, mulheres guerreiras “[...] muito brancas e altas, com os cabelos longos e trançados na cabeça. Possuem membros grandes e andam nuas, tampando somente suas vergonhas. Cada uma delas equivale na guerra a dez índios” (p. 45).

A segunda, em ordem de cronologia, é uma expedição que já parte em busca deste mítico Eldorado, iniciada em 1559 por Pedro de Urzúa e finalizada pela figura emblemática de Lope de Aguirre. Na empreitada, que se inicia com inúmeros problemas, Lope de Aguirre assassina os comandantes, assume o 
controle e desafia o poder real, “[...] depois de atravessar o rio Amazonas, sair no Caribe e dar a volta pelo Panamá, para libertar o continente do jugo espanhol" (p. 53). Essa campanha, marcada pela carta que este insurgente escreve ao rei espanhol acusando-o de crueldades, inclui a imagem da Amazônia como um locus onde "está presente também o sentido separatista, libertador da coroa espanhola, que aqui se acha favorecido pelo isolamento geográfico, num ambiente que se percebe repleto de riquezas naturais" (p. 57).

A terceira construção parte do imaginário sobre o maligno, onde existe uma associação que apresenta uma lógica que foge à racionalidade europeia, compõe um "mundo endemoninhado, inclinado à insensatez" (p. 91). A noção de mundo, construída pelos amazônidas, tinha uma lógica própria, com deuses e crenças particulares que em muito se distanciavam dos padrões europeus.

Finalmente, a autora discorre sobre a empreitada patrocinada pela coroa portuguesa, comandada por Pedro Teixeira, com nítidas intenções associadas às questões de poder territorial e conquista simbólica da região. Nessa viagem, Teixeira parte de Quito, em 16 de fevereiro de 1639, com o objetivo de percorrer a mesma rota de Orellana e chegar a foz do rio Amazonas, no então estado do Grão-Pará. A expedição relatada pela crônica do jesuíta Cristóbal da Acuña possui um tom descritivo de precisão geográfica - útil para a navegação e logística militar. Acuña narra com tom lírico da emoção paradisíaca, que humaniza, por meio do recurso poético, a natureza. Acrescenta também, informações sobre as técnicas de produção e conservação de alimentos, sobre a fertilidade das terras, de peixes e animais para consumo, sobre as festas indígenas e sobre a responsabilidade catequizadora da igreja frente aos "naturais".

Estes embates, entre frentes de expansão demarcadora dos territórios, eram próprios do contexto do processo de Expansão Ultramarina, que à época era dominado por Portugal e Espanha. Após este período inicial, há modificações significativas na história da humanidade. Os fluxos financeiros advindos da exploração ultramarina, que a despeito de ingressarem pela península ibérica, eram retransmitidos a outras nações por suas relações comerciais ou dívidas, fomentaram também as inovações e grandes descobertas científico-tecnológicas.

Como citado anteriormente, este momento é chave para a construção da relação Ocidente-Oriente criada, como apontado por Said (1990), a partir de uma relação de poder estabelecendo as distinções de "o outro" e "o bárbaro", para incluir em seu arcabouço conceitual todos aqueles povos que não pertenciam à cultura europeia, os quais estavam então em formação. Este processo tem a ver com o conceito de "geopolítica do conhecimento" de Mignolo (2003), e 
está representado na batalha pela hegemonia do conhecimento científico, onde França e Inglaterra darão as cartas neste momento.

Logo, vê-se que novos espaços do conhecimento, que são também espaços de poder e competição entre os Estados, são criados. Dentre os quais, Pizarro cita os enciclopedistas, que a partir de um processo de inventariação do mundo, buscam sua racionalização diferente da centralidade teológica do período anterior. A marca da passagem de um período que se convencionou chamar modernidade, é dada com as Revoluções Francesa e Inglesa (tecnológica).

Neste período de mudanças, no limiar do século XVI, há o nascimento das sociedades científicas. Este importante marco, favorece ampliação de questionamentos filosóficos, que outrora eram respondidos pela fé e agora passam a ser respondidos pelas ciências. O contexto apresentado, impele as missões científicas para conhecer o mundo.

A "Missão científica para a América" partiu em 1735 com intuito de determinar a forma da terra. Nesta missão, de caráter europeu, participou La Condamine, pesquisador que expressou o modelo de discurso ocidental-europeu da modernidade emergente em seus escritos. A autora foca neste pesquisador, por ser ele o responsável pela descrição detalhada do caucho e seus processos.

Nos escritos e discursos de La Condamine, além da reprodução de um modelo de "literatura de sobrevivência", há uma busca por explicar racionalmente alguns mitos construídos sobre o "Novo Mundo", isto é, investigá-los sob uma perspectiva moderna. Ademais, a concepção mais científica do mundo não isentava seus partícipes do preconceito europeu face aos indígenas, de modo que Pizarro aponta as limitações da construção da alteridade científica deste período de embate entre modernidade e antiguidade.

Cada vez mais a informação científica se mescla com informações econômicas e comerciais, aqui o meio ambiente aparece claramente com sentido utilitário. Esta forma de compreensão da natureza também é reflexo da disputa no campo do conhecimento, onde opõem-se Filósofos versus Naturalistas, Saber versus Experiência. Inserido nesta contenda, Humboldt viaja para as Américas em 1799, este traz um olhar voltado para a diversidade ambiental, maravilhado com a natureza local propõe uma "geografia das plantas". Situa a natureza em uma nova perspectiva descritiva, acrescentando componente emotivo e afetivo. Este pesquisador carrega um olhar transdisciplinar.

Humboldt desmistifica a lenda do Eldorado. Porém, em seu foco natural, os grupos indígenas ainda são vistos como pertencentes a um estágio inferior ou atrasado da humanidade. Mesmo assim, pode-se considerar que há um novo posicionamento da Amazônia com seus escritos. Após este período, Pizarro cita 
um rol de pesquisadores naturalistas que vêm para a Amazônia com perspectivas mais holísticas, interdisciplinares. Porém, é nesta época que se difundem ideias sobre um pretenso "vazio demográfico" da região.

A autora insere o capítulo seguinte como composição ao terceiro tipo de discurso. Trata das diferenças entre os trabalhos com o caucho (Castilloa ulei) e o látex (Hevea brasiliensis). Essas diferenciações se dariam por conta da forma de extração, um corta e o outro "risca", um é itinerante e o outro fixo, um destruidor e o outro colonizador. Apesar desta diferenciação, assim como em demais obras sobre o período da borracha, nota-se que a autora utiliza as terminologias caucho, borracha, látex e seringa mais ou menos enquanto sinônimos, ao que pese indicar processos e plantas distintas. Neste sentido, Barão do Caucho não poderia ser o mesmo que Barão da Borracha. Pizarro não adentra este tema que talvez mereça mais estudos.

Trata ainda das estruturas bases do seringal, com seu modelo de estradas e barracões, as formas como os "aviadores" recrutavam e mantinham cativos seus trabalhadores, através do endividamento. Ela explica de forma sucinta a metodologia para extrair a seiva do látex, dada a partir de práticas tradicionais de grupos indígenas. Toda essa estrutura é estabelecida para dar vazão à demanda da expansão no mercado da borracha, quando Charles Goodyear desenvolve o processo de vulcanização, e posteriormente J. B. Dunlop desenvolve e patenteia os pneus.

A forma como a autora apresenta as diferenças entre as áreas de exploração do Peru e do Brasil, onde no primeiro, os trabalhadores seriam indígenas, enquanto no segundo, a mão-de-obra seria advinda do Nordeste do país, reflete a forma como ela trata a divisão dos três discursos. Ou seja, ao apresentar o discurso indígena, dá pouco ou camuflada VOz a indígenas brasileiros que formam grande parte da mão-de-obra, sobretudo no primeiro ciclo da exploração da seiva. A autora fala brevemente das correrias feitas contra indígenas, para sua captura (FAULHABER; MONSERRAT, 2009).

Para Pizarro, aviador seria o mesmo que regatão, e talvez fosse relevante que ela pudesse retomar esse posicionamento por outra perspectiva. A autora pontua as principais casas comerciais da época em Manaus e Iquitos. Ademais da importância destas paragens para a economia analisada, seria relevante incluir Belém e Porto Velho, uma vez que boa parte do processo envolvido na extração da borracha mantém relações imbricadas com a construção da Estrada de Ferro Madeira Mamoré, sendo que o Porto de Santo Antônio (distante $7 \mathrm{~km}$ de Porto Velho) condensava quase todo desembarque da borracha produzida do Acre à Bolívia. Para sanar possíveis curiosidades sobre os temas específicos das 
importâncias regionais e a discussão da diferenciação regatão-aviador, podemos indicar as leituras de Santos (1980) e Weinstein (1993).

A partir da importância das casas aviadoras, a autora apresenta os formadores do primeiro tipo de discurso, os personagens pelo lado dos patrões, classificados por ela como aviadores, dentre os mais relevantes estão Fitzcarrald e Júlio Cesar Arana. Este último, apelidado de "o sócio de deus", contratou em 1917 o então fotógrafo Silvino Santos, para produzir um filme sobre a extração da borracha em seus domínios, a fim de melhorar sua imagem. Estas foram as primeiras cenas da Amazônia. Esses recursos narrativos evidenciam no discurso o lado positivo da economia da borracha, como será analisado mais adiante.

A hegemonia das grandes casas é abalada a partir de 1911, momento em que houve alterações importantes com a quebra do monopólio da borracha da Amazônia, quando mudas e sementes são levadas para a Ásia ${ }^{1}$. Este processo de quebra econômica lança ao interior da floresta, contingentes populacionais em busca de sobrevivência (garimpo, ocupações de lotes, ribeirinhos etc.). A autora fala, de modo breve, sobre os "soldados da borracha", que perfazem o segundo ciclo da borracha no Brasil durante a Segunda Guerra Mundial.

Este discurso formado em torno da borracha, composto por três vozes, é definidor da história da Amazônia. É uma história que tem a ver com os movimentos de consolidação das fronteiras nacionais. Além disso, percebese evidente que o ambiental da época remetia à influência cultural europeia, especialmente francesa (Belle Époque). Esforços das elites locais à época eram no sentido de reproduzir a sofisticação de além mar, provar o distanciamento da barbárie rumo à civilização. O Teatro Amazonas, em Manaus, era o símbolo da "Paris dos Trópicos".

Deste processo é que surgem as três vozes que a autora analisa: 1) do lado do poder, os barões do caucho, de outro ponto, 2) os intelectuais da época que analisam essa sociedade e configuração econômico-ambiental, e 3) os trabalhadores envolvidos, seringueiros/indígenas.

Sobre os barões do caucho, a autora salienta a importância que estes personagens adquirem na lógica de levar a "modernidade e a civilização" à selva bárbara. Essa imposição da modernidade é uma bandeira do Ocidente que traz civilização e progresso, pela lei do mais forte, a barbárie autorizada em nome da civilização. Nestes personagens, a épica pessoal é a tônica individualizante. O comércio tem e impõe a força civilizadora. A condição de selvageria indígena faz com que eles resistam à implantação da civilização (p. 133). O indígena é que

Para mais informações sobre as pesquisas realizadas pelo governo brasileiro enviando ao Oriente o pesquisador Huber, ver Castro, Sanjad e Romeiro (2009). 
ataca o civilizado e, por conseguinte a própria civilização. "O barão do caucho se aproveita dos elementos produzidos pela modernidade, sustenta este discurso, mas, ao mesmo tempo, instala seu negócio sobre estruturas econômicas e sociais pré-capitalistas" (p. 135). Porém, o resultado disso era uma modernização deformada (p. 136).

Ao tratar do segundo grupo de discursos, o dos intelectuais, a autora se apoia em três escritores referenciais - o brasileiro Euclides da Cunha (1909), o peruano Carlos Valcárcel (1915), e o colombiano José Eustásio Rivera (1924). Cunha e Rivera representam seus países em comissões de demarcação de fronteiras, ao passo que Valcárcel foi juiz em um caso envolvendo a casa aviadora Arana e interesses ingleses. Ora tratando narrativas históricas, ora romanceadas, os autores selecionados trazem o panorama de agruras enfrentadas pelos trabalhadores da borracha.

Nesses escritos é possível perceber que, tanto a natureza quanto as populações pobres envolvidas são consideradas sujeitos partícipes da história, como evidencia Euclides da Cunha. Em Rivera, vê-se a força da selva que devora, ela é um personagem completo. Os discursos utilizados são de sujeitos comprometidos com a construção de suas nações, com a consolidação de suas fronteiras; e ainda com aspectos de justiça social face às iniquidades exploratórias dos trabalhos da seringa.

Ambos adquirem um viés coletivizador, com discurso nacionalista. A autora poderia ter citado, ainda, outros trabalhos de expressividade provenientes desta época, e que, por certo poderiam contribuir em suas análises. Dentre os quais, podemos citar Oswaldo Cruz (1913), que viaja ao Norte em missão sanitária a inspecionar a construção da Estrada de Ferro Madeira-Mamoré (EFMM), e Neville Craig (1947), engenheiro americano da EFMM, ambos, além de relatarem as condições de vida dos trabalhadores da borracha e sua economia, também apresentaram a convergência desenvolvimentista que interligava Belém, Manaus e Porto Velho por sua relação econômica, e Brasil-Bolívia por conta da questão do Acre e da própria construção da EFMM.

Sobre o terceiro discurso, representado por aviados indígenas, a autora separa as narrativas que dão conta da situação indígena no comércio da borracha também a partir de três tipos de relatos: 1) levantamentos acadêmicos (Iribertegui, Venezuela); 2) relatos orais (entrevistas próprias à autora, personagens do Peru); e 3) mitos (usando um autor de nome Niño, sem identificar o país ou etnias abordadas). Nestes relatos ela expõe as formas de tratamento dispensado às populações indígenas, em comparação aos demais trabalhadores do caucho, cujas condições eram ainda piores. 
Dentro do processo de recrutamento relatados, estão as "correrias" caçadas organizadas em busca de escravizar indígenas no trabalho do caucho ou da seringa. Apesar de reconhecer a crueldade com que estas populações eram tratadas, incluindo as torturas, os relatos apresentados estão circunscritos ao processo das "correrias" e não exatamente no "trabalho" destes grupos com a borracha e suas relações com os patrões.

Nos relatos orais de indígenas apresentados pela autora, são novamente evidenciadas as dificuldades enfrentadas nesta prática análoga à escravidão imposta aos trabalhadores, e toda uma sorte de inculcações que modificaram seus imaginários. No tocante ao mito, Pizarro cita a importância desta ferramenta, porém não apresenta maiores detalhes, pois a fonte que ela utiliza trabalha com um grupo que não deixa claro os fatos (por ele chamado de mitos fechados).

Percebe-se no texto que a autora não apresenta maiores informações sobre as mazelas das populações indígenas durante o trabalho com a borracha, tal qual fez com os outros trabalhadores. Apesar desta breve lacuna, Ana Pizarro inclui em seu lugar, a literatura de cordel, advinda de migrantes do Nordeste brasileiro, dando relevância aos escritos que denunciam as dificuldades de trabalho no Norte e a ilusão da Amazônia, da borracha, como o Eldorado. Nas denúncias, encontramos a forma como os patrões arregimentavam trabalhadores por meio de promessas irrealizáveis pela própria estrutura da economia da borracha.

No quarto capítulo, a autora dedica-se a escrever sobre a pluralidade mais recente da Amazônia, citando algumas dimensões de sua multiplicidade. Antes de adentrar nessas dimensões, Ana Pizarro ressalta a necessidade de contextualização sobre o surgimento destas vozes plurais amazônicas. Meados das décadas de 1960 e 1970, período da ditadura militar no Brasil, era latente a intenção do discurso de modernização da Região Amazônica, com a promoção de um projeto geopolítico para a construção de rodovias (e um abandono nas vias fluviais de transporte) para escoamento das riquezas naturais, o que atrairia investimentos de capital nacional e internacional. "As estradas fluviais deram lugar às grandes rodovias, à construção de hidrelétricas a partir de enormes diques, [...]. Tudo isso ocorria em prejuízo das populações locais e do funcionamento normal dos ecossistemas" (p. 167). É então que surge uma nova organização do trabalho e novos problemas, conflitos e contradições, além da concentração de renda e indicadores sociais alarmantes. 
Nesse período, a voz que se destacava era a do poder. Já no século XX, foi possível perceber uma pluralidade de realidades, com populações diversas: quilombolas, ribeirinhos, indígenas, caboclos, entre outros. Tais povos, detentores de grande conhecimento, deveriam servir de base para a elaboração de qualquer proposta de desenvolvimento que se almeje propor. Voltando às dimensões abordadas pela autora, a intenção não é organizar essas pluralidades, e sim examinar as vozes que se entrecruzam e se encontram na múltipla Amazônia.

A primeira dimensão aborda a estética ilustrada, que preserva nas cidades da região a referência cultural da selva, dos conhecimentos presentes no discurso oral e escrito, demonstrando um compromisso e uma tentativa contra a marginalização da Amazônia.

A segunda é sobre os relatos amazônicos e suas as comunidades habitantes, que trazem em sua narrativa um universo mitológico carregado de imaginários que se misturam com a realidade. Esse mundo 'encantado' explica e dá sentido às relações do ser humano com a natureza.

A terceira dimensão faz alusão aos “encantados". Por conta do isolamento das comunidades amazônicas, foram criadas leis próprias e mais especificamente os elementos encantados, tais como o boto, o curupira, a cobra-grande para explicar alguns acontecimentos.

A quarta se baseia nos discursos e imaginários sociais ameaçados pela modernização. Isso porque ribeirinhos, pequenos garimpeiros, quilombolas, indígenas e etc., costumam lutar contra a criação de hidrelétricas, mineradoras, missões religiosas e outros que tentam transformá-los em força de trabalho, ignorando suas relações com aquele ambiente.

A quinta dimensão refere-se à oralidade e à literatura dos povos indígenas, que contam suas histórias sem a necessidade de intermediários, possibilitando o espraiamento de pluralidades indígenas e rompendo com os preconceitos guiados por noções de erudição classicista das "belas letras".

Um exemplo onde se pode perceber essas dimensões citadas é o caso do Areal, "[...] um vasto lugar de areia branca, desabitado, e importante na vida das comunidades já que residem naquela época desde o tempo dos antigos, "encantados" muito poderosos, que cuidam do lugar" (p. 196). A relação que o grupo local estabelece com o Areal não só revela a singularidade no modo pelo qual entendem, compreendem e explicam o mundo a sua volta, como também expõe a ameaça de desaparecimento desta cultura, a partir da construção de uma 
ponte que liga esta comunidade ao centro urbano. A partir deste momento, o Areal passa a ser explorado mercadologicamente. Com a construção da ponte, perdem-se os "encantados", os imaginários e uma parte da história daquelas comunidades, somados aos problemas ambientais e sociais que acompanham o "processo civilizatório".

Pensar o Brasil, e mais exatamente a Amazônia, exige considerar a cosmologia e história das populações tradicionais locais para compreender a multiplicidade de modos de pensar e viver que nela coexistem. Saberes e experiências dessas populações compreendem um universo não fragmentado, uma totalidade holística, onde o ser humano encontra-se imbricado aos seres naturais e sobrenaturais, não perfazendo, portanto, coro à separação decartiana do plano humano-natural que vigora na lógica materialista, a qual é característica da sociedade contemporânea do meio urbano.

No quinto capítulo, o livro trata sobre a cultura das drogas na Amazônia, com sua variedade de plantas alucinógenas, e da existência de organizações de produção e mercantilização de drogas lícitas e ilícitas. Na esteira deste processo tem-se ainda outras ações ilegais, como comércio bélico e extração ilegal de madeira, seguindo um rastro de violência gerado pelo tráfico de entorpecentes. Salienta a autora que o transporte dessas drogas, obviamente também ilegal, ocorre por via aérea (em aeroportos clandestinos), por terra (geralmente caminhões com fundo falso) e rios (dependendo das circunstâncias, se a época do ano permitir).

Em oposição à ilegalidade, a utilização de plantas alucinógenas na Amazônia também está presente em rituais de algumas etnias da região. A dimensão espiritual está na essência do xamanismo², onde muitas comunidades acreditam nas "plantas dos deuses", utilizadas por xamãs ou pajés para alcançar outro estágio de compreensão da vida, o que, de acordo com Regan (apud PIZARRO, 1941, p. 246), “Os espíritos o ensinam a curar e o fortalecem para que possa se defender dos espíritos maus".

Os rituais xamânicos, com seu uso religioso de alucinógenos e a busca da liberação do inconsciente por meio de uma disciplina do transe - que era a dimensão que as práticas religiosas indígenas buscavam alcançar - vão de encontro à cultura racionalista existente na contemporaneidade, que são traços enraizados desde a colonização europeia na América Latina. Esse contexto se

2 Xamanismo é um termo utilizado para definir um conjunto de crenças ancestrais que envolvem conhecimentos sobre o uso de plantas, práticas de contato com seres míticos sagrados. 
baseia no elemento de identidade sociocultural, onde os ritos xamânicos eram considerados pela Igreja e pelo Estado, como ameaças ao seu domínio e suas crenças, devendo ser, portanto, abolidos.

No epílogo, a autora aborda as festividades envolvendo o Círio de Nazaré, em Belém, onde há uma mistura instâncias religiosas e profanas. Segundo ela, trata-se de um embate entre ordem e desordem, onde o Círio se encontra com a Festa da Chiquita - uma celebração de caráter profano que agrega transexuais, travestis e homossexuais, além da população em geral. Pizarro trabalha com esta noção para demonstrar que não há um discurso unitário que expresse a Amazônia, mesmo quando pré-estabelecido em uma situação institucional, como é o caso do Círio.

Além disso, a autora aponta que essas múltiplas vozes que compõem a Amazônia assinalam a diversidade, um universo multifacetado que inclui também reivindicações de respeito aos ecossistemas, em nome da manutenção das gerações seguintes. Porém "o discurso atual, que envolve a Amazônia, parece ser o da reivindicação ecológica. Mas a discussão teórica é externa à região" (p. 255). E decorre disto, que os demais problemas, tão urgentes quanto a questão ambiental, acabem relegados a um segundo plano. Apesar das intensas discussões ambientais e sociais dos últimos cinquenta anos, a configuração da Amazônia ainda está no embate entre a posição dos moradores locais e a interação entre os agentes externos, ora preservacionistas, ora pretendentes a explorar os recursos de maneira intensiva.

A autora finaliza com uma assertiva que reitera a importância do trabalho de dar vozes aos atores locais, como foi realizado em seu livro: "Estudar seus discursos é também se colocar numa perspectiva que permite visualizar grandes problemas ao futuro da humanidade, no atual jogo de poder internacional sobre a região" (p. 255).

\section{REFERÊNCIAS}

CASTRO, A. R. M.; SANJAD, N.; ROMEIRO, D. S. Da pátria da seringa à borracha de plantação: Jacques Huber e seus estudos sobre a cultura das heveas no Oriente (1911-1912). Bol. Mus. Para. Emílio Goeldi. Cienc. Hum., Belém, v. 4, n. 3, p. 503-545, set.-dez. 2009. 
CRAIG, Neville B. Estrada de Ferro Madeira-Mamoré: História trágica de uma expedição. São Paulo-Rio de Janeiro-Recife-Bahia-Pará-Porto Alegre: Cia Editora Nacional - Brasiliana, 1947.

CRUZ, Oswaldo. Relatório sobre as condições médico-sanitárias do vale do Amazonas. Rio de Janeiro: Typographia Jornal do Commercio, 1913.

FAULHABER Priscila; MONSERRAT, Ruth (Org.). Tastevin e a Etnografia Indígena. Rio de Janeiro: Museu do Índio/FUNAI, 2009. (Série Monografias) MIGNOLO, Walter. Histórias locais/projetos globais: colonialidade, saberes subalternos e pensamento liminar. Belo Horizonte: Editora UFMG, 2003.

SAID, Edward. Introdução. In: Orientalismo: o Oriente como invenção do Ocidente. São Paulo: Companhia das Letras, 2007. p. 13-39.

SANTOS, Roberto. História Econômica da Amazônia (1800-1920). São Paulo: T. A. Queiroz, 1980.

WEINSTEIN, Bárbara. A borracha na Amazônia: expansão e decadência (1850-1920). São Paulo: HUCITEC, 1993. 



\section{RESENHA}

CAVALCANTI, Clóvis. Pensamento socioambiental e a economia ecológica: nova perspectiva para pensar a sociedade. Revista Desenvolvimento e Meio Ambiente, Curitiba, v. 35, p. 169-178, 2015.

Anna Paula Santos Paiva - Acadêmica do curso de Ciências Econômicas da Universidade Estadual de Montes Claros (UNIMONTES). E-mail: annapaulaspaiva@gmail.com

$\mathrm{O}$ artigo "Pensamento socioambiental e a economia ecológica: nova perspectiva para pensar a sociedade" apresenta as duas correntes que embasam sobre o relacionamento do crescimento econômico e meio ambiente, no qual o autor da obra toma uma posição.

O autor Clóvis Cavalcanti é economista ecológico, professor da Universidade Federal de Pernambuco, pesquisador da Fundação Joaquim Nabuco, presidente de honra da Sociedade Brasileira de Economia Ecológica (EcoEco) e presidente eleito da Sociedade Internacional de Economia Ecológica (ISEE).

O artigo está estruturado em três seções. A primeira seção do artigo, intitulada "Visão da problemática econômico-ecológica", retrata sobre a forma transdisciplinar da economia ecológica, que não faz parte nem da esfera da economia ou da ecologia. Nesta seção, o autor também relata o papel da economia, que é a ciência que estuda sobre os desejos humanos que são infinitos, em contraposição aos recursos finitos.

Na segunda seção, relacionada ao meio ambiente e ao processo econômico, o autor descreve a visão econômica da economia, ou também chamada de economia convencional, e em contrapartida a essa teoria explica sobre a visão ecológica da economia, ou em outras palavras, economia ecológica. $\mathrm{Na}$ linha tradicional, o fluxo monetário do sistema econômico é restrito apenas entre família e empresa, sendo o meio ambiente tratado como uma externalidade, e 
que não representa um limite para o sistema econômico. Já para a economia ecológica, os recursos entram no sistema econômico, passam pelo processo de throughput, que traduzido significa transumo, e por seguinte saem do processo como lixo. Neste processo não é gerada riqueza e a economia corresponde a uma parcela dentro do ecossistema.

Em sua última seção (três), Cavalcanti cita referências de autores que atuam no âmbito da economia convencional e da economia ecológica. A primeira possui autores como Milton Friedman e Robert Solow. Para a segunda linha, são citados Georgescu-Roegen e Herman Daly, que consoante Cavalcanti (2015), é o maior nome da economia ecológica nos dias atuais.

Após a descrição das seções, como relatado anteriormente, o autor da obra é um economista ecológico, no qual acredita que o crescimento econômico é limitado pelo meio ambiente. Segundo Cavalcanti (2015, p. 171) "Não se trata de aceitar um dogma de fé, mas de reconhecer inquestionável evidência: não existe sociedade (e economia) sem sistema ecológico, mas pode haver meio ambiente sem sociedade (e economia)". A economia ecológica aborda questões de como o comportamento humano interfere sobre o meio ambiente e qual a consequência gerada por essa interação.

Exemplificando o tema em discussão acerca da economia ecológica, deve-se observar que apesar dessa visão do autor, atualmente o presidente dos Estados Unidos, Donald Trump, tem apresentado um ponto de vista diferente que rejeita os indícios de aquecimento global. A mais recente notícia, de junho de 2017, é a saída dos Estados Unidos do Acordo de Paris sobre o clima, no qual visava a redução de emissões de gases de efeito estufa. Na visão de Trump, o Acordo de Paris tem conduzido ao baixo crescimento econômico, impactando negativamente no nível de empregos gerados, e por sua vez, inibindo o progresso econômico da economia americana (JORNAL DA USP, 2017).

Porém, para Cavalcanti (2015), no momento presente, o crescimento econômico é estipulado como uma norma. Contudo, crescimento é aumento do produto e esse aumento gera escassez de recursos. Deve-se ressaltar que para o autor, o crescimento não é necessariamente ruim, pois é preciso, sobretudo, para satisfazer a necessidades básicas das pessoas que vivem à margem da sociedade.

Contrariamente ao pensamento de Cavalcanti (2015), em março de 2017, o presidente americano Donald Trump encerrou o Clean Power Plan, que era um projeto de política ambiental do presidente anterior, Barack Obama. Este plano, consolidado em 2015, visava restringir a emissão de gases do efeito estufa com a finalidade de conter o aquecimento global. Ainda para o presidente em exercício, o fim dessa medida, além de interromper a intromissão do governo nas questões 
econômicas relacionadas ao crescimento do produto, acabava com as regras impostas que limitam os empregos (WELLE, 2017).

Percebe-se até aqui duas linhas divergentes de pensamento. Enquanto Cavalcanti em seus estudos tem priorizado os aspectos que resguardam o meio ambiente em contrapartida ao próprio crescimento, Trump tem enfatizado a relevância do crescimento econômico como fator que se sobrepõe a todos os demais. De acordo com Cavalcanti (2015, p. 177), "não existe no mundo natural o fenômeno de crescimento contínuo; quando isso parece acontecer, o final é sempre catastrófico". Portanto, as medidas de Trump podem inibir o desenvolvimento sustentável, dado a incapacidade do governo americano em perceber a importância dos aspectos relacionados à responsabilidade ambiental.

Em vista disso, essa discussão é relevante por se tratar de um tema atual em que põe em destaque qual questão é mais importante para a população, se o meio ambiente ou o crescimento econômico ainda que diante da degradação ambiental, consoante perspectiva de Cavalcanti (2015). É um assunto que deve ser debatido para que se alcancem resultados que sejam favoráveis para ambas as áreas. Dada essa situação, são levantadas hipóteses a respeito do que pode de fato gerar o estado de bem-estar da população, isto é, se este bem-estar deverá estar relacionado ao meio ambiente, no sentido de favorecer questões básicas como saúde, ou se os empregos gerados, mesmo sob condições de degradação de recursos, se sobrepõem à necessidade de preservação ambiental. Questões como essas podem induzir a economia ao enfrentamento de uma série de externalidades negativas ou positivas geradas pelo crescimento econômico. As negativas se referem ao gasto maior com saúde e perda de recursos naturais, e as positivas são relativas ao ganho de emprego e consequentemente da renda, logo, é estabelecido o questionamento de qual das externalidades possui a maior relevância para a população no quesito bem-estar.

\section{REFERÊNCIAS}

CAVALCANTI, Clóvis. Pensamento socioambiental e a economia ecológica: nova perspectiva para pensar a sociedade. Revista Desenvolvimento e Meio Ambiente, Curitiba, v. 35, p. 169-178, 2015.

RÁDIO USP repercute adeus de Trump ao Acordo de Paris. Jornal da USP. São Paulo, 02 jun. 2017. Disponível em: <http://jornal.usp.br/atualidades/radiousp-repercute-adeus-de-trump-ao-acordo-de-paris/>. Acesso em: 17 jul. 2017. 
WELLE, Deutsche. Trump age para acabar com legado ambiental de Obama.

Carta Capital. 28 mar. 2017. Disponível em: <https://www.cartacapital.com. $\mathrm{br} /$ internacional/trump-age-para-acabar-com-legado-ambiental-de-obama $>$. Acesso em: 17 jul. 2017.

Texto submetido à Revista em 20.08.2017

Aceito para publicação em 21.10.2017 
Artigos

The logic of the valorization of natural resources in Brazil: historical relationship between the electricity sector and the mining industry in the Amazon

A lógica de valorização dos recursos naturais no Brasil: relação histórica entre o setor elétrico e o setor mineral na Amazônia

André Cutrim Carvalho e Cleyton Alves Candeira Pimentel

Interfaces dos saberes ambientais: complexidade e educação política difusa

nterfaces of environmental knowledge: complexity and diffuse policy education

Antonio Teixeira de Barros

Mudanças climáticas: efeitos sociais sobre povos e comunidades tradicionais da Amazônia

Climate change: social effects on people and traditional communities in the Amazon

Thereza Cristina Cardoso Menezes e Ana Carla dos Santos Bruno

Representação descritiva comprometida com o desenvolvimento das mulheres: quais critérios importam?

Descriptive representation committed to the development of women: what criteria matter?

Rayza Sarmento

A construção da rodovia BR-153 na fronteira e urbanização da cidade de Araguaína, Tocantins

The construction of the BR-153 road at the border and urbanization in the city of Araguaína, Tocantins

Roberto Souza Santos

A habitação de interesse social no Brasil e sua expressão em Manaus

The social interest housing in Brazil and its expression in Manaus

Elane de Azevedo Pires e Marcelo Gustavo Aguilar Calegare

Analysis of industry based on resources and institutions National Desazolves case

Análise da indústria com base em recursos e instituições Caso de Desasufros Nacional

José G. Vargas-Hernández e Gabriela Sarahí González González

Comunidades negras no Ceará: da invisibilidade à formação dos quilombos contemporâneos

Black communities in Ceará: from invisibility to the formation of contemporary quilombos

Leilane Oliveira Chaves e Edson Vicente da Silva

Dinâmicas da agricultura familiar com cultura do dendezeiro no município de Moju, na Amazônia paraense

Dynamics of family agriculture with oil palm crops in the municipality of Moju, Amazon region of the state of Pará, Brazil

João Santos Nahum, Cleison Bastos dos Santos e Ana Cláudia Alves de Carvalho

Mudanças socioambientais no uso da terra em Altamira, Amazônia oriental

Environmental changes in land use in Altamira, Eastern Amazon

Maristela Marques Silva, Francisco Assis Oliveira e Antônio Cordeiro Santana

Agricultura de corte e queima e alternativas agroecológicas na Amazônia

Slash and burn agriculture and agroecological alternatives in the amazon

Anna Karyne Costa Rego e Osvaldo Ryohei Kato

Aprendizagem experiencial na formação de gestores socioambientais

Experencial learning in formation of leaders in social and environmental management

Walterlina Brasil, Solange Arrolho e Berenice Simão

\section{Resenhas}

Livro: PIZARRO, Ana. Amazônia: as vozes do rio: imaginário e modernização.

Trad. Rômulo Monte Alto. Belo Horizonte: Editora da UFMG, 2012.

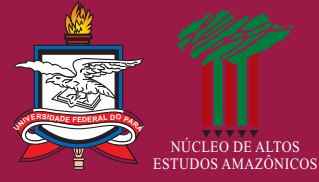

Cesar Mauricio de Abreu Mello, Juliana Azevedo Hamoy e Leonard J. Grala Barbosa

Livro: CAVALCANTI, Clóvis. Pensamento socioambiental e a economia ecológica: nova perspectiva para pensar a sociedade. Revista Desenvolvimento e Meio Ambiente, Curitiba, v. 35, p. 169-178, 2015.

Anna Paula Santos Paiva 